\title{
PROPOSTA DE INTEGRAÇÃO DE PARCEIROS NA FORMAÇÃO E GERÊNCIA DE EMPRESAS VIRTUAIS
}

\author{
Geraldo Nunes Corrêa
}

Tese de doutorado apresentada à Escola de Engenharia de São Carlos, da Universidade de São Paulo, como parte dos requisitos para obtenção do Título de Doutor em Engenharia Mecânica.

ORIENTADOR: Prof. Dr. Carlos Frederico Bremer

\section{São Carlos}


À minha esposa, Luciana, que sempre esteve ao meu lado.

\section{Agradecimentos}


Antes de tudo agradeço a Deus por iluminar meu caminho na realização deste trabalho.

Ao orientador e amigo Bremer por sempre me indicar a direção correta e por ter me oferecido várias oportunidades.

Ao Prof. Tit. Henrique Rozenfeld que viabilizou o início da realização deste trabalho e que me ofereceu um importante apoio em diferentes etapas.

Ao Prof. Dr. A.-W. Scheer pelo aceite fornecido para a realização do estágio na Alemanha.

À Prof. Dra. Solange Oliveira Resende pela ajuda prestada em São Carlos enquanto estive fora do país e pelas sugestões dadas para o aprimoramento do trabalho.

Ao CNPq, pela bolsa concedida.

À CAPES, pela bolsa concedida para o estágio no exterior.

Ao DAAD, pela bolsa concedida para o curso de alemão em Mannheim.

Ao Marcos que foi responsável pela implementação do "site" Internet realizada neste trabalho.

Aos amigos que fiz na Universtät des Saarlandes, em especial ao Arnold que foi responsável pela minha estadia em Saarbrücken.

Às secretárias de pós-graduação da mecânica, Ana Paula e Beth, que sempre me atenderam prontamente.

Ao Núcleo de Manufatura Avançada - NUMA - por todos os recursos indispensáveis para a realização deste trabalho.

Finalmente, agradeço aos meus pais e aos meus irmãos pelo apoio e torcida em meus caminhos.

\section{SUMÁRIO}


LISTA DE TABELAS...................................................................................................

LISTA DE ABREVIATURAS................................................................................................... IV

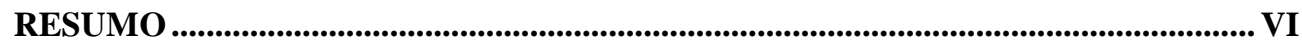

ABSTRACT ..................................................................................................................................VII

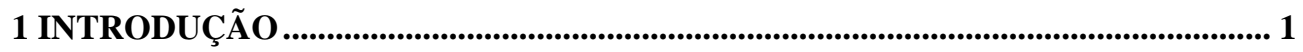

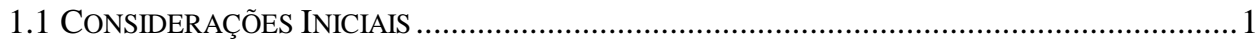

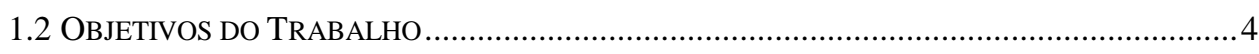

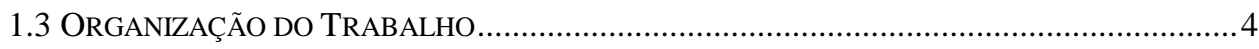

2 REVISÃO BIBLIOGRÁFICA ............................................................................ 6

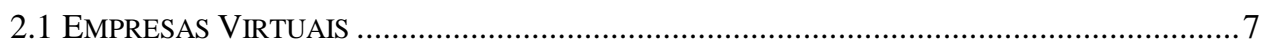

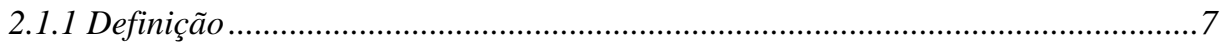

2.1.2 Diferenciação de Empresa Virtual dos Tipos de Cooperação ................................8

2.1.3 A Empresa Virtual: Restruturação de Grandes e Pequenas Empresas................10

2.1.4 A Necessidade de Mecanismos de Coordenação ..................................................13

2.1.5 Definição de uma Organização Virtual ...............................................................15

2.1.5.1 Requisitos para a Formação de uma Organização Virtual ............................................17

2.1.5.2 Ciclo de Vida de uma Empresa Virtual dentro de uma Organização Virtual ..............19

2.1.5.3 Descrição das Responsabilidades dentro da Organização Virtual ................................22

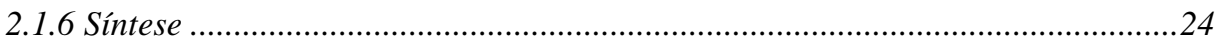

2.2 FoRMAÇÃo da CADEIA DE VALORES DE UMA EMPRESA VIRTUAL …….........................26

2.3 ALgUNS PROJETOS SOBRE EMPRESAS VIRTUAIS......................................................28

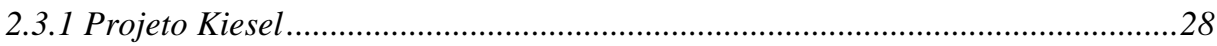

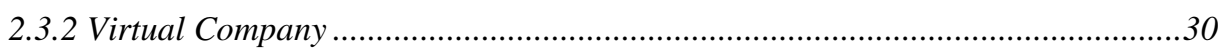

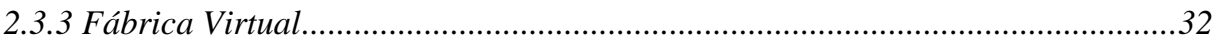

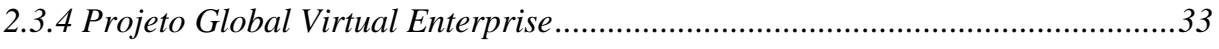

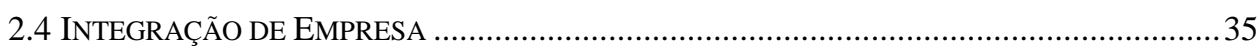

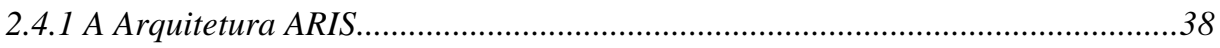

2.4.2 Metodologia de Integração ........................................................................41

2.4.2.1 Metodologia de Integração de Empresas .......................................................................42

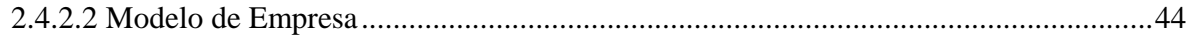

2.4.3 Aplicação da Modelagem de Processos de Negócios ...........................................46 
2.4.3.2 Simulação de Processos de Negócios ……..............................................................50

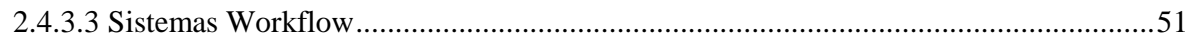

3 METODOLOGIA DE DESENVOLVIMENTO DO TRABALHO ............................. 55

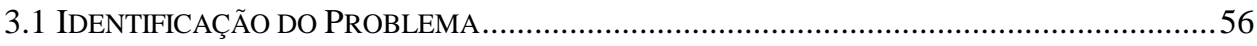

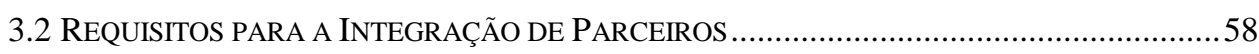

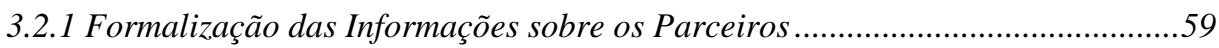

3.2.2 As Fases do Ciclo de Vida e seus Requisitos.....................................................60

3.2.3 Requisitos da Tecnologia de Informação .......................................................6

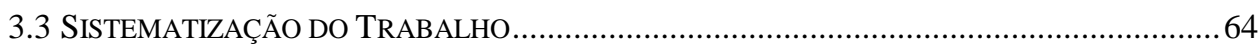

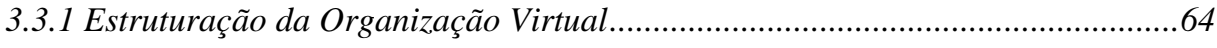

3.3.2 Otimização do Processo de Modelagem ...........................................................66

3.3.3 Relacionamento dos Modelos Utilizados na Proposta........................................69

3.3.4 Definição da Tipologia da Empresa Virtual a ser tratada no Trabalho..............71

4 INTEGRAÇÃO DE PARCEIROS EM EMPRESAS VIRTUAIS ................................ 73

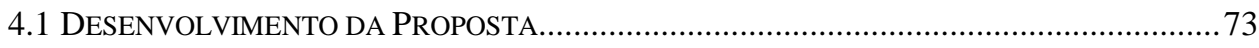

4.2 O MODELO DE EMPRESA EM UMA ORGANIZAÇÃO VIRTUAL ......................................75

4.2.1 Classificação de Processos de Negócios em uma Organização Virtual ..............81

4.2.2 A Geração do Modelo de Empresa ....................................................................82

4.3 Detalhamento do Ciclo de Vida Proposto Pelo Projeto KieSEl ......................84

4.4 DETALHAMENTO DAS ATIVIDAdES DE INTEGRAÇÃo DE PARCEIROS .............................92

4.4.1 Gerência do Modelo de Empresa .......................................................................99

4.4.2 Integração dos Modelos de Representação dos Parceiros...................................94

4.4.3 Simulação de Processos .....................................................................................96

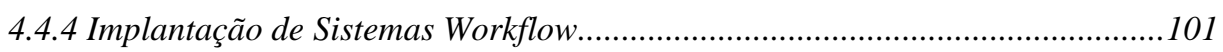

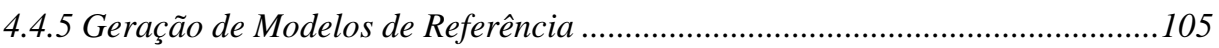

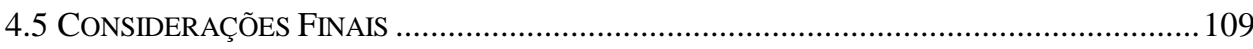

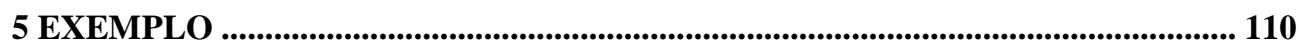

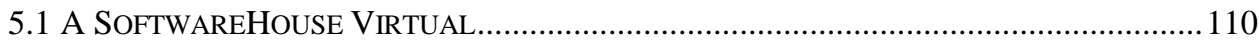

5.1.1 Estrutura Organizacional e Operacional............................................................ 112

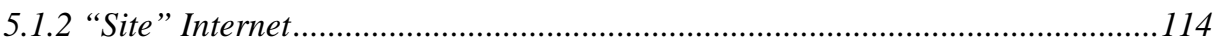

5.2 SimulaÇÃO dA FormaÇÃO E OPERAÇÃO DE UMA EMPRESA VIRTUAL ...................... 117

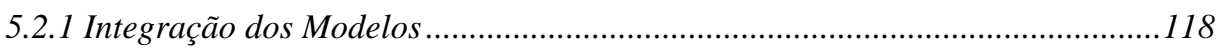

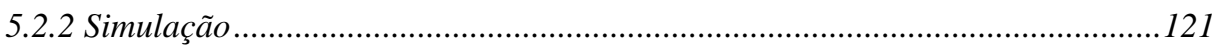

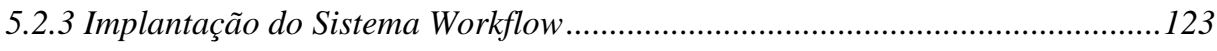

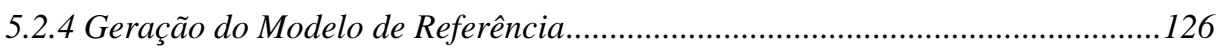


6 CONCLUSÕES E TRABALHOS FUTUROS......................................................... 129

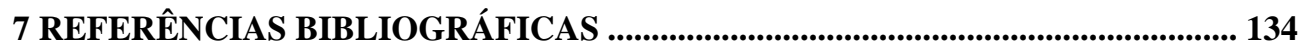

ANEXO I - DESCRIÇÃO DE ALGUNS MÉTODOS DA FERRAMENTA ARIS.... 141 


\section{LISTA DE FIGURAS}

FIGURA 1: ASPECTOS TRABALHADOS PELAS FILOSOFIAS .......................................................... 1

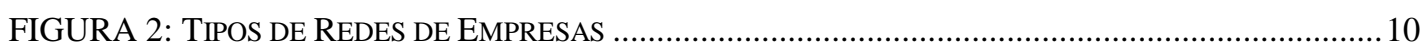

FIGURA 3: DESENVOLVIMENTO DE ESTRUTURAS ORGANIZACIONAIS ......................................... 11

FIGURA 4: FORMAÇÃO DE EMPRESAS VIRTUAIS A PARTIR DA CADEIA DE FORNECEDORES (GRIESE, 1992)

FIGURA 5: INFRA-ESTRUTURAS NECESSÁRIAS PARA A FORMAÇÃO DE EMPRESAS VIRTUAIS...............14

FIGURA 6: FORMAÇÃO DE EMPRESAS VIRTUAIS A PARTIR DE UMA ORGANIZAÇÃO VIRTUAL ..............16

FIGURA 7: CICLO DE VIDA DE EMPRESAS VIRTUAIS (KOCIAN ET AL., 1997) .................................20

FIGURA 8: RESPONSABILIDADES DENTRO DA ORGANIZAÇÃO VIRTUAL ...........................................23

FIGURA 9: FORMAS DE GERAÇÃO DE EMPRESAS VIRTUAIS ........................................................26

FIGURA 10: SEQÜÊNCIA DE ATIVIDADES EM UMA EMPRESA VIRTUAL (BREMER, 1997).................28

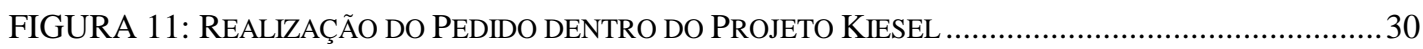

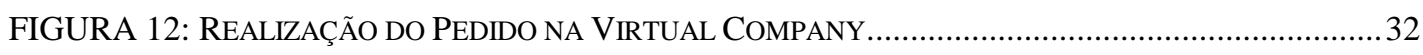

FIGURA 13: PROJETO GLOBAL VIRTUAL ENTERPRISE (BREMER ET AL., 1998) ............................... 34

FIGURA 14: RELACIONAMENTO ENTRE AS ENTIDADES DO PROJETO GVE ......................................35

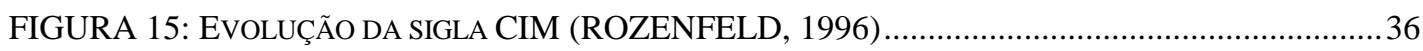

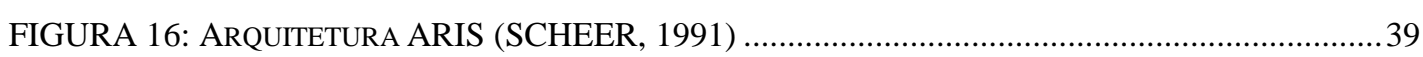

FIGURA 17: ARIS - HOUSE OF BUSINESS ENGINEERING (SCHEER, 1996) ....................................40

FIGURA 18: AS TRÊS DIMENSÕES DA METODOLOGIA DE INTEGRAÇÃO DE EMPRESAS ......................43

FIGURA 19: MODELO DE EMPRESA E SEUS COMPONENTES (RENTES, 1995) .................................46

FIGURA 20: ÁREAS DE ATUAÇÃo DA ModELAGEM DE PRoCESSOS DE NEGÓCIO ..............................47

FIGURA 21: Planos de AbSTRAÇÃo PARA A CONSTRUÇÃo de MODElOS DE REFERÊNCIA

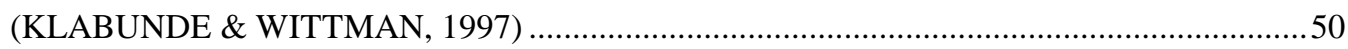

FIGURA 22: ARQUITETURA DE UM SISTEMA DE GERENCIAMENTO DE WORKFLOW ...........................52

FIGURA 23: MODELO DE REFERÊNCIA DO WFMC (WFMC, 1997) .............................................53

FIGURA 24: RELACIONAMENTO ENTRE O CICLO DE VIDA E OS CONCEITOS ......................................59

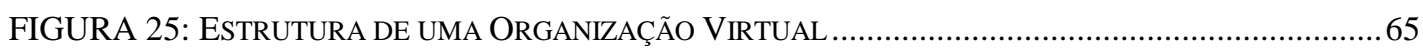

FIGURA 26: ESTRUTURA PARA CLASSIFICAÇÃO DE PROCESSOS DO PROJETO GIPP ..........................69

FIGURA 27: DESCRIÇÃO DOS TIPOS DE MODELOS UTILIZADOS NA PROPOSTA....................................70

FIGURA 28: FORMAÇÃO DE EV DE PRODUÇÃO VERSUS DE SERVIÇOS .............................................71

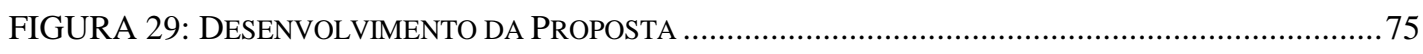

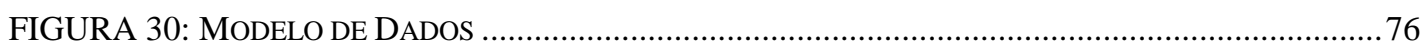

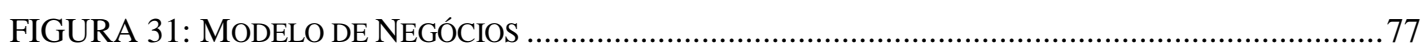

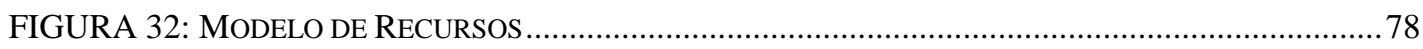




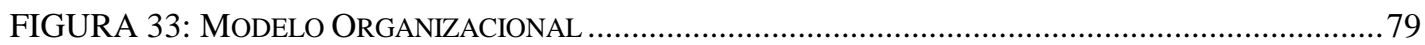

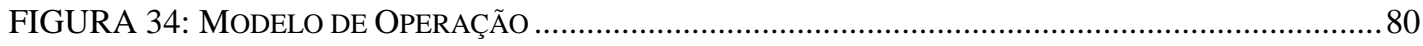

FIGURA 35: CLASSIFICAÇÃO DOS SERVIÇOS NA ORGANIZAÇÃO VIRTUAL …………………………..... 81

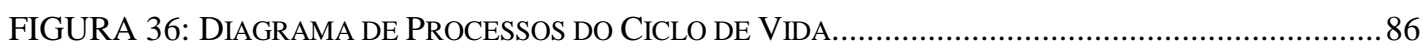

FIGURA 37: CLASSIFICAÇÃO DOS SERVIÇOS NA FERRAMENTA ARIS .................................................93

FIGURA 38: DETALHAMENTO DO PROCESSO PARA A SIMULAÇÃO …………………………………....97

FIGURA 39: SEQÜÊNCIA DE ATIVIDADES No ProceSSO DE SIMULAÇÃo..................................................99

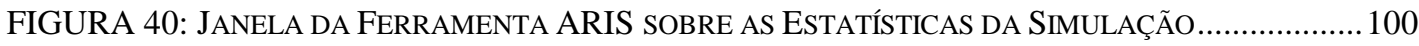

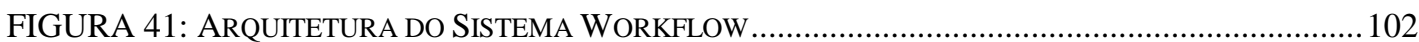

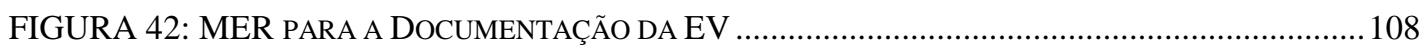

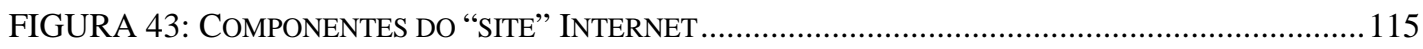

FIGURA 44: PÁGINA DE APRESENTAÇÃO DOS RECURSOS ..............................................................................

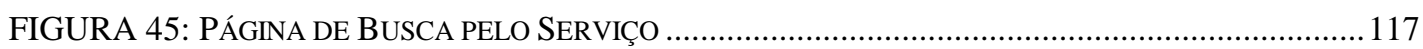

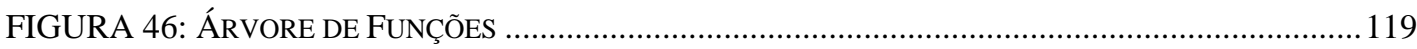

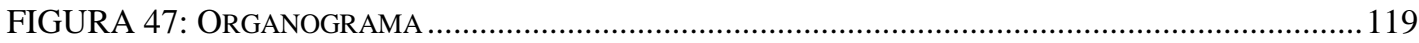

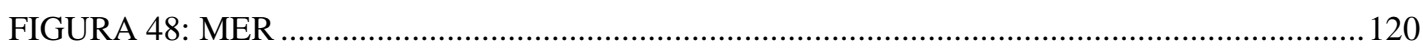

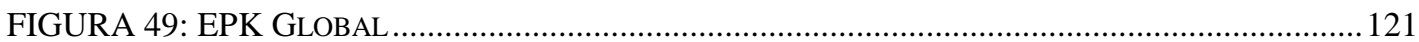

FIGURA 50: TEMPO GASTO NO CENÁRIO SEM O SISTEMA WORKFLOW ..............................................122

FIGURA 51: TEMPO GASTO NO CENÁRIO COM O SISTEMA WORKFLOW …………………………......... 123

FIGURA 52: CADASTRO DE USUÁRIOS DO SISTEMA WORKFLOW ………………………................... 124

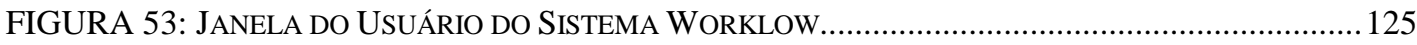

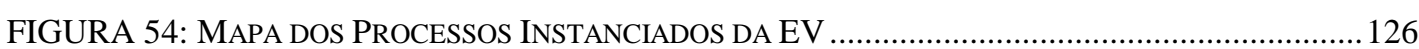

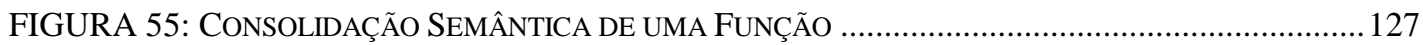

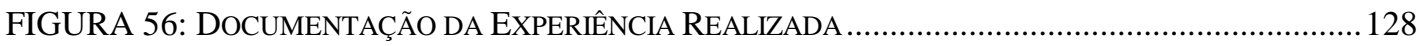




\section{LISTA DE TABELAS}

TABELA 1: CLASSIFICAÇÃO DE COOPERAÇÕES ENTRE EMPRESAS ..........................................................

TABELA 2: RELAÇão dos ConCEITOS das duAS ÁREAS DE PESQUISA .................................................57

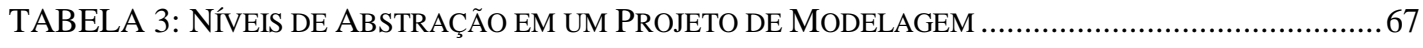

TABELA 4: ClaSSIFICAÇÃO DOS SERVIÇOS DA SOFTWAREHOUSE VIRTUAL.......................................111 


\section{LISTA DE ABREVIATURAS}

\begin{tabular}{|c|c|}
\hline AMEF & - Agile Manufacturing Enterprise Forum \\
\hline API & - Application Program Interface \\
\hline ARIS & - Architektur für integrierte Informationssysteme \\
\hline BPR & - Business Process Reengineering \\
\hline BMBF & - Bundesminiterium für Bildung, Forschung und Technologie \\
\hline CIM & - Computer Integrated Manufacturing \\
\hline CIMOSA & - Computer Integrated Manufacturing - Open System Architecture. \\
\hline CORBA & - Common Request Broker Architecture \\
\hline CPI & - Continous Process Improvement \\
\hline EDI & - Eletronic Data Interexchange \\
\hline EIS & - Enterprise Information System \\
\hline EPK & $\begin{array}{l}\text { - Ereignisgesteuerte Prozeßkette - Diagrama de Processos Controlado por } \\
\text { Eventos) }\end{array}$ \\
\hline EV & - Empresa Virtual \\
\hline FTP & - File Transfer Protocol \\
\hline GiPP & $\begin{array}{l}\text { - Geschäftsprozeßmanagement mit integrieten Produkt- und } \\
\text { Prozeßmodellen“ -- Gerência de Processos de Negócios com Modelos } \\
\text { integrados de Produto e Processo }\end{array}$ \\
\hline GVE & - Global Virtual Enterprise \\
\hline IE & - Integração de Empresa \\
\hline IWI & - Institut für Wirstschaftsinformatik \\
\hline MER & - Modelo Entidade-Relacionamento \\
\hline MIE & - Metodologia de Integração de Empresas \\
\hline OV & - Organização Virtual \\
\hline
\end{tabular}


PCP - Planejamento e Controle da Produção

PME - Pequena e Média Empresa

SQL $\quad$ - Structured Query Language

STEP - Standard for the Exchange of Product Model Data

TCP/IP - Transport Control Protocol / Internet Protocol

TI

- Tecnologia da Informação

WfMC - Workflow Management Coalition 


\section{RESUMO}

CORRÊA, G. N. (1999) Proposta de Integração de Parceiros na Formação e Gerência de Empresas Virtuais. São Carlos, 1999. 147p. Tese (Doutorado), Escola de Engenharia de São Carlos, Universidade de São Paulo.

Com a globalização da economia as empresas estão buscando diferentes formas de cooperação para aumentarem a sua competitividade. Neste contexto, o conceito de Empresa Virtual está sendo pesquisado como uma alternativa para aumentar os ganhos dentro de uma cooperação entre empresas. No entanto, o tipo de cooperação Empresa Virtual corresponde a uma área de pesquisa na qual diferentes mecanismos estão sendo explorados para a sua consolidação. A formação de uma rede estável entre empresas é difundida por vários projetos europeus como uma condição necessária para o surgimento sistemático de Empresas Virtuais. A esta rede estável dá-se o nome de Organização Virtual. O sucesso da formação e gerência de uma Empresa Virtual com as empresas que pertencem à uma Organização Virtual depende diretamente do processo de integração entre as mesmas. O objetivo deste trabalho consiste em aplicar conceitos e ferramentas difundidos pela área de Integração de Empresas na formação e gerência de uma Empresa Virtual, dentro de uma Organização Virtual, visando a integração dos parceiros. Para tanto, foi realizada uma adaptação do conceito de modelo de empresa para a representação formalizada dos parceiros da Organização Virtual e um detalhamento das atividades do ciclo de vida de uma Empresa Virtual, entre as quais encontram-se as atividades do processo de integração. Um exemplo de Organização Virtual foi elaborado para validar a aplicação da proposta.

Palavras-chave: Empresa Virtual; Organização Virtual; Modelagem de Processos 


\begin{abstract}
CORRÊA, G. N. (1999) Proposal of Partners Integration in the Formation and Management of Virtual Enterprises. São Carlos, 1999. 147p. Tese (Doutorado), Escola de Engenharia de São Carlos, Universidade de São Paulo.
\end{abstract}

With the economy globalization, enterprises are looking for different forms of cooperation aiming increase their competitiveness. In this context, the concept of Virtual Enterprise is being researched as an alternative to increase the gains inside a cooperation among enterprises. However, the type of cooperation called Virtual Enterprise corresponds to a research area in which different mechanisms are being explored for its consolidation. The formation of a stable network among enterprises is diffused by several European projects as a necessary condition for the systematic appearance of Virtual Enterprises. This stable network is called Virtual Organization. The success of the formation and management of a Virtual Enterprise whose enterprises that belong to a Virtual Organization depends directly on the integration process among the same ones. The objective of this work consists of applying concepts and tools diffused by the area of Enterprise Integration in the formation and management of a Virtual Enterprise, inside of a Virtual Organization, seeking the partners' integration. For this, an adaptation of the concept of enterprise model was accomplished for the formalized representation of the Virtual Organization partners and a specification of the activities of the life cicle of a Virtual Enterprise, among these there are the activities of the integration process. An example of Virtual Organization was elaborated to validate the application of the proposal.

Keywords: Virtual Enterprise; Virtual Organization; Process Modeling 


\section{Introdução}

\subsection{Considerações Iniciais}

A invasão das indústrias japonesas nos domínios ocidentais, trazendo consigo novos conceitos de manufatura e de gerência, iniciou a procura por novas filosofias que aumentassem a competitividade das indústrias americanas e européias. Entre as filosofias resultantes deste processo de procura podem ser exemplificadas o CIM - Computer Integrated Manufacturing, Gerência Baseada no Tempo, Gerência Baseada por Custos, Reengenharia de Processos de Negócios, entre outras. Dois aspectos podem ser ressaltados na observação de cada uma: o trabalho da visão estratégica e a adaptação da estrutura organizacional e operacional (Figura 1).

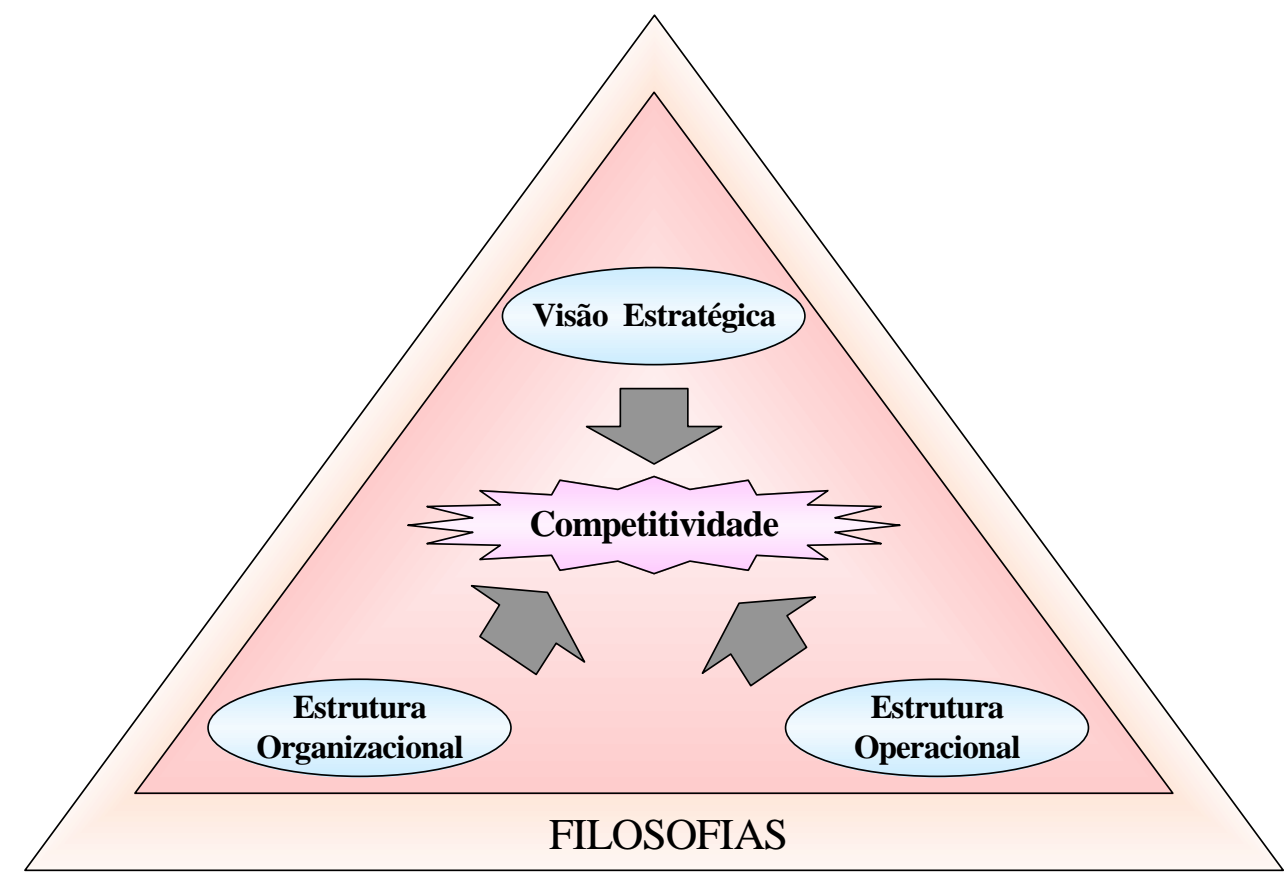

FIGURA 1: Aspectos Trabalhados pelas Filosofias 
HAMMEL \& PRAHALAD (1994) afirmam que o forte gerenciamento da visão estratégica é característica inerente às empresas de sucesso, onde a sua implantação depende da observação de diferentes dimensões, partindo de uma previsão do futuro até a internalização das metas por parte de cada empregado. O monitoramento do mercado através da identificação de suas necessidades constitui o primeiro passo para a definição da visão estratégica. Além do cliente, a evolução de novas tecnologias impõe requisitos que devem ser perseguidos. Produtos e serviços inovadores podem alterar a definição de mercados existentes ou mesmo possibilitar a exploração de novos nichos. Em outras palavras, a inovação pode revolucionar hábitos e consequentemente abrir novos mercados que até então não eram articulados ou definidos (TREGOE et al., 1993).

No entanto, a definição de uma visão estratégica não é suficiente para o ganho de competitividade, especialmente em mercados dinâmicos. O tempo para o lançamento de novos produtos constitui-se em uma das métricas mais importantes de monitoramento para a realização de uma oportunidade. A agilidade/flexibilidade de uma empresa em responder às expectativas do mercado depende de sua estrutura organizacional e operacional. A formalização destas estruturas corresponde a um passo eficaz para o melhoramento das métricas que representam a agilidade/flexibilidade de uma empresa (SCHEER, 1991).

Diferentes abordagens mostraram a relevância ou influência de diferentes técnicas para a otimização operacional de uma empresa, como por exemplo a visão baseada por processos, a redução e horizontalização de níveis hierárquicos, a utilização da tecnologia da informação, a formação de times interdisciplinares, e mais atualmente, a difusão do conceito de competência essencial.

O conceito de competência essencial auxilia a empresa a identificar os recursos (humanos e físicos) e o conhecimento necessários para colocá-la em uma posição diferenciada no mercado, oferecendo produtos e/ou serviços com qualidade e preços competitivos (JÜRGENS, 1997). A identificação de competências essenciais de uma empresa baseia-se na análise da estrutura do produto ou do serviço indicando os elementos que unem aspectos da visão estratégica e da operação de uma empresa, ou seja, integra tecnologias, processos, recursos e "know-how" a uma determinada oportunidade. Assim, a estruturação da unidade proveniente desta identificação vem se mostrando adequada às exigências de agilidade do mercado (MÜLLER, 1997).

A cadeia de valores referente à exploração de uma oportunidade contém, por sua vez, diferentes tipos de competências essenciais, que pode envolver diferentes tipos de 
processos de negócio ou de fabricação. Neste sentido, de acordo com o aumento da complexidade do produto/serviço e com a necessidade de conquista de diferentes mercados, independentes da distância, uma solução completa mostra-se mais eficaz quando há a cooperação entre diferentes empresas, onde cada uma exerce sua competência na cadeia (KATZY, 1997a).

Entre os tipos de cooperação que vem sendo realizados pelo mercado pode-se destacar: aliança estratégica, "joint venture", "franchise", representação de vendas, subcontratação, terceirização, entre outros (MERTENS \& FAISST, 1995). O termo cooperação entre empresas pode ser analisado sob diferentes aspectos, entre os quais três teorias básicas podem ser destacadas (KAUFMAN et al., 1990):

- a teoria dos custos de produção, que estuda o efeito da quantidade e envolve os conceitos sobre economia de escala e de escopo;

- a teoria dos custos de transação, que envolve de uma maneira geral a problemática da coordenação de atividades financeiras da cooperação, entre as quais podem ser citadas os custos da transferência de informações, de negociações, de controle e de reorganização;

- a teoria do risco, que engloba a pesquisa sobre investimentos, especializações, segurança, custos de oportunidades de negócios e preços.

Entre os fatores que contribuem para o sucesso de uma cooperação, a pressão pela redução dos custos de transação consiste no elemento motivador para descoberta de novos mecanismos. Através da evolução da tecnologia da informação torna-se possível a implementação de novas alternativas para a comunicação e coordenação entre os parceiros de uma cooperação que além de aumentar a agilidade na troca de informações, reduzem o seu custo.

Neste contexto insere-se o conceito Empresa Virtual - EV - como um tipo de cooperação entre empresas para a exploração ágil de oportunidades e com menores custos de transação. Este conceito realiza o relacionamento entre o ciclo de vida de um produto ou serviço e o ciclo de vida de uma empresa, onde o projeto do primeiro implica na formação, operação e dissolução de uma cooperação entre empresas, que existirá enquanto o produto ou serviço for requisitado pelo mercado (BERNUS \& NEMES, 1995).

Assim como qualquer tipo de cooperação, a realização de uma EV envolve a integração e coordenação de diferentes empresas. Desta maneira, os recursos e conceitos desenvolvidos na área de Integração de Empresas podem ser utilizados para apoiar a 
formalização do ciclo de vida de uma EV. Termos como arquitetura de integração, metodologia, modelo de empresa, entre outros, que ajudaram e ajudam empresas a atingirem seus objetivos estratégicos de competitividade através do entendimento de sua operação, podem agora ser adaptados para o referido contexto e contribuir para a consolidação deste tipo de cooperação entre empresas.

\subsection{Objetivos do Trabalho}

O objetivo principal deste trabalho de doutoramento consiste na descrição do processo de formação de Empresas Virtuais dentro de uma Organização Virtual. Baseado nesta descrição, é proposto um processo de integração de parceiros com a aplicação de conceitos e ferramentas desenvolvidos pela área de Integração de Empresas. Para tanto, os seguintes objetivos específicos podem ser traçados:

- descrever projetos de pesquisa relacionados ao tema e identificar os mecanismos utilizados para a otimização o processo de formação de EV's;

- utilizar uma arquitetura de integração e uma ferramenta computacional para a representação dos processos e padronização das informações das empresas parceiras da $\mathrm{OV}$;

- formalizar o ciclo de vida de uma EV a ser gerada dentro da OV;

- aplicar conceitos e ferramentas consolidados na área de Integração de Empresas (tais como modelagem e simulação de processos, sistemas workflow e modelos de referência) no processo de integração de uma EV.

\subsection{Organização do Trabalho}

Este trabalho está organizado da seguinte forma:

Capítulo 2: apresenta a referência bibliográfica da tese que envolve a definição de conceitos relativos à área de Empresas Virtuais e de Integração de Empresa. Referente à primeira área são apresentadas algumas definições que envolvem o conceito de Empresas e Organizações Virtuais e alguns projetos de pesquisa que exploram o tema. Referente à área de Integração de Empresas são definidos termos como Arquitetura de Referência, Metodologia, Modelo de Empresa, Simulação, Modelos de Referência e Sistemas Workflow. 
Capítulo 3: apresenta a metodologia utilizada para o desenvolvimento do trabalho, onde são ressaltados a focalização do problema, a descrição dos requisitos necessários e a sistematização de alguns elementos chaves à elaboração da proposta.

Capítulo 4: apresenta a proposta de integração dos parceiros durante o ciclo de vida de uma EV. Nesta proposta são abordados uma adaptação do conceito de modelo de empresa para o contexto de uma Organização Virtual, um detalhamento das fases de um ciclo de vida para uma EV e a aplicação dos diferentes recursos da área de Integração durante o referido ciclo de vida.

Capítulo 5: apresenta um exemplo de Organização Virtual com algumas empresas fictícias da área de Tecnologia de Informação. Um pedido é elaborado envolvendo diferentes empresas e, então, é aplicada a proposta de integração dos parceiros no ciclo de vida da EV. Um "site" Internet foi implementado para ser utilizado como um recurso de divulgação dos produtos e serviços da Oganização Virtual.

Capítulo 6: apresenta as conclusões que podem ser levantadas pela realização deste trabalho de pesquisa e sugere alguns temas de trabalhos futuros. 


\section{Revisão Bibliográfica}

A cooperação entre empresas parece se firmar como uma alternativa para a exploração rápida e a baixo custo de diferentes mercados. Isso acontece com a utilização comum de diferentes recursos ou competências que cada empresa traz para a rede. A quebra dos limites de uma empresa é motivada pelas exigências de uma presença ampla, partindo do âmbito regional até nível global (KAUFMAN et al.,1990). Neste sentido, surgem os aspectos do investimento e do risco correspondente, onde a divisão de ambos por empresas interessadas em uma determinada oportunidade torna-se uma solução mais segura.

A partir destas razões é colocado o desafio tanto na teoria como na prática para o desenvolvimento de diferentes formas de cooperação e entre elas encontra-se a Empresa Virtual. À esta forma é creditada a capacidade de conquista de mercados nacionais e internacionais e de reação flexível a mudanças (GORANSON, 1995). No entanto, é necessário precisar questões referentes a conceitos estruturais e mecanismos funcionais para que a Empresa Virtual se estabeleça como forma de cooperação.

Neste sentido, este capítulo visa apresentar uma referência bibliográfica que aborda os principais conceitos e mecanismos que suportam a formação e gerência de uma Empresa Virtual, entre os quais pode-se destacar a formação de uma organização entre empresas predispostas à este tipo de cooperação. Para a otimização da integração de parceiros em Empresas Virtuais a serem formadas dentro de uma organização previamente estabelecida, são apresentados alguns recursos da área de Integração de Empresas como parte da referência bibliográfica da tese. 


\subsection{Empresas Virtuais}

\subsubsection{Definição}

$\mathrm{Na}$ literatura podem ser encontradas diferentes definições para o conceito de Empresa Virtual. O termo em língua inglesa "Virtual Corporation" foi publicado pela primeira vez em 1986 por MOWSHOWITZ (1986). A partir dele surgiram várias tentativas de se difundir o conceito, onde DAVIDOW \& MALONE (1992) conseguiram um relativo consenso através da publicação de um livro que mostra uma visão do desenvolvimento futuro de empresas e afirma que o tipo de cooperação Empresas Virtuais possui a maior chance de sobrevivência.

Antes de apresentar algumas definições, é interessante discutir o termo virtual empregado na denominação. Para DAVIDOW \& MALONE (1992) o termo relaciona-se primeiramente sobre a arte da organização no sentido institucional. "O observador externo vê uma estrutura quase sem contornos, com linhas de divisão constantemente mutáveis entre empresa, fornecedor e cliente". Por outro lado, há publicações onde o termo é comparado à recursos computacionais, que de uma maneira geral significa que todos as características de um objeto está presente, menos o objeto em si. Juntando as duas observações resulta em um objeto que tem todas as características de uma empresa, sem ser uma empresa com registro legal.

Uma definição para Empresa Virtual - EV - como forma de cooperação, referenciada por diversas publicações, foi dada por BYRNE et al. (1993): "Empresa Virtual é uma rede temporária de empresas independentes - fornecedores e clientes, mesmo sendo rivais ligados pela tecnologia de informação para compartilhar habilidades, custos e permitir o acesso comum aos mercados dos mesmos. Não possuirá nem escritório central e nem organograma. Não terá hierarquia e nem integração vertical. Na mais pura forma do conceito, cada empresa que se liga com outras para criar uma empresa virtual será requisitada por sua essência. Contribuirá apenas aquelas que se ocuparem com suas competências essenciais".

No espaço da língua alemã a discussão a respeito começou um pouco mais tarde. Uma interessante perspectiva trazem MERTENS \& FAISST (1995) quando explicam que a expectativa em torno de EV é porque esta determina o extremo domínio da estrutura operacional sobre a estrutura organizacional e é vista como um conseqüente progresso não 
somente de organizações orientadas por processos, mas também pela integração do processamento de informações entre empresas. Segundo MERTENS \& FAISST (1995) uma EV pode ser definida como uma "cooperação entre empresas para a realização de missões, nas quais desiste-se da formação de novas instalações ou da formalização contratual através de Joint Ventures ou Consórcios ou mesmo da compra de novas filiais”. Uma distinção entre os diferentes tipos de cooperação é dada na próxima seção.

Uma observação pode ser ressaltada de acordo com as diferentes propostas de definição do termo. As origens para se tentar esclarecê-lo são diferentes, mas no entanto, propagam de uma maneira geral as mesmas características de aproveitamento de oportunidades de uma maneira rápida com baixo risco. Uma definição para o termo EV que consegue retratar de uma maneira sintética esses diferentes aspectos é proposta por ARNOLD \& HÄRTLING (1995): “empresa virtual é uma forma de cooperação legal de empresas, pessoas elou instituições independentes que formam uma capacidade comum de entendimento sobre um negócio. As unidades cooperadoras dividem o trabalho de acordo com suas competências essenciais e atuam na geração de ofertas sobre terceiros como unidade básica. A institucionalização de órgãos centrais para o desenvolvimento, realização e gerenciamento de EV não é necessária”.

\subsubsection{Diferenciação de Empresa Virtual dos Tipos de Cooperação}

O objetivo de uma cooperação entre empresas baseia-se sempre na missão comum de explorar um determinado mercado. Desta maneira, surge a necessidade de uma classificação na qual as várias formas de cooperação podem ser diferenciadas. De acordo com OLBRICH (1994), existem quatro fundamentos gerais para a classificação, mostrada na Tabela 1. Uma discussão sobre cada tipo de conexão entre empresas foge do escopo deste trabalho.

Uma EV possui características pertencentes às demais formas de cooperação, onde torna-se necessário, assim, fornecer uma diferenciação entre as mesmas. A seguir são apresentadas algumas diferenças entre EV e outras formas mais conhecidas de cooperação (MERTENS \& FAISST, 1995). 
TABELA 1: Classificação de Cooperações entre Empresas

\begin{tabular}{|l|l|l|l|}
\hline número de conexão & conexão não contratual & conexão contratual & conexão de capital \\
\hline redes & Comitê Normativo & Consórcio & "Capital Ventures" \\
& Associações & Licença de vendas & "Joint Ventures" \\
conexão trilateral & Cartéis & Representação & \\
conexão bilateral & Acordo & Acordo tecnológico & Fusão \\
& & Troca de patentes & \\
& & Transações de mercado & \\
\hline
\end{tabular}

- Aliança estratégica: A ligação entre as empresas em uma EV é maior que em uma aliança estratégica, uma vez que a comunicação entre times resultantes de sua formação mantém maior contato. Além disso, aliança estratégica está mais orientada para um setor de mercado, enquanto que o mercado da EV compõem dos mercados definidos por cada empresa. Geralmente alianças estratégicas são realizadas por grandes empresas, enquanto que EV se adapta melhor a pequenas e médias empresas.

- Conglomerado: Contrário ao conglomerado de empresas não existe em EV’s nenhum contrato de controle e também nenhuma participação financeira é necessária. A formação de EV's pode resultar-se da reformulação de conglomerados.

- Cartel: A EV não funciona como Cartel para a regulação ou restrição da competição, ao invés disso os parceiros, à principio, são complementares um ao outro mas não possuem posição dominante no mercado.

- Consórcio: EV e consórcios são parentes entre si, onde ambos ajustam à cooperação para a realização de uma missão com tempo determinado. A diferença encontra-se na formalização da cooperação, a qual é muito maior em consórcios. Consórcios típicos como por exemplo para a construção de uma ponte ou para a emissão de ações seguem modelos comprovados, ou seja, a apresentação da configuração de uma EV é mais complicada. 
- “Joint Venture": A principal diferença é a não necessidade de abertura de uma firma na formação de uma EV.

Como foi abordado, uma EV corresponde à uma rede de empresas. Neste contexto, o termo rede pode ser entendido como modelo de apresentação e/ou de pensamento para coletar, estruturar e coordenar os relacionamentos de uma empresa com clientes, fornecedores e concorrência (KATZY et al., 1996). Contratos de fornecedores, contratos de transporte, serviços de logística, comunicação por EDI e processos de negócios unem as empresas em uma rede. A premissa válida aqui consiste no pensar para a rede e não para a própria empresa. Há três tipos de redes, como mostra a Figura 2.

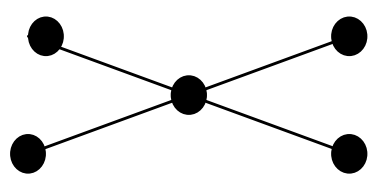

Rede estratégica

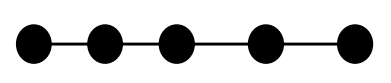

Redes Lineares

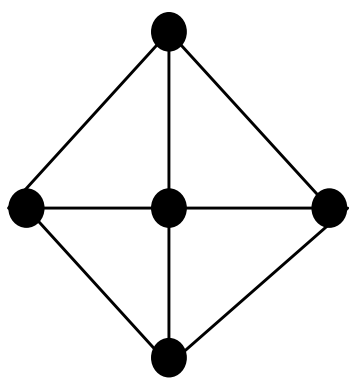

Rede dinâmica

\section{FIGURA 2: Tipos de Redes de Empresas}

A rede estratégica está orientada para o mercado servindo para a obtenção de certas metas e é formada com a direção de uma empresa ao centro, como por exemplo Nike, Puma ou mesmo montadoras de automóveis. Todas as atividades são controladas por esta empresa.

Redes Lineares adaptam-se de acordo com a cadeia de valores. O operação linear desde o fornecedor de matéria-prima passando pelo produtor até o cliente é apropriada para conseguir o aumento da eficiência no processo de logística.

Redes dinâmicas caracterizam-se por um intenso e variável relacionamento de empresas, o que é difundido pelo tipo de cooperação EV. Exemplos deste tipo de rede são os projetos de cooperação a nível regional, como na área da construção civil.

\subsubsection{A Empresa Virtual: Restruturação de Grandes e Pequenas Empresas}

De acordo com as revoluções industriais, as grandes empresas surgiram das necessidades de produção em massa para a redução de preço ao consumidor (economia de 
escala), produzindo com isso organizações gigantescas com administração geograficamente centralizadas. Através dos requisitos atuais de flexibilidade, combinado à insegurança de mercado e complexidade do produto, as grandes empresas estão sendo obrigadas a procurar novas formas de organização que ajustem flexibilidade ao seu fator de competitividade. Uma evolução destas formas de organização pode ser vista na Figura 3 (EMMRICH et al., 1997).

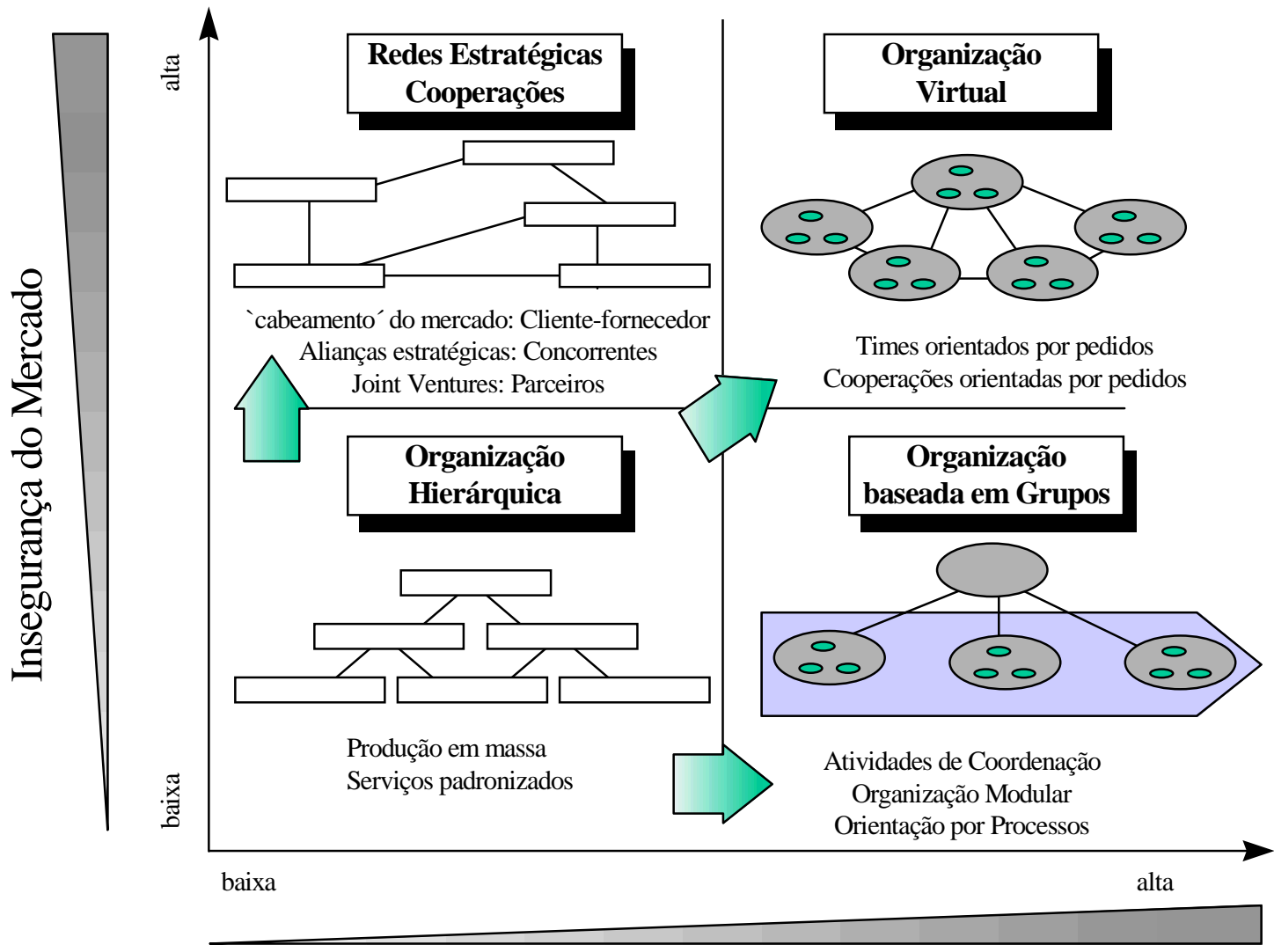

\section{Complexidade do Produto}

\section{FIGURA 3: Desenvolvimento de Estruturas Organizacionais}

Como pode ser observado na Figura, quanto maior a complexidade do produto e a insegurança do mercado, as grandes empresas se orientam por pedidos com base na formação de grupos (competências essenciais). Neste sentido, o desafio ou a dificuldade que essas empresas encontram consiste na quebra de seus níveis hierárquicos para a formação de uma nova estrutura organizacional baseada em competências essenciais (JÜRGENS, 1997). Essa reestruturação conduz a formação de unidades menores de negócios que se “comunicam" entre si para a exploração de oportunidades. 
Há setores, no entanto, onde o tamanho da empresa permanece grande para atender a necessidade de fabricação de produtos como na área automotiva, do aço, do petróleo, das telecomunicações, entre outros. Em outras palavras, unidades pequenas não suportam as exigências impostas pela complexidade de fabricação (OLBRICH, 1994).

O ponto comum entre as duas perspectivas de observação para a formação de uma EV, de um lado a reestruturação de grandes empresas e por outro a cooperação de PME's, consistem na concentração sobre competências essenciais. No entanto, a PME possui uma vantagem neste processo por ter uma estrutura organizacional menos complexa e um número relativamente menor de competências a serem gerenciadas.

O processo de virtualização na cooperação entre empresas, principalmente no caso de PME's, começa no próprio relacionamento fornecedor/cliente, ou seja, uma PME procura a formação de uma cadeia de fornecedores e de clientes que a mantenha competitiva, podendo fazer parte de alianças estratégicas. A consolidação com parceiros em uma rede é viabilizada através de contatos de longa duração. A formação de redes dinâmicas a partir de uma cadeia de fornecedores fornece uma tendência nova onde o objetivo é a formação de cooperações baseadas em pedidos entre as empresas cujos contatos foram livres de conflitos, dando origem assim às EV's (GRIESE, 1992).

A Figura 4 apresenta a evolução de cadeias de fornecedores em duas regiões distintas, onde através de um processo de seleção natural sobrevivem apenas as empresas que possuem melhores condições de negócio. Um último estágio neste processo consiste na criação de um Broker que, além de realizar o contato com clientes e fornecedores, gerencia informações sobre as empresas que apresentam as melhores propostas nas duas regiões. 


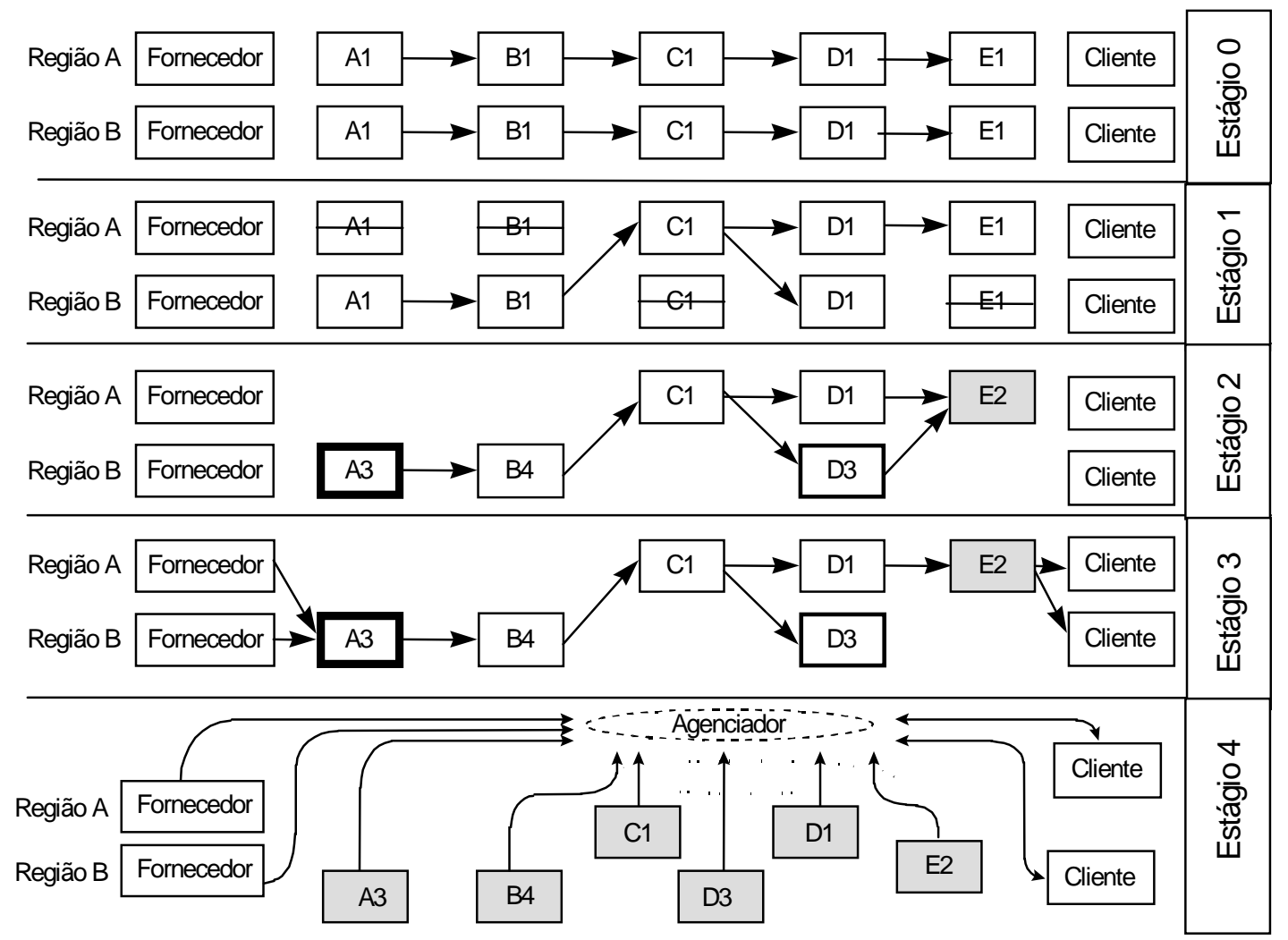

FIGURA 4: Formação de Empresas Virtuais a partir da Cadeia de Fornecedores (GRIESE, 1992)

A desvantagem da perspectiva de redes dinâmicas formadas a partir de PME's consiste nas atividades de coordenação, uma vez que envolve diferentes empresas de tamanhos semelhantes, onde os interesses de cada uma devem ser conformados.

\subsubsection{A Necessidade de Mecanismos de Coordenação}

Até aqui foram abordados os caminhos ou motivos que levam a formação de uma $\mathrm{EV}$, ou seja, a necessidade de realizar oportunidades agilmente com redução dos custos de produção e transação. No entanto, a realização propriamente dita da formação e gerência de uma EV não é facilmente encontrado na literatura. A maior parte das publicações ressaltam as vantagens da formação de uma EV e não como ela é realizada realmente (ARNOLD \& HÄRTLING, 1995).

Problemas clássicos de cooperações entre empresas não são observados amplamente como a divisão do risco, do ganho, dos custos, o monitoramento de prazos de entrega, entre outros relacionados à coordenação entre os parceiros. Neste sentido, existem diferentes perspectivas onde mecanismos podem ser gerados para apoiar a realização de uma EV, ou 
seja, o seu ciclo de vida. Segundo GORANSON (1995), há quatro infra-estruturas onde os aspectos de uma cooperação entre empresas e sua coordenação devem ser tratados. Em outras palavras, os mecanismos devem ser associados de acordo com o conhecimento destas infra-estruturas e seu relacionamento entre si.

Atualmente os mecanismos explorados concentram-se nas camadas de informação e física do modelo proposto por Goranson, no qual os aspectos legais e sociais ainda demonstram dificuldades em ser detalhados (ARNOLD \& HÄRTLING, 1995). Uma ordem de prioridade no estabelecimento das infra-estruturas pode ser observada na Figura 5, onde a camada de informação representa um requisito fundamental e a conexão física entre os parceiros não consiste em condição vital para a realização da EV.

O fator confiança entre os parceiros exerce por sua vez um papel decisivo para o sucesso na formação de uma EV, o que ressalta a importância da exploração na área social/cultural. Uma vez que há a divisão de risco e lucro entre parceiros, e com isso a dependência da atuação dos mesmos, há a necessidade do estabelecimento de mecanismos não técnicos para gerenciar a cooperação.

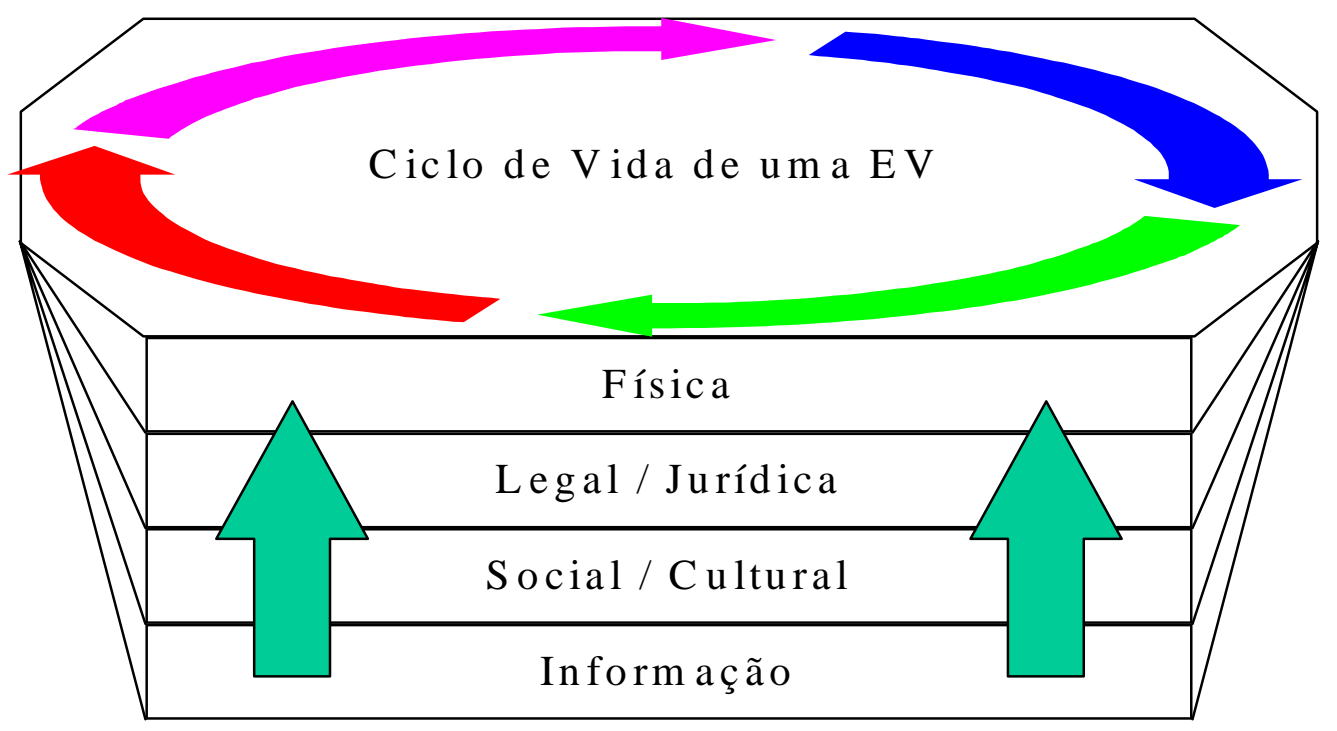

FIGURA 5: Infra-estruturas Necessárias para a Formação de Empresas Virtuais

A camada legal ocupa-se com a viabilização de novas formas de cooperação que utilizam o meio eletrônico, ou seja, como criar leis para regulamentar o mercado eletrônico. Por outro lado, o processo de regulamentação de responsabilidades na cooperação também necessitam de mecanismos viabilizadores (SOMMERLAD, 1996). 
De uma maneira geral, mecanismos devem ser estabelecidos no sentido de viabilizar a cooperação ágil de acordo com o preenchimento dos requisitos em cada camada exposta acima. Neste sentido, além da pergunta por que?, a formação de uma EV deve conter respostas para a pergunta como? se realiza essa cooperação ágil.

De acordo com alguns projetos europeus, o estabelecimento de uma organização entre empresas predispostas à formação de EV's otimiza o processo de integração e coordenação dos parceiros. Em outras palavras, a base para a aplicação de mecanismos de coordenação corresponde a prévia organização entre as empresas para a exploração de oportunidades de negócio. Desta maneira, são apresentados a seguir:

- uma definição para o termo Organização Virtual;

- os requisitos para a sua formação;

- o ciclo de vida de uma EV dentro de uma Organização Virtual.

- uma definição de responsabilidades para a sua coordenação.

\subsubsection{Definição de uma Organização Virtual}

De acordo com TOFFLER (1980), a história humana pode ser dividida em quatro grandes eras, caracterizadas pelos nômades, pela agricultura, pela indústria e agora pela informação. As civilizações correspondentes à cada era possuem determinadas características da forma de organização:

- Primeiro as pessoas organizavam-se em pequenos grupos de acordo com as habilidades como a caça;

- A hierarquia cresceu com o advento da agricultura;

- A era industrial trouxe o nascimento da burocracia e

- A era da informação traz as redes.

Uma rede é um tipo de organização que se origina como um projeto básico para a construção de um grupo social. No contexto de empresas, redes significam cooperações estáveis ou dinâmicas com a finalidade de explorar oportunidades de mercado. A formação de times (ou grupos) dentro destas redes possuem caraterísticas semelhantes aos antigos grupos nômades, onde determinadas especialidades (competências) para a caça precisavam ser agrupadas (NETAGE, 1996). 
Desta maneira, uma rede baseada em pequenas empresas apoiada pela informação e baseada em competências transformam-se nos grupos de caça da era da informação. Neste sentido, uma Organização Virtual pode ser definida como "uma rede estável de empresas, destinada a formação de EV's, interligadas de acordo com suas competências essenciais e estratégias de mercado e suportada pela utilização da tecnologia de informação”. No entanto a utilização da tecnologia da informação não consiste em uma condição essencial, e sim viabilizadora para o aumento da performance de uma cooperação (KOCIAN \& SCHEER, 1996).

Em outras palavras, uma Organização Virtual - OV - pode ser vista como uma plataforma estável onde empresas trocam informações a respeito de oportunidades de mercado e consequentemente utilizam-se dessa cooperação para a formação rápida de uma EV, uma vez que uma estrutura organizacional já está presente (Figura 6).

EV1

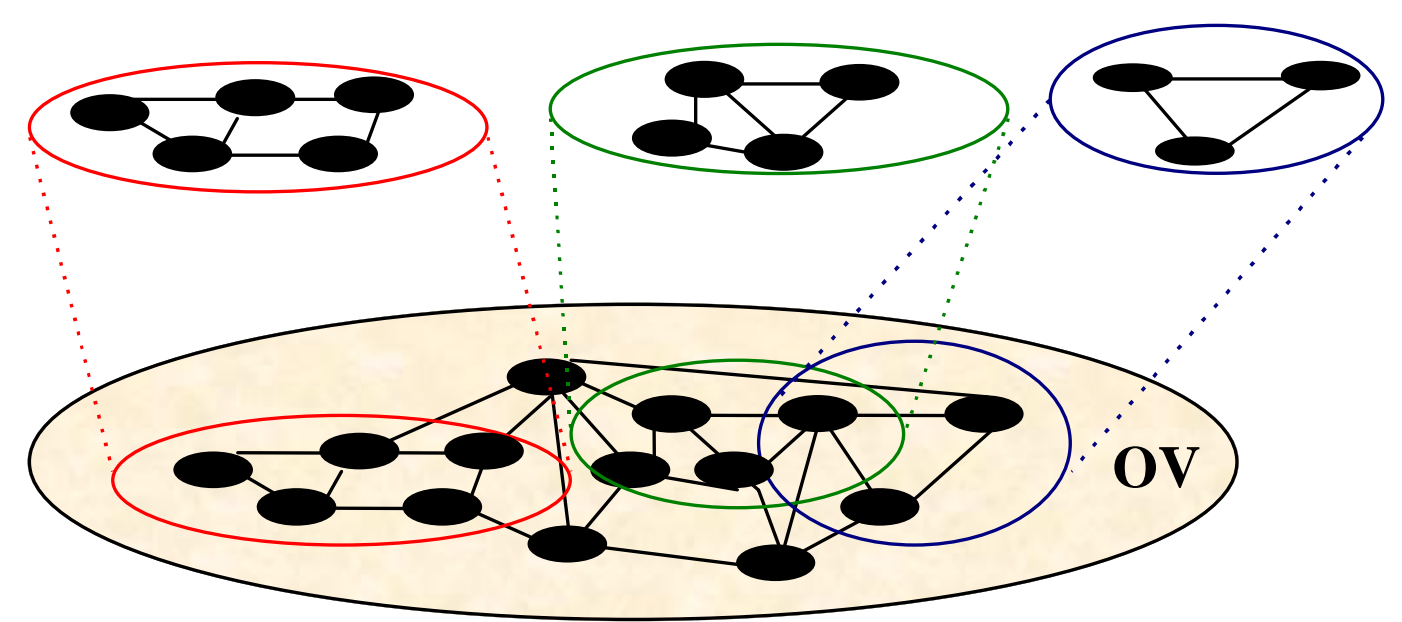

\section{FIGURA 6: Formação de Empresas Virtuais a partir de uma Organização Virtual}

Um modelo para a construção desta plataforma (OV) pode ser observado no projeto Virtuelle Fabrik da Universidade de St. Gallen - Suíça (KATZY et al. 1997). Este modelo contém quatro fases principais para a formação de rede estável de cooperação:

1. Esclarecimento: corresponde a interligação de um time básico (o técnico da rede mais cerca de 10 empresas) e a definição dos limites da área de atuação;

2. Planejamento: refere-se ao planejamento de projetos e financiamento; 
3. Construção: fundação da rede como uma organização juntamente com a definição de papéis e regras para o processo de coordenação. Nesta fase existe ainda a transferência de know-how para a difusão das competências existentes na rede.

4. Operação: prolongamento da rede através da admissão de novos parceiros e início de aquisição e desenvolvimento de ordens de pedido

A iniciativa para a formação de uma rede estável pode ter diferentes origens, entre as quais ressalta-se os projetos de pesquisas financiados por instituições governamentais. $\mathrm{Na}$ prática, a formação destas plataformas pode surgir através da expansão da cadeia tradicional de fornecedores à nível regional, mas no entanto apresenta uma velocidade menor devido a construção das camadas de infra-estruturas (GRIESE, 1992). Um caso que pode ser observado na prática baseia-se no desenvolvimento de banco de dados sobre consultores empresariais através da ação de uma pessoa que gerencia todas as informações, formando assim a figura do Broker (BREMER, 1997).

EV's podem surgir ainda através da exploração de oportunidades em mercado eletrônico ou bolsas de cooperação na Internet (LANG \& PIGNEUR, 1997);(ODENDAHL et al., 1997). Nesses casos, problemas culturais devido ao não conhecimento profundo dos prováveis parceiros em uma cooperação trazem obstáculos ao sucesso da exploração da oportunidade. Além disso, o acoplamento entre as competências essenciais não é tão forte quanto ao conhecimento mútuo em uma rede estável.

A estrutura da OV deve ser construída com base nas camadas de infra-estrutura apresentadas na seção 2.1.4, ou seja, mecanismos devem ser elaborados para suportar o processo de coordenação entre os parceiros de uma OV de acordo com as diferentes perspectivas. A formalização destes mecanismos traz maior transparência na relação entre os parceiros e consequententemente atua nos fatores sócio-culturais relevantes ao sucesso do empreendimento (KOCIAN et al., 1997). Desta maneira, a OV em si pode ser vista como uma base para a implementação de mecanismos para a formação e gerência de EV.

\subsubsection{Requisitos para a Formação de uma Organização Virtual}

Os aspectos relevantes à formação de uma Organização Virtual podem ser observados com uma perspectiva cultural, pois envolve a maneira de se pensar e consequentemente de se gerir negócios (KOCIAN et al., 1997). Três aspectos podem ser discutidos: a cultura da confiança, a cultura da competência e a cultura da tecnologia da informação. 
A cultura da confiança relaciona-se aqui com os aspectos de cooperação entre empresas, onde envolve interesses de pessoas e empresas. A ética é então colocada em pauta e o conhecimento sobre as pessoas ou empresas que têm interesses em comum torna-se o primeiro passo para a geração desta cultura. Portanto, onde for possível, o contato pessoal (olho no olho) é necessário e quando não for possível, a tecnologia de telecooperação consiste em um mecanismo alternativo viável (SYDOW, 1996). O fortalecimento da confiança entre os parceiros pode ser auxiliado pela formação de grupos de trabalho com diferentes finalidades, entre os quais pode-se destacar:

- desenvolvimento de diretrizes para a Organização Virtual (por exemplo, regras gerais de condução, financiamento de ações, etc);

- elaboração das condições necessárias para a admissão de outros parceiros;

- reconhecimento e desenvolvimento de competências essenciais, assim como inovação do produto e cursos comuns de especialização;

- definição de mercados-alvo e atividades de marketing.

A utilização de um órgão neutro (aqui definido como o moderador) é por sua vez de vital importância para a cristalização da confiança, principalmente nas situações de conflitos (MILLARG, 1997). Outros papéis dentro da OV como o auditor ou o coordenador de desempenho podem ser utilizados para esta finalidade. Na seção 2.2.3 é dada uma visão geral sobre os papéis em uma OV.

A cultura da competência trata sobre as questões do Poder e do Saber, ou seja, tanto dos recursos imateriais (procedimentos, know-how) como dos recursos materiais (máquinas). Assim, o termo competência dentro de uma OV relaciona-se com o que cada empresa pode oferecer de maneira diferenciada para o cliente, ou seja, com preço e qualidade atraentes. Isto só é possível quando a empresa apresenta uma relação de diferentes tipos de recursos, onde o conhecimento está em primeiro plano (BOOS \& JARMAI, 1994). Assim, a identificação de uma competência em uma empresa ocorre através das seguintes características:

- proporciona um maior valor agregado por parte do cliente;

- é resistente contra imitação ou substituição e

- oferece diferentes possibilidades de aplicação segundo a configuração de seus recursos (REIß \& BECK, 1995). 
Portanto, para que uma empresa seja admitida na OV é necessário que a mesma forneça suas estratégias relacionando os recursos que possui. Com isso, a OV torna-se apta a definir os recursos que a compõe e assim a elaborar estratégias dentro da cultura de competências. A formação de uma EV consiste na associação de competências complementares que geram assim toda a cadeia de valor agregado.

A cultura da tecnologia da informação consiste na utilização dos recursos computacionais para o processamento de dados, que é de vital importância para os processos de comunicação entre os parceiros de uma OV. Entre esses processos de comunicação encontram-se os de coordenação e entendimento de uma cooperação (ARNOLD, 1996). A forma eletrônica destes processos contribuem para a redução dos custos de transação através de questões como:

- quais informações são transmitidas entre quais parceiros sobre quais meios de comunicação?

- em qual nó (computador) essas informações estão armazenadas e em quais sistemas?

- como são administrados os direitos de acesso sobre essas informações, ou como é gerada a base de dados distribuída?

- quais são as conseqüências organizacionais na utilização da tecnologia da informação para uma determinada empresa?

Desta maneira, para a formação de uma $\mathrm{OV}$, a observação destes três aspectos podem ser considerados como requisitos. Dependendo do tipo de atuação da organização, na área de serviços ou de fabricação de produtos, estes requisitos possuem maior ou menor nível de influência para o sucesso da mesma (ZWICKER, 1996). No entanto, o aspecto da confiança assume sempre um papel central em qualquer tipo de organização, suportando um fator decisivo maior que a utilização da tecnologia de informação no caso de uma cooperação.

\subsubsection{Ciclo de Vida de uma Empresa Virtual dentro de uma Organização Virtual}

Um modelo de ciclo de vida foi proposto pelo "Agile Manufacturing Enterprise Forum"(AMEF), no qual foram estabelecidas as fases desde a criação até a dissolução de uma EV (GORANSON, 1995). Cada fase envolve decisões que são suportadas por diferentes métodos e ferramentas e por um sistema de métricas. No entanto, esta proposta 
pode ser considerada genérica, servindo como modelo para a formação de EV's independentemente se as empresas estão em uma organização ou não. Dentro do Projeto Kiesel da Universidade de Saarland - Alemanha - o modelo proposto pelo AMEF foi reprojetado para a sua utilização dentro de uma OV. O ciclo de vida resultante é mostrado na Figura 7 e apresenta seis fases principais (KOCIAN et al., 1997).

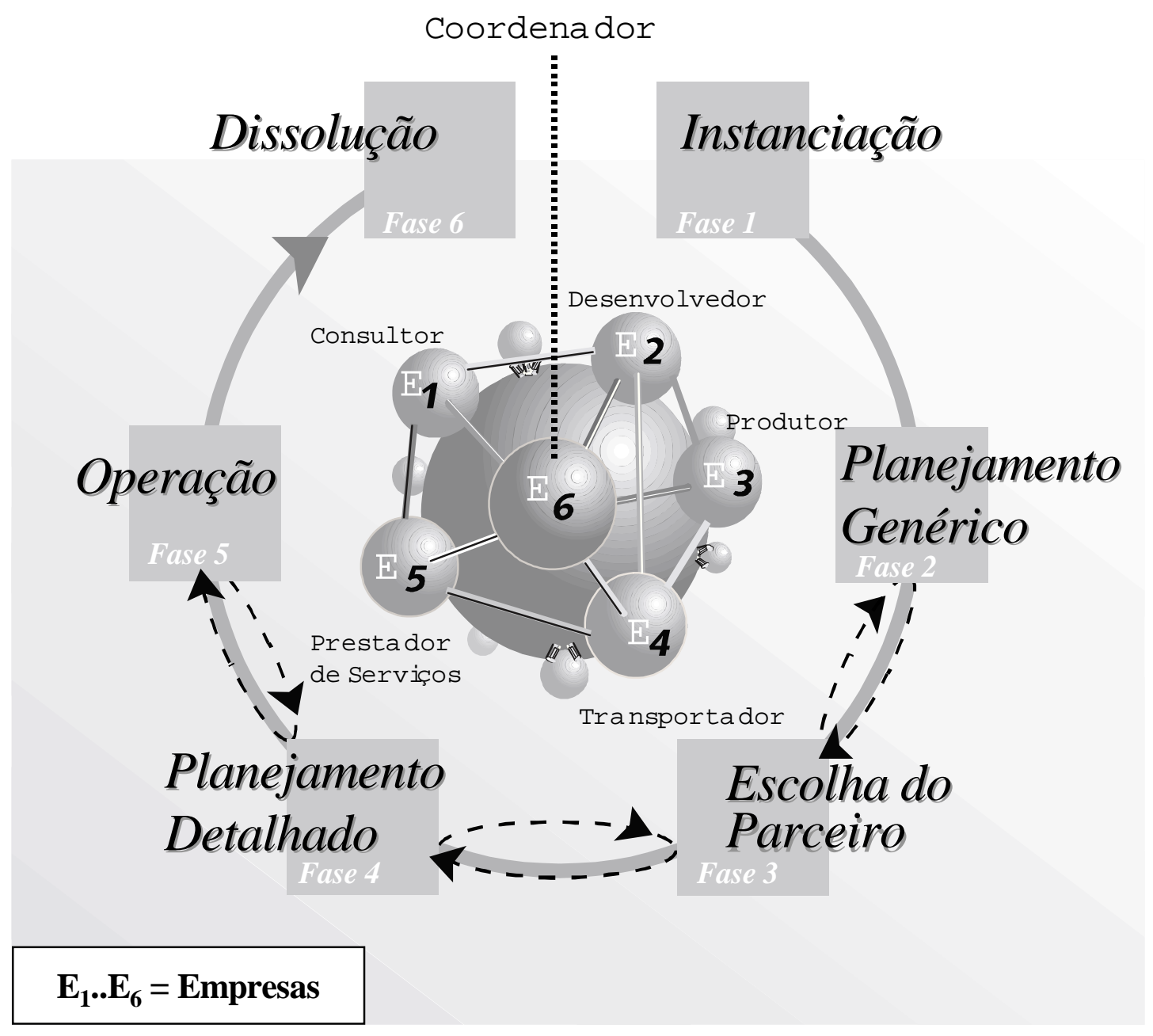

FIGURA 7: Ciclo de Vida de Empresas Virtuais (KOCIAN et al., 1997)

Como pode ser observado na Figura 7, uma instância de EV pode conter competências como consultoria, desenvolvimento, produção, transporte e prestação de serviços que são representadas por diferentes empresas. No centro, encontra-se o processo de coordenação da referida EV que é executado por um de seus parceiros.

A instanciação de uma EV pode ocorrer de duas variantes. A variante reativa corresponde à requisições de ofertas por parte de clientes em produtos ou serviços que são divulgados pela OV. A instanciação proativa corresponde aos resultados do processo de 
elaboração de visão estratégica da OV realizado por grupos (parceiros) específicos para esta finalidade. Após a definição da viabilidade da oportunidade segue então uma descrição completa da mesma para a próxima fase.

Para o planejamento genérico, os parceiros podem utilizar-se de resultados de projetos anteriores como ponto de saída para a implementação. Assim, nesta fase a descrição da oportunidade é relacionada com as competências necessárias para realizá-la, onde diferentes cenários com modelos organizacionais e de operação genéricos podem ser gerados e comparados. As interfaces entre as competências são analisadas e os fluxos de informações e de materiais são descritos genericamente. Informações sobre custo e tempo ideais são levantadas para a implantação de um sistema de índices de desempenho. Este sistema é o mecanismo básico para o monitoramento da operação da EV pois indica tanto a necessidade de reestruturação como de dissolução.

A seleção de parceiros é feita com base nas informações resultantes da fase anterior. Cada parceiro interessado em participar da EV deve apresentar suas informações sobre custo, tempo e disponibilidade (capacidade) de seus recursos. Um moderador dentro da OV analisa as informações e seleciona os parceiros que farão parte da EV. Assim, a figura de um moderador é necessária em casos onde haja disputa para uma competência oferecida por mais de um parceiro. Caso uma determinada competência não esteja no centro ou exista deficiência de capacidade, a procura de um novo parceiro é realizada conforme as condições estabelecidas pelas regras de admissão na OV.

No planejamento detalhado ocorre o detalhamento das estruturas organizacional e operacional elaboradas afim de suportar a integração dos parceiros selecionados. Os fluxos de informações e de materiais são também detalhados e aprovados por todos. A elaboração de uma visão estratégica específica para a EV é realizada contendo inclusive um plano de dissolução. A cultura da confiança é expandida à medida que os planos de dissolução são seguidos à regra. Aspectos como responsabilidade legal e direitos de utilização são determinados também nesta fase.

A operação da EV é então iniciada com base nos detalhamentos realizados na fase anterior. As ordens de pedido são executadas e cada parceiro exerce sua competência, como por exemplo na Figura 7 a empresa E2 realiza o desenvolvimento e a empresa E3 a produção. O processo de coordenação (empresa E6) controla a operação da EV como um todo e consequentemente a atuação de cada parceiro. Um processo de monitoramento, como parte do processo de coordenação, é implantado nesta fase e tem como base a freqüente 
análise do sistema de índices de desempenho, alimentado com dados da atuação conjunta dos parceiros. Assim, os resultados do processo de monitoramento indicam tanto a necessidade de reconfiguração como a de dissolução da EV.

A dissolução da $\mathrm{EV}$ acontece quando determinados índices de desempenho, previstos no plano de dissolução elaborado no planejamento detalhado, são atingidos. A partir da decisão de dissolução, algumas atividades são realizadas como o armazenamento de informações (modelos, índices, parceiros, etc.) para uso futuro e a distribuição dos direitos adquiridos. O sucesso da realização da última fase de uma EV influência diretamente o sucesso da OV como um todo, uma vez que os conflitos que possam ser gerados aqui não prejudique o fator confiança, condição necessária para a sobrevivência da OV.

\subsubsection{Descrição das Responsabilidades dentro da Organização Virtual}

De acordo com o que foi exposto nas seções anteriores surge a necessidade de se levantar as responsabilidades sobre as atividades dentro da OV. Estas responsabilidades (ou papéis) estão bem definidas na Fábrica Virtual de St. Gallen (Suíça), e por isso são detalhados a seguir (Figura 8) (MILLARG, 1997).

A entrada de uma ordem de pedido ou consulta por parte do cliente pode ser realizada de duas maneiras, como já foi dito. Na maneira proativa, a entrada de uma ordem é realizada através de um Broker, que possui um profundo conhecimento da área de atuação da OV. Com posse da descrição da competência de cada parceiro presente na OV, o Broker explora os possíveis mercados para os produtos e serviços que a OV pode oferecer. A aquisição da ordem de pedido através do Broker compreende uma definição geral de preços e benefícios à respeito do produto ou serviço em questão. Neste momento, o Broker realiza a intermediação entre o cliente e a OV. Desta maneira, as atividades do Broker relacionam-se com a primeira fase do ciclo de vida. 


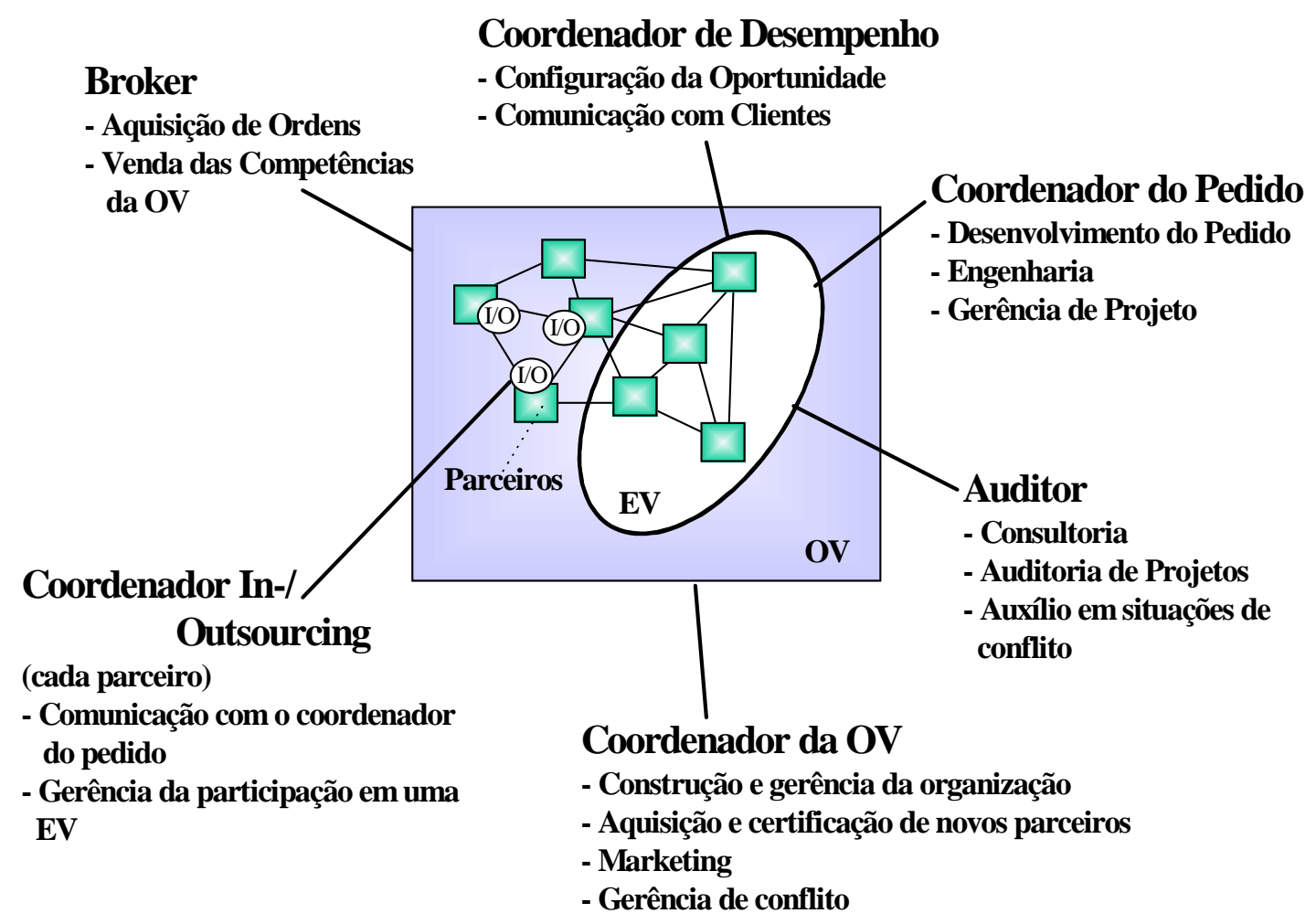

FIGURA 8: Responsabilidades dentro da Organização Virtual

(MILLARG, 1997)

Descrita uma ordem de pedido ou uma consulta, entra em ação o coordenador de desempenho que elabora a configuração da EV para a realização da oportunidade pela OV. Entre suas atividades podem ser destacadas:

- integração das competências dos parceiros presentes na OV;

- identificação das estruturas organizacional e operacional ideais;

- especificação detalhada da ordem de pedido assim como a elaboração de documentos para a sua realização;

- estabelecimento de métricas gerais de desempenho em termos de custo e tempo para cada competência necessária à EV;

- seleção dos parceiros e configuração final para o cliente. A consulta a bolsas de cooperações pode ser realizada caso não haja parceiro na OV para o cumprimento total da oportunidade;

- implantação de sistemas de apoio à operação da EV. 
O coordenador do pedido representa um outro papel importante na fase de operação da EV, uma vez que possui a função de integrar as diferentes firmas, tanto a nível cultural como técnico. A certificação da qualidade, tanto no produto quanto em sua entrega, é realizada juntamente com os responsáveis em cada empresa, os coordenadores in-/ outsourcing.

Os coordenadores in-/ outsourcing participam primeiramente na formação da EV fornecendo ao coordenador de desempenho informações sobre custo, tempo e capacidade para o cálculo do custo do pedido. $\mathrm{Na}$ operação da $\mathrm{EV}$, os coordenadores in-/outsourcing zelam pela coordenação de cada empresa no que tange à prazos e consequentemente a operação interna da empresa.

O cumprimento das regras de comportamento durante a operação da EV é policiado por um auditor. A posição do auditor é neutra e atua como um conselheiro nas situações de conflito, exercendo assim uma atividade de acoplamento entre OV, parceiros e cliente.

O coordenador geral da organização ocupa-se com a formação e gerência da OV através da aquisição e certificação de novos parceiros. Além disso, entre suas atividades pode-se destacar:

- qualificação de parceiros através de cursos;

- formação da base de confiança a ser explorada pelos parceiros e gerenciamento nas situações de conflito;

- construção da infra-estrutura de comunicação e informação;

- realização de atividades de marketing.

\subsubsection{Síntese}

Conforme pode ser encontrado na literatura, existem diferentes formas que viabilizam a geração de EV's, tais como mercado eletrônico (ODENDAHL et al., 1997), relacionamento entre empresas na cadeia de fornecedores (GRIESE, 1992), agenciador independente de informações (FAISST \& MERTENS, 1997) e organizações virtuais (KOCIAN \& SCHEER, 1996). Essas diferentes formas para a geração de uma EV podem ser agrupadas em três grupos distintos: sem a intermediação de nenhuma entidade, através de um Agenciador (Broker) ou dentro de uma Organização Virtual (Figura 9).

O primeiro grupo corresponde a iniciativa de uma empresa que, ao perceber uma oportunidade de negócio, procura parcerias para realizá-la. Essa procura pode acontecer de 
diferentes maneira, tais como no meio eletrônico, na relação de empresas que mantém contato, em feiras, em bolsas de cooperação, entre outras. A principal barreira nesta forma de geração de uma EV corresponde ao não conhecimento prévio entre as empresas, o que pode gerar problemas tanto na integração física (troca de informações) como na integração social (desentendimento na forma de gerenciamento, confiança, entre outros).

O segundo grupo corresponde à atuação de um Broker que, além de conhecer as competências de diferentes empresas, possui um profundo conhecimento sobre o mercado. Neste sentido, o principal recurso utilizado por um Broker consiste na formação e manutenção de um banco de dados que contém informações sobre as competências de diferentes empresas e características de diferentes mercados. Ao identificar uma oportunidade no mercado, ele a associa às competências necessárias e entra em contato com as empresas que estão em seu banco de dados. Esta forma de geração pode apresentar menos problemas no aspecto social desde que o Broker transmita um postura de confiança e selecione as empresas que tenham capacidade de cumprir os compromissos a serem estabelecidos.

O último grupo relaciona a formação de uma Organização Virtual com empresas que forneçam produtos ou serviços de forma diferenciada, ou seja, que focalizam a sua atuação nas suas competências (recursos e conhecimento). A estrutura formalizada da Organização Virtual (através de seus processos de coordenação, de um ciclo de vida estruturado e da definição de responsabilidades) visa derrubar as barreiras encontradas por outras formas de geração e consequentemente suportar o surgimento sistemático de Empresas Virtuais. Dessa forma, o sucesso do estabelecimento de uma Organização Virtual pode suportar um maior número de formação de Empresas Virtuais. 


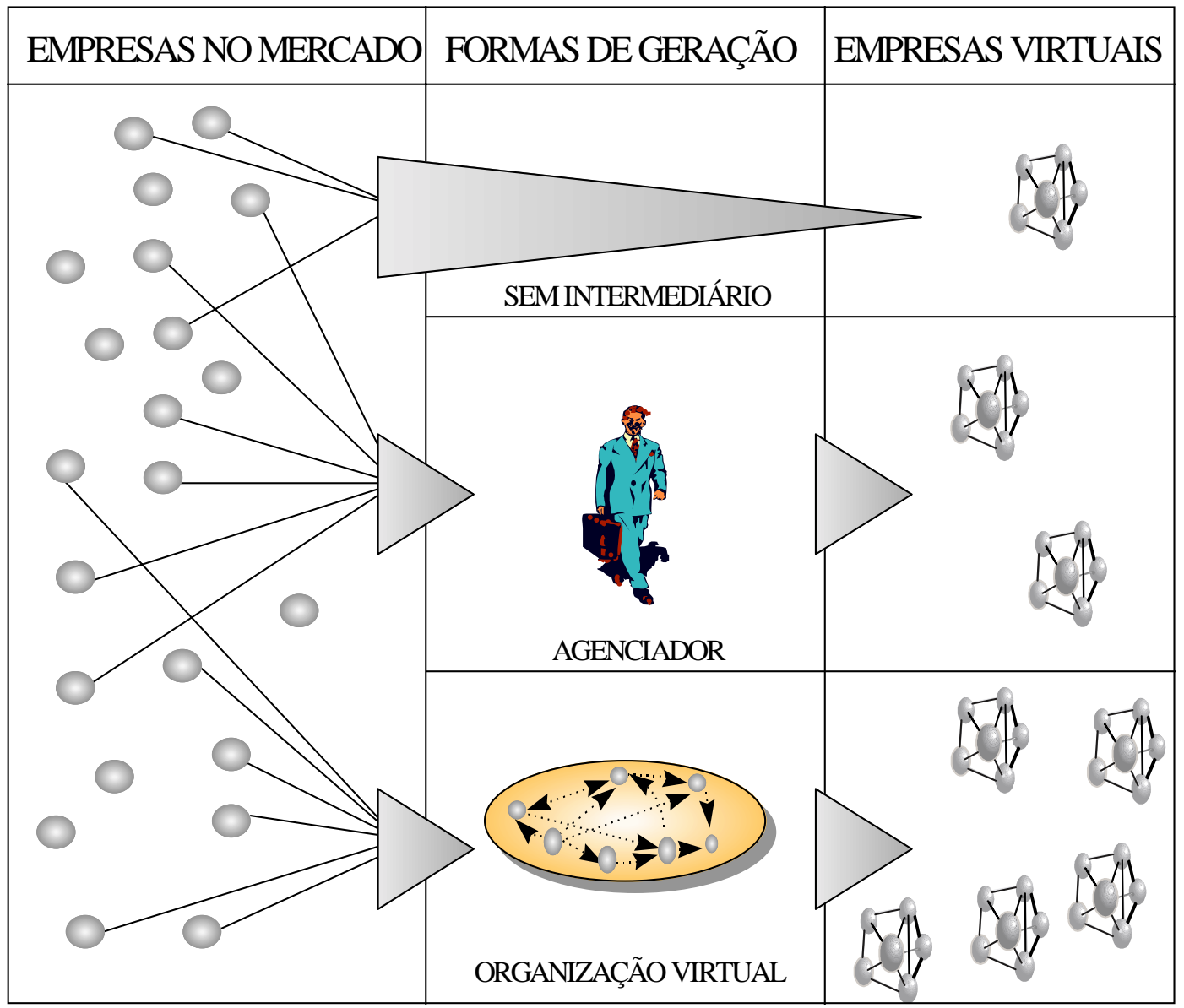

FIGURA 9: Formas de Geração de Empresas Virtuais

Portanto, este trabalho focaliza a formação de EV's a partir de uma Organização Virtual, com a utilização de um ciclo de vida, formalizado em diferentes fases, e a definição de responsabilidades para a execução das atividades de coordenação entre os parceiros. Como já foi dito, o principal foco do trabalho consiste na aplicação dos recursos da área de Integração de Empresas na integração dos parceiros durante o ciclo de vida de uma Empresa Virtual, dentro de uma Organização Virtual. Esta integração dos parceiros visa a formação da cadeia de valores da Empresa Virtual, onde algumas observações são dadas a seguir.

\subsection{Formação da Cadeia de Valores de uma Empresa Virtual}

Definida uma oportunidade de negócio a ser explorada pela OV inicia-se o processo de integração das competências de diferentes empresas. O resultado desta integração é a geração de Processos Distribuídos de Negócios que são realizados por diferentes empresas e 
representam a cadeia de valores de uma EV. No entanto, a complexidade de integração das empresas envolve vários fatores. A partir da consolidação de interesses de formação de uma $\mathrm{EV}$, existem os aspectos de conformação de capacidade, prazos e custos entre as diferentes empresas, ou seja, uma integração das informações gerenciais (KATZY, 1997b).

Concluída esta primeira instância de integração de interesses e capacidade, é iniciada a integração real dos processos. Para isso, é necessário um padrão de representação para os processos das empresas (KOSANKE, 1996). Segundo HRONEC (1993), a cadeia de valores de uma empresa é formada basicamente por processos primários, os quais são suportados pelos processos de gestão e de apoio. Por definição, processos

$\Rightarrow$ primários possuem um cliente (mesmo que interno a empresa) claro e que tem influência direta nos negócios da empresa. Como exemplo de processos primários encontram-se vendas, marketing, faturamento, entre outros;

$\Rightarrow$ de gestão gerenciam determinados parâmetros ou fatores dos processos primários, onde destacam-se o planejamento estratégico, da qualidade e de custos;

$\Rightarrow$ de apoio suportam os primários e são necessários para a execução destes. Como exemplo podem ser citados compras/suprimentos, planejamento financeiro e de recursos humanos (estes são responsabilidades de cada empresa dentro da OV).

Como uma EV deve se apresentar como uma unidade única para o meio externo, a sua cadeia de valores deve possuir os mesmos elementos que estão presentes na cadeia de valores de uma empresa tradicional. Neste sentido, uma EV pode ser entendida como um conjunto de processos distribuídos realizados por diferentes empresas (MÜLLER, 1997).

No entanto, uma outra perspectiva deve ser observada para que o processo de integração entre os processos seja transmitido de uma forma mais clara. Na Figura 10, a cadeia de uma EV está apresentada graficamente, onde a seqüência de atividades que representam os processos distribuídos está determinada (BREMER, 1997).

Portanto, a modelagem das empresas dentro da OV é recurso importante para o processo de integração. Informações padronizadas sobre recursos, organização, dados e processos facilitam a elaboração das interfaces entre as empresas. Na seção 2.4.3 é destacada a utilização da modelagem de empresas como atividade central de integração. 


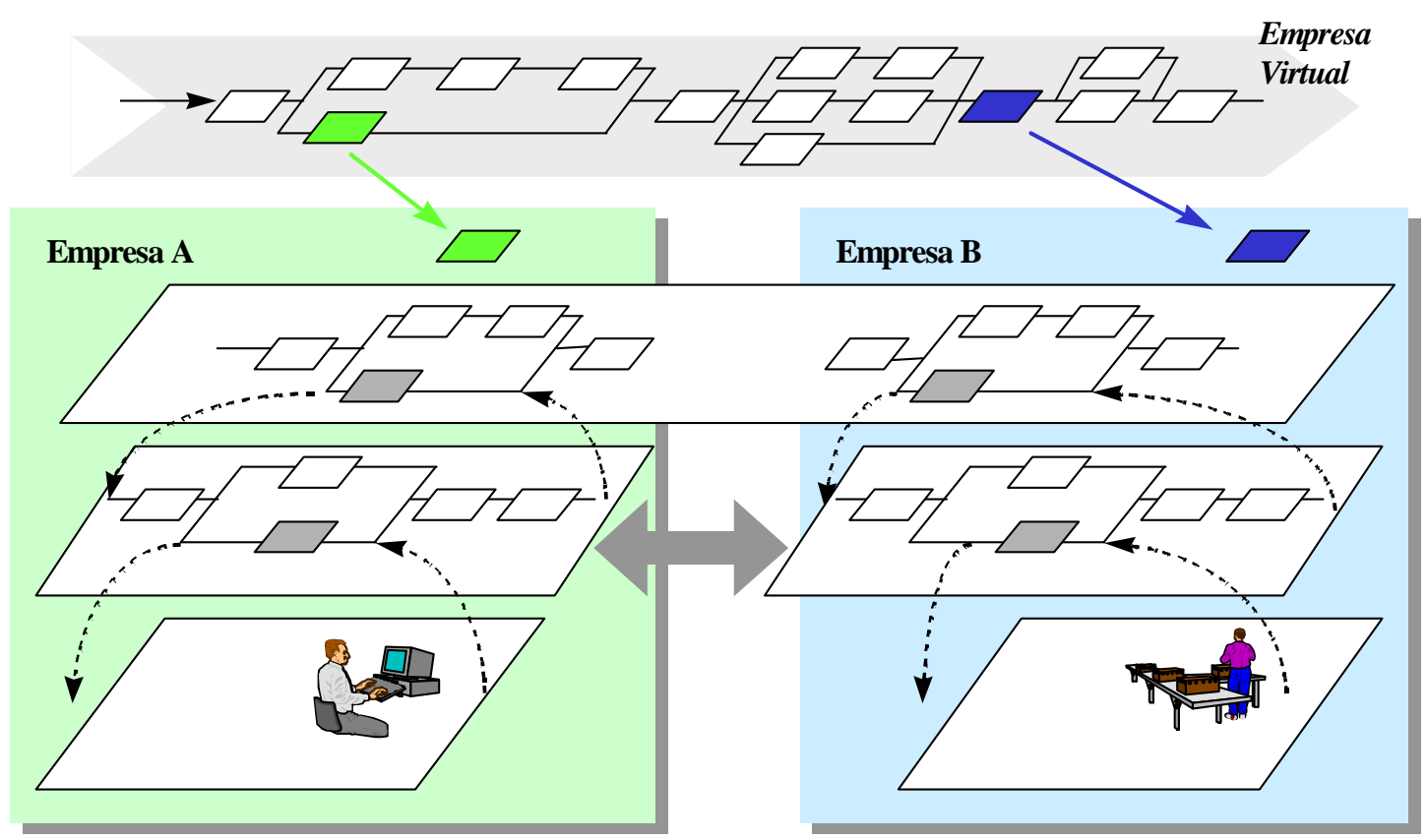

FIGURA 10: Seqüência de Atividades em uma Empresa Virtual (BREMER, 1997)

Neste sentido, fica identificada a necessidade de se buscar os recursos estabelecidos na área de Integração de Empresas para a otimização do processo de integração dos parceiros em EV's. Porém, antes de abordar sobre estes recursos, são apresentados alguns projetos dos quais foram levantados alguns dos mecanismos de coordenação de uma EV citados anteriormente.

\subsection{Alguns Projetos sobre Empresas Virtuais}

Nesta seção são apresentados quatro projetos que visam estabelecer mecanismos eficazes na consolidação do tipo de cooperação Empresa Virtual. Três deles são estritamente europeus (um na Alemanha e dois na Suíça) e o quarto atua a nível internacional envolvendo a Alemanha, o Brasil e o México.

\subsubsection{Projeto Kiesel}

O projeto de pesquisa Kiesel é financiado pelo „Bundesminiterium für Bildung, Forschung und Technologie“ - BMBF - (Ministério alemão para a Formação, Pesquisa e Tecnologia) e está previsto para um prazo de 3 anos tendo seu início em março de 1996. Kiesel é a abreviação para „Kooperationsmodell für virtuelle Kompentezzentren am Beispiel der Umwelttechnik“ (Modelo de Cooperação para Centros Virtuais de 
Competências com exemplo em Técnicas relativas ao Meio Ambiente) (KOCIAN \& SCHEER, 1996). A coordenação do projeto é realizada por uma pesquisadora da "Universität des Saarlandes".

O projeto concentra-se principalmente em nível regional onde todos os parceiros pertencem ao estado alemão de Saarland. Esses parceiros, PME's, estão reunidos em um centro (organização) onde são discutidos por um lado temas em comum à área de Meio Ambiente e por outro conceitos de cooperação de empresas onde a definição de Competências Essenciais e a formação de Empresas Virtuais constituem o aspecto central de pesquisa. Os principais obstáculos para a realização das cooperações, que são estudados no centro, concentram-se no problema da confiança, na escolha de parceiros, na realização de contratos, no problema do tempo e na comunicação.

As competências definidas pelo centro podem ser classificadas segundo consultoria geral, cursos de aperfeiçoamento, consultoria jurídica, auditoria e prevenção. Desta maneira, esses tipos de serviços são aplicados por exemplo à assuntos como economia de energia, poluição em geral (ar, água, sonora) e depósitos de lixos.

A construção da estrutura da confiança possui dois mecanismos básicos. Por um lado existe a atuação de um órgão neutro assumido pelo Centro para a Produtividade e Tecnologia (ligada à câmara da indústria e comércio do estado) que exerce o papel de moderação em situações de conflito. Por outro, o centro possui atividades gerais, como projetos de investimento, que são realizadas em determinados períodos e com isso há a possibilidade do contato pessoal para a discussão de metas comuns.

Como um requisito necessário para a participação no projeto, cada parceiro teve que providenciar acesso a Internet e endereço eletrônico, em cima do qual é realizado parte do controle de comunicação. Uma Intranet foi desenvolvida para tal finalidade. Além disso, existe a apresentação do projeto na Internet, juntamente com a oferta de serviços. Atualmente não é realizada nenhuma ordem de pedido que envolva mais de um parceiro pois o objetivo é concretizar a estrutura da organização. A instanciação de EV's, ou seja, de uma cooperação entre os parceiros ainda está sendo discutida. A realização do pedido é feita como mostra a Figura 11. 


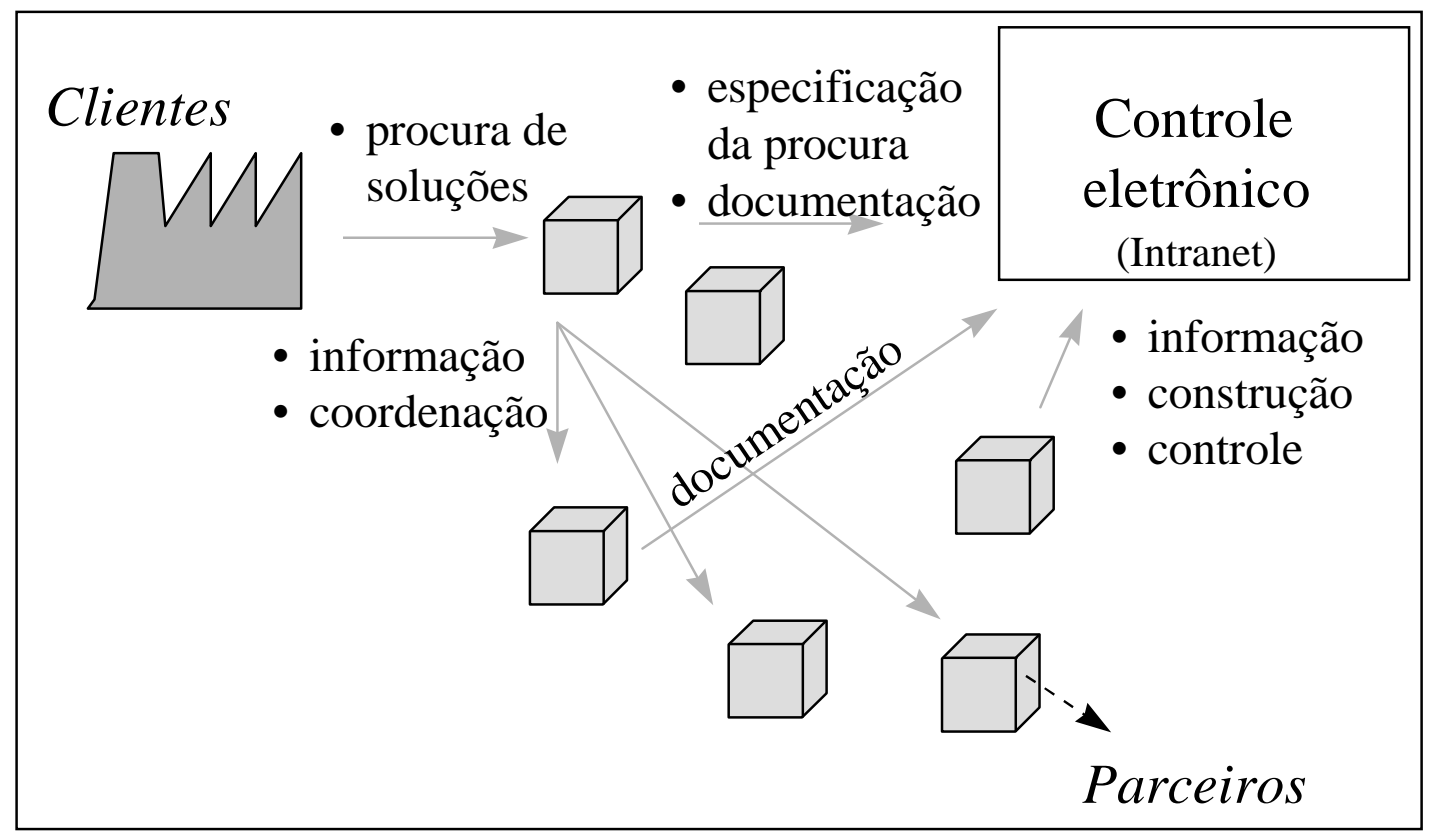

FIGURA 11: Realização do Pedido dentro do Projeto Kiesel

\section{(KOCIAN \& SCHEER, 1996)}

A procura de soluções pode ser realizada através de um "Information-Broker" (agente que armazena e administra as informações do centro) que a redireciona para o parceiro responsável por fornecer o serviço correspondente.

\subsubsection{Virtual Company}

Ao contrário do projeto Kiesel a Virtual Company surgiu da iniciativa de uma empresa suíça de consultoria que baseada no seguinte lema conseguiu se expandir para outros parceiros: Não é o tamanho de uma empresa que é importante, e sim o tipo e a qualidade de seus produtos, e sobretudo, a capacidade de se adaptar rapidamente à novas situações e sem muito esforço (ZWICKER, 1996). Além disso, a expansão se deve muito a definição de objetivos claros, entre os quais podem ser destacados:

- ampliação da própria oferta através da utilização de competências essenciais e clientes de outros parceiros;

- flexibilidade e curtos caminhos de decisão através da eliminação de níveis hierárquicos, características inerentes ao ambiente de PME's e

- ações ou atividades comuns como troca de idéias e experiências ou estratégias de marketing. 
As competências essenciais que se encontram na Virtual Company estão relacionadas à tecnologia de informação, tais como banco de dados relacionais, sistemas operacionais, integração de sistemas, redes corporativas, linguagens de programação, entre outras. Essas tecnologias são utilizadas em projetos de reengenharia de processos de negócios, "downsizing" e certificação da qualidade. Desta maneira, os serviços oferecidos pela organização podem ser divididos em consultoria, planejamento, engenharia, realização e cursos. Estes serviços também estão presentes na Internet.

A admissão de um parceiro na organização tem que ser realizada através da indicação de um membro da mesma, que se torna parceira pela sua atuação. A firma interessada tem que atuar basicamente na área de serviços e deve principalmente fornecer algo diferenciado para que não haja situações de concorrência. O número máximo previsto para a atuação da organização é de 25 empresas. Caso haja situações de concorrência, é colocado em prática um código de comportamento, o qual cada parceiro deve estar ciente e de acordo no processo de admissão. $\mathrm{O}$ código baseia-se nas seguintes diretrizes:

- respeito aos interesses dos parceiros de acordo com a qualidade e competência dos mesmos;

- cada parceiro possui as mesmas obrigações dentro da organização, contribuindo com os mesmos valores de anuidades, utilizadas para a administração e iniciativas comuns de marketing. Desta maneira, cada parceiro também possui os mesmos direitos, como por exemplo na votação referente à exclusão de um parceiro e

- a cooperação aberta e transparente é difundida entre os parceiros. Cada parceiro deve oferecer o seu ciclo de clientes para que tenha acesso aos clientes de outros parceiros.

Diferente do projeto Kiesel, onde há um "Information-Broker" central, na Virtual Company cada parceiro recebe a procura por parte do cliente e a traz para o conhecimento de outros parceiros, quando não possui todas as competências necessárias (Figura 12). 


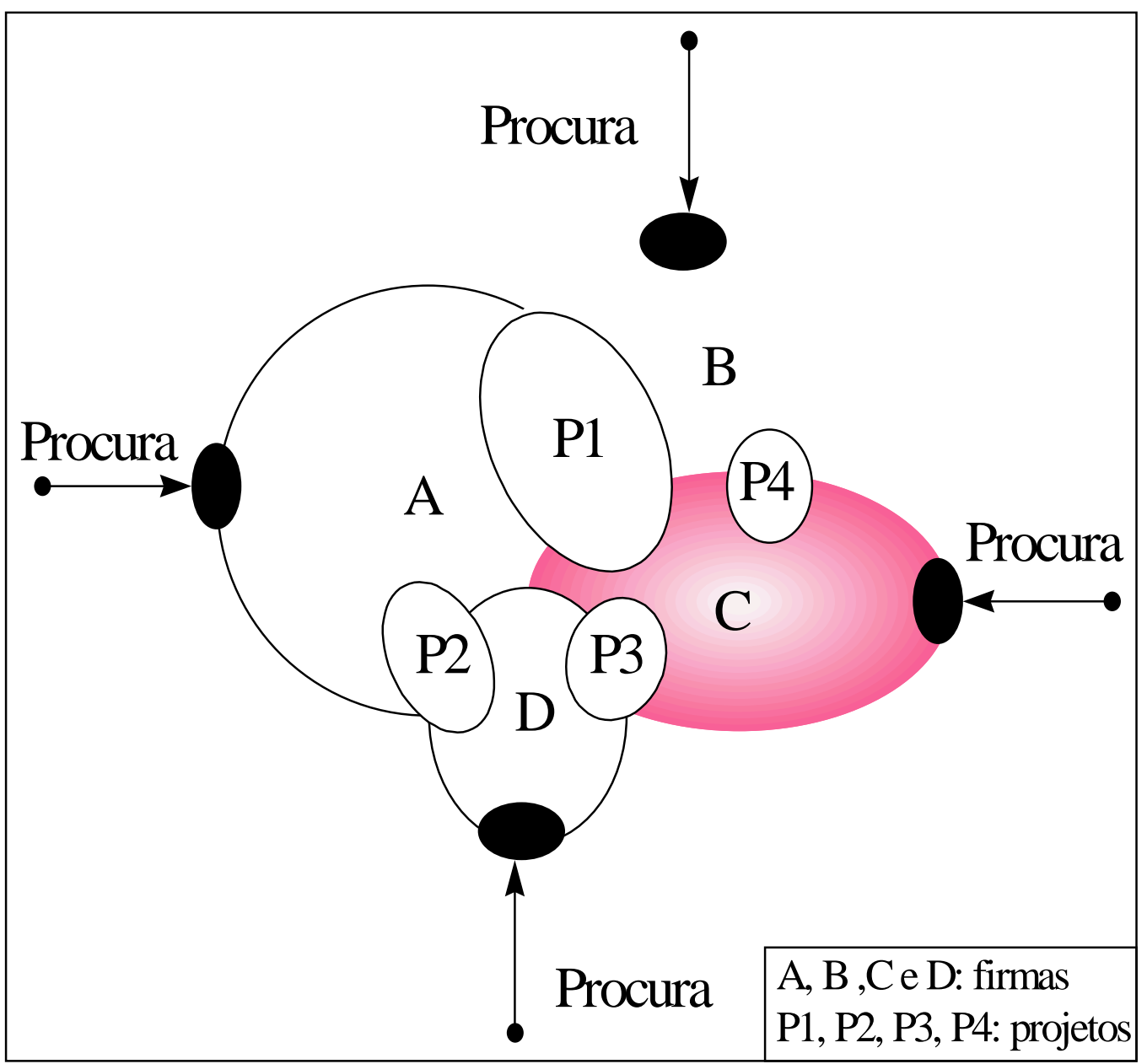

FIGURA 12: Realização do Pedido na Virtual Company

A realização do pedido é feita então com a execução de projetos que envolve mais parceiros. Por exemplo, na Figura, o projeto P1 é realizado pelas firmas A, B e C onde a procura pode ter sido por A.

\subsubsection{Fábrica Virtual}

O projeto Fábrica Virtual é desenvolvido pela Universidade de St. Gallen (Suiça), onde a criação e operação de uma fábrica virtual é testada. O objetivo é, através da combinação flexível de competências essenciais, atingir um aumento da capacidade de competição das empresas participantes, além de se aproveitar, de uma melhor maneira, oportunidades de mercado. A base do projeto é o trabalho conjunto em uma rede de empresas, que representa um conjunto de competências disponíveis. Deste conjunto são unidas as competências necessárias para se atender uma determinada oportunidade de 
mercado. Pela duração da referente oportunidade (ou pedido) é formada e operada uma Fábrica Virtual (KATZY, 1997a)

Característica principal no trabalho conjunto é a eliminação de contratos legais de cooperação. Em seu lugar é utilizado um contrato padrão, onde não constam detalhes da cooperação, mas somente algumas "regras do jogo“. Para tanto, é tido como necessário um alto grau de confiança entre os parceiros da fábrica virtual, obtida através de um encontro constante e periódico entre os responsáveis das empresas participantes.

O Instituto de Gerência Tecnológica (ITEM) da Universidade de St. Gallen assume no projeto a função de gerente da rede de empresas, tanto pelo lado de manutenção do relacionamento entre os participantes da rede, quanto pelo lado técnico onde o ITEM tem como responsabilidade criar uma base de dados de competências das empresas (SCHUH, 1997). Assim, busca-se reduzir o tempo de formação das fábricas virtuais através de uma busca otimizada das competências necessárias. Todavia nenhuma tecnologia mais sofisticada de comunicação e informação tem sido utilizada, somente fax e telefone, além de encontros pessoais.

O estado atual do projeto está limitado aos processos de produção, onde sua expansão para processos de desenvolvimento de produtos e pesquisa conjunta está prevista. Além disso, está em planejamento o desenvolvimento de uma ferramenta para a gestão dos pedidos e da produção.

\subsubsection{Projeto Global Virtual Enterprise}

O Global Virtual Enterprise - GVE - consiste na formação de uma cooperação a nível mundial entre empresas, universidades e agências governamentais para aumentar o seu desenvolvimento econômico e de negócios, baseado no paradigma de Empresas Virtuais (BREMER et al., 1998) (Figura 13). Os parceiros do projeto são:

- Instituto Tecnologico y de Estudios Superiores de Monterrey (ITESM) / México

- Laboratorium für Werkzeugmaschinen und Betriebslehre (WZL) - RWTH Aachen / Alemanha

- Universidade de São Paulo - Campus de São Carlos (USP) / Brasil 


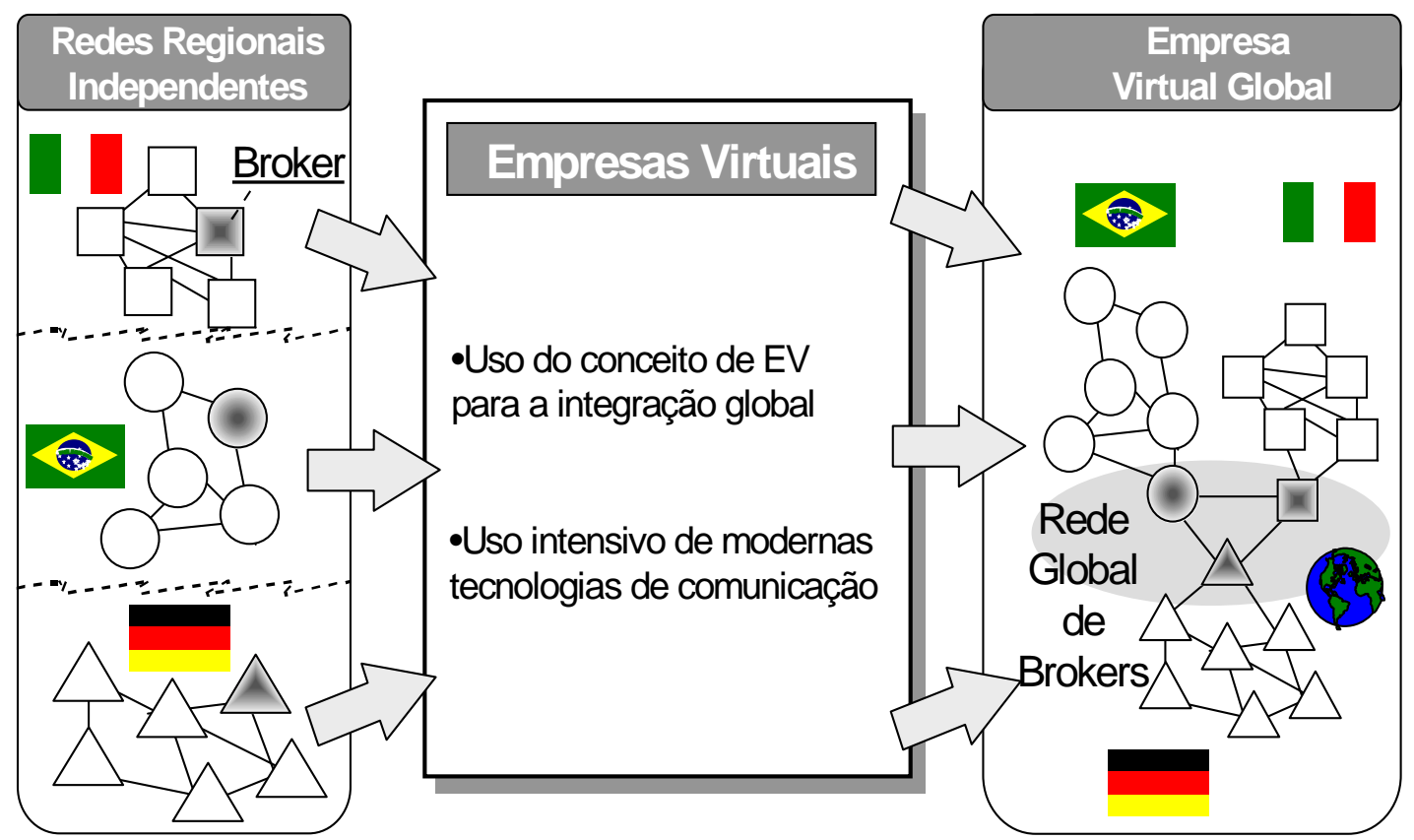

FIGURA 13: Projeto Global Virtual Enterprise (BREMER et al., 1998)

Como pode ser observado na Figura, a intenção do GVE é, em um primeiro momento, a formação de redes regionais independentes através da atuação de um Broker e, em seguida, a formação de uma rede global de empresas integradas pelos Brokers. Para isso, o processo de padronização tanto das informações como da utilização da TI assume um papel central para o sucesso do projeto.

O enfoque é dado na utilização de PME's para a formação das redes regionais, tendo em vista a sua importância, já ressaltada anteriormente. O setor a ser explorado é o de indústrias, e desta maneira, pelo lado brasileiro a intenção consiste na formação de uma rede de PME's de alta tecnologia da cidade de São Carlos e região.

Para a viabilização destes objetivos, o projeto apresenta três entidades (Figura 2-14):

- Grupo Virtual de Indústrias: agregação de companhias de setores diversos da indústria, com competências de enfoque bem definido, com o propósito de ganhar acesso a novos mercados e oportunidades de negócio por alavancagem de seus recursos;

- Agenciador de EV's: esta entidade é responsável pela busca de oportunidades no ambiente global e habilita a criação das Empresas Virtuais. O Broker da Empresa Virtual desempenha os processos de procura e seleção de parceiros e configura infra-estruturas adequadas para formação/dissolução (físicas, legais, sócio-culturais, informação). Para atingir seu objetivo o Broker usa os serviços fornecidos pelo Grupo Virtual de Indústrias; 


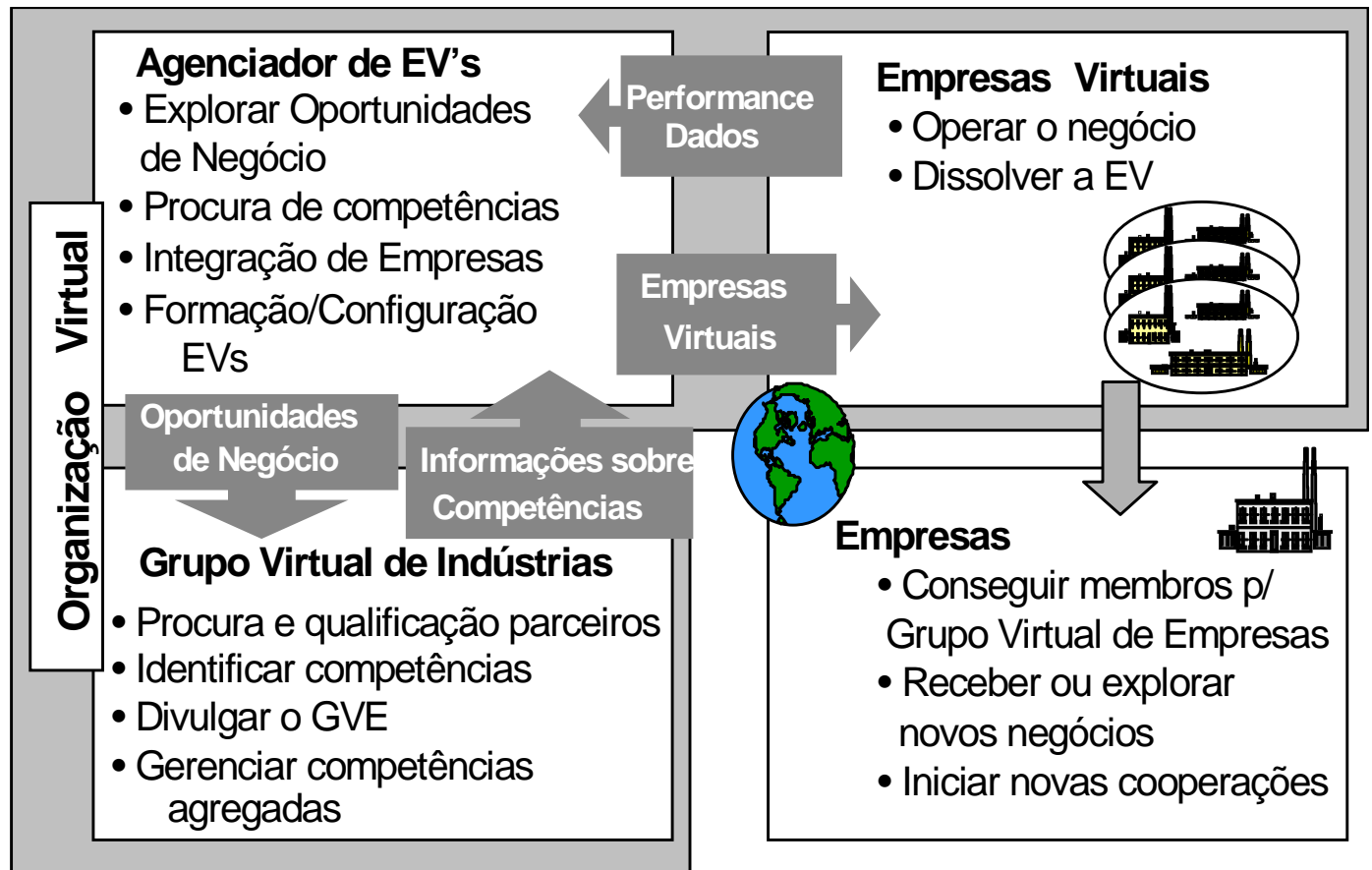

\section{FIGURA 14: Relacionamento entre as Entidades do Projeto GVE}

- Empresas Virtuais: redes temporárias de companhias independentes ligadas por Tecnologia da Informação e que compartilham competências, infra-estruturas e processos de negócios, com o propósito de preencher novos requisitos de mercado.

Para cada uma destas entidades os membros do GVE já definiram quais são os processos relacionados, ou seja, qual a função de cada uma e como elas se relacionam. Este relacionamento é dado na forma de geração de um produto, como por exemplo, no relacionamento entre o Grupo Virtual de Indústrias e o Broker, o produto são as informações sobre as competências dos parceiros a serem utilizadas pelo Broker para a formação de Empresas Virtuais.

\subsection{Integração de Empresa}

A partir da globalização da economia, a concorrência entre as empresas tornou-se mais acirrada determinando uma procura maior por melhoria de performance. Neste contexto, o termo "Integração de Empresa" possui um papel central que vem sendo discutido há duas décadas, representadas por diferentes conceitos ou propostas.

$\mathrm{Na}$ década de 70, grandes empresas fizeram investimentos vultuosos na implantação de sistemas computacionais que de um lado resultaram em um aumento do desempenho, mas 
por outro apresentaram enormes dificuldades para modificações nos mesmos. Isto provocou uma decepção na relação custo/benefício de implantação de tais sistemas (SCHEER, 1995).

Desta maneira, surgiu então o conceito de "Arquitetura", com a qual uma empresa poderia representar o seu funcionamento sobre diferentes perspectivas, representadas por recursos humanos, estrutura organizacional, informação e processos de manufatura. Nesta época as metodologias ainda enfatizavam a utilização de recursos da Tecnologia da Informação, o que mais uma vez decepcionou as empresas que se utilizaram do conceito de Arquitetura sobre esta perspectiva (ROZENFELD, 1996).

Um conceito que surgiu na década de 80 e vem sendo pesquisado até os dias de hoje é o "Computer Integrated Manufacturing" - CIM. Como Rozenfeld mostra, este conceito mudou seu foco de atenção para se ajustar as necessidades das empresas em busca de melhora de desempenho (ROZENFELD, 1996). Na sigla, o foco saiu da letra "C" para letra "I", ou seja, a utilização do computador, da Tecnologia da Informação passou a ser uma das visões na qual uma empresa é observada (Figura 15). O termo Integração assumiu assim o papel central para a melhora de desempenho de uma empresa.

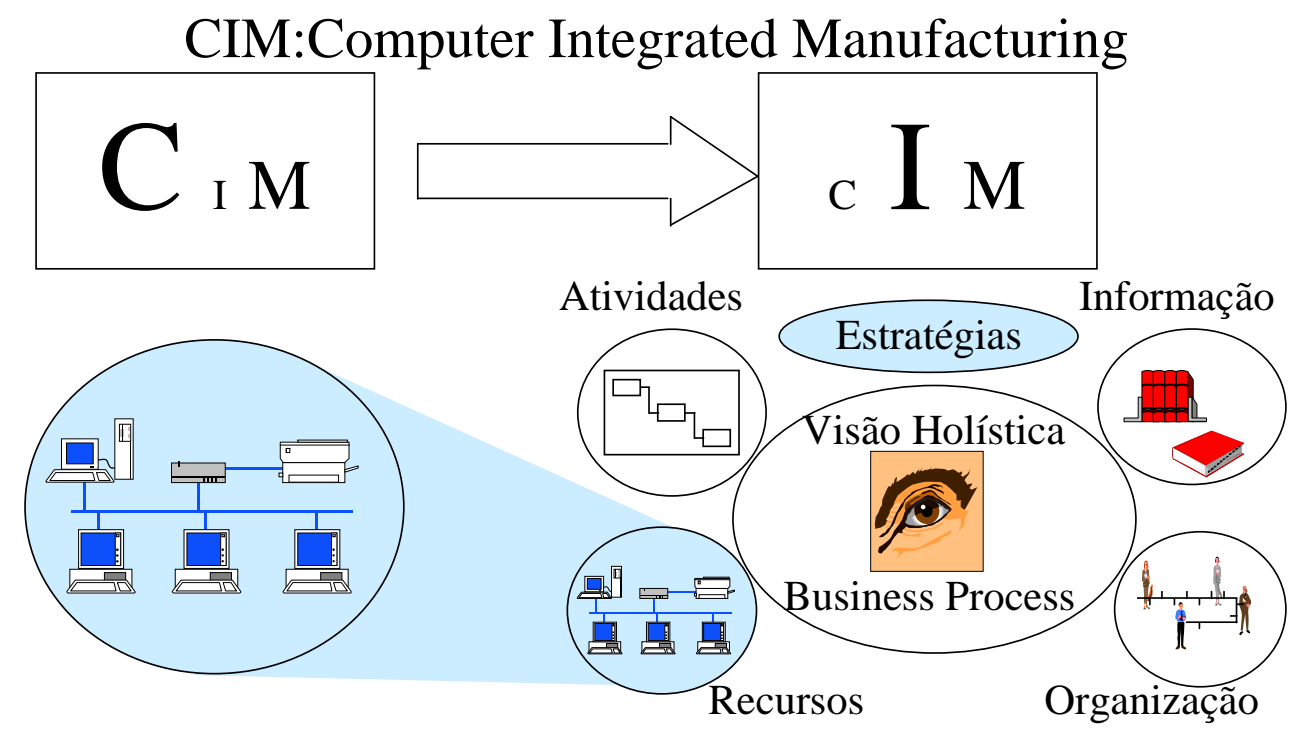

FIGURA 15: Evolução da sigla CIM (ROZENFELD, 1996)

Segundo RENTES (1996), visão holística de uma empresa equivale a se ter uma "imagem única", sintética de todos os elementos da empresa, tais como estratégias, atividades, informações, recursos e organização, assim como suas interrelações.

Para a construção desta visão holística o conceito de "Business Process" (Processo de Negócio) é fundamental. Um Processo de Negócio é um "fenômeno que ocorre dentro 
das empresas que corresponde à um conjunto de atividades muitas vezes interdepartamentais e/ou interdisciplinares, associadas às informações que manipula, utilizando os recursos e a organização da empresa, gerando uma saída de valor para o cliente. Forma uma unidade coesa e deve ser focalizado em um tipo de negócio, que normalmente está direcionado a um determinado mercado/cliente, com fornecedores bem definidos" (ROZENFELD, 1996).

Dentro deste contexto, o termo Integração de Empresa - IE - questiona sobre os processos de negócio da empresa que, antes mesmo de reprojetá-los, investiga como os mesmos podem ser melhorados utilizando-se da tecnologia e recursos humanos. Neste sentido, as filosofias/conceitos que tratam a IE identificam e descrevem a missão da empresa, objetivos, estratégias, metas e restrições, estruturas organizacionais, recursos, e todos os processos de negócios e gerenciamento na cadeia de valores do produto. Além disso, essas filosofias/conceitos identificam tanto os requisitos dos processos de negócio como as opções de soluções, apresentam projetos alternativos e fornecem caminhos de implementação à nível estratégico, tático e operacional (NELL, 1995).

Ressaltada a importância da utilização dos conceitos sobre IE, é necessário apresentar os mecanismos que viabilizam os objetivos difundidos por esta área do conhecimento. Entre os principais mecanismos podem ser citados (WILLIAMS et al., 1995):

- a utilização de uma arquitetura de referência para a realização da modelagem da situação atual das empresas;

- a utilização de uma ferramenta computacional para o armazenamento eletrônico das informações levantadas nas empresas:

- a utilização de uma metodologia para guiar o processo de otimização da empresa.

$\mathrm{Na}$ literatura e na prática existem diferentes arquiteturas sendo utilizadas. Entre elas pode-se destacar o CIMOSA e o ARIS. Cada uma delas foi desenvolvida com o propósito de padronizar a representação lógica de uma empresa. Uma discussão de cada uma delas foge do escopo deste trabalho. No entanto, pode-se afirmar que o ARIS teve uma difusão maior devido à funcionalidade que a ferramenta computacional, que suporta a utilização da arquitetura de mesmo nome, oferece através de diferentes componentes. Isto pode ser confirmado através do ranking, publicado pelo Gartner Group em 1996, das ferramentas utilizadas em projetos de reorganização de empresas (SAARBRUCKER ZEITUNG, 1996). Neste ranking ARIS se encontra em posição de liderança. Neste sentido, a próxima seção descreve a arquitetura e ferramenta ARIS. 


\subsubsection{A Arquitetura ARIS}

A arquitetura ARIS (“Architektur für integrierte Informationssystem” - Arquitetura para Sistemas Integrados de Informação) foi elaborada por Scheer para apoiar a aplicação do conceito CIM, onde o processamento integrado das informações, necessárias às tarefas técnicas e operacionais de uma empresa, consistia no objetivo principal (SCHEER, 1991). Em outras palavras, ARIS foi desenvolvida para suportar, a princípio, o desenvolvimento de sistemas integrados de informação. No entanto, ARIS está sendo utilizada atualmente também para outras duas atividades largamente difundidas: a descrição e otimização de Processos de Negócios e a implantação de Sistemas Integrados de Gestão (SCHEER, 1996).

A arquitetura ARIS está dividida em quatro visões distintas: Organização, Função, Dados e Controle (Figura 16). Para cada visão existem diferentes métodos que podem ser utilizados para descrever o mundo real. A interligação entre as diferentes visões ocorre pela de Controle. Nesta visão existem diferentes métodos com elementos que também pertencem à métodos das outras visões.

Para a descrição dos Processos de Negócio o método mais importante concentra-se na visão de Controle e chama-se EPK ("Ereignisgesteuerte Prozeßkette" - Diagrama de Processos Controlado por Eventos). Este diagrama contém dois elementos básicos (função e evento). $\mathrm{O}$ evento contém informações que inicializam as funções que por sua vez produzem eventos, e assim formando a seqüência de atividades que estão em um processo. 


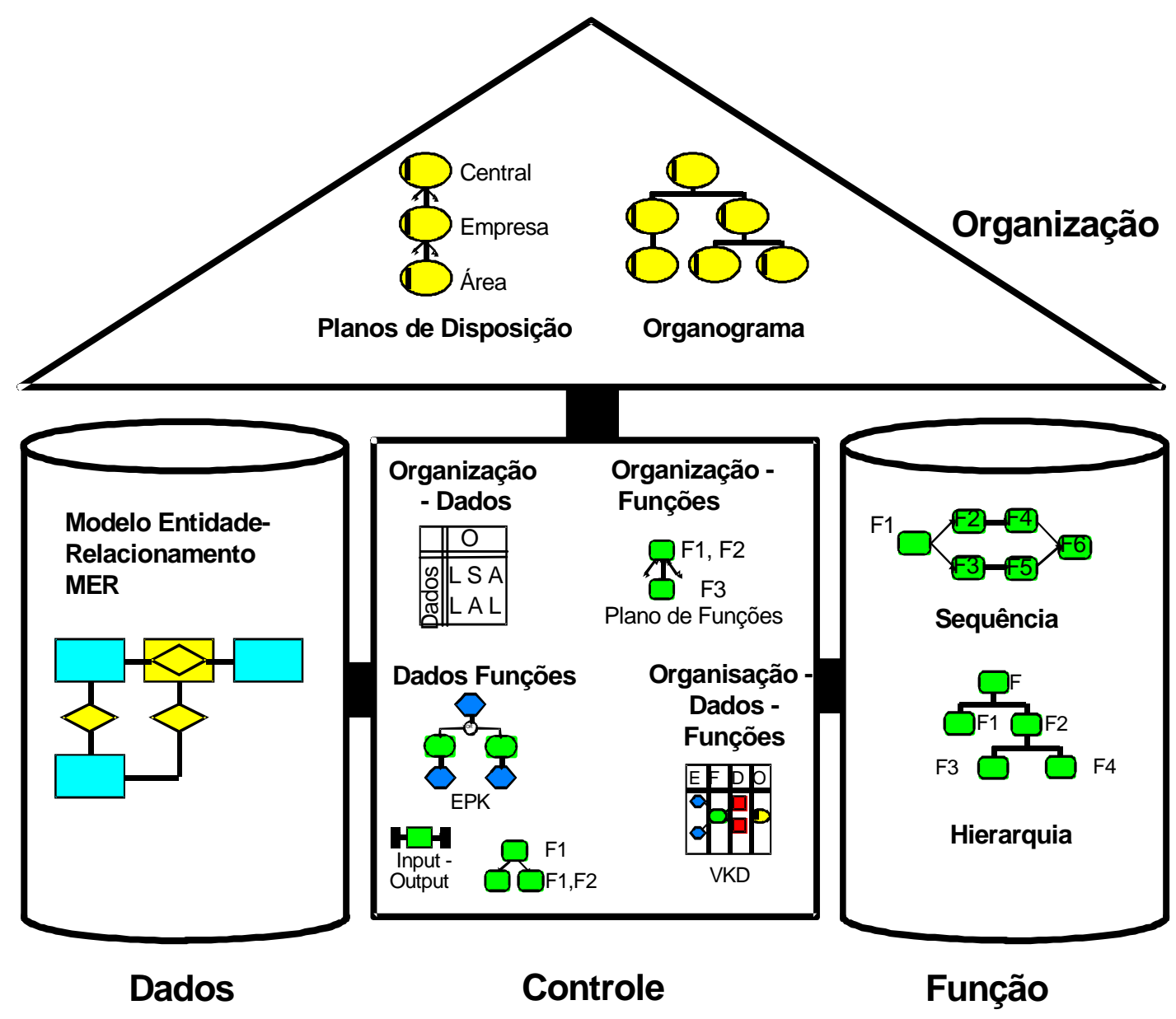

FIGURA 16: Arquitetura ARIS (SCHEER, 1991)

$\mathrm{Na}$ área de otimização de processos, ARIS evoluiu de uma ferramenta de modelagem para um novo conceito que realiza um maior controle nas atividades de reorganização dos processos. Este novo conceito denominado ARIS "House of Business Engineering“" separa os aspectos de modelagem e realização do processo em quatro planos distintos: otimização do processo, gerência do processo, workflow e aplicações (Figura 17). 


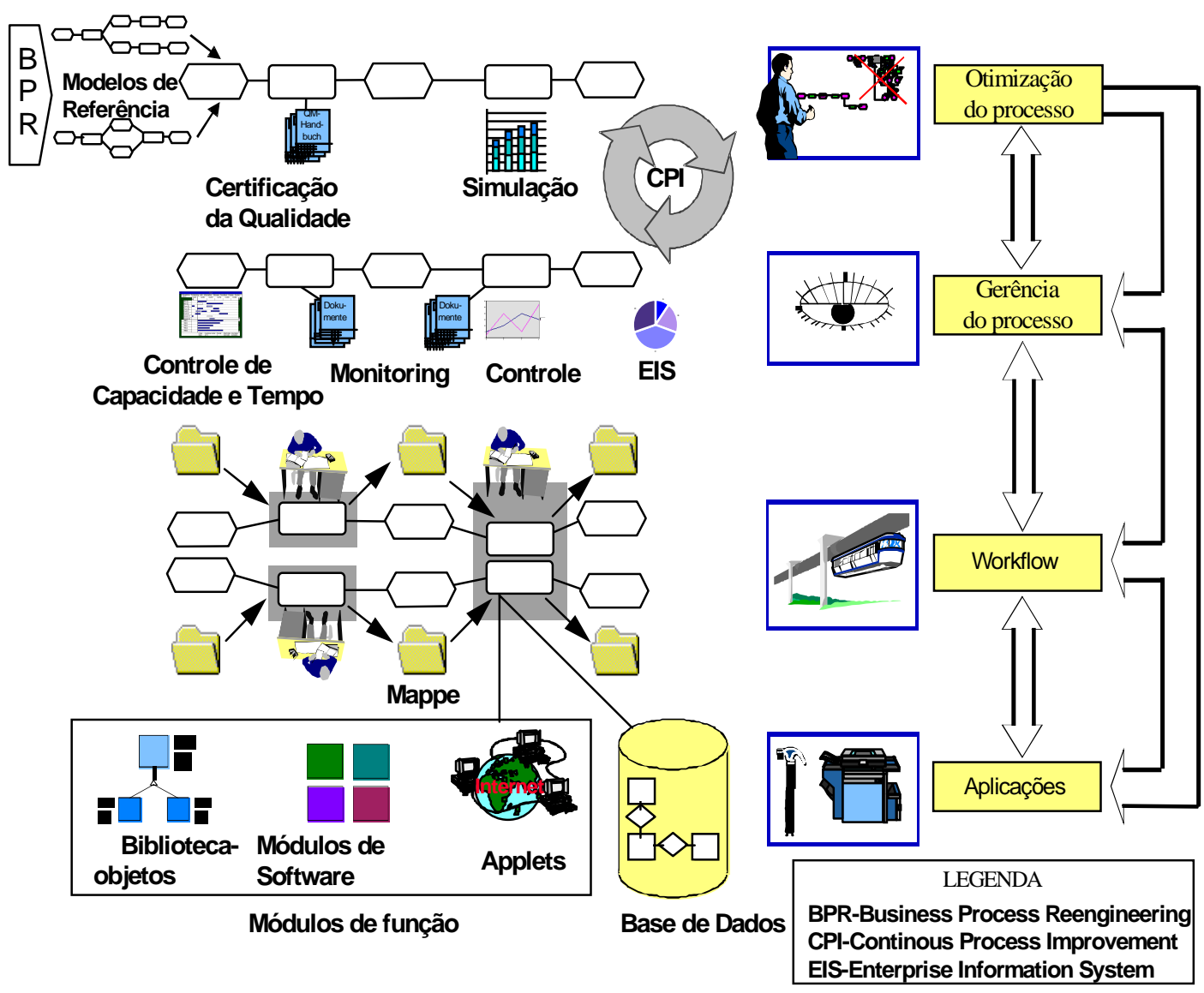

FIGURA 17: ARIS - House of Business Engineering (SCHEER, 1996)

O primeiro plano corresponde a otimização dos processos a nível descritivo ou de modelos, onde a utilização de modelos de referência servem como base para a geração de modelos ideais. Além disso, a simulação de processos indica o comportamento dinâmico do funcionamento de um processo, e com isso, pode apontar pontos de melhoria que são difíceis de perceber através de uma análise estática. Por último, neste plano ainda pode haver a geração de manuais de qualidade.

A gerência do processo corresponde aos sistemas de informação gerenciais que de uma certa maneira monitoram a operação dos processos e indicam a necessidade de alterações. Assim, os dois primeiros planos podem constituir a base para a aplicação do processo de melhoria contínua ("Continuous Process Improvement" - CPI).

Os dois últimos planos correspondem a operação real do processo, onde o sistema workflow controla o fluxo de trabalho que é executado por diferentes estações de trabalho. Nestas estações, diferentes aplicativos podem ser utilizados, que por sua vez, podem ter sido gerados a partir dos modelos descritos na ferramenta. A descrição do fluxo de trabalho, do 
processo em si, que é fundamental para implantação do sistema workflow, também é modelado na ferramenta.

\subsubsection{Metodologia de Integração}

$\mathrm{Na}$ literatura podem ser encontradas diferentes metodologias que abordam o tema Integração de Empresas. Essas metodologias diferem-se de acordo com a aplicação de diferentes conceitos e/ou tecnologias. Isto pode ser verificado observando-se a evolução do que antes era o planejamento e a implantação dos componentes CIM para metodologias de gerência da mudança em um ambiente altamente competitivo (BREMER, 1995).

Este trabalho não visa realizar a comparação entre diferentes metodologias de integração e tampouco discutir a sua situação a nível nacional, e sim mostrar a sua relevância em projetos de melhoria. Neste ponto, vale ressaltar que uma metodologia necessita comportar os seguintes componentes (WILLIAMS et al., 1995):

- um modelo de referência genérico que mostre a estrutura do projeto a ser estudado;

- um ou mais formalismos de modelagem que viabiliza a criação de modelos para estudálos e avaliá-los;

- uma técnica estruturada para todo o programa de execução, passo por passo, até uma situação futura considerando o monitoramento da evolução dos objetivos e restrições específicas;

- critérios de avaliação do desempenho com os quais a situação futura pode ser comparada em relação à vários pontos de vista (econômicos, confiança. etc.).

De uma maneira geral, uma técnica estruturada ou uma metodologia é um conjunto de passos a ser seguido para resolver um problema. Dentro do conceito de uma metodologia de integração, a técnica estruturada deve cobrir todo o ciclo de vida do projeto de integração o qual é dividido em várias etapas (análise, projeto, desenvolvimento, implementação e operação). Cada passo da metodologia deve ser definido precisamente e baseado em uma estrutura de projeto padronizado fornecendo o conjunto de atores para os quais o trabalho deve ser igualmente bem definido (NELL, 1995).

Como um exemplo que segue as diretrizes citadas acima, é apresentada a seguir uma metodologia de integração de empresas que atualmente está sendo desenvolvida na Escola 
de Engenharia de São Carlos da Universidade de São Paulo. Esta metodologia ressalta a utilização do conceito de modelo de empresa, fundamental na execução deste trabalho.

\subsubsection{Metodologia de Integração de Empresas}

De acordo com as novas tendências, a Metodologia de Integração de Empresas MIE - do Projeto Integração do Núcleo de Manufatura Avançada (NUMA) da USP de São Carlos baseia-se no conceito de Change Management (RENTES et al., 1996). Segundo este conceito, as mudanças que ocorrem em uma empresa acontecem de maneira circular, onde a definição de novos objetivos e metas e a proposição de novos processos é sempre reinicializada ao final de cada implementação de um projeto ou sempre que se julgar necessário.

A MIE é resultado de trabalhos de diferentes pesquisadores desde a última década, onde já houve a elaboração de diferentes cenários de integração em uma Fábrica Integrada Modelo. Além disso, houve também projetos com indústrias que enriqueceram tanto o desenvolvimento como a aplicação da metodologia. O principal objetivo da MIE consiste na formalização de uma arquitetura para sistematizar, organizar e integrar vários métodos relacionados. Três dimensões podem ser consideradas na aplicação da MIE (Figura 18).

A primeira é a dimensão Metodologia de Intervenção, que envolve passos a serem seguidos no processo de integração da empresa, com a sugestão de uma seqüência a ser implementada. Nesta dimensão é proposta uma lógica de condução para o projeto de integração assim como um formalismo para o levantamento das informações.

A próxima é a dimensão de Processos Empresariais ou de Processos de Negócios que focaliza diferentes tipologias de empresas orientando a diferenciação dos métodos de intervenção para cada tipo. De acordo com o tipo da empresa a ser integrada, as classes de Processos de Negócios devem ser identificadas assim como as filosofias e conceitos correspondentes para serem utilizados no processos de gerência da mudança (do Change Management). De acordo com estes conceitos uma seqüência de performance é estabelecida, possibilitando recomendações com focos bem definidos para a mudança do Processo de Negócio. 


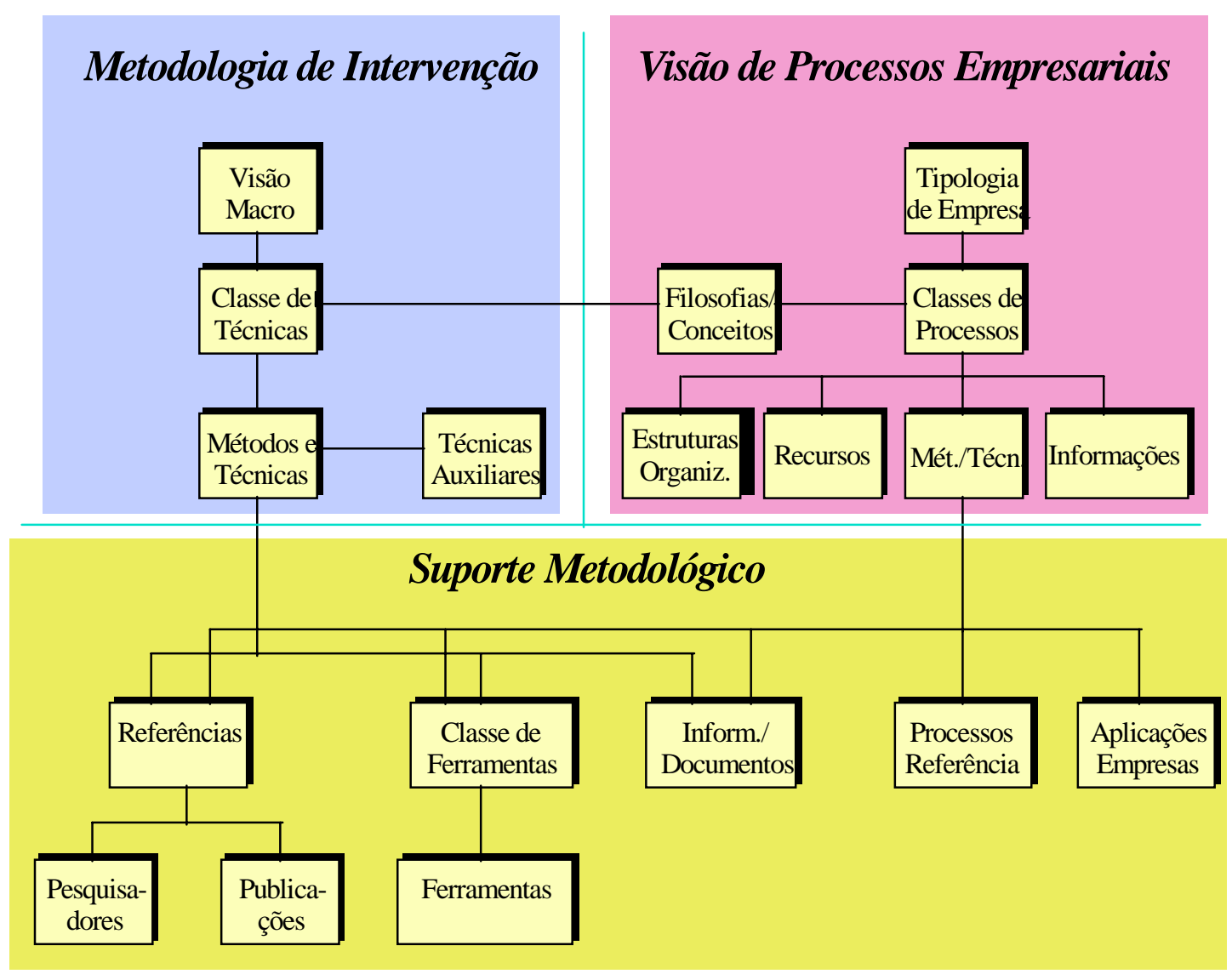

FIGURA 18: As três Dimensões da Metodologia de Integração de Empresas

(RENTES et al., 1996)

A última dimensão é a de Suporte Metodológico que oferece, como o próprio nome diz, suporte metodológico, ferramental e de conhecimento para a aplicação dos métodos de intervenção. Esta dimensão contém instrumentos para o estabelecimento da Visão de Processos de Negócios e para o processo de condução dos métodos de intervenção.

A dimensão Metodologia de Intervenção tem um papel central na aplicação da MIE, pois ela indica o processo de mudança da empresa. Isto ocorre em três etapas onde cada uma é composta por várias fases específicas. A etapa inicial, denominada Integração de Objetivos, tem o objetivo de obter uma visão genérica da empresa, através da especificação de suas estratégias, seus fatores críticos de sucesso e a sua forma atual de operação. Baseada nestas informações, os projetos de modernização que melhor se ajustam a realidade (ou requisitos) da empresa são definidos. Esta etapa é dividida em três fases: Diagnóstico da Situação Atual, Definição de Estratégias Organizacionais e Definição das Ações de Integração. Cada fase pode ser vista como uma classe de técnicas de intervenção que pode ser encontrada na literatura. 
A segunda etapa, Integração de Processos, envolve a realização de um plano de integração funcional da empresa. De acordo com as Ações de Integração, definidas junto com a empresa, os projetos que devem ser adotados são identificados. O conjunto de atividades nesta etapa são normalmente muito complexos, nem sempre sendo possível a aplicação de uma forma global. Assim, de acordo com os objetivos e requisitos obtidos na primeira etapa da metodologia, apenas algumas fases devem ser focalizadas, orientando os esforços da empresa para ações que possibilitam maiores ganhos. As fases para esta etapa podem ser divididas em Desenvolvimento/Reengenharia, Gerenciamento de Custos, Seleção ou Desenvolvimento de Soluções.

Na última etapa da MIE, Operacionalização, os projetos de modernização são detalhados, implementados e mantidos. A migração para as novas formas de operação é suportada pelas informações que foram obtidas durante a primeira etapa. As fases desta etapa são a Implantação de Processos, a Implantação de Sistemas e a Melhoria Contínua.

Neste trabalho, alguns procedimentos aplicados por essa metodologia de intervenção são adaptados no ciclo de vida de uma EV, ou seja, fases como elaboração de estratégias, definição de ações de integração são aspectos também tratados na formação de uma EV.

Vale ressaltar que para a execução de uma metodologia de integração é imprescindível a utilização de um formalismo para a representação padronizada da empresa. Para esta finalidade, uma metodologia pode utilizar-se do conceito de Modelo de Empresa, como é o caso da MIE.

\subsubsection{Modelo de Empresa}

$\mathrm{Na}$ literatura podem ser encontradas diferentes definições para o termo Modelo de Empresa. Segundo KOSANKE (1992) apud MENDES (1996) ${ }^{1}$, o modelo de empresa deve refletir a realidade o melhor possível e ser utilizado para controlar e monitorar suas

${ }^{1}$ KOSANKE, K. (1992) CIMOSA a european development for enterprise integration. part 1: An Overview. In: ENTERPRISE INTEGRATION MODELING, 1., MA, USA, 1992. Proceeding of the first international conference, apud MENDES, J. V. (1996) Desenvolvimento de um Método para Modelagem de Operação no Contexto de uma Metodologia de Integração de Empresas. Dissertação (Mestrado), EESC - USP. 
operações. Essas operações devem ser descritas em termos de sua funcionalidade e comportamento dinâmico. O modelo deve ser constituído por sub-modelos, que representam diferentes aspectos da empresa e, as mudanças ocorridas a nível de sub-modelos devem se refletir no modelo total. O modelo também deve apresentar diferentes níveis de abstração, pois assim é possível utilizar modelos para suporte nas decisões estratégicas, táticas e operacionais.

ROZENFELD et al. (1992) definem o modelo de empresa como sendo uma ferramenta que viabiliza e suporta diversas atividades de implantação de novas tecnologias, filosofias e métodos na manufatura. Ele deve servir de suporte para:

- entendimento do complexo funcionamento de uma empresa;

- suporte para a integração de objetivos e estabelecimento de estratégias;

- padronização de nomenclatura e procedimentos;

- suporte para resolução de problemas existentes, através de uma visão objetiva do negócio;

- suporte para integração lógica;

- suporte para o desenvolvimento e funcionamento de um gerenciador de fluxo de informações.

RENTES (1995) desenvolveu o Modelo de Empresa utilizado pela MIE, detalhada na seção anterior. Este modelo é composto de cinco modelos de menor nível, interrelacionados e que fornecem uma visão diferenciada da empresa, como apresentado na Figura 19.

Estes modelos correspondem à visões diferenciadas da empresa, porém com pontos de interseção bem definidos entre elas. Para a representação destes modelos foi utilizado o formalismo do Modelo Entidade-Relacionamento (MER). 


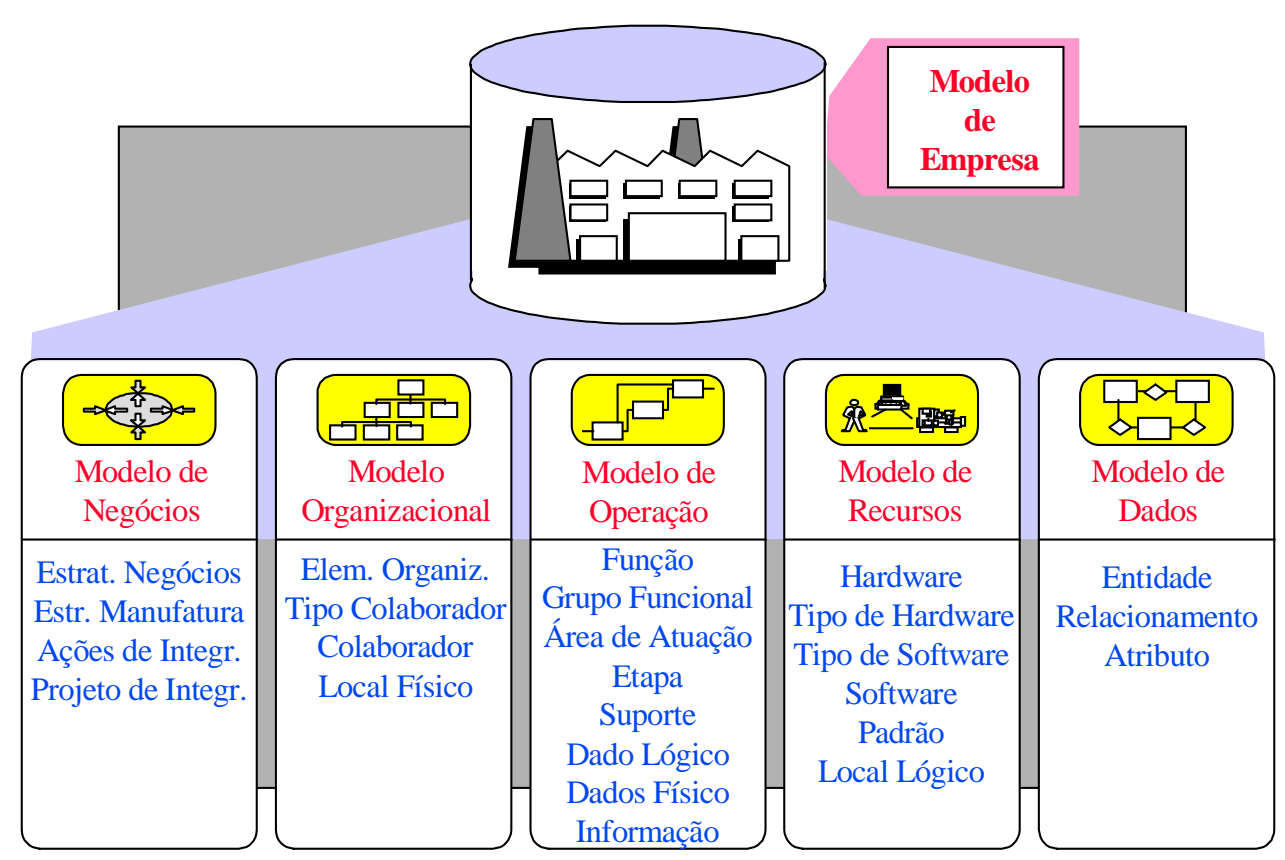

FIGURA 19: Modelo de Empresa e seus Componentes (RENTES, 1995)

\subsubsection{Aplicação da Modelagem de Processos de Negócios}

Como foi citado, um elemento fundamental em uma metodologia de integração consiste na elaboração do modelo de empresa, onde o modelo operacional descreve a nível abstrato como os processos de negócios de uma empresa operam. A partir do entendimento de seu funcionamento, a realização de diferentes atividades pode ser desenvolvida, como mostra a Figura 20 (REITER \& STICKEL, 1997).

O processo de modelagem consiste em uma atividade primária de uma metodologia, uma vez que a integração acontece primeiro no mundo lógico (ou dos modelos) e a seguir no mundo real de operação. As vantagens do modelo de empresa já foram citadas anteriormente. 


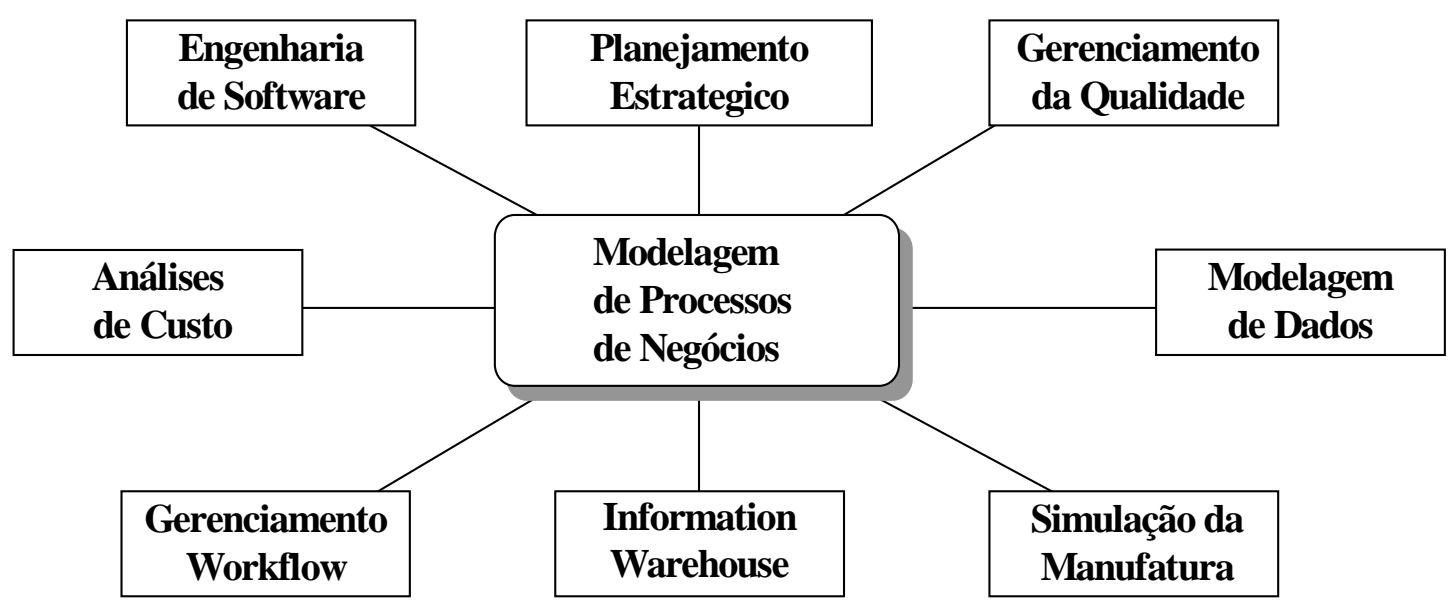

FIGURA 20: Áreas de Atuação da Modelagem de Processos de Negócio

(REITER \& STICKEL, 1997)

Neste contexto, a utilização de um padrão para a representação das informações a serem levantadas torna-se requisito necessário para suportar o processo de modelagem e consequentemente para a elaboração do modelo de empresa. Além da representação da informação, a padronização atualmente está sendo levada em consideração no processo de modelagem em si. Em outras palavras, procura-se determinar o que é para ser modelado, com quais métodos, com qual nível de detalhamento, entre outras questões (NELL, 1995).

A realização deste trabalho relaciona-se com duas atividades citadas na Figura (simulação e workflow) e uma outra que consiste na utilização de modelos de referência para a elaboração de modelos específicos à uma empresa. Estas atividades otimizam a integração dos processos de negócios de uma empresa e são tratadas a seguir por fazer parte central do trabalho.

\subsubsection{Modelos de Referência}

Diferentes definições para Modelos de Referência podem ser encontradas na literatura, de acordo com a sua área de aplicação, como por exemplo modelagem de dados (HARS, 1994), manufatura integrada por computador (CIM) (GIELINGH \& SUHM, 1993), modelagem integrada do produto e do processo (ZIMMERMAN, 1996). De uma maneira geral, essas definições mostram que um Modelo de Referência pode ser caracterizado apenas com características genéricas (sintaxe) e que depende diretamente da área e do caso de aplicação. Neste sentido, existem diferentes tipos de Modelos de Referência, como os que se relacionam: 
- com características da tipologia de indústrias de um determinado setor;

- à modelagem de processos de negócios;

- à modelagem de funções ou departamentos de uma empresa;

- à descrição da funcionalidade de um software;

- à condições de integridade de um modelo de dados para uma determinada área de aplicação;

- à procedimentos como desenvolvimento e customização de software, implantação de sistema da qualidade;

- à arquitetura como por exemplo o modelo de referência ISO-OSI que descrevem uma metodologia para implementação de sistemas.

Entre as aplicações para um Modelo de Referência encontram-se a otimização e simulação de processos de negócios, cursos, documentação de customizações de software, benchmarking, escolha ou desenvolvimento de software (IDS, 1995).

A definição que é tratada para o desenvolvimento deste trabalho refere-se ao gerenciamento de processos de negócio baseado em modelos. Neste sentido, HARS (1994) define Modelos de Referência como padrões (modelos) para a elaboração de um ou mais modelos específicos. Eles devem conter um determinado grau de generalidade, ou seja, um modelo de referência deve ser utilizado para a elaboração de mais de um modelo específico. Além disso, um modelo de referência deve ser customizável, ou seja, fornecer métodos para a geração de modelos específicos.

Em outras palavras, um modelo de referência deve funcionar como uma base de discussão, uma sugestão formal ou semi-formal para a elaboração de modelos específicos, fazendo com que as informações referentes ao projeto de um processo de negócio sejam transparentes para as pessoas que participam do projeto.

Vários aspectos podem ser tratados no que se refere a geração, manutenção e utilização de modelos de referência. Neste sentido, algumas características podem ser consideradas importantes para qualquer metodologia, entre as quais podem ser destacadas (KLABUNDE \& WITTMAN, 1997):

- construção modular: um modelo de referência pode ser construído com diferentes submodelos (ou módulos) menores, os quais podem ser classificados em diferentes níveis de hierarquia; 
- integração de variantes como instanciações de um modelo padrão: em relação direta com a modularidade está a capacidade de se gerar variantes de um mesmo modelo de referência. Para isto, três planos podem ser caracterizados (procedimento top-down): processo principal, processo parcial e módulo do processo (Figura 21). As variantes acontecem no terceiro nível, onde diferentes módulos podem ser utilizados para um mesmo processo;

- adaptabilidade: no plano de módulo do processo são colocados à disposição diferentes instanciações de um processo de negócio, dependente do produto e/ou processo), de modo que o modelo possa ser adaptado aos requisitos de uma empresa;

- generalidade: no plano mais abstrato um modelo de referência pode ser aplicável à qualquer segmento dentro de um setor econômico, ou até mesmo ser aplicado em outro setor;

- conhecimento/experiência: em um modelo de referência devem conter tanto informações de casos práticos de aplicações como informações provenientes de pesquisas;

- evolução: o modelo de referência deve ou pode possuir um desenvolvimento contínuo, ou seja, alterações e complementações devem poder ser facilmente representadas e documentadas, através da administração de versões;

- diferentes níveis de detalhamento: nos três planos de um modelo de referência (processo principal, processo parcial e módulo do processo) o nível de detalhamento cresce de cima para baixo. Um objeto no plano mais abstrato corresponde à um número maior de objetos nos planos inferiores;

- unicidade semântica e sintática: a utilização de termos em modelos devem ser semântica e sintaticamente únicos. Por essa razão um catálogo de termos deve ser utilizado para a elaboração de modelos de referência. 


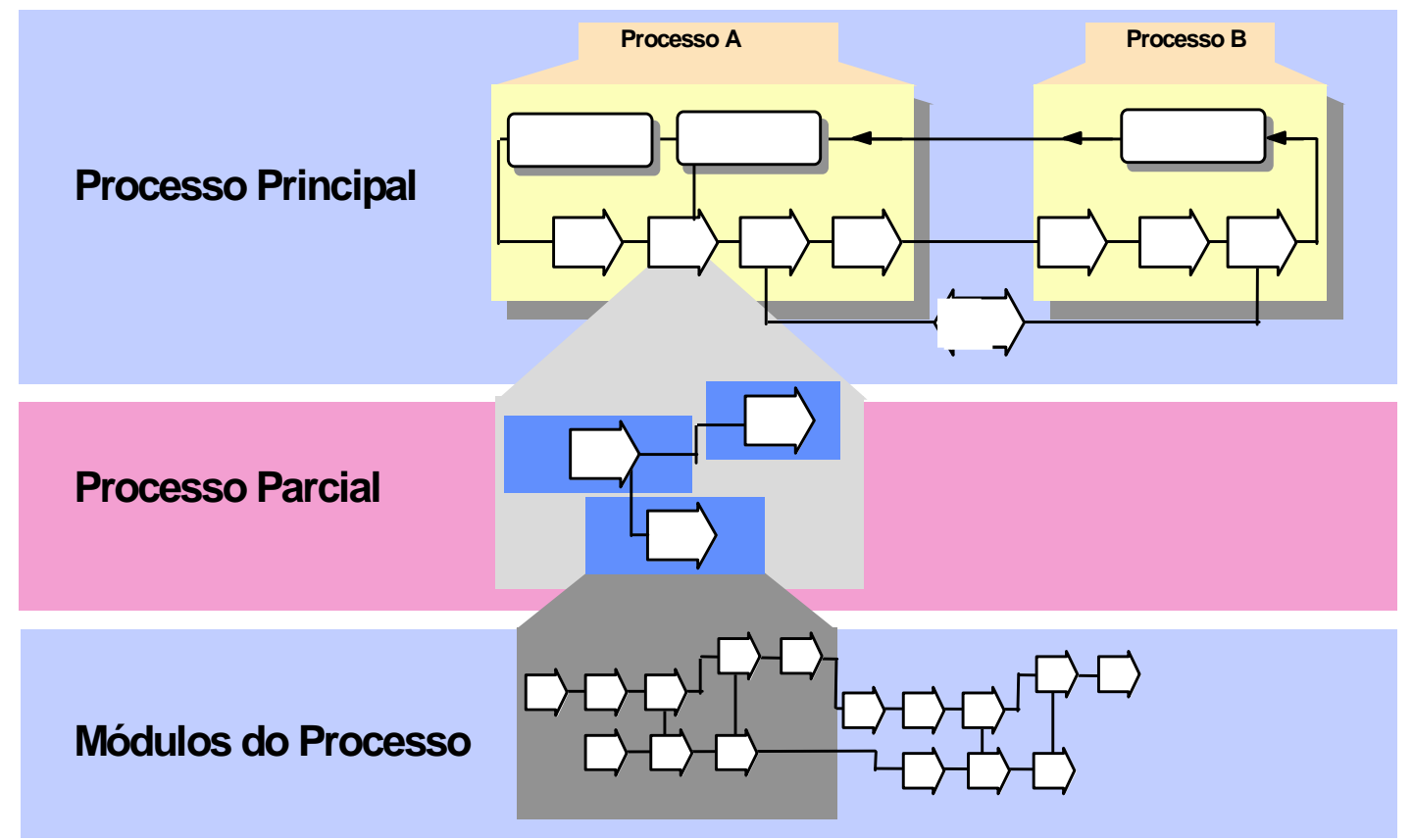

FIGURA 21: Planos de Abstração para a Construção de Modelos de Referência (KLABUNDE \& WITTMAN, 1997)

\subsubsection{Simulação de Processos de Negócios}

O processo de simulação consiste em um procedimento para a análise de sistemas, cujo os experimentos não são realizados no sistema real e sim com um modelo do sistema (REITER \& STICKEL, 1997). Ao contrário de uma otimização em um modelo estático a simulação fornece o comportamento dinâmico de um sistema de acordo com uma execução temporal.

O processo de simulação já comprovou a sua eficácia na otimização dos processos de manufatura, e de acordo com SCHEER (1996), verifica-se que seus benefícios também estão sendo utilizados pelos processos de escritório. Assim, com a ajuda dos modelos diferentes situações podem ser testadas de acordo com diferentes configurações dos modelos.

Através da análise de um modelo com suas alternativas, a simulação possibilita uma experimentação sistemática de processos de negócios. Isto significa que uma seqüência de cenários diferentes podem ser pesquisados observando-se sua efetividade, antes que uma decisão deva ser encontrada. Dessa maneira, a situação atual de um processo de negócio pode ser comparada com diferentes alternativas ou soluções mediante a análise da efetividade. 
O resultado de uma simulação é dado através de estatísticas que retratam a análise dinâmica do processo. As estatísticas ou resultados de diferentes cenários apresentam vantagens e desvantagens de cada situação com relação à situação atual do processo de negócio. Em outras palavras, elas mostram a transparência de causa e efeito de cada alteração. Assim, uma visão geral da complexidade sob uma possível situação futura facilita a tomada decisão para a otimização do processo de negócio.

Atributos como custo, tempo, probabilidade, entre outras, são a base para a construção das estatísticas. No entanto, algumas são criadas em tempo de execução da simulação como, por exemplo, tempo de espera para que uma determinada pessoa efetue a sua atividade em um processo de negócio. Desta maneira, o comportamento dinâmico da execução entre os processos pode ser observado.

Assim, os objetivos do processo de simulação podem ser resumidos genericamente da seguinte maneira (IDS, 1996a):

- validar alterações e modificações do processo de negócio (p. ex.. tempo, custo);

- levantar ineficiência da estrutura do processo, ou seja, de sua execução e, com isso, reconhecer processos que não são capazes de serem executados;

- reconhecer e quantificar gargalos de execução, ou seja, identificar onde é necessário maior quantidade de recursos, principalmente humanos;

- reconhecer pontos de melhoria na execução atual do processo de negócio;

- analisar quantitativamente diferentes cenários para a tomada de decisão de melhoria do processo;

- possibilitar otimização operativa do processo.

Desta maneira, a simulação mostra-se como um mecanismo eficaz na Engenharia de Processos de Negócio.

\subsubsection{Sistemas Workflow}

Como o próprio nome diz, o gerenciamento do fluxo de trabalho ("workflow") é de extrema importância na gerência de processos de negócio. A tecnologia decorrente deste gerenciamento está sendo amplamente explorado por negócios em uma variedade de indústrias (REITER \& STICKEL, 1997). Sua característica primária é a automação de 
processos envolvendo combinações de atividades humanas e baseada em máquina, particularmente aquelas envolvendo interação com ferramentas e aplicações da Tecnologia da Informação. Desta maneira, um Workflow (ou fluxo de trabalho) pode ser definido como a "automação ou facilitação computadorizada de um processo de negócio, no inteiro ou em parte" (GALLER \& SCHEER, 1994) .

Um sistema de gerenciamento de workflow fornece a automação procedural de um processo de negócio pelo gerenciamento da seqüência de atividades de trabalho, requisitando o recurso humano e/ou da TI relacionado para a realização das mesmas. Assim, um sistema workflow pode ser definido como um sistema que completamente define, gerencia e executa fluxos de trabalho através da execução do software que é dirigida por uma representação computadorizada do fluxo lógico de trabalho (IDS, 1996b). A Figura 22 apresenta uma arquitetura para a geração de sistemas workflow.

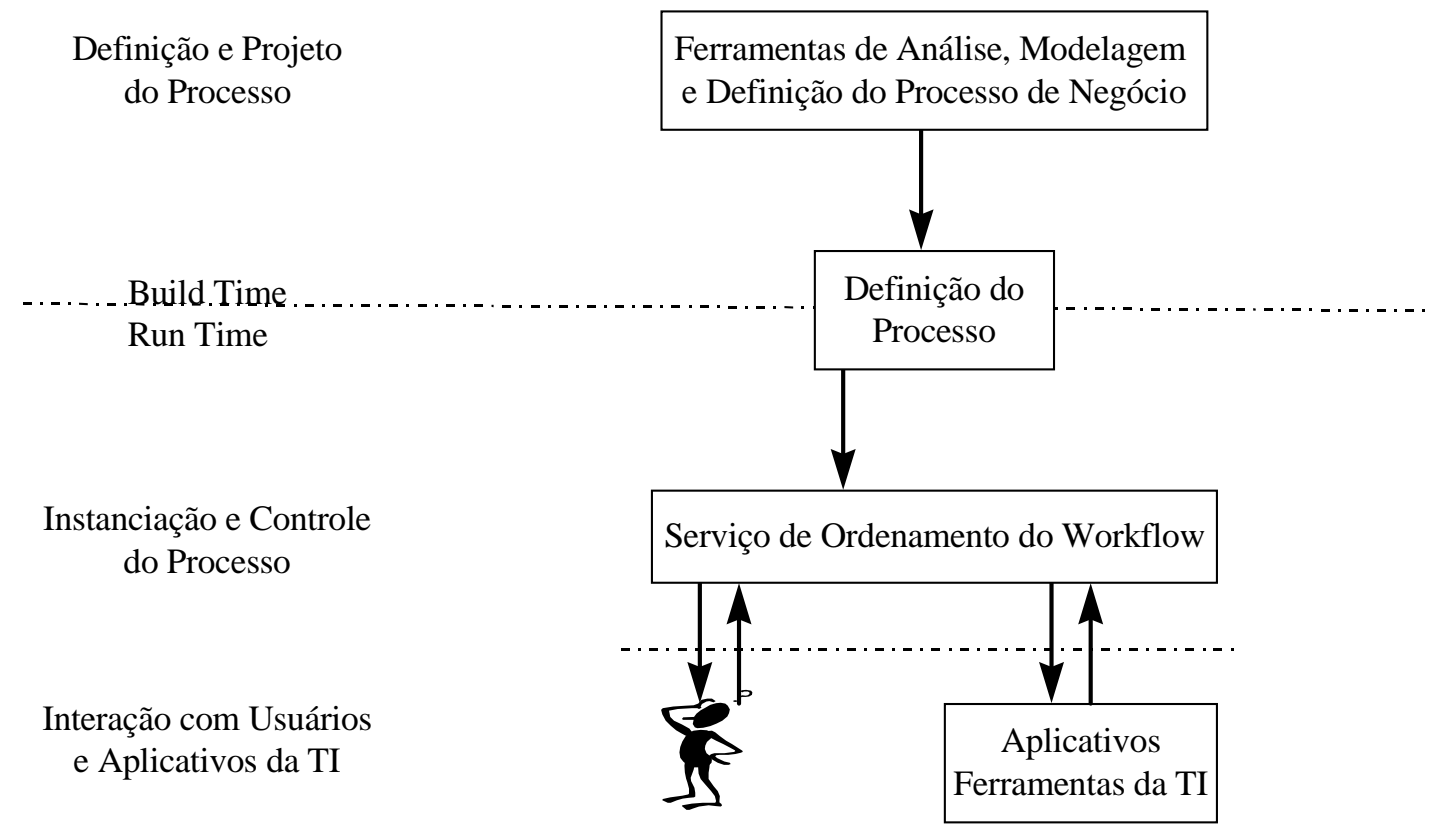

\section{FIGURA 22: Arquitetura de um Sistema de Gerenciamento de Workflow}

Um processo individual de negócio pode ter um ciclo de vida variando de minutos a dias (ou mesmo meses), dependendo de sua complexidade e da duração das várias atividades constituintes. Tais sistemas podem ser implementados em diferentes maneiras, usando uma larga variedade de recursos da TI e de infra-estrutura de comunicação. Além disso, os sistemas podem operar em ambientes que vão de pequenos locais até entre empresas 
(GALLER, 1997). No entanto, para rodar entre empresas a necessidade de padronização de interfaces torna-se requisito essencial. Neste sentido, o "Workflow Management Coalition" WfMC $^{1}$ - tem trabalhado para fornecer um modelo de referência. O WfMC (1997) já reconheceu que todos os produtos de gerenciamento de workflow que estão presentes no mercado possuem algumas características comuns, capacitando-os a encontrar um nível de interoperabilidade através do uso de padrões comuns para várias funções.

Assim, o WfMC foi estabelecido para identificar as áreas funcionais que realizam a interface entre diferentes sistemas de workflow e desenvolver especificações para a implementação de produtos nesta área. A Figura 23 apresenta o modelo de referência do WfMC com as interfaces que padronizam a comunicação entre diferentes produtos.

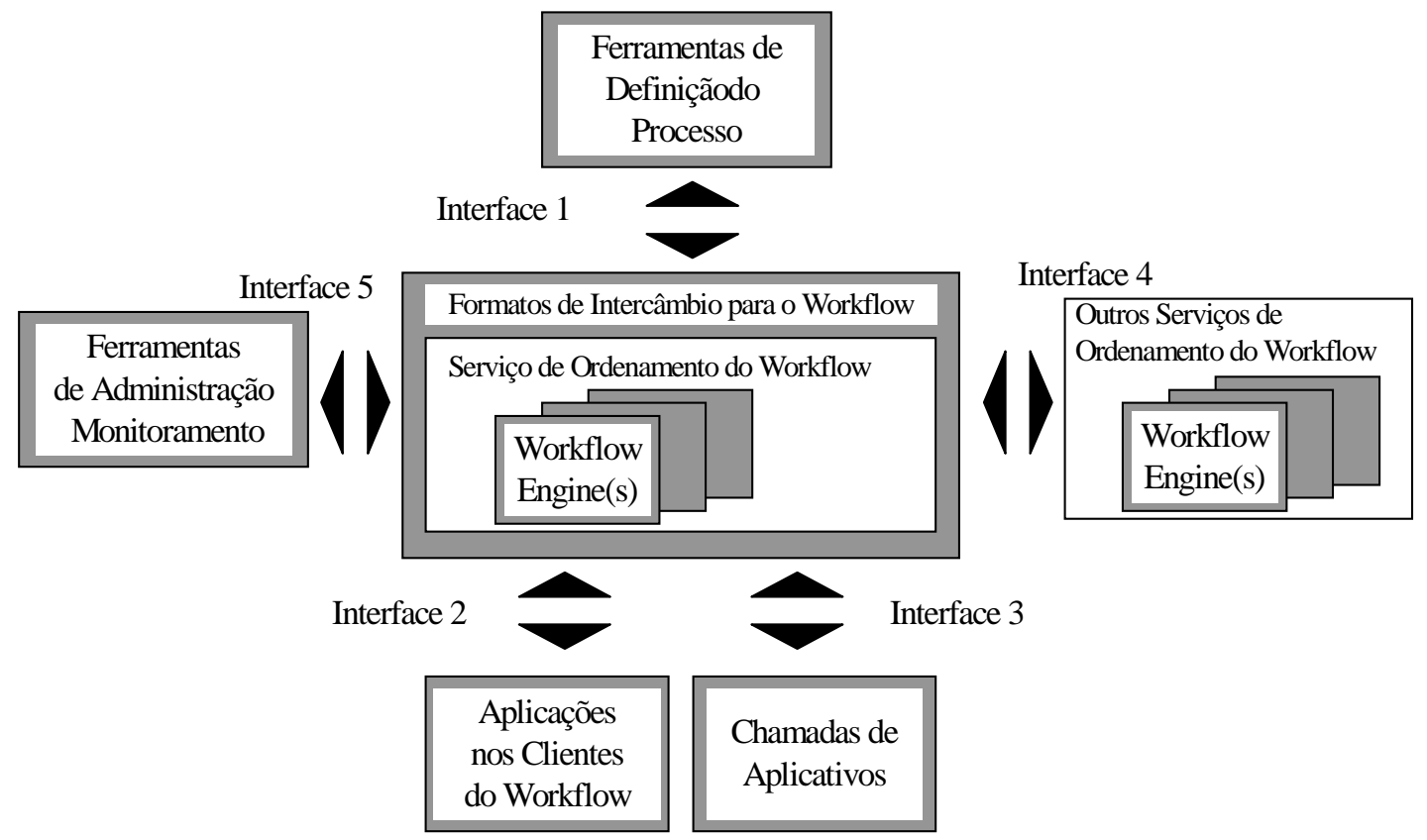

FIGURA 23: Modelo de Referência do WfMC (WfMC, 1997)

Workflow geralmente é associado com Reengenharia de Processos de Negócios ("Business Process Re-engineering” - BPR), que por sua vez está associado com avaliação, análise, modelagem, definição e subsequente implementação operacional do processo de negócio de uma organização. Embora nem todas atividades da reengenharia resultem em

${ }^{1} \mathrm{O}$ WfMC é um grupo de pesquisa formado por diferentes empresas ligadas à área de Workflow Management Systems e a universidade de Eddinbourg. 
implementações de workflow, a sua tecnologia é freqüentemente uma solução apropriada, pois ela fornece a separação do procedimento lógico do negócio e seu suporte operacional da TI. 


\section{Metodologia de Desenvolvimento do Trabalho}

$\mathrm{Na}$ literatura podem ser encontradas diferentes classificações para a metodologia do trabalho científico. Segundo a classificação proposta por Dane, este trabalho de pesquisa pode ser considerado como exploratório, pois as atividades realizadas tiveram como objetivo (DANE, 1990):

a) a descrição de um novo tipo de cooperação entre empresas (Empresa Virtual);

b) a escolha de uma forma de geração de EV's para a aplicação da proposta do trabalho;

c) a elaboração de um método para o processo de integração dos parceiros na formação de EV's.

O cumprimento destes objetivos foi realizado de acordo com a execução das seguintes etapas da metodologia:

- identificação do problema: durante a exposição sobre o conceito de EV foi abordada a necessidade de mecanismos para suportar a comunicação e a coordenação entre os parceiros de uma cooperação. No entanto, para se identificar exatamente o foco do problema tratado neste trabalho algumas atividades preliminares foram realizadas, as quais estão descritas na seção 3.1;

- levantamento de requisitos: para viabilizar a otimização do processo de integração dos parceiros em EV's foram levantados alguns requisitos, apresentados na seção 3.2;

- sistematização de aspectos fundamentais à realização da proposta: algumas atividades foram realizadas no sentido de sistematizar os conceitos que foram apresentados no capítulo de referência bibliográfica e que são utilizados na proposta deste trabalho (seção 3.3). Entre essas atividades quais pode-se destacar:

$\Rightarrow$ a estruturação da OV a ser utilizada no trabalho;

$\Rightarrow$ a aplicação de conceitos de padronização e classificação no processo de modelagem; 
$\Rightarrow$ a especificação da área de atuação dos produtos e serviços a serem oferecidos pela OV;

- elaboração da proposta: as atividades que representam a integração de parceiros em EV's, com a utilização de recursos da área de Integração de Empresas, são apresentadas no capítulo 4;

- realização de um exemplo: a aplicação da proposta elaborada é realizada na forma de um exemplo, ilustrado no capítulo 5.

\subsection{Identificação do Problema}

O objetivo inicial deste trabalho era a elaboração de uma metodologia de consolidação de Pequenas e Médias Empresas - PME's. De acordo com as pesquisas iniciais, foram constatados diferentes problemas ou obstáculos que dificultam a consolidação de PME's. Esses obstáculos podem ser agrupados, de uma maneira geral, em falta de capacidade administrativa, insuficiência técnica do produto/serviço e falta de capital (recursos) (CHÉR, 1991).

No entanto, verificou-se também a dificuldade de se trabalhar com os pequenos e médios empreendedores, que, por um lado alegam falta de tempo e, por outro, contam com a sua maneira independente de conduzir seu negócio. A partir das pesquisas realizadas ao longo do trabalho, foi possível o contato com a literatura sobre o conceito de Empresas Virtuais, o que alterou o objetivo inicial citado.

Essas pesquisas indicaram que o conceito de Empresas Virtuais consistia em uma excelente alternativa para os problemas de PME's através das vantagens já apresentadas no Capítulo 2. Porém, várias publicações atestavam a necessidade de mecanismos de coordenação para esta forma de cooperação entre empresas, onde o estabelecimento das atividades de integração dos parceiros foi caracterizada como uma meta ajustada para o trabalho de doutoramento.

Em face da identificação do novo foco do trabalho, surgiu a oportunidade de se realizar um estágio no exterior que perfeitamente se encaixava neste novo contexto, pois no instituto de pesquisa de destino havia projetos envolvendo as duas áreas, viabilizando assim a aquisição de conhecimento e obtenção de maior experiência sobre o assunto. O local do estágio foi o Institut für Wirstschaftsinformatik - IWI - da Universidade de Saarland (Alemanha), onde a ferramenta ARIS foi desenvolvida como protótipo, mas que agora é de 
responsabilidade da firma IDS Prof. Scheer, que tem representação no Brasil. No instituto, além de projetos com indústrias que envolviam a aplicação da ferramenta, havia um projeto de pesquisa sobre uma Organização Virtual.

Desta maneira, o objetivo do estágio consistiu em adquirir experiência na aplicação do House of Business Engineering e auxiliar na pesquisa sobre Organização e Empresa Virtual, cujo projeto (Kiesel) foi apresentado no capítulo anterior.

Conforme a experiência adquirida nos projetos do instituto alemão e juntamente com uma pesquisa bibliográfica também em língua alemã foi possível a delimitação exata do objeto de pesquisa deste trabalho: a aplicação de conceitos da área de Integração de Empresas para a integração de parceiros no ciclo de vida de uma EV. Além disso, dois conceitos abordados sobre Organização Virtual são também utilizados como mecanismos fundamentais para a realização da proposta. A Tabela 2 mostra uma relação completa dos conceitos utilizados neste trabalho de pesquisa.

TABELA 2: Relação dos Conceitos das duas Áreas de Pesquisa

\begin{tabular}{|l|ll|}
\hline & \multicolumn{1}{|c|}{ Conceitos } \\
\hline \multirow{2}{*}{ Organização Virtual } & - Ciclo de vida \\
& - - Entidades \\
\hline & - Metodologia de Integração \\
& - Modelo de Empresa \\
& - Arquitetura de Integração \\
& - Ferramenta Computacional \\
Integração de Empresas & - Modelagem de Processos \\
& - Simulação de Processos \\
& - Modelos de Referência \\
& - Sistemas Workflow \\
\hline
\end{tabular}

Desta forma, o problema baseia-se no relacionamento destes diferentes conceitos, difundidos por diferentes projetos de pesquisa conforme apresentado no capítulo anterior, para viabilizar a integração dos parceiros em EV's. Como ponto de partida para a resolução do problema, encontra-se as atividades do ciclo de vida de uma EV, as quais devem ser formalizadas para referenciar os demais conceitos citados. 


\subsection{Requisitos para a Integração de Parceiros}

Esta seção apresenta os requisitos necessários para a integração dos parceiros em EV's dentro de uma OV. Como dito, estes requisitos estão relacionados com cada fase do ciclo de vida de uma $\mathrm{EV}$, onde devem existir atividades que correspondam ao processo de integração. Aqui vale ressaltar que o ciclo de vida proposto pelo projeto Kiesel foi selecionado por ser o único, entre os analisados, a apresentar uma formalização de suas atividades dentro de uma $\mathrm{OV}$.

No entanto, o ciclo de vida do Kiesel corresponde à uma proposta inicial que necessita ser detalhada para que se torne aplicável em um ambiente real de uma OV. Neste sentido, os diferentes conceitos citados devem ser relacionados com cada fase do ciclo de vida. A Figura 24 mostra resumidamente quais são os requisitos em cada fase do ciclo de vida necessários ao processo de integração. Porém, antes de descrever os requisitos relacionados à cada fase, faz-se necessário apresentar a condição necessária à realização de todo o processo de integração: a formalização das informações sobre os parceiros.

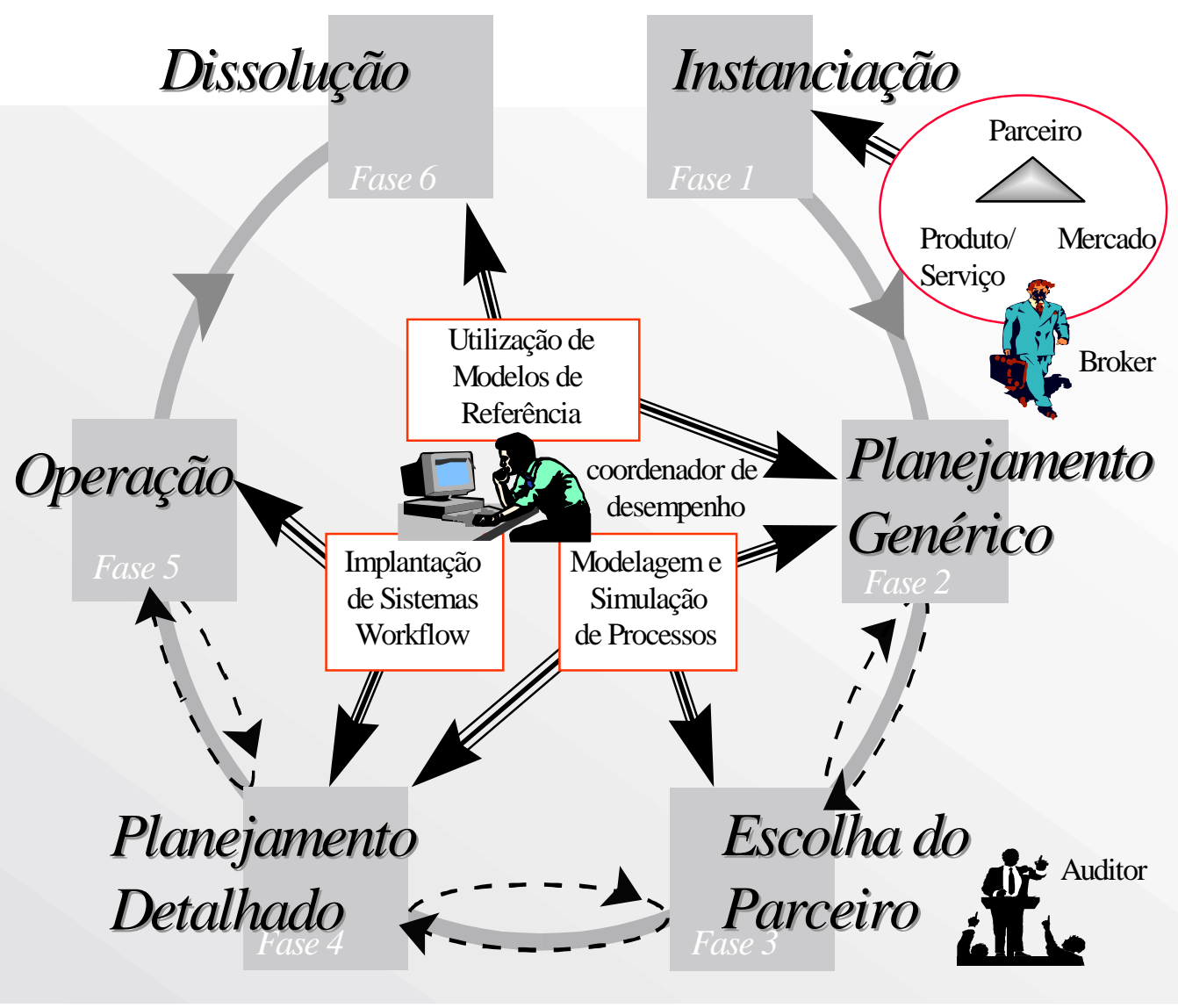




\section{FIGURA 24: Relacionamento entre o Ciclo de Vida e os Conceitos}

\subsubsection{Formalização das Informações sobre os Parceiros}

A utilização de um padrão para a representação das informações sobre os parceiros de uma OV consiste no requisito principal para a realização da proposta deste trabalho. Neste sentido, a utilização de uma arquitetura de integração é a base para a formalização destas informações. Como já foi mencionado, uma arquitetura de integração viabiliza uma análise de acordo com diferentes visões de um processo (como dados, funções, recursos, organização). Assim, o conceito de modelo de empresa pode ser utilizado no contexto de OV's, uma vez que a descrição formalizada dos parceiros é necessária ao processo de otimização.

Desta maneira, o modelo de empresa proposto por RENTES (1995) pode ser utilizado neste contexto, mediante a satisfação de alguns requisitos, tais como:

- maior exploração da visão de recursos, ou seja, mapeamento das informações referentes não só aos equipamentos/máquinas como também recursos humanos (especialistas) dos parceiros. Um modelo de comunicação que represente a integração física dos parceiros deve ser agregado ao modelo de recursos, descrevendo a implementação da rede física dos parceiros juntamente com os aplicativos utilizados;

- o modelo organizacional deve abrigar agora a descrição de cada empresa como unidade organizacional da OV;

- o modelo de negócios deve fornecer estratégias que utilizam uma mesma forma de representação dos produtos, serviços e mercados dos parceiros da OV, o que contribui para a clareza do processo de exploração de uma oportunidade;

- o modelo de dados deve representar apenas as informações que suportam o fluxo entre as diferentes atividades em um plano genérico;

- o modelo operacional, parte central do trabalho, deve fazer o levantamento das atividades dos parceiros, indicar o seu seqüenciamento e descrever as informações e os recursos que utilizam. Além disso, o modelo operacional deve apresentar o local de realização das atividades. Esta representação operacional deve fornecer diferentes níveis de abstração para que não só uma visão genérica facilite um acordo geral de exploração de uma oportunidade específica de mercado mas também uma visão detalhada viabilize a integração dos serviços dos parceiros. 
A partir da utilização de um padrão comum para a representação dos parceiros em uma OV surge ainda a necessidade relativa a elaboração e gerência de modelos. A elaboração de modelos deve ficar a cargo de cada parceiro, no que se refere a descrição de sua empresa. Neste sentido, alguns requisitos devem ser preenchidos, tais como:

- a difusão do conceito de modelo de empresa juntamente com os métodos a serem utilizados em cada visão;

- tanto a elaboração como a gerência dos modelos deve ser auxiliada por uma ferramenta computacional que oferece maior flexibilidade e segurança. A ferramenta ARIS é utilizada neste trabalho para esta finalidade;

- um tipo de classificação para os processos dos parceiros viabiliza a gerência do armazenamento dos modelos;

- mecanismos para a troca de modelos entre os parceiros e a OV devem ser elaborados para auxiliar a comunicação. O processo de modelagem é, desta maneira, distribuído;

Como foi visto, os conceitos de arquitetura e modelo de empresa e a utilização de uma ferramenta computacional suportam uma metodologia de integração. Neste contexto, uma metodologia de integração corresponde às fases do ciclo de vida de uma EV. Para que as atividades presentes em cada fase do ciclo de vida utilizem as informações formalizadas no modelo de empresa da OV alguns requisitos devem ser obedecidos, os quais são apresentados na próxima seção.

\subsubsection{As Fases do Ciclo de Vida e seus Requisitos}

Como foi descrito, a instanciação de uma EV dentro de uma OV pode ocorrer de duas maneiras: reativa ou proativa. Para ambas alternativas a descrição formalizada do modelo de negócios da OV é fundamental, onde deve haver uma priorização dos mercados a serem explorados conjuntamente pelos parceiros. Assim, cada parceiro deve apresentar os produtos e serviços que oferecem e os mercados que atuam.

O Broker da OV utiliza-se destas informações presentes no modelo de negócios para a busca de ordens de pedido. Identificada uma oportunidade de negócio ele deve fornecer uma descrição completa sobre preço, prazo e quais os produtos e/ou serviços que devem compor a futura cooperação. 
A partir da descrição da oportunidade de negócio fornecida pelo Broker, inicia-se o processo de formação da EV e consequentemente de integração dos parceiros. Na fase de planejamento genérico as estruturas organizacional e operacional ideais da EV devem ser esboçadas. Para isso, a atividade de modelagem de processos, suportada pela utilização de uma ferramenta computacional (ARIS), deve ser aplicada para a geração dos modelos correspondentes. Modelos de referência podem ser analisados para a formação de um cenário ideal, ou seja, conceitos que foram utilizados com sucesso em experiências anteriores podem ser aplicados novamente na EV sendo formada. No entanto, estes modelos só serão gerados após a documentação das primeiras experiências de formação de EV's dentro da OV.

Essas atividades são realizadas por um coordenador de desempenho com diferentes habilidades, ou seja, na OV tem que haver um papel bem definido que seja responsável pela execução do processo de modelagem. Entre as habilidades necessárias para este coordenador de desempenho pode-se destacar:

- conhecimento sobre a área de atuação da OV afim de relacionar a oportunidade identificada com a formação de uma cadeia ideal de valores;

- experiência sobre a utilização de modelos de referência para a comparação de diferentes cenários e conseqüente geração otimizada das estruturas organizacional e operacional;

- conhecimento sobre modelagem e simulação de processos utilizando a ferramenta escolhida para a geração das estruturas ideais (ARIS, no caso);

O principal recurso da área de Integração de Empresas que pode ser utilizado para suportar a otimização da escolha de parceiros consiste na utilização de resultados de um processo de simulação. Este processo analisa as diferentes empresas, que desejam fornecer o mesmo produto ou serviço, de acordo com seus dados como custo, tempo e capacidade de realização.

O coordenador de desempenho deve aplicar o processo de simulação, segundo alguma metodologia a ser elaborada dentro da OV, nas empresas concorrentes e fornecer os resultados à um Auditor que, junto com as informações sobre o histórico das empresas (cumprimento de prazos, qualidade, etc.), escolhe os parceiros que formarão a EV.

Escolhidas as empresas, inicia-se a integração dos modelos que representam os parceiros. Nesta fase o coordenador de desempenho deve apresentar uma habilidade social pois é o responsável pela coordenação entre os coordenadores in/ -outsourcing de cada 
empresa para o detalhamento das estruturas organizacional e operacional da EV. O detalhamento é realizado através da utilização das informações dos parceiros, onde diferentes métodos da ferramenta ARIS são aplicados. O processo de simulação pode ser novamente aplicado para a identificação do cenário ideal de operação, onde os resultados na forma de estatísticas servem para a sua validação entre os parceiros.

Com base na estrutura operacional detalhada, pode-se definir diferentes processos de apoio à EV, como o sistema de custeio, o sistema da qualidade e o controle de prazos. Esses processos devem ser definidos em conjunto com o coordenador de desempenho da OV e os coordenadores in/- outsourcing dos parceiros e servem de base para a definição de estratégias da EV sendo formada.

A otimização da operação da EV pode ser realizada pela implantação de um sistema workflow para suportar o processo de gerência do pedido. Este tipo de sistema traz duas grandes vantagens para a operação da EV: o monitoramento eletrônico do pedido e a redução do tempo de transferência de documento entre os diferentes parceiros. No entanto, para que o sistema workflow seja utilizado três condições devem ser satisfeitas:

- o coordenador de desempenho deve apresentar a habilidade necessária para a instalação e configuração deste tipo de sistema;

- uma metodologia de implantação de sistemas workflow deve ser desenvolvida e então aplicada pelo coordenador de desempenho;

- os parceiros devem ser treinados para a utilização do sistema workflow, o que deve corresponder à uma fase da metodologia acima.

$\mathrm{Na}$ fase de dissolução, a experiência realizada deve ser armazenada para suportar futuras formações de EV's dentro da OV. Neste sentido, os modelos utilizados devem descritos conforme o que foi realizado durante a operação da EV, permanecendo, assim, gravados eletronicamente como uma base de dados da ferramenta ARIS.

No entanto, nem todas as informações relativas à operação da EV podem ser descritas diretamente nos modelos. Algumas informações, como tempo de duração da EV, clientes atendidos, setor econômico explorado, opinião de cada parceiro, entre outras, devem ser armazenadas utilizando-se algum outro mecanismo. A geração de uma base de dados eletrônica formaliza o relacionamento entre as informações a serem gravadas, facilitando a sua recuperação. Dessa forma, a formação de uma EV é otimizada pela manipulação 
(eletrônica) de informações formalizadas de diferentes experiências realizadas dentro da OV.

\subsubsection{Requisitos da Tecnologia de Informação}

Para suportar a realização da proposta deste trabalho alguns recursos da TI devem ser utilizados. Como já foi mencionado, a ferramenta ARIS é utilizada para suportar as atividades de otimização da integração dos parceiros em EV's. Para a sua instalação, dois computadores (um servidor e um cliente) devem ser utilizados dentro da OV para a geração dos modelos que representam os parceiros e consequentemente para a sua aplicação na atividade de integração dos parceiros. Vale ressaltar que, por problemas técnicos, cliente e servidor não rodam em um mesmo computador. Assim, o servidor deve:

- armazenar a ferramenta ARIS e consequentemente os modelos que representam os diferentes parceiros;

- viabilizar a implantação de um servidor workflow para abrigar os processos que suportam as EV's. A administração deste servidor workflow (direitos de acesso, instanciação de processos, controle em tempo real de execução, etc.) é realizada pelo coordenador de desempenho que também é responsável pela instalação dos clientes nos parceiros.

Na implantação de sistemas workflow utilizando a ferramenta ARIS, o software servidor estabelece uma restrição de rodar apenas no sistema operacional Windows NT 3.5.1. Os clientes rodam tanto neste sistema operacional como no Windows 95. Além disso, para a comunicação entre os clientes e o servidor do sistema workflow é necessária a utilização de um protocolo de comunicação específico, o Common Request Broker Architecture CORBA.

Além da ferramenta ARIS, outros recursos da TI podem suportar o processo de otimização, tais como:

- desenvolvimento de uma base de dados centralizada que armazene informações gerenciais da OV. Para tanto, é necessária a utilização de um sistema de gerenciamento de banco de dados relacionais - SGBDR;

- implantação de um servidor Intranet para viabilizar a organização eletrônica de uma agenda comum, de propostas de marketing, de planejamento estratégico, entre outras atividades; 
- implementação de um servidor Internet para a divulgação dos produtos e serviços presentes na $\mathrm{OV}$.

Para a implantação dos dois últimos recursos citados é necessária a utilização de um software para o desenvolvimento de servidores e páginas Internet.

Portanto, a integração física entre os parceiros e a OV é essencial para a aplicação da proposta deste trabalho, a qual deve ser viabilizada através de acesso à Internet e de endereços eletrônicos. Desta maneira, cada parceiro deve disponibilizar um computador em sua empresa para que seja possível a instalação das interfaces necessárias à integração física.

\subsection{Sistematização do Trabalho}

A integração dos parceiros durante o ciclo de vida de uma EV ocorre pela utilização dos conceitos citados na Tabela 2, ou seja, pela aplicação da modelagem e simulação de processos, pela implantação de sistemas workflow e pela geração de modelos de referência. No entanto, para que se formalize a aplicação destes recursos faz-se necessário sistematizar quatro pontos chaves:

- estruturação do ambiente de operação da OV;

- otimização do processo de modelagem dos parceiros;

- relacionamento dos modelos utilizados;

- definição da tipologia da EV a ser tratada no trabalho.

\subsubsection{Estruturação da Organização Virtual}

Como já foi dito, em uma OV há diferentes processos de coordenação e responsabilidades que devem ser atribuídos à diferentes pessoas ou empresas. A distinção da estrutura organizacional da OV em entidades diferentes facilita o estabelecimento destas atribuições. A estrutura organizacional da OV utilizada neste trabalho é composta por três entidades: coordenador, parceiros, e a própria Empresa Virtual. Estas entidades foram identificadas de acordo com um processo de generalização realizado na estrutura do Projeto GVE. 
Como pode ser visto na Figura 25, o relacionamento entre as entidades indica o ciclo de vida de uma EV, ou seja, as informações sobre os parceiros são utilizadas pela entidade coordenadora, que com a identificação de uma oportunidade de negócio, inicia o processo de formação da EV. A operação da EV ocorre independentemente da entidade coordenadora da OV. Uma descrição sobre cada entidade é dada a seguir.



FIGURA 25: Estrutura de uma Organização Virtual

- Parceiros: representa a descrição das empresas presentes na OV. À cada parceiro é associado um coordenador in-/ outsourcing que é responsável pela comunicação com a OV. A sua tarefa é fornecer uma descrição formalizada dos produtos/serviços e mercados explorados pela empresa que representa. $\mathrm{Na}$ formação de uma $\mathrm{EV}$, ele representa os interesses de sua empresa na fase escolha dos parceiros do ciclo de vida e auxilia o processo de integração validando as informações dos modelos que estão presentes na base de dados da OV. 
- Coordenador: responsável pela gerência dos parceiros que estão associados à OV. Cinco responsabilidades podem ser associadas à esta entidade: o coordenador da $\mathrm{OV}, \mathrm{o}$ agenciador de pedidos, o coordenador de desempenho, o auditor e os coordenadores in-/ outsourcing. As atividades relacionadas à cada uma destas responsabilidades já foram citadas no capítulo 2. Vale ressaltar que os coordenadores in-/ outsourcing são associados à entidade coordenadora uma vez que estes exercem os processos de coordenação apresentados na Figura, ou seja, para cada processo citado pode haver a formação de grupos responsáveis pela sua execução.

- Empresa Virtual: corresponde à associação de determinados parceiros dentro da OV para a exploração de uma oportunidade específica de negócio, ou seja, um subconjunto de parceiros realizam o processo de formação e operação de uma EV de maneira autônoma dentro da OV. Três responsabilidades estão associadas a esta entidade: o coordenador desempenho (implantação e gerência do sistema workflow), o auditor (para situações de conflito) e os coordenadores in-/ outsourcing (gerência da comunicação de sua empresa com as demais). Cada parceiro pode participar de diferentes EV's.

Dessa forma, a formação e gerência da EV ocorre através das entidades com a participação direta do coordenador de desempenho e dos coordenadores in-/ outsourcing de cada parceiro selecionado. Neste processo então são aplicados os mecanismos propostos neste trabalho para a otimização da integração dos parceiros.

\subsubsection{Otimização do Processo de Modelagem}

Dois conceitos adicionais que otimizam o processo de modelagem são apresentados como mecanismos complementares para auxiliar o processo de abstração e armazenamento das informações sobre os parceiros presentes em uma OV: padronização e classificação. Estes conceitos são utilizados tanto em projetos de consultoria da firma que desenvolve a ferramenta ARIS como em projetos de pesquisa, o que indica a sua relevância. A otimização do processo de modelagem proporciona uma maior eficiência na aplicação das atividades de simulação de processos, geração de modelos de referência e implantação de sistema worfklow.

A padronização das informações contribui para a difusão de um entendimento comum entre os parceiros de uma OV. Para esta finalidade, o padrão utilizado neste trabalho baseia-se na arquitetura ARIS para a representação das informações inerentes às empresas dentro da OV. A forma de representação não se restringe apenas à utilização de um 
determinado método dentro de uma arquitetura, mas também a diferentes níveis de abstração e a diferentes tipos de classificação em que uma informação pode ser armazenada.

Como já foi dito, a arquitetura, e consequentemente, a ferramenta ARIS está dividida em quatro visões diferentes, onde cada uma oferece diferentes métodos para a descrição da realidade da empresa. Estes métodos possuem por sua vez diferentes níveis de abstração, por um lado mais próximo de uma descrição textual sem muito formalismo e por outro com o formalismo necessário para implementação de aplicativos computacionais. A Tabela 3 apresenta os diferentes planos onde os métodos podem ser utilizados. Esses planos foram levantados na firma IDS Prof. Scheer e representam os resultados de diferentes projetos de consultoria realizado por seus funcionários (IDS, 1996c).

\section{TABELA 3: Níveis de Abstração em um Projeto de Modelagem}

\section{O quê?}

\section{Plano 1: Genérico}

Plano Genérico para a Inserção de Modelos Genéricos

Plano 2: Descritivo
Modelos Genéricos para diferentes
finalidades:
- Otimização dos Processos de
Negócios,
- Aquisição de Softwares Aplicativos,
- Desenvolvimento de software

\section{Plano 3: Detalhado}

Detalhamento a nível de implementação dos modelos genéricos

\section{Como se documenta?}

Cenários de Processos com o método da Matriz de Escolha de Processos e com descrições textuais

* Elaboração de modelos EPK para a representação dos processos

* Descrição textual de cada modelo de processo

* Definição dos objetos pertencentes ao processo

* MER

* Detalhamento do EPK (Controle do fluxo + Objetos de informação + Responsabilidades + Utilização de classe de aplicativos computacionais)

* Descrição textual de cada modelo de processo

* Definição dos atributos dos objetos

* Detalhamento do MER

Como pode ser observado na Tabela, o EPK é o método central da ferramenta, a partir do qual são feitas as ligações com os demais elementos de outros métodos e consequentemente com as outras visões. Além disso, um EPK pode ser detalhado através de outro EPK e formando assim uma hierarquia de representação. O Modelo Entidade-Relacionamento 
(MER), método que descreve formalmente as informações, também é amplamente utilizado na visão de dados. A escolha dos métodos a serem utilizados depende da situação de cada empresa e da finalidade do projeto a ser implantado (como descrito no Plano 2), mas no entanto os níveis de abstração permanece.

Além do EPK e do MER, outros métodos são utilizados para detalhar o processo de modelagem dos parceiros da OV, dos quais podem ser destacados os seguintes:

- Fluxo de Informação que determina quais informações devem ser compartilhadas entre os processos, e com isso consiste em um método auxiliar que é explorado no detalhamento dos processos, ou seja, no plano 3;

- Organograma que identifica a estrutura organizacional de cada empresa, principalmente com a apresentação dos recursos humanos disponíveis. Este método é essencial para os planos 2 e 3 , pois mostra onde e quem realiza cada função.

- Árvore de Funções que apresenta a hierarquia de funções nos processos de negócio, fornecendo a possibilidade de uma análise separada a respeito das atividades em um processo. Este método é essencial aos três planos de modelagem, uma vez que o próprio nome hierarquia define a sua aplicabilidade.

Uma definição juntamente com a apresentação dos elementos pertencentes para cada método, segundo a firma que comercializa a ferramenta ARIS, é dada no Anexo I.

Para o armazenamento dos processos dos parceiros há necessidade de se estabelecer um mecanismo de classificação dos mesmos. Diferentes propostas de classificação podem ser encontradas na literatura como em SCHEER (1995), HRONEC (1993), FORSCHUNGSZENTRUM KARLSRUHE (1995), as quais tratam principalmente a empresa de manufatura. Neste trabalho é observada a proposta do projeto alemão GiPP "Geschäftsprozeßmanagement mit integrierten Produkt- und Prozeßmodellen" (Gerência de Processos de Negócios com Modelos integrados de Produto e Processo) onde a estrutura para a classificação dos modelos é dada na Figura 26.

O projeto GiPP pesquisa a realização integrada de processos de negócio e produto com base na aplicação de modelos e, por isso, diferencia a modelagem do processo com a do produto. Nesta estrutura, cada modelo é inserido conforme diferentes descritores (gerais, relacionados ao processo, ao produto e à empresa), classificado como processo direto ou de apoio e observado sob diferentes perspectivas (cultural, social, estratégica, etc.). 


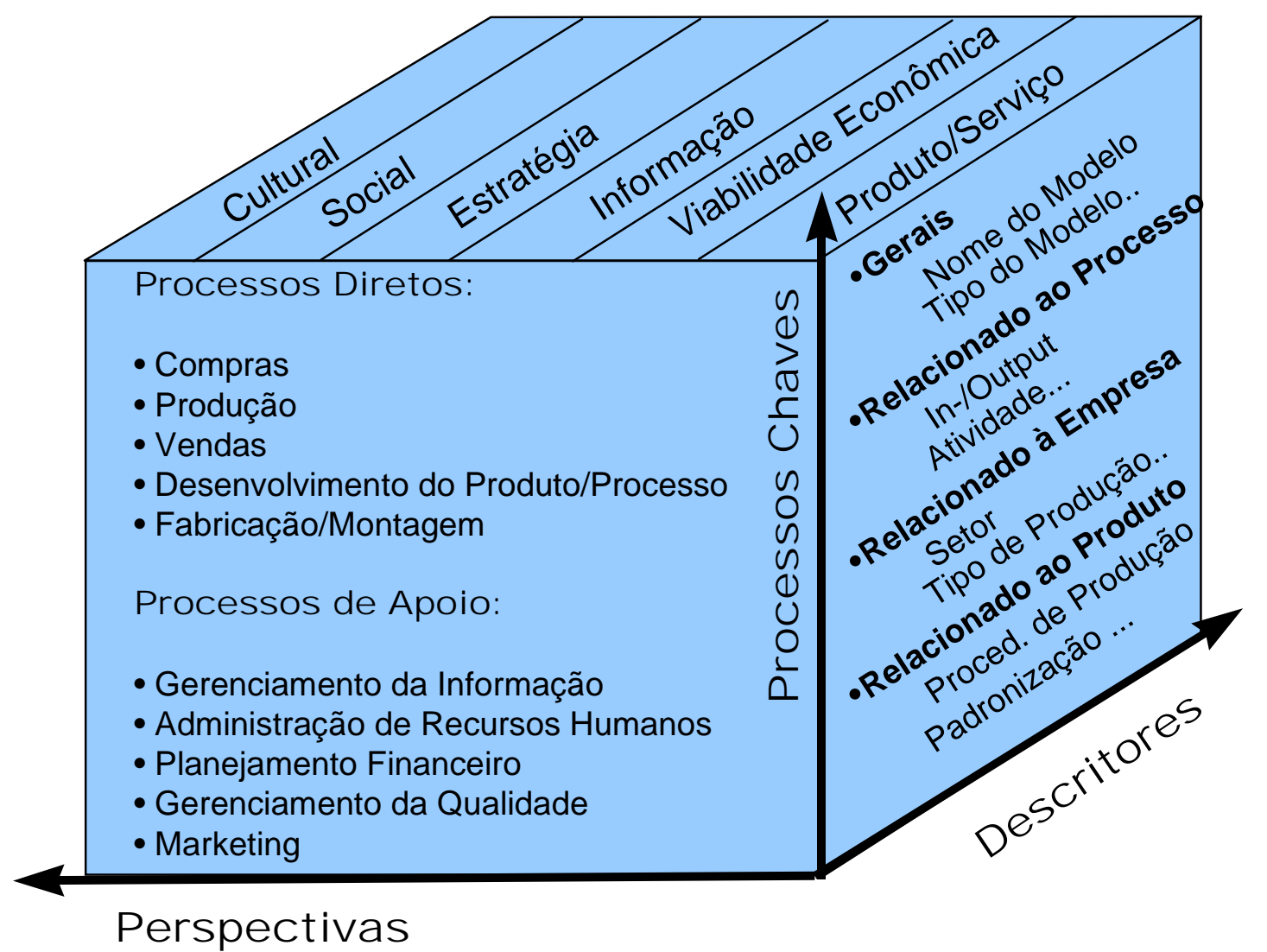

\section{FIGURA 26: Estrutura para Classificação de Processos do Projeto GiPP}

Os níveis de abstração e o tipo de classificação a serem utilizados neste trabalho referem-se à utilização da própria ferramenta ARIS, uma vez que estes são frutos de projetos já realizados em empresas, certificando assim a sua aplicabilidade. A estruturação dos níveis de abstração ou planos de modelagem prevê a utilização dos métodos oferecidos pela ferramenta em diferentes perspectivas de análise.

Desta maneira, estes conceitos adicionais são aplicados ao processo de modelagem para oferecer uma maior capacidade de abstração das informações sobre os parceiros da OV e suportar um melhor nível de entendimento entre o coordenador de desempenho e os coordenadores in-/ outsourcing no processo de integração.

\subsubsection{Relacionamento dos Modelos Utilizados na Proposta}

O processo de otimização da integração de parceiros proposto neste trabalho baseiase na utilização de diferentes modelos (Figura 27). Como já foi mencionado, o modelo de empresa consiste no principal conceito utilizado para representação das informações dos 
parceiros da OV, o qual é detalhado através de diferentes visões. Neste trabalho, cada uma destas visões é representada segundo o formalismo do MER e, por isso, também é referenciada por modelo. Por exemplo, a visão organizacional do modelo de empresa de uma OV é tratada na proposta deste trabalho como modelo organizacional.

Além disso, a representação dos modelos organizacional, de operação e de dados é suportada por diferentes métodos da ferramenta ARIS, os quais também são referenciados por modelos. Por exemplo, a representação da execução do serviço de um parceiro é feita através de um modelo EPK a ser armazenado na ferramenta ARIS, o qual faz parte da visão operacional do modelo de empresa da OV.

\begin{tabular}{|c|c|c|c|c|}
\hline \multicolumn{5}{|c|}{ Modelo de Empresa } \\
\hline $\begin{array}{c}\text { Modelo de } \\
\text { Dados }\end{array}$ & $\begin{array}{l}\text { Modelo de } \\
\text { Operação }\end{array}$ & $\begin{array}{c}\text { Modelo } \\
\text { Organizacional } \\
\end{array}$ & $\begin{array}{c}\text { Modelo de } \\
\text { Recursos }\end{array}$ & $\begin{array}{l}\text { Modelo de } \\
\text { Negócios }\end{array}$ \\
\hline \multirow[t]{4}{*}{$\begin{array}{l}\text { modelo } \\
\text { MER }\end{array}$} & $\begin{array}{cc}\text { modelo } & \text { modelo } \\
\text { EPK } & \text { Árvore de } \\
\mathcal{L} & \text { Funções }\end{array}$ & \multirow[t]{4}{*}{$\begin{array}{l}\text { modelo } \\
\text { Organograma }\end{array}$} & & \\
\hline & modelo genérico & & & \\
\hline & modelo descritivo & & & \\
\hline & modelo detalhado & & & \\
\hline Renreser & o na Ferran & ta ARIS & & \\
\hline
\end{tabular}

FIGURA 27: Descrição dos Tipos de Modelos Utilizados na Proposta

Por último, o método EPK pode ser utilizado nos diferentes níveis de abstração abordados na seção 3.3.2. Assim, a representação do serviço de um parceiro é realizada através de modelos EPK's nos três níveis de abstração:

- um modelo EPK genérico;

- um modelo EPK descritivo para cada função do modelo EPK genérico;

- um modelo EPK detalhado para cada função do modelo EPK descritivo. 


\subsubsection{Definição da Tipologia da Empresa Virtual a ser tratada no Trabalho}

O ambiente de operação para a referida estrutura de uma OV pode ser representado para qualquer setor da economia mas, no entanto, uma delimitação da área de atuação otimiza os mecanismos propostos através de sua especialização ao referido contexto.

Como pode ser encontrado na literatura, alguns projetos de pesquisa exploram a empresa de produção e outros a cooperação entre empresas na área de serviços. O processo de integração de parceiros no setor produtivo apresenta uma maior complexidade pois o processo de produção também pode ser distribuído dependendo da oportunidade a ser explorada. Em outras palavras, subconjuntos da estrutura do produto podem ser produzidos por diferentes empresas.

Para isso, o processo de Planejamento e Controle da Produção - PCP, que em uma empresa já é fonte de várias dificuldades, passa a se tornar um grande obstáculo para o sucesso deste tipo de EV devido a complexidade de integração de recursos físicos de diferentes empresas (Figura 28). No entanto, quando a entidade coordenadora da cooperação baseia-se em uma grande empresa, que terceiriza alguns processos da cadeia de valor e mantém para si o processo de vendas e marketing, os PCP's de cada empresa são realizados de acordo com as necessidades da empresa líder, o que facilita o processo de integração.

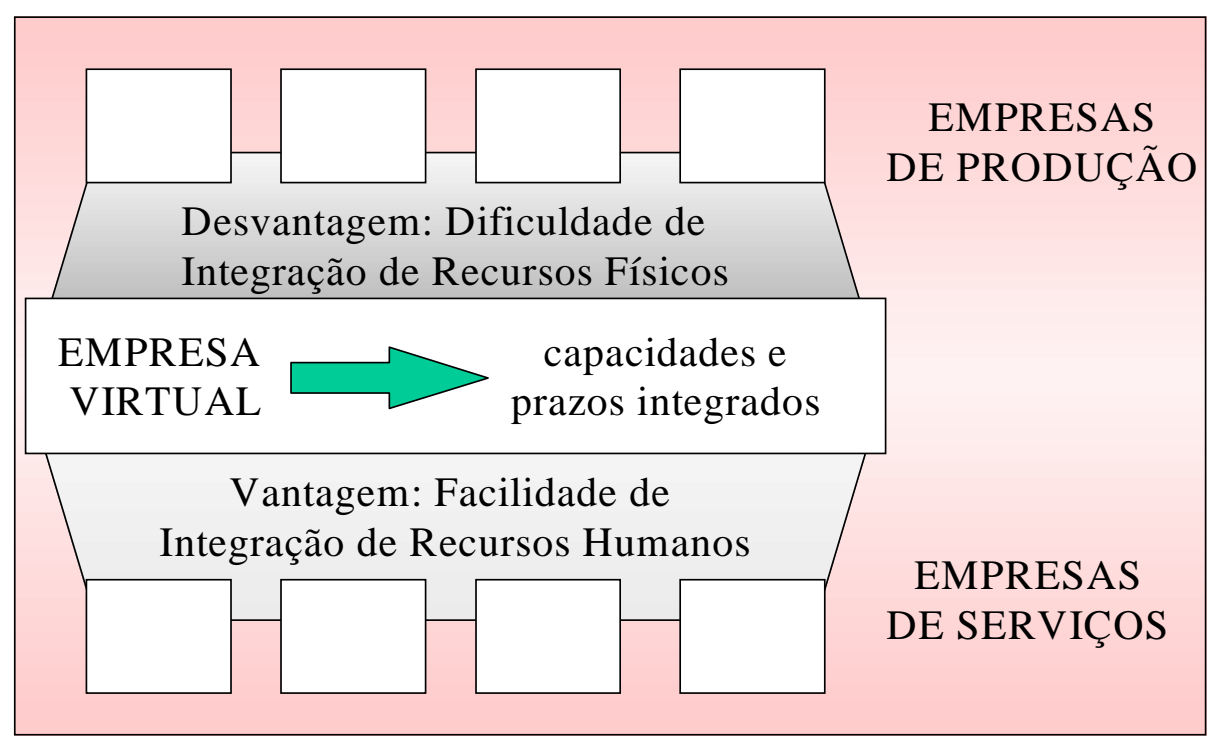

FIGURA 28: Formação de EV de Produção versus de Serviços 
A maior dificuldade de integração de parceiros em uma EV de produção corresponde ao ajuste integrado das capacidades dos parceiros e a definição comum de prazos. Assim, a integração do processo de PCP entre diferentes empresas fornece o requisito principal para a formação de uma EV de produção. Para isso, a área de integração de aplicativos, principalmente com a utilização de tecnologias como orientação a objetos e Internet, influencia diretamente o futuro deste tipo de EV. Além disso, o processo de desenvolvimento de novos produtos deve ser explorado como atividade comum entre os parceiros de uma OV para auxiliar o processo de integração do PCP.

Devido às dificuldades apresentadas acima, este trabalho procura então explorar as alternativas referentes à área de serviços, uma vez que a integração dos recursos humanos que os executam nas diferentes empresas representam uma menor complexidade de integração. Esta menor complexidade pode ser representada por dois fatores:

- pela maior facilidade de aumento da capacidade de uma empresa de serviço através da contratação (podendo ser inclusive de caráter temporário) de novos funcionários, ao contrário da dificuldade de aquisição de novos equipamentos;

- pela capacidade de comunicação entre os próprios recursos humanos (especialistas) das diferentes empresas, auxiliando o processo de integração das atividades dos mesmos para a elaboração de um serviço comum.

Como exemplo para a validação da proposta deste trabalho, o setor explorado foi o de serviços na área da Tecnologia da Informação. Dentro do setor da TI, um serviço, assim como um produto, pode ser composto por outros serviços, o que constitui a base para a cooperação entre empresas na exploração de uma oportunidade de negócio. Desta maneira, as competências dos parceiros de uma OV que atende à um determinado setor de serviços deve estar devidamente estabelecidas para que a oferta de um serviço comum seja vantajosa para um cliente potencial. 


\section{Integração de Parceiros em Empresas Virtuais}

Como já foi abordado nos capítulos anteriores, o objetivo principal deste trabalho de consiste na integração de parceiros na formação e gerência de Empresas Virtuais dentro do ambiente de uma Organização Virtual. Este trabalho é apresentado da seguinte maneira neste capítulo:

- desenvolvimento da proposta;

- adaptação do conceito de modelo de empresa para a representação dos parceiros de uma Organização Virtual;

- detalhamento das fases do ciclo de vida de uma Empresa Virtual proposto pelo projeto Kiesel com a enumeração das atividades propostas para a integração dos parceiros;

- apresentação da atividades de integração com a utilização dos conceitos e ferramentas da área de Integração de Empresas.

\subsection{Desenvolvimento da Proposta}

O desenvolvimento da proposta deste trabalho dividiu-se em duas etapas: formalização das informações sobre os parceiros de uma OV e aplicação das atividades de integração no ciclo de vida de uma EV.

Neste trabalho, o processo de formalização das informações acontece durante o estabelecimento dos parceiros de uma OV (construção da OV), onde para esta finalidade é utilizado o conceito de modelo de empresa. Desta maneira, o modelo de empresa em uma OV representa eletronicamente, na forma de diferentes visões, as informações sobre os seus parceiros. Para a geração do modelo de empresa dentro de uma OV foram detalhadas algumas atividades através da interação entre um coordenador de desempenho e os coordenadores in-/ outsourcing de cada parceiro. Para suportar o armazenamento e 
recuperação das informações do modelo de empresa um esquema de classificação dos serviços foi adaptado para este contexto.

A utilização do modelo de empresa foi viabilizada através de um detalhamento das fases do ciclo de vida para uma EV, o qual foi baseado na proposta do projeto Kiesel. Desta forma, as informações formalizadas no modelo de empresa são utilizadas nas atividades do ciclo de vida para suportar o processo de integração dos parceiros. Como mencionado, a aplicação de conceitos e ferramentas da área de Integração de Empresas representam o processo de integração, que, por sua vez, é realizado através de diferentes atividades no ciclo de vida.

A Figura 29 mostra a seqüência de aplicação destes conceitos e ferramentas, inicializada pela identificação de uma oportunidade de negócio. Para a aplicação de cada recurso foram elaboradas diferentes atividades, o que representa o foco central da proposta deste trabalho.

O coordenador de desempenho não foi ilustrado na Figura mas ele é responsável pela realização de todas as atividades relacionadas ao processo de integração de parceiros.

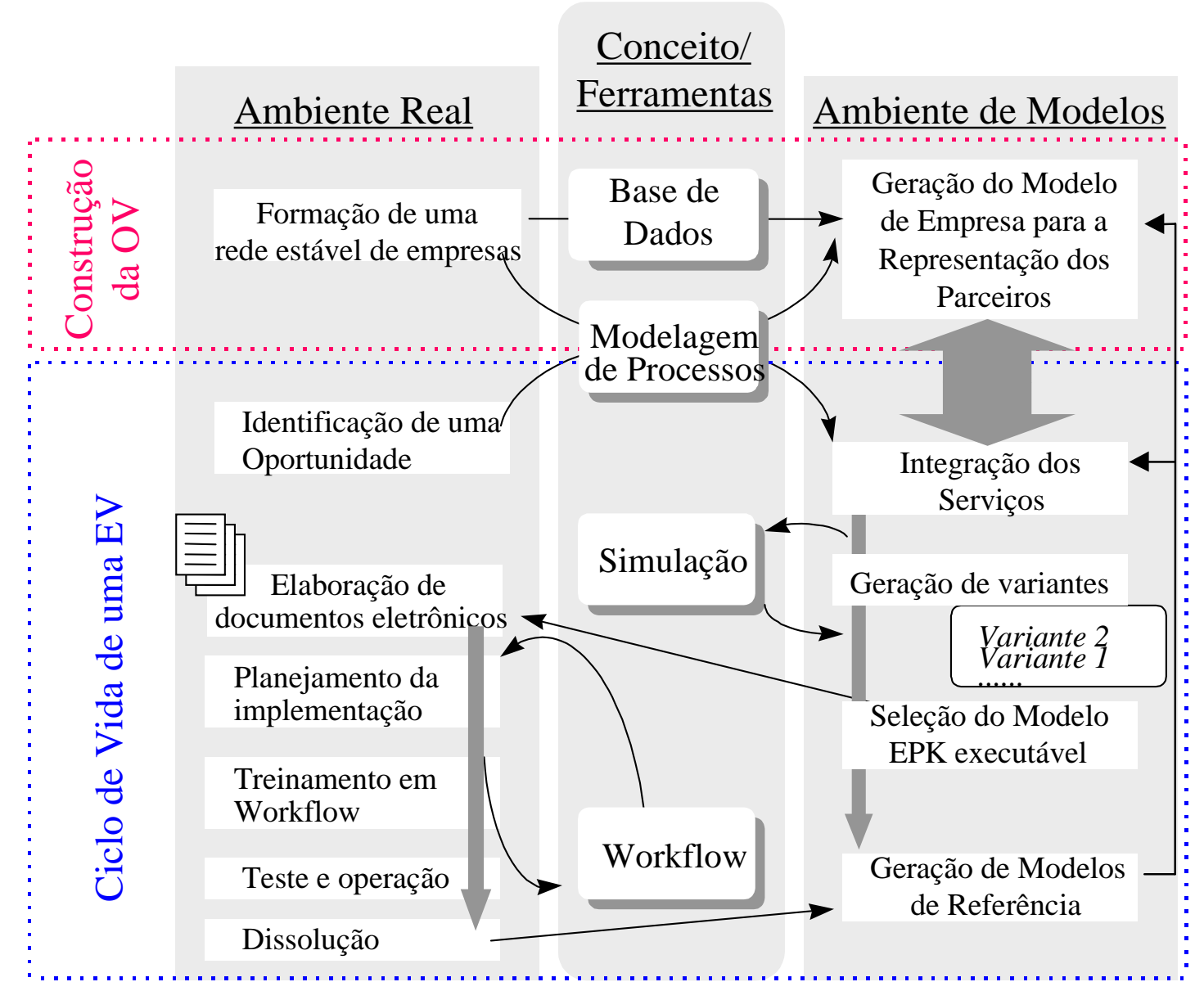




\section{FIGURA 29: Desenvolvimento da Proposta}

\subsection{O Modelo de Empresa em uma Organização Virtual}

O conceito de modelo de empresa é utilizado neste trabalho para a formalização das informações sobre os parceiros da OV. Para a realização desta atividade foi utilizado como base o modelo de empresa proposto por RENTES (1995), o qual teve que ser adaptado para incluir a perspectiva de diferentes empresas ao invés de diferentes departamentos em uma única empresa. A descrição do modelo de empresa adaptado é feita utilizando o formalismo do MER, ou seja, os elementos que descrevem cada visão é representado na forma de entidades e relacionamentos. Esta forma de descrição representa, então, a meta base de dados do modelo de empresa.

Como foi descrito, o modelo de empresa é composto por sub-modelos que representam visões diferenciadas de uma mesma situação, ou seja, a representação da informação é feita segundo diferentes perspectivas como estratégica, organizacional, operacional, de dados e de recursos. Para cada uma destas visões algumas modificações tiveram que ser realizadas.

O Modelo de Dados contém em sua meta base de dados, além das entidades básicas de um MER (Entidade e Relacionamento), uma entidade adicional que representa um Parceiro da OV (Figura 30). Assim, as informações que estão sendo modeladas através de Entidade e Relacionamento podem ser associadas ao Parceiro que as mesmas pertencem. Além disso, o relacionamento da entidade Entidade com a estrutura do Serviço a ser oferecido pela $\mathrm{OV}$ oferece um suporte maior no processo de integração dos parceiros, relacionando as informações (representadas pelas entidades) de todos os serviços necessários para a formação da EV. 


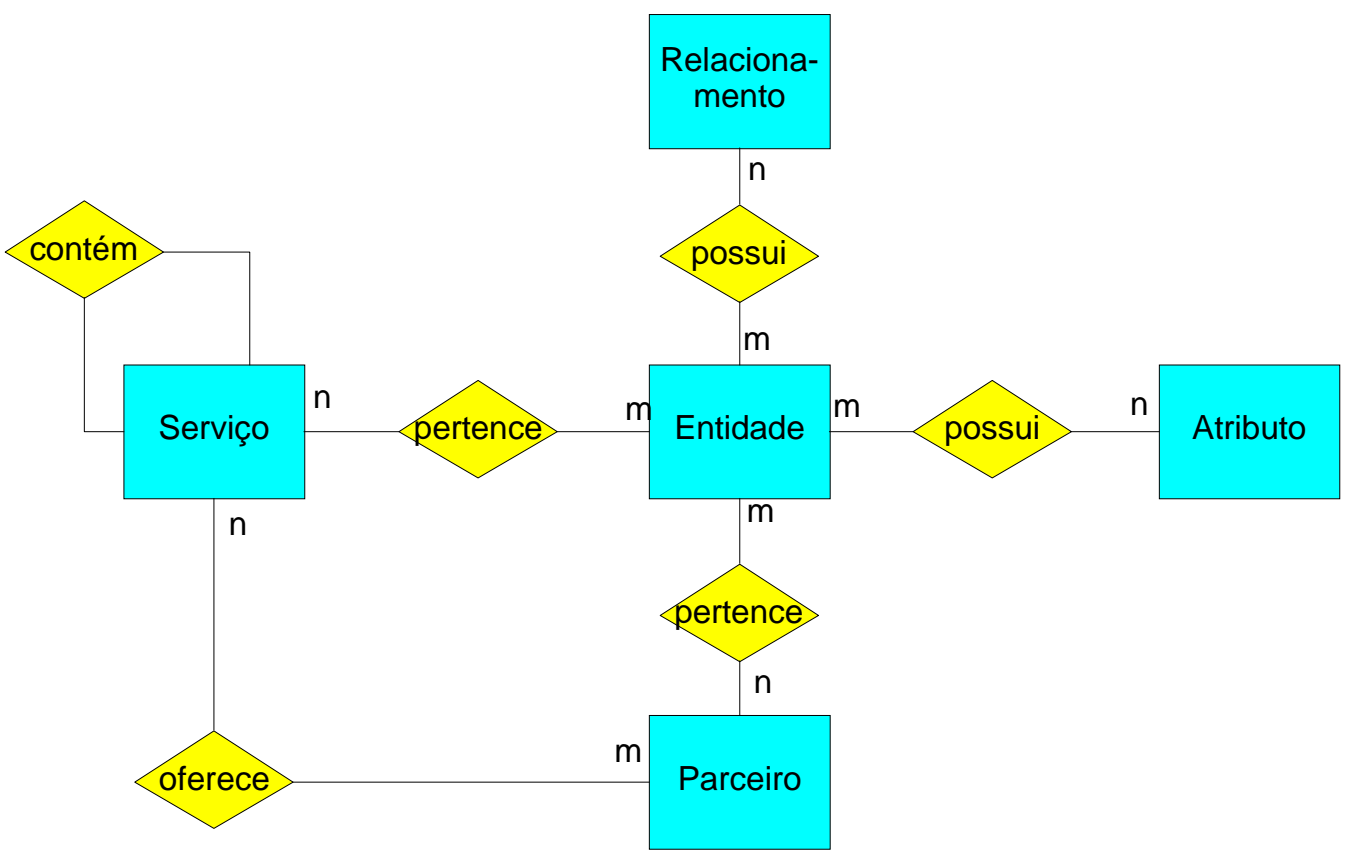

FIGURA 30: Modelo de Dados

O relacionamento entre as entidades Parceiro e Serviço é utilizado na definição da visão estratégica de negócios, onde uma matriz de oportunidades futuras é construída. Esta matriz, que no caso de uma OV é tridimensional (devido aos eixos serviço/produto, parceiro e mercado), indica qual serviço deve ser prioritariamente explorado. Este relacionamento entre Parceiro e Serviço ainda pode ser utilizado para a divulgação dos serviços oferecidos pela OV através da apresentação de suas empresas na Internet.

O Modelo de Negócios apresenta as seguintes entidades mostradas na Figura 31. Através do processo de elaboração da visão estratégica, como um dos processos de coordenação da OV, são levantados todos os Serviços oferecidos por cada Parceiro e todos os possíveis Mercados que podem ser explorados pela associação dos mesmos. O relacionamento entre um Serviço e um Mercado pode ser visto como uma oportunidade, que dependendo da análise do Broker, traça estratégias de exploração ou observação das oportunidades. 


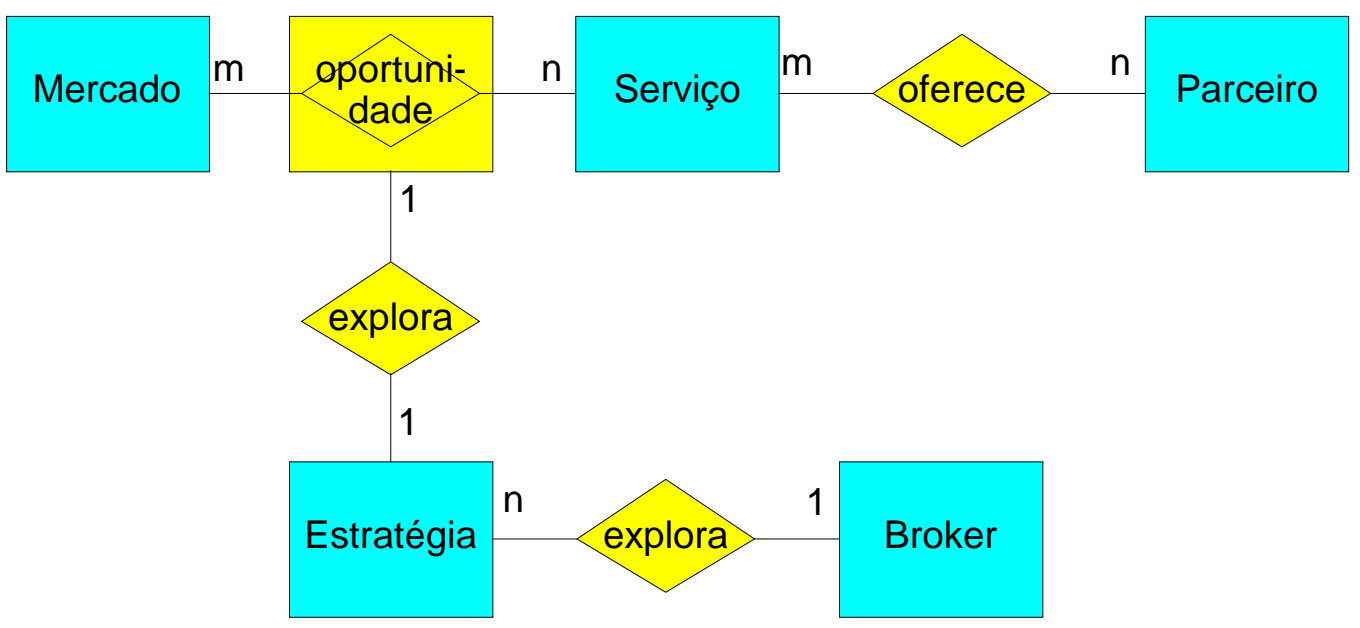

FIGURA 31: Modelo de Negócios

O Modelo de Recursos apresentado por Rentes procura indicar qual tipo de software pode ser executado em qual tipo de hardware. Neste trabalho, uma descrição em termos de Hardware e Software para cada Parceiro visa suportar a formação de uma EV, indicando quais recursos suportam os processos de negócios dos parceiros (Figura 32).

De acordo com as necessidades de uma OV e do conceito de competência essencial para a formação de uma EV, a modelagem de recursos envolve ainda o levantamento de Especialistas. Por exemplo, para a área de TI, alguns especialistas são o projetista de banco de dados, o projetista de redes, o analista de sistemas, entre outros. Estes especialistas geralmente estão associados à uma determinada área de aplicação, ou seja, à um determinado Setor Econômico, tais como saúde (hospitais, clinicas), empresas de manufatura, setor público (prefeituras, secretarias), setor agropecuário, entre outros.

Por último, a entidade Recurso Internet relaciona-se com a comunicação a ser realizada dentro da OV. Como foi dito, a comunicação tem como base a utilização da Internet sendo necessário para isso alguns recursos como endereço eletrônico, browser, software de FTP e de vídeo conferência, entre outros. 


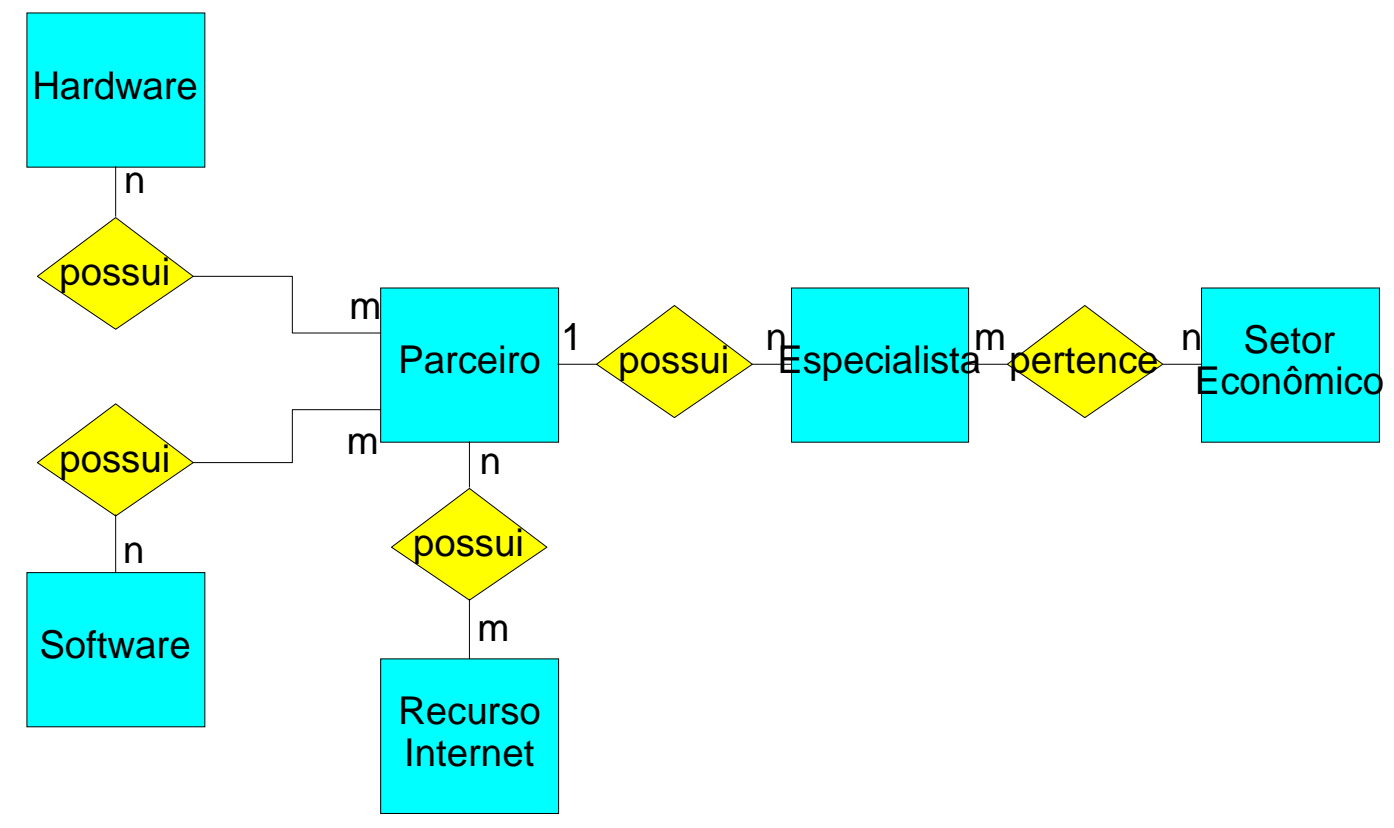

FIGURA 32: Modelo de Recursos

O Modelo Organizacional indica a estrutura da plataforma na qual os parceiros estão associados e, assim, da OV como um todo, indicando ainda quais as pessoas (aqui tratadas também como Colaboradores) que participam do processo de formação de uma EV (Figura 33). Um Elemento Organizacional corresponde a um parceiro com todas as suas Representações e que participa da Organização Virtual. A formação da estrutura organizacional de uma Empresa Virtual é feita de acordo com a integração dos diferentes elementos organizacionais que estão presentes na OV. Os colaboradores, que podem corresponder à especialistas, estão associados aos elementos organizacionais. 


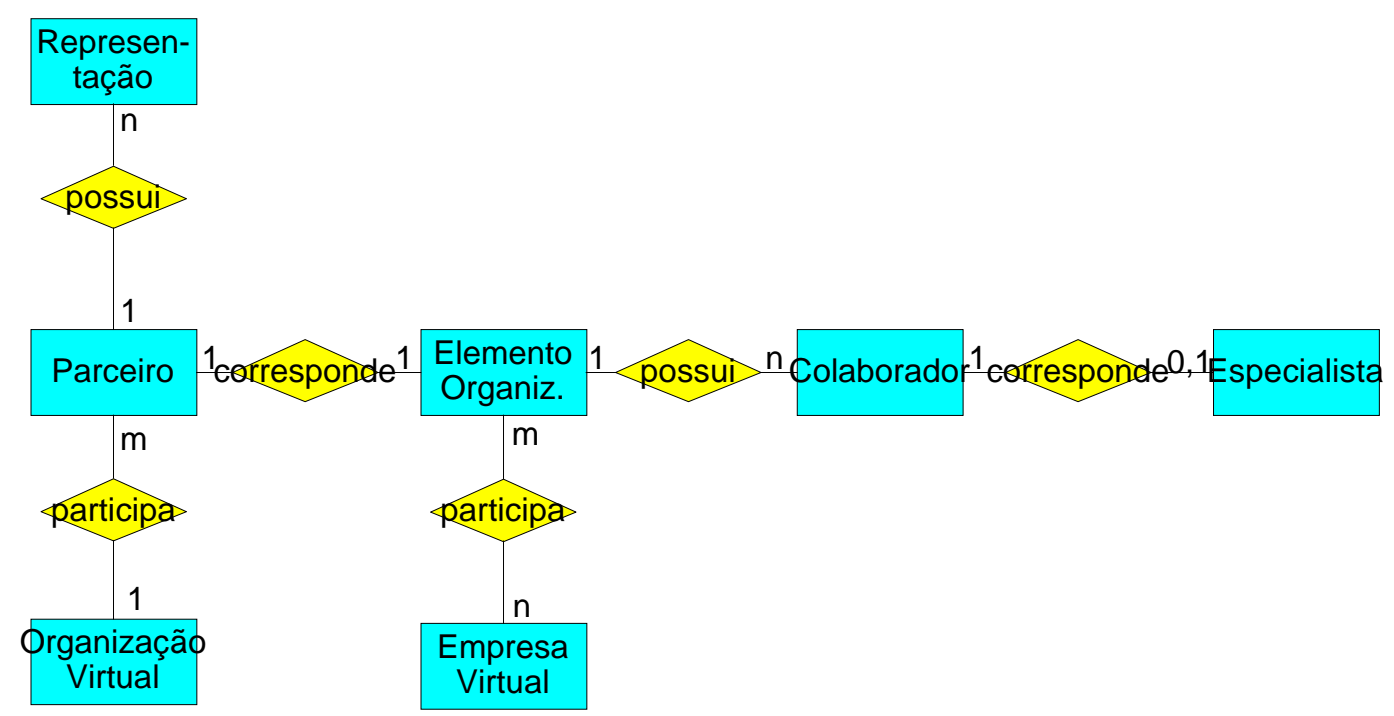

FIGURA 33: Modelo Organizacional

O Modelo de Operação fornece o suporte fundamental para a realização deste trabalho, onde uma descrição dos serviços presentes na OV representa o requisito principal para a integração dos parceiros na formação e gerência de uma EV (Figura 34). A construção deste modelo baseia-se no formalismo apresentado pelos métodos da ferramenta ARIS, onde o EPK consiste na principal forma de representação dos serviços.

O modelo apresentado por RENTES (1995) mostra os elementos Função e Grupo Funcional para a diferenciação de níveis de abstração. Esses níveis de abstração são apresentados neste trabalho de acordo com o relacionamento recursivo do elemento Função. Neste trabalho, um Serviço é descrito como uma associação de funções, que por sua vez podem ser detalhadas através de outras funções. Há três níveis de abstração (apresentados na seção 3.3) onde as funções podem ser detalhadas. A função pode ser realizada de acordo com a utilização de algum Suporte como, por exemplo, o uso de algum aplicativo. 


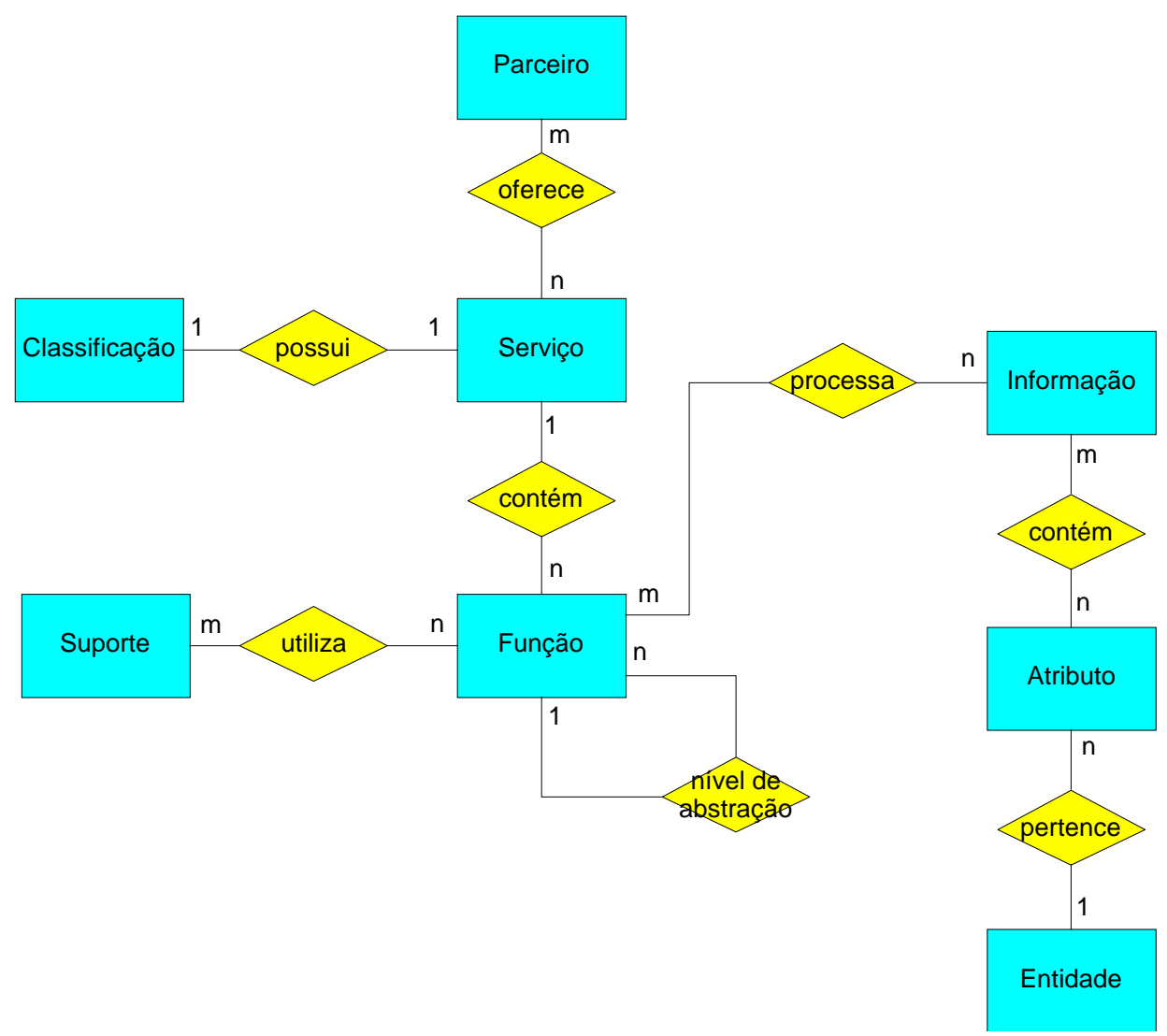

FIGURA 34: Modelo de Operação

A informação que deve fluir entre os serviços, e consequentemente entre as suas funções, é detalhada através do relacionamento entre as entidades Função e Informação. A entidade Atributo indica a composição de cada informação, ou seja, os dados que ela contém. No caso de integração de aplicativos, a entidade Entidade referencia as tabelas que devem ser geradas para apoiar esta atividade.

Para auxiliar o armazenamento dos modelos referentes aos serviços dos parceiros algum tipo de Classificação deve ser usado. Toda a atividade de integração dos serviços é baseada na utilização de modelos, ou seja, a integração ocorre a princípio a nível lógico (mundo dos modelos) antes de se operar realmente a EV. Desta maneira, os modelos devem estar devidamente armazenados segundo algum tipo de classificação para facilitar a sua recuperação durante as atividades de otimização da integração dos parceiros. Para esta finalidade, a classificação proposta pelo Projeto GiPP alemão é utilizada neste trabalho pois esta valoriza a utilização dos modelos para a otimização dos processos de negócios. No entanto, é necessário uma adaptação para o contexto de OV's apresentado a seguir. 


\subsubsection{Classificação de Processos de Negócios em uma Organização Virtual}

A estrutura proposta pelo Projeto GiPP apresenta três dimensões onde os processos de negócios e seus modelos podem ser classificados (Figura 35). Os Processos Chaves estão divididos em Processos Primários e de Apoio. Neste trabalho, os Processos Primários podem ser relacionados com os serviços que são diretamente oferecidos aos clientes da $\mathrm{OV}$, tais como Desenvolvimento, Consultoria, Venda, Curso, entre outros. A escolha do tipo de serviço a ser oferecido depende do perfil dos parceiros que formam a OV.

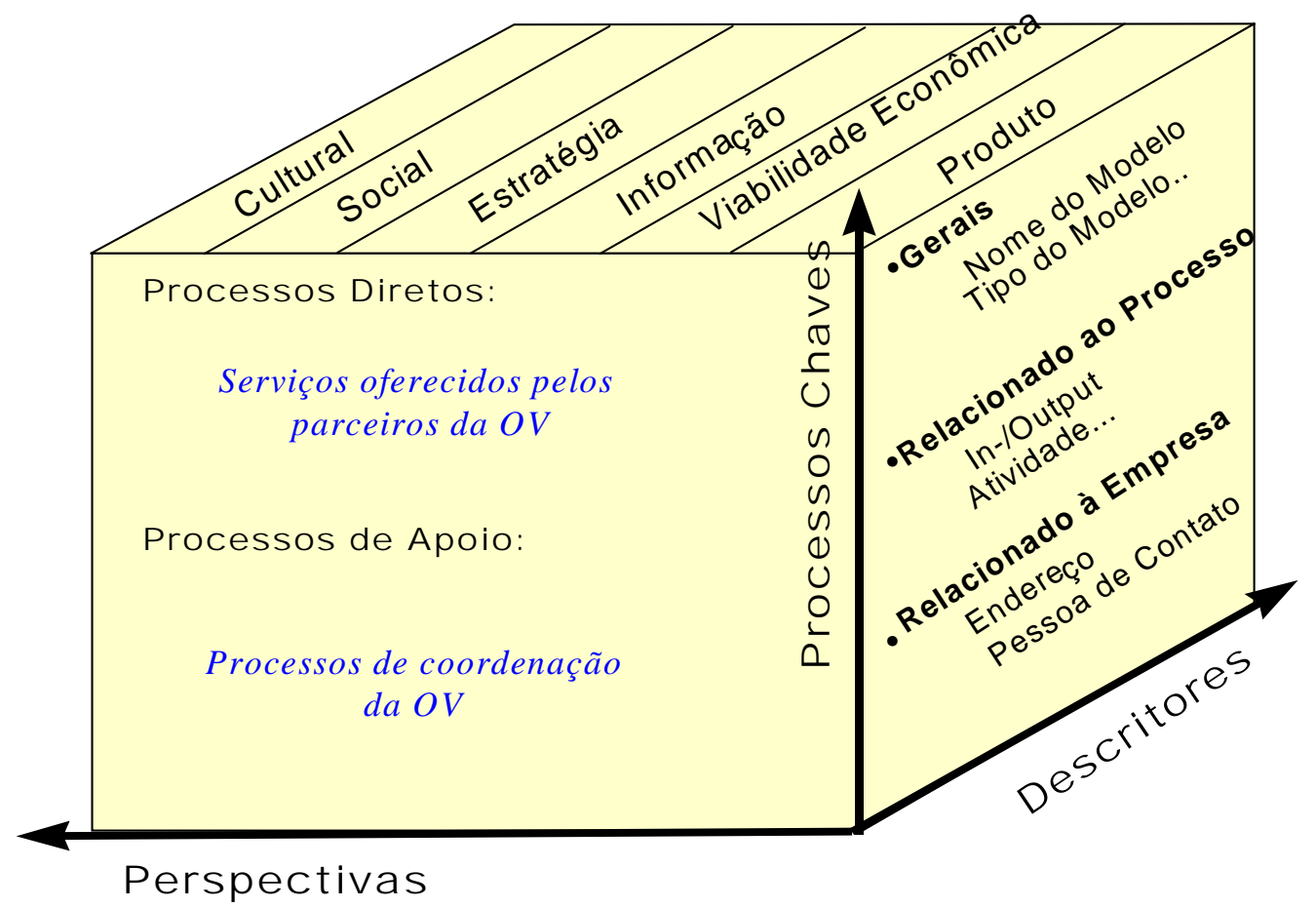

FIGURA 35: Classificação dos Serviços na Organização Virtual

Os processos de apoio, aqui, representam os processos de coordenação da $\mathrm{OV}$, os quais são executados por seus parceiros. Entre estes processos podem ser destacados o desenvolvimento de novos serviços, o gerenciamento da informação, o planejamento estratégico e financeiro, Marketing, entre outros. O objetivo de implantação destes processos é o de suportar o desenvolvimento e consolidação da OV como uma organização que oferece serviços com qualidade e preços competitivos.

Cada serviço pode ser observado segundo diferentes perspectivas. De um ponto de vista cultural e social um serviço exige certas habilidades ou competências (por exemplo 
capacidade de comunicação) das pessoas que pertencem ou executam o mesmo. $\mathrm{O}$ aspecto motivacional também é observado de acordo com estes parâmetros, dizendo quais técnicas podem ser utilizadas para melhorar o desempenho do processo correspondente. Cada serviço pode ainda ser relacionado com outros parâmetros como:

- estratégia: indica o potencial de exploração de um serviço em um determinado mercado;

- informação: indica as informações necessárias para a execução do serviço;

- viabilidade econômica: relaciona os custos associados a um serviço com a finalidade de comparação com serviços concorrentes:

- produto: indica quais os produtos que suportam a execução do serviço.

A dimensão dos descritores caracterizam os serviços como modelos, onde alguns itens devem ser detalhados. Todo modelo possui um nome que se refere diretamente ao serviço e é elaborado segundo algum formalismo, ou seja, o tipo do modelo. Além destes, a elaboração do modelo já relaciona quais atividades que são executadas pelo serviço, utilizando quais informações (como fluxo de informações entre as atividades do processo) e aonde são executadas. Esta descrição é feita utilizando a ferramenta ARIS. Por último, há a referência sobre qual parceiro da OV o serviço deve ser associado, ou seja, que empresa o executa.

\subsubsection{A Geração do Modelo de Empresa}

Apresentada a estrutura para a classificação dos modelos, agora é necessário alimentá-la com as informações referentes aos parceiros da OV e consequentemente poder gerar o modelo de empresa. Como já foi dito, este trabalho de doutoramento focaliza apenas a exploração do modelo de operação. Para a realização desta atividade presume-se a utilização da plataforma descrita anteriormente, onde a Internet é o meio de comunicação para a transferência das informações.

Aqui vale ressaltar que a geração do modelo de empresa ocorre paralelamente com a construção da OV, como mostra a Figura 29. Isto significa que os parceiros iniciais da OV inicializam a sua concepção e as demais empresas, que forem se associando, vão expandindo o modelo de empresa. Os aspectos relacionados com as regras de admissão e de conduta de parceiros não são tratados neste trabalho. 
A geração do modelo de empresa é suportada pela realização de um curso de nivelamento a respeito da atividade de modelagem de processos e seus benefícios. Como já foi dito, o formalismo para a representação dos serviços é fornecido pela ferramenta ARIS. Uma parte fundamental dentro do curso de nivelamento consiste na explicação da classificação a ser utilizada pela OV. Em outras palavras, cada parceiro deve saber aonde suas competências se encaixam na classificação proposta na seção anterior.

Para a não geração de custos extras para os parceiros da OV, no sentido de aquisição da ferramenta, o coordenador de desempenho apresenta, dentro do curso de difusão, os métodos a serem utilizados juntamente com a explicação de cada elemento pertencente ao mesmo. Assim, os modelos podem ser elaborados utilizando qualquer editor gráfico e podem ser transferidos via e-mail.

Caso uma empresa dentro da OV deseje realizar algum trabalho de modelagem e otimização de processos, o coordenador de desempenho pode oferecer consultoria, indicando quais os padrões utilizados pela OV e sugerindo, através de sua experiência nesta atividade, alternativas para aumentar o desempenho dos serviços. Esta atividade de consultoria não deve visar lucros, uma vez que os benefícios são para ambos.

A geração do modelo de empresa, então, depende da participação de cada parceiro. A pessoa de contato em cada empresa (os coordenadores in-/outsourcers) que está associada à OV é responsável pelo envio das informações requisitadas pelo coordenador de desempenho. Estas informações são agrupadas em diferentes métodos da ferramenta ARIS, que são os seguintes:

- Modelo Entidade-Relacionamento: fornece as informações que são utilizadas nos serviços. Como este trabalho não visa a integração de aplicativos, o detalhamento à nível de atributos não é necessário, importando apenas uma descrição de cada entidade e de seus relacionamentos;

- Organograma: fornece a estrutura organizacional de cada empresa indicando também os seus recursos humanos (especialistas). Estas informações viabilizam ao coordenador de desempenho desenhar logicamente uma integração estrutural entre as diferentes empresas e montar um banco de dados sobre os especialistas que a OV disponibiliza;

- Árvore de Funções: fornece uma visão hierárquica sobre as atividades ou funções que uma empresa desenvolve. Esta visão suporta a elaboração dos modelos que representam os serviços uma vez que as suas funções são formalizadas e agrupadas. 
- Diagrama de Processos: fornece uma descrição sobre o funcionamento dos serviços, que na ferramenta ARIS representa a visão de controle que une as demais visões. Em outras palavras, o método EPK apresenta a seqüência de atividades juntamente com as informações que são utilizadas, aonde são realizadas e quem as realiza. Este diagrama pode ser apresentado em diferentes níveis de abstração.

Estes diagramas possuem a seguinte seqüência para serem elaborados: organograma, árvore de funções, MER e diagrama de processos. Esta seqüência é aconselhada pelos próprios projetos da firma que desenvolveu a ferramenta ARIS, a IDS Prof. Scheer, através da experiência de seus projetos de consultoria com empresas (IDS, 1995). O motivo desta seqüência é justificado pela disponibilidade de informações na elaboração de diagramas, ou seja, quando se desenha a hierarquia das funções tem-se em mente quem as realiza e quando se estabelece o MER tem-se a noção aonde suas informações podem ser utilizadas.

Como pode ser observado, as informações a serem fornecidas por estes diagramas devem ser trabalhadas distribuidamente, ou seja, cada parceiro elabora seus diagramas segundo o formalismo difundido pelo coordenador de desempenho. A visão estratégica por sua vez envolve interesses de negócios em comum, e por isso deve ser elaborada conjuntamente pelos parceiros da OV.

Os diagramas ou modelos gerados pelos parceiros são então colocados na ferramenta ARIS pelo coordenador de desempenho. Estes modelos podem ser colocados nas páginas do servidor Internet para suportar a explanação dos serviços oferecidos pela OV. Cada parceiro é responsável pela verificação dos modelos na Internet e consequentemente por sua correção, informando ao coordenador as modificações necessárias.

\subsection{Detalhamento do Ciclo de Vida Proposto pelo Projeto Kiesel}

Até agora foi descrito como as informações sobre os serviços são geradas e armazenadas. A partir da representação destas informações inicia-se então o processo de integração dos serviços dos parceiros para a formação e gerência de uma EV.

O processo de integração dos parceiros começa na elaboração da visão estratégica, onde são identificadas as oportunidades reais para a formação de uma EV. A partir da identificação da oportunidade, as informações sobre os parceiros são acessadas para viabilizar o processo de integração dos parceiros e consequentemente o ciclo de vida de uma 
EV. Neste sentido, nesta seção é apresentado o detalhamento das fases do ciclo de vida proposto pelo projeto Kiesel. Esse detalhamento é suportado pela representação de diagramas de processos da ferramenta ARIS, ou seja, as fases e atividades que compõem o método são representadas da mesma maneira que se descreve os serviços dos parceiros (Figura 36).

A primeira fase do método corresponde a exploração de oportunidades de negócios, realizada nos encontros dos parceiros para a definição da visão estratégica. Cada oportunidade é analisada, conjuntamente, segundo o mecanismo da matriz de oportunidades, ou seja, para cada mercado que os parceiros trazem para a OV é verificado quais os serviços comuns que podem ser explorados ou não. No diagrama, quando uma oportunidade deve ser explorada, a função Explorar Oportunidade (A1) gera um evento chamado Oportunidade é plausível. O mesmo evento é gerado quando a procura por um serviço integrado é realizada por um cliente, dependendo da disponibilidade de recursos dos parceiros.

O detalhamento da função Explorar Oportunidade é realizado através de outro diagrama de processos que contém outras funções, apresentando um outro nível de abstração para a representação da função mais genérica. Entre as funções que especificam Explorar Oportunidade pode-se destacar:

- cadastrar cada serviço oferecido pelos parceiros da OV;

- cadastrar os mercados explorados por cada parceiro;

- elaborar a matriz de oportunidades a partir do resultado das atividades citadas acima;

- elaborar propostas ideais de atuação comum;

- discutir propostas através de reuniões entre os parceiros;

- caracterizar cada proposta ou oportunidade apresentada, definindo prioridades ou estratégias para a sua exploração;

- cadastrar procura de clientes;

- analisar a viabilidade de realização da procura;

- avaliar disponibilidade da capacidade de realização dos parceiros;

- analisar a viabilidade de admissão de novos parceiros para atender a oportunidade sendo explorada; 
- cadastrar e conformar modelos dos serviços de novos parceiros;

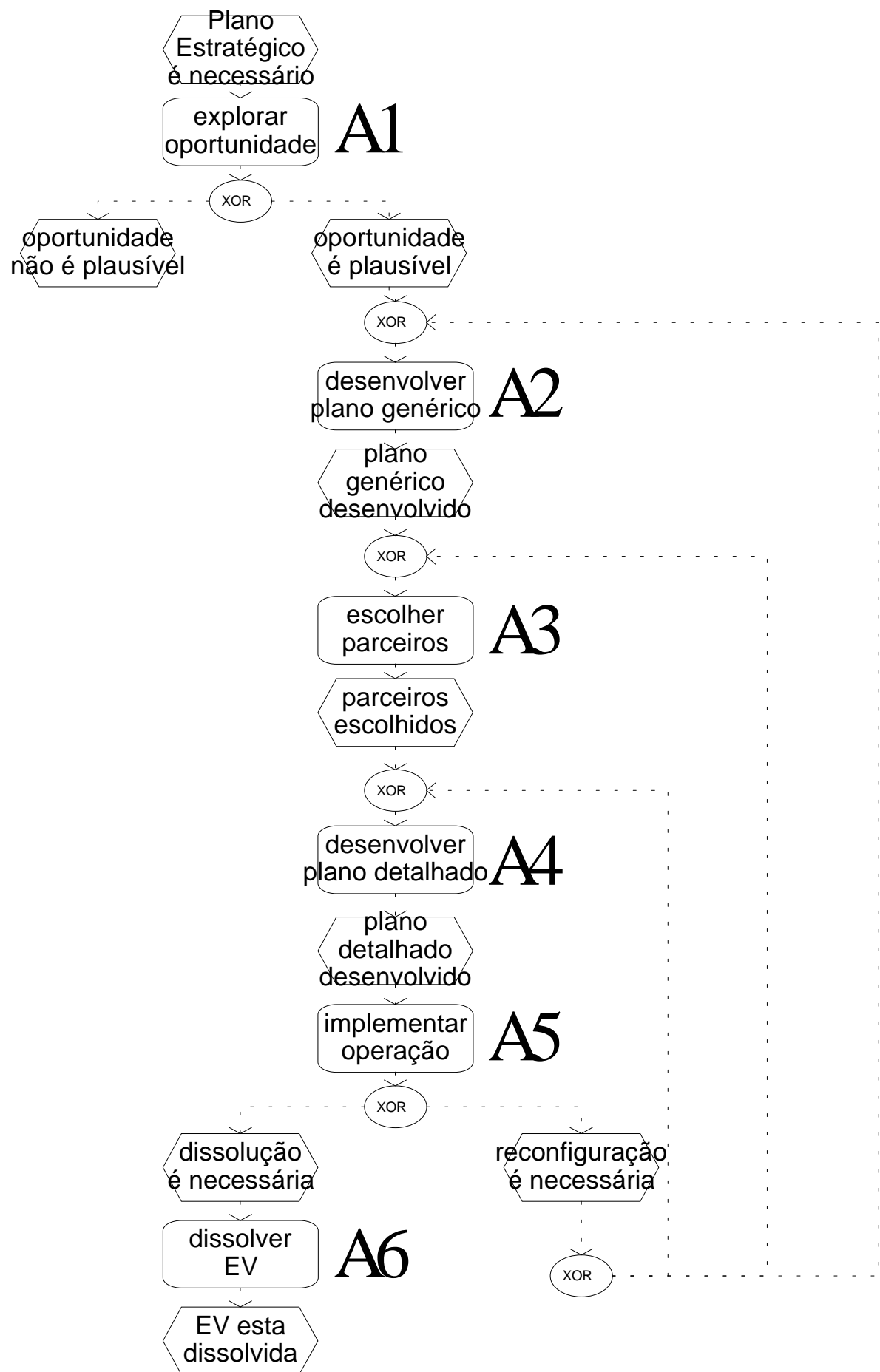

\section{FIGURA 36: Diagrama de Processos do Ciclo de Vida}

Outras funções ainda podem ser citadas para a função Explorar Oportunidades, mas no entanto este trabalho concentra-se nas fases posteriores à esta. $\mathrm{O}$ resultado desta função, 
que consiste no relacionamento entre a oportunidade identificada com os serviços necessários para a sua realização, é o ponto inicial para as atividades de otimização da integração de parceiros.

Assim, a próxima função Desenvolver Plano Genérico (A2) realiza uma integração ideal dos serviços a serem oferecidos pela EV que está sendo formada. Desta forma, uma cadeia de valor para o cliente é estabelecida de uma maneira ótima sem as informações sobre capacidade de cada parceiro. Capacidade aqui refere-se à agenda de trabalho dos parceiros e não à sua habilidade de realizar o projeto sendo explorado. Portanto, informações sobre tempo e custo ótimos são estimadas pelo coordenador de desempenho. Neste sentido, as funções inerentes à esta fase estão diretamente relacionadas à otimização da integração dos parceiros, entre as quais destacam-se (obs. as funções que se relacionam ao processo de otimização da integração de parceiros são marcadas por $\Rightarrow$ ):

- elaborar plano estratégico para a EV, através do levantamento de uma previsão de pedidos;

$\Rightarrow$ identificar a cadeia ideal de valores para o cliente com base nos serviços levantados na fase anterior;

$\Rightarrow$ acessar os modelos cadastrados na ferramenta ARIS e colocá-los em uma mesma base de dados;

$\Rightarrow$ elaborar modelo utilizando o método EPK que represente a cadeia global do serviço a ser oferecido pela EV que está sendo formada;

$\Rightarrow$ simular o modelo ideal para identificar pontos de melhoria no serviço integrado;

$\Rightarrow$ consultar modelos de referência para auxiliar a formação desta cadeia ideal. Os modelos de referência são elaborados a partir de EV's já realizadas;

$\Rightarrow$ definir estrutura organizacional ideal;

- definir condições para a formação da estrutura organizacional da EV, como proximidade do cliente, número de representações de cada parceiro, entre outros;

- elaborar documentos para controlar a comunicação entre os parceiros, planejando assim o fluxo de informações entre as empresas;

- elaborar documento contendo regras gerais para a formação, operação e dissolução da EV e sua configuração ideal em termos de representação de processos; 
- elaborar um sistema de métricas para apoiar a formação e monitoramento da EV. Este monitoramento auxilia a identificação de situações de reconfiguração da EV ou de sua dissolução;

- definir recursos humanos necessários, principalmente especialistas.

A representação dos serviços para a formação da cadeia ideal de valores baseia-se na identificação de atividades em um nível de abstração macro, ou seja, as atividades pertencem ao plano genérico (detalhado no capítulo 3). Assim, nesta fase a principal preocupação consiste na elaboração de um cenário ideal para a operação da EV. A partir deste cenário ideal são escolhidos então os parceiros, onde cada função neste nível macro é detalhado com as informações dos parceiros, ou seja, com a representação de seus serviços.

Parte integrante deste cenário inicial baseia-se na elaboração de um documento contendo diretrizes gerais para a formação e dissolução da EV. Entre os itens abordados neste documento encontram-se o plano estratégico da EV e o plano de dissolução. O plano estratégico dedica-se a orientar a operação da EV indicando os mecanismos para a conquista de novos clientes para o serviço sendo oferecido pela mesma. O plano de dissolução indica claramente as situações onde a EV deve ser reconfigurada ou parar de operar, contribuindo para a não geração de conflitos entre os parceiros e consequentemente para o fator confiança dentro da OV.

A função Escolha de Parceiros (A3) utiliza-se do cenário ideal e os documentos elaborados na fase anterior para identificar as empresas que podem participar da EV em questão. Esta fase só é necessária na evidência de que mais de um parceiro pode realizar a mesma atividade dentro da cadeia de valor. As representações dos parceiros detalham então as atividades macros estabelecidas no cenário ideal. Vale ressaltar que esta fase é realizada pelo coordenador de desempenho, sem a presença dos parceiros. Assim, o coordenador utiliza as informações sobre eles, cadastradas em sua base de dados.

Os critérios a serem utilizados para a seleção de um parceiro no caso de conflito baseia-se nas métricas de custo, tempo e capacidade (competência) para a realização da EV. Além disso, fatores como conduta em cooperações anteriores podem ser analisados para suportar a decisão de qual parceiro deva participar da EV sendo formada.

Entre as funções desta fase do ciclo de vida encontram-se:

- identificar parceiros que possam realizar a mesma atividade na cadeia de valor; 
$\Rightarrow$ copiar modelos dos parceiros para a base de dados da EV em questão na ferramenta ARIS;

$\Rightarrow$ identificar atividades sem parceiros cadastrados para a sua realização, ou seja, identificar a ausência de competências na OV que correspondam às necessidades da oportunidade sendo explorada;

- procurar novo parceiro;

$\Rightarrow$ modelar parceiro novo;

$\Rightarrow$ simular o detalhamento de cada parceiro para uma mesma atividade, no caso de conflito;

- analisar métricas necessárias para a escolha;

- identificar estrutura inicial de custos por processos;

- escolher e comunicar parceiros;

- agendar reunião entre os parceiros para a realização do planejamento detalhado;

Assim, o resultado da fase de Escolha dos Parceiros consiste na verificação da possibilidade de realizar a oportunidade por parte de cada empresa selecionada, de acordo com as necessidades baseadas em tempo, custo e capacidade. A partir da identificação desta situação, os parceiros são comunicados e uma data é proposta para o início da fase de Desenvolver Plano Detalhado (A4). Nesta fase, as estruturas organizacional e operacional de cada empresa são detalhadas e integradas logicamente e conformadas com a capacidade de cada uma, ou seja, a agenda de cada parceiro é observada para o estabelecimento da cadeia final de valores.

O detalhamento dos modelos que representam os serviços dos parceiros chega agora ao terceiro nível de abstração onde cada função deve ser detalhada com atributos como custo, tempo, especialistas relacionados, modo de operação (manual ou eletrônico), software de apoio, entre outros. Estes atributos serão citados na próxima seção quando são detalhadas as atividades de otimização da integração dos parceiros.

Além do estabelecimento lógico das estruturas organizacional e operacional, existem outras atividades que merecem ser citadas. A seguir são apresentadas algumas funções que pertencem à fase:

- estabelecer papéis relacionados com a operação da EV;

- detalhar plano estratégico elaborado na fase de Explorar Oportunidades; 
- detalhar plano de dissolução estabelecendo-se métricas que caracterizam a necessidade de se dissolver ou reconfigurar a $\mathrm{EV}$;

- detalhar sistema de métricas para o monitoramento da EV;

$\Rightarrow$ detalhar estrutura organizacional da EV;

$\Rightarrow$ integrar os modelos que representam os serviços dos parceiros;

$\Rightarrow$ simular a integração dos modelos;

$\Rightarrow$ identificar estrutura operacional ideal com os modelos dos parceiros;

- especificar documentos a serem utilizados para a troca de informações entre os parceiros;

$\Rightarrow$ estabelecer o fluxo de informações;

- estabelecer a estrutura de custos por processos;

- configurar a utilização de recursos da Internet, como vídeo conferência, lista de e-mails, banco de dados, entre outros;

$\Rightarrow$ projetar sistema de workflow;

Como pode ser observado, esta fase de Desenvolver Plano Detalhado envolve funções, onde o sucesso da operação da EV é influenciado diretamente pela clareza estabelecida no mundo lógico, ou seja, o mundo real de operação deve refletir o que foi planejado em conjunto entre os parceiros. Este planejamento suportado pela modelagem de processos auxilia o entendimento comum, tornando-se ponto de referência para a solução de conflitos.

O principal resultado que pode ser salientado desta fase consiste na elaboração de modelos integrados que suportam integração física dos parceiros, que acontece na próxima fase, a Operação (A5) real da EV. Nesta fase, há a princípio a implementação de recursos da TI como a implantação do sistema workflow ou de gerência de projetos. Somente a partir desta instalação inicial que o Processo de Gerência do Pedido começa a ser executado, ou seja, os serviços que formam a cadeia de valor ao cliente começam a serem executados. Assim, entre as funções que compõem esta fase pode-se destacar:

$\Rightarrow$ implantar sistema workflow;

$\Rightarrow$ implantar sistema de gerência de projetos; 
- monitorar sistema de métricas;

- identificar situação para a reconfiguração da EV;

- identificar situação para a dissolução da EV;

- controlar prazos;

- controlar capacidade;

- gerenciar pedido;

Uma das funções citadas acima referencia a necessidade de interromper a execução da EV e então realizar a fase de Dissolução (A6). Esta necessidade de interromper é ocasionada principalmente pela falta de pedidos, situação esta indicada pelo monitoramento do sistema de métricas elaborado.

Independente do motivo, o plano de dissolução elaborado na fase de Planejamento Genérico é colocado em prática, onde procura-se armazenar os resultados obtidos para futuras oportunidades.

O primeiro aspecto a dissolver relaciona-se com a rede formada entre as empresas, onde diferentes interfaces foram implementadas para viabilizar a integração física dos parceiros. Os modelos utilizados são armazenados na ferramenta e uma descrição da experiência como um todo é realizada e armazenada na OV. Desta maneira, um importante resultado desta fase consiste na realimentação do modelo de empresa da OV através da elaboração de modelos de referência.

Assim, as principais funções desta fase de dissolução são:

$\Rightarrow$ desconfiguração dos recursos da TI instalados;

$\Rightarrow$ gerar/atualizar modelos de referência;

- elaborar documento de descrição geral do funcionamento da EV;

- difusão dos resultados entre os parceiros da OV;

A maior tarefa do coordenador de desempenho consiste em armazenar formalmente os resultados obtidos através da consolidação dos modelos e do armazenamento de informações gerenciais na base de dados. 


\subsection{Detalhamento das Atividades de Integração de Parceiros}

Apresentadas as atividades que representam as fases do método de formação e gerência de uma EV, agora são detalhadas aquelas que se relacionam com o processo de integração de parceiros, foco principal deste trabalho. Todas as atividades de integração tem como base a utilização do modelo de empresa adaptado para o contexto de Organizações Virtuais. Neste sentido, o primeiro detalhamento apresentado nesta seção refere-se a gerência deste modelo de empresa na ferramenta ARIS, ou seja, como os modelos que representam os parceiros podem ser armazenados e utilizados para a formação de Empresas Virtuais. Desta forma, a atividade de modelagem corresponde à utilização do modelo de empresa para a integração dos parceiros.

Portanto, a integração de parceiros na formação e gerência de EV's corresponde à realização de cinco atividades:

- gerência do modelo de empresa;

- integração dos modelos que representam os parceiros;

- simulação dos serviços;

- geração de um sistema workflow;

- geração de modelos de referência.

\subsubsection{Gerência do Modelo de Empresa}

A gerência do modelo de empresa refere-se às atividades que envolvem a manipulação da representação formalizada das informações sobre os parceiros. O primeiro passo envolve a classificação desta representação na base de dados que representa a OV. Em outras palavras, os modelos gerados pelos parceiros para a sua representação são cadastrados na ferramenta ARIS em apenas uma base de dados, onde a classificação utilizada foi abordada na seção 4.3.1.

Fundamental para a classificação dos serviços dos parceiros no ARIS é o seu conceito de grupos, que corresponde a definição de pastas ou diretórios. A criação de um grupo tem por objetivo o armazenamento de processos que estão relacionados entre si. Assim, a base de dados da OV é composta por um grupo raiz, de nome Organização Virtual, 
que por sua vez possui dois grupos cadastrados, Processos Diretos e Processos de Apoio (Figura 37).

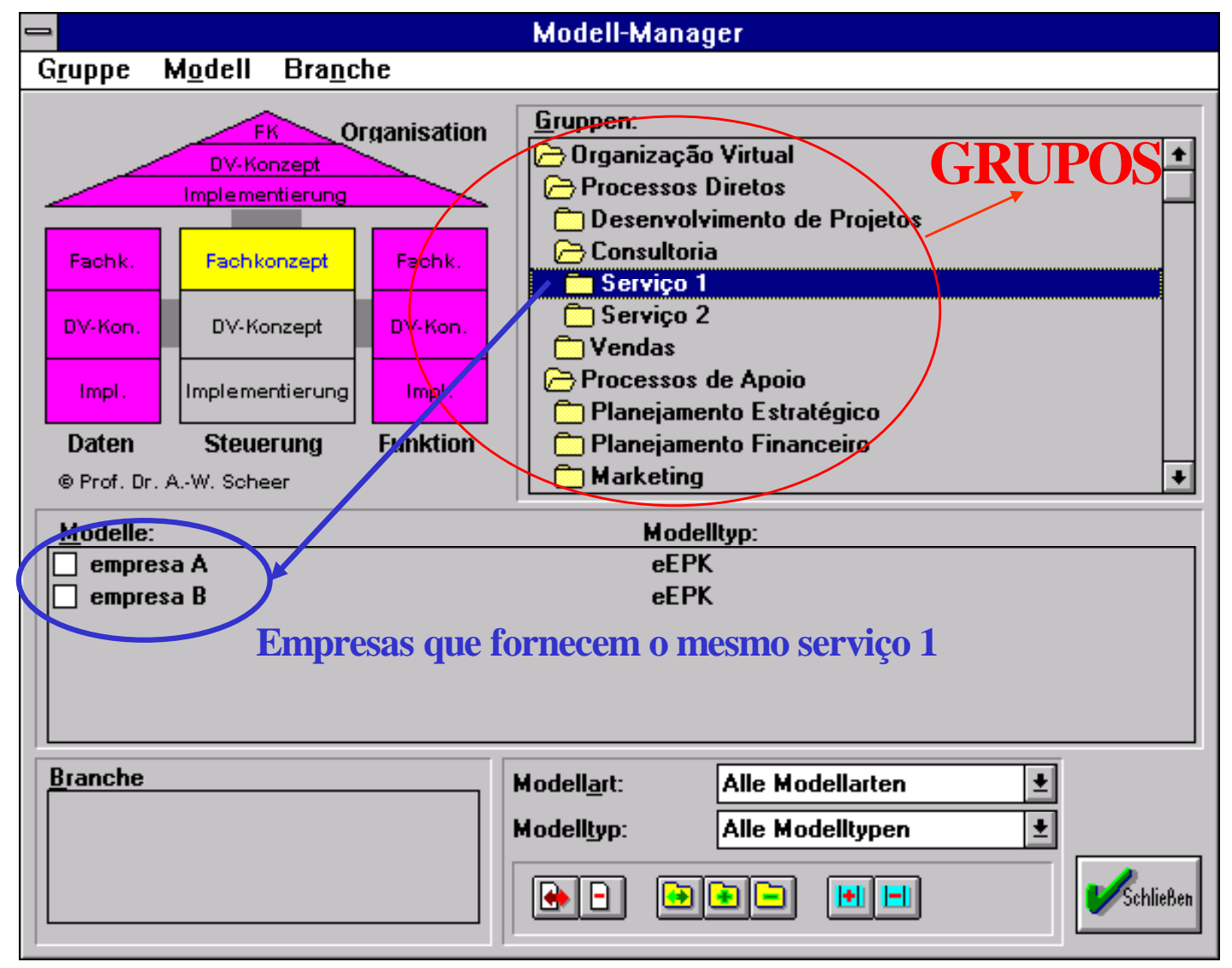

FIGURA 37: Classificação dos Serviços na Ferramenta ARIS

O grupo de Processos Diretos possui outros três grupos, Desenvolvimento de Projetos, Consultoria e Vendas, conforme a classificação apresentada. Os processos que representam os serviços oferecidos pelos parceiros da OV são armazenados embaixo de um destes grupos, de acordo com a sua classificação. O grupo Processos de Apoio armazena os processos que são realizados de maneira conjunta entre os parceiros, correspondendo aos processos de coordenação da OV.

Debaixo de cada grupo que representa um Processo Direto são relacionados então todos os serviços que podem ser oferecidos pela OV, sendo que a descrição de um serviço específico corresponde à representação de um processo elaborado por um parceiro. Diferentes empresas podem oferecer o mesmo tipo de serviço dentro da OV, sendo estes representados debaixo de um mesmo grupo na base de dados do ARIS. Desta maneira, para viabilizar a distinção entre o modelo de um parceiro de outros, os mesmos são armazenados 
com o nome da empresa que representa. Na Figura 37 há dois modelos de nomes empresa A e empresa B que realizam o mesmo tipo de serviço 1.

Como já foi abordado, os modelos que representam os serviços dos parceiros são elaborados por eles mesmos e enviados à OV. O coordenador de desempenho cadastra os modelos na base de dados do ARIS gerando, assim, uma parte do modelo de empresa da OV. Além da gerência dos modelos fornecidos pelos parceiros, a entidade coordenadora da OV gerencia também as informações representadas pelo modelo de recursos e de negócios, para os quais a ferramenta ARIS não possui elementos de representação formal. Desta forma, as informações destes modelos são armazenadas em uma base de dados de acordo com os respectivos MER's apresentados na seção 4.3.

Portanto, para gerenciar o modelo de empresa da OV, o coordenador de desempenho deve administrar duas bases de dados: do ARIS, que contém os modelos que representam os serviços dos parceiros, e do Access que mantém informações que não podem ser representadas na forma de diagramas.

\subsubsection{Integração dos Modelos de Representação dos Parceiros}

Como já foi dito, a integração dos modelos começa com a identificação de uma oportunidade, atividade realizada dentro do processo de planejamento estratégico. Esta identificação de oportunidades é feita através de uma análise do mercado a ser explorado por um serviço integrado, composto por soluções de diferentes parceiros.

Identificada a oportunidade a ser explorada pela OV, inicia-se então as atividades relacionadas à integração dos parceiros, onde o método de formação e gerência da EV baseia-se na utilização de modelos dos serviços cadastrados na ferramenta ARIS. A própria identificação da oportunidade já fornece a relação de serviços que devem ser explorados pela EV a ser formada.

Aqui vale ressaltar que para a realização desta atividade de integração assume-se que todos os serviços identificados para a exploração da oportunidade já estejam presentes na OV. Caso haja a necessidade de se cadastrar um novo parceiro, as atividades relacionadas à gerência do modelo de empresa é requisitada para viabilizar a continuidade das atividades relacionadas à integração dos modelos.

Desta maneira, a partir da identificação dos serviços a serem utilizados na EV em formação e de suas representações como modelos EPK's, o coordenador de desempenho 
gera uma nova base de dados na ferramenta ARIS. Nesta base de dados, o coordenador cria um modelo EPK que representa a cadeia global de valor do serviço específico a ser oferecido. De acordo com o Broker, informações relativas à tempo, custo e capacidade ideais são colocados no modelo para viabilizar a sua simulação genérica.

Após esta fase de elaboração e otimização do serviço global no nível genérico procede-se a escolha de parceiros, onde as informações sobre cada um devem ser verificadas. Para isso, o coordenador de desempenho transporta para a base de dados gerada os modelos correspondentes da base de dados que representa a OV (ou o modelo de empresa da OV), como foi descrito na seção anterior. Em outras palavras, existe uma base de dados que representa a OV e outras que representam cada instância de uma EV.

A criação dos grupos para cada EV depende da oportunidade sendo explorada, ou seja, para cada serviço identificado na oportunidade é criado um grupo na base de dados que está sendo implementada.

Caso haja concorrência para a execução de um serviço, os modelos dos concorrentes são transportados para debaixo do mesmo grupo, mas gravados com o nome da empresa que representam. Após a simulação destes modelos e a verificação do melhor que se adapta as condições da EV sendo formada, o modelo não selecionado é apagado da base de dados.

Desta maneira, após a geração inicial da base de dados com a criação de grupos na ferramenta ARIS, a importação de modelos a partir da base de dados da OV e a seleção dos parceiros, o coordenador de desempenho realiza as seguintes atividades com os modelos:

- geração da árvore integrada de funções através da junção dos modelos correspondentes trazidos da base de dados da OV, ou seja, através da utilização da descrição enviada pelos parceiros;

- identificação do organograma da EV juntamente com a descrição dos recursos humanos necessários;

- geração do modelo comum de dados através de uma análise das informações pertencentes aos serviços de cada parceiro;

- detalhamento da cadeia global de valor do serviço integrado através da associação de cada uma de suas funções nele presente com um dos modelos dos parceiros escolhidos. Assim, uma função da cadeia global é relacionada com o modelo de um parceiro. 
Realizadas estas atividades, os modelos estão inicialmente integrados mas não totalmente otimizados, ou seja, a primeira etapa de integração aplicada ao conceito de EV's corresponde à integração dos diferentes modelos dos parceiros a nível lógico. Assim, a complementação do processo de integração dos parceiros é realizada nas atividades subsequentes, que são detalhadas nas seções seguintes.

\subsubsection{Simulação de Processos}

Como já foi dito, o objetivo da simulação é trazer maior segurança na tomada de decisões no processo de integração dos serviços dos parceiros na EV. Através da utilização das estatísticas resultantes da aplicação da simulação o coordenador de desempenho altera a configuração dos modelos para se atingir a integração ideal dos parceiros. Para isso, o coordenador de desempenho necessita:

- definir algumas informações importantes dentro dos modelos de processos na ferramenta ARIS.

- utilizar uma metodologia de aplicação do processo de simulação.

As informações relevantes ao processo de simulação na ferramenta ARIS devem ser inseridas nos modelos EPK global e de cada parceiro. As informações que são globalmente definidas relacionam-se com o EPK (serviço global) gerado a partir da definição da oportunidade para a EV. Desta maneira, as informações relevantes são:

- a unidade de tempo onde se pode medir a execução do serviço global (hora, dia, semana, mês, ano);

- o número de ocorrências do serviço na unidade de tempo;

- o tempo total que o serviço deve ser simulado.

Essas informações dependem do contexto no qual a EV está sendo formada e são detalhadas conforme mostra a Figura 38. O número de ocorrências é definido como um atributo do primeiro evento do processo, ou seja, este evento indica o número de vezes que o processo deve ser executado na unidade de tempo. O tempo total é escolhido em cada execução do processo de simulação.

Aqui vale ressaltar que o tempo e custo de cada função são colocados na forma de diferentes atributos no ARIS. Para tempo existem três atributos que o caracterizam: de transmissão das informações, de ajuste (setup) e de execução propriamente. Para custo 
existem outros 7 atributos: material, pessoal, artigos de escritório, energia, manutenção, juros e participação em diferentes custos gerais.

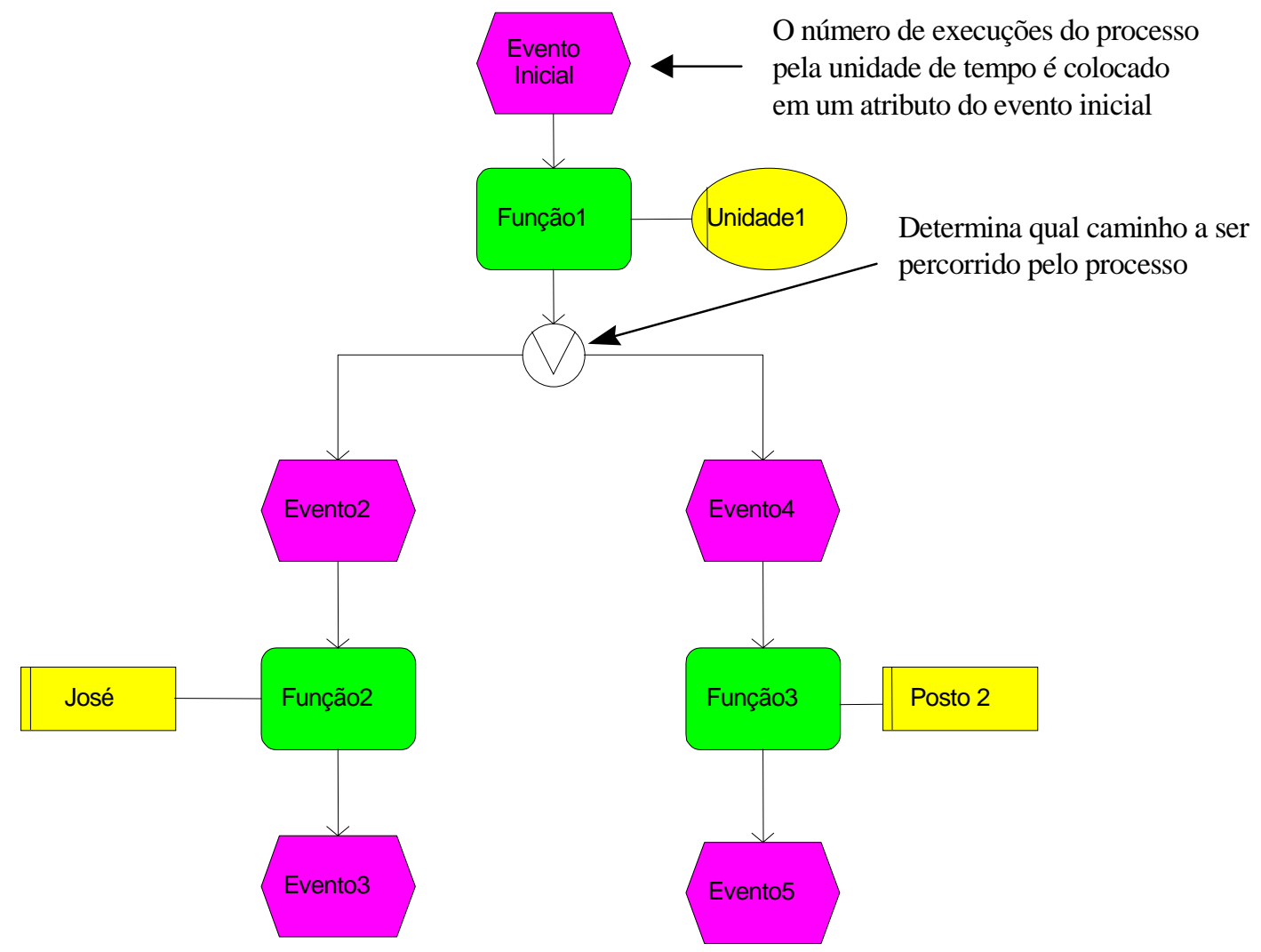

FIGURA 38: Detalhamento do Processo para a Simulação

Para cada detalhamento das funções contidas no modelo genérico, que define o serviço global, o coordenador de desempenho define também algumas informações importantes para o processo de simulação. Em outras palavras, para cada modelo que detalha uma função no EPK global, o coordenador define:

- a capacidade de execução de cada função dentro do serviço do parceiro, indicada no relacionamento entre a função e o elemento organizacional;

- a probabilidade de se executar diferentes caminhos dentro da estrutura do serviço, indicada nos conectores lógicos OR.

Com relação a capacidade de execução de uma função, cada parceiro tem a possibilidade de associar à mesma uma pessoa, um posto de trabalho ou uma unidade organizacional de acordo com o formalismo da ferramenta ARIS. Para posto de trabalho e unidade organizacional pode-se definir ainda quantas pessoas estão aptas a realizar tal atividade. 
Os atributos de tempo e custo para cada atividade do serviço é definido pelo próprio parceiro. No entanto, uma revisão não apenas destes atributos como também da capacidade de execução de uma atividade é realizada com os parceiros para a confirmação das informações presentes nos modelos.

Após a definição das informações dentro dos modelos na ferramenta ARIS, tentando se obter a melhor descrição possível da realidade de cada empresa, inicia-se o processo de otimização do processo utilizando-se a simulação, que corresponde a adoção da seguinte metodologia:

1. verificação de valores ideais em termos de custo, tempo e capacidade para o serviço global. Dependendo da complexidade do serviço a ser oferecido, a estrutura do processo correspondente pode ser alterada indicando a paralelização de funções, o que diminui o tempo total gasto. Esta atividade é aplicada na fase de Planejamento Genérico do método de formação e gerência;

2. após o relacionamento das funções do EPK global com os modelos dos parceiros, iniciase o processo de seleção de parceiros, ou seja, para uma mesma função que possua mais de uma forma de detalhamento simula-se os diferentes modelos. Nesta situação, as variantes de um modelo para o processo de simulação correspondem aos próprios modelos dos parceiros. Assim o coordenador de desempenho não altera a composição dos modelos, sendo de sua responsabilidade fornecer as estatísticas resultantes da simulação de cada um. As variáveis tempo, custo e capacidade de execução indicam os fatores determinantes para a tomada de decisão;

3. realizada a seleção dos parceiros, o processo de otimização do serviço global final, que representa a cadeia da EV, começa a ser realizado. Nesta fase, o conceito de variantes de um processo é fundamental para a elaboração de diferentes cenários de execução da EV, os quais são simulados e avaliados de acordo com as estatísticas. Desta maneira, dentro da fase de Planejamento Detalhado do método de formação e gerência de uma EV, os passos do processo de simulação são (Figura 39): 


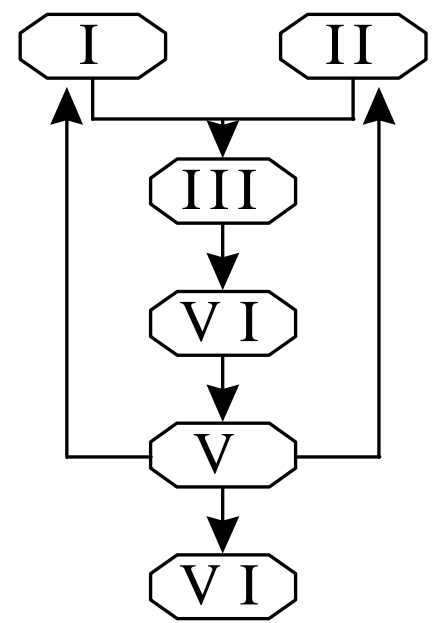

FIGURA 39: Seqüência de Atividades no Processo de Simulação

I. identificar recursos da tecnologia da informação (suporte tecnológico) que podem ser utilizados para a otimização da integração dos serviços dos parceiros.

II. analisar modelos de referência de EV's já dissolvidas ou em operação para a identificação de soluções que podem ser reutilizadas;

III. levantar ineficiência da estrutura da integração do serviço no que se refere a paralelização de atividades;

IV.reconhecer e quantificar gargalos de execução, ou seja, identificar onde é necessário maior quantidade de recursos, principalmente humanos;

V. analisar quantitativamente diferentes cenários para a tomada de decisão;

VI.decidir estrutura final do processo.

O modelo EPK global inicial levantado nas fases de Planejamento Genérico e Escolha de Parceiros é analisado a partir da fase III da metodologia, ou seja, a estrutura operacional e organizacional da EV é verificada de acordo com os dados de tempo, custo e capacidade fornecidos. Nesta atividade inicial não é pensada a inclusão de novos recursos da tecnologia da informação, além daqueles que já são utilizados pelos parceiros.

A partir da reorganização do modelo EPK global inicial, propostas de implantação de novos recursos tecnológicos, fase I, são então avaliadas com a geração de novos modelos que suportem a operação da EV. As fases referentes à análise da estrutura destes modelos e à incidência de gargalos de execução são novamente testadas e analisadas quantitativamente de acordo com as estatísticas resultantes do processo de simulação na ferramenta ARIS. 
A seguir, os modelos de referência são observados, fase II, para a identificação de algum método ou recurso tecnológico que possa ser reutilizado. Havendo a possibilidade de reutilização de mecanismos adotados em experiências anteriores, o modelo global é alterado e as fases seguintes da metodologia são realizadas novamente.

As atividades citadas acima são realizadas conjuntamente com os parceiros, onde, para esta finalidade, a estrutura de comunicação da OV é utilizada. A comunicação entre os parceiros visa proporcionar a discussão e consequentemente o detalhamento dos conceitos e propostas de otimização do modelo global. Durante o processo de simulação, as propostas de alteração da estrutura do modelo global e de implantação de suportes tecnológicos indicam a elaboração de novas variantes (cenários) do serviço integrado, o que suportam o processo de tomada de decisão.

Um importante recurso para a validação de um cenário consiste na análise das estatísticas fornecidas pelo processo de simulação. Existem diferentes tipos de estatísticas fornecidas pela ferramenta, no entanto, neste trabalho, é verificada apenas as que se relacionam com tempo, custo e capacidade. Um exemplo envolvendo as estatísticas de custos totais ("Gesamtkosten"), custos de materiais ("Materialkosten") e custos de pessoal ("Personalkosten”) para a simulação de um determinado serviço da TI é mostrado na Figura 40.

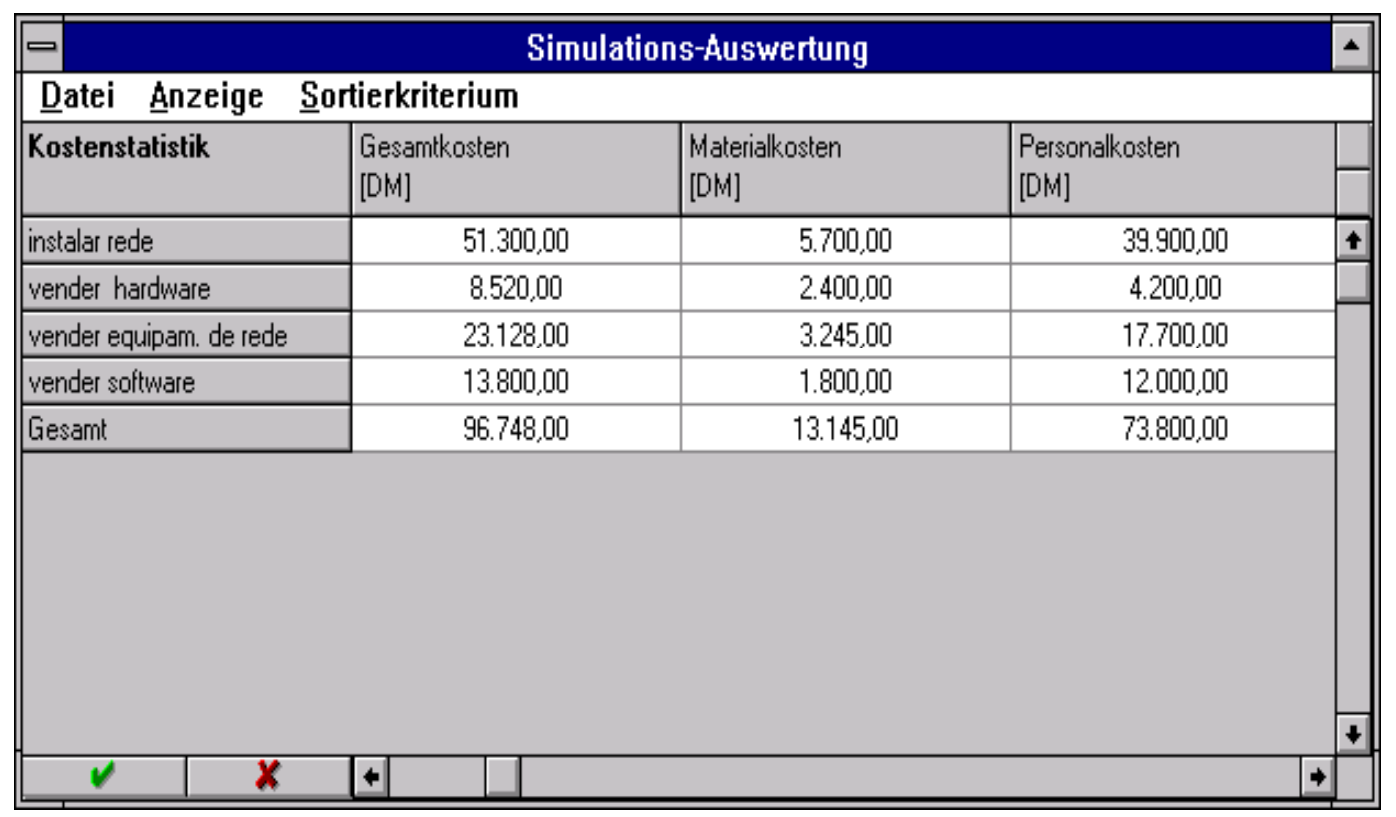

FIGURA 40: Janela da Ferramenta ARIS sobre as Estatísticas da Simulação 
As estatísticas indicam, a nível lógico, qual a melhor alternativa a ser escolhida entre as variantes levantadas no processo de simulação, uma vez que abordam fatores críticos (custo, tempo e capacidade) para o desempenho de uma EV. No entanto, as estatísticas resultantes não são o único meio para a tomada de decisão. A própria participação dos parceiros no processo de discussão indica o nível de comprometimento dos mesmos para a realização da EV, e consequentemente, na escolha da alternativa mais adequada. Em outras palavras, na necessidade de implantação de novos recursos para a operação otimizada da EV, os parceiros devem estar igualmente comprometidos. Caso contrário, outra alternativa é escolhida.

\subsubsection{Implantação de Sistemas Workflow}

O sistema workflow visa apoiar a execução do processo de gerência de pedidos, que atravessa a fronteira das empresas. No entanto, para suportar a realização de pedidos na EV, a implantação de sistemas workflow depende da utilização de uma arquitetura e de uma metodologia. Ambos requisitos estão diretamente relacionados com a funcionalidade da ferramenta a ser utilizada, o ARIS Workflow.

A arquitetura segue a estrutura de comunicação da $\mathrm{OV}$, onde um elemento central realiza as atividades de coordenação dos parceiros que estão a ele interligados. Assim, no escritório central da OV encontra-se, além do componente de modelagem da ferramenta ARIS, o servidor do sistema workflow (Figura 41). Aqui vale ressaltar que tanto a base de dados do componente de modelagem e simulação como o servidor workflow estão no mesmo equipamento. Os clientes do sistema workflow encontram-se nos parceiros da EV.

O componente workflow da ferramenta ARIS segue o modelo de referência especificado pelo WfMC, comentado no capítulo 2. Neste modelo, a interface entre servidor e cliente é realizada através de uma implementação do CORBA, que pode ser executado usando a estrutura da Internet, viabilizando assim a integração física entre os parceiros. Através desta arquitetura física, na qual a comunicação entre os parceiros é realizada, viabiliza-se a execução eletrônica do processo de gerência do pedido. 


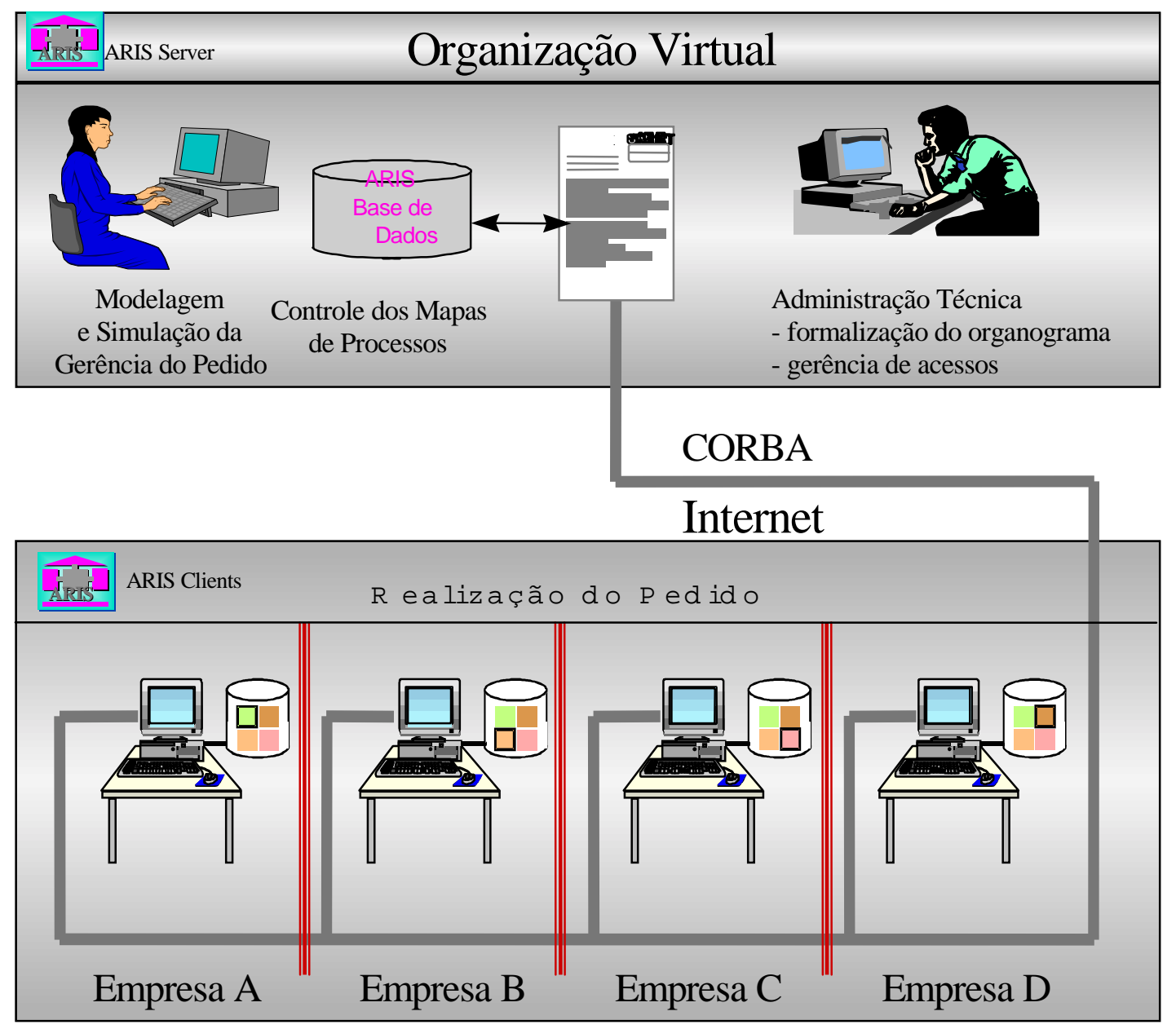

FIGURA 41: Arquitetura do Sistema Workflow

A seguir são mostrados, então, os passos da metodologia para a implantação do sistema workflow, os quais podem ser agrupados nas seguintes etapas:

- geração do modelo executável;

- difusão do modelo e modo de operação entre os parceiros da EV;

- operação.

A geração do modelo executável é iniciada a partir da identificação do modelo a ser utilizado para a gerência do pedido. Este modelo é gerado partir do modelo EPK global. No entanto, algumas modificações devem ser feitas em outros modelos para viabilizar a transformação do modelo global em modelo executável. As atividades relacionadas a esta etapa são as seguintes:

1. elaboração do modelo de dados comum: os modelos fornecidos pelos diferentes parceiros devem ser integrados de modo que o entendimento sobre a estrutura das 
informações seja comum. No sistema workflow do ARIS, uma entidade suporta diretamente um documento, ou seja, os atributos de uma entidade correspondem aos campos de um documento que flui entre os parceiros.

2. elaboração dos documentos no Microsoft Word: a partir da descrição dos atributos das entidades são elaborados então os documentos no Word que irão fluir entre as empresas através da Internet. No Word, para cada atributo da entidade definido no modelos de dados é colocado um campo de formulário onde o usuário entra com as informações correspondentes. Na definição do campo de formulário no Word existe um atributo Indicador onde pode ser associado o nome do atributo da entidade no ARIS, viabilizando assim a integração entre os aplicativos (Word e ARIS Workflow). Os outros aplicativos do Microsoft Office também podem ser utilizados, como o Excel e o Access. Neste trabalho será abordada apenas a utilização do Word.

3. detalhamento do organograma: as pessoas que vão participar do processo de realização do pedido devem ser descritas e associadas a qual empresa (unidade organizacional) pertencem no organograma. Além disso, um elemento denominado Papel ainda pode ser utilizado no organograma e associado a diferentes pessoas, ou seja, um papel que executa uma determinada função pode ser assumido por diferentes pessoas. Assim, quando um usuário acessa o servidor workflow, uma janela se abre colocando à disposição quais são os papéis que ele pode assumir e consequentemente quais as funções que pode executar.

4. detalhamento do diagrama de processos: as funções presentes no modelo global são associadas à um único elemento organizacional. Este é o modelo limpo, com apenas três elementos: função, evento e elemento organizacional. No caso da função ser executada com ajuda de aplicativos, este detalhamento deve ser realizado em um modelo que se denomina Diagrama de Associação de Aplicativos, onde são associadas à função as entidades (que correspondem aos documentos) e os aplicativos correspondentes.

5. estabelecimento dos usuários do sistema workflow: no ARIS, a descrição de uma pessoa em um modelo não caracteriza que ela tenha direito de acesso ao modelo executável no sistema workflow. Para viabilizar isto, na própria ferramenta de modelagem devem ser cadastradas as pessoas que são usuárias do sistema workflow.

6. transformação dos modelos em modelos executáveis: a partir das alterações citadas acima, o modelo EPK pode ser transformado em um modelo executável pelo sistema de workflow. Isto é realizado apenas acionando-se uma opção no menu da ferramenta de 
Modelagem. Caso não haja nenhum problema de configuração nos modelos, o processo correspondente já pode ser instanciado no servidor workflow.

Desta maneira, a partir da geração do modelo executável o processo de realização do pedido já pode ser instanciado e executado pelos usuários, que correspondem aos parceiros que participam da EV. O direito de instanciação do processo de gerência do pedido é dado apenas ao usuário que realiza a primeira função modelada no diagrama de processos. A partir desta instanciação, o fluxo de trabalho segue conforme modelado, onde cada usuário, ao entrar no sistema workflow, realiza as funções que lhe são associadas. Assim, cada usuário realiza sua função, armazena os resultados de seu processamento no servidor workflow e dá direito que a próxima função possa ser acionada.

No entanto, para que cada usuário tenha acesso ao servidor workflow e consequentemente ao processo instanciado, um cliente deve ser instalado em cada parceiro da EV. Assim, as atividades da próxima etapa da metodologia são as seguintes:

1. instalação dos clientes: o coordenador de desempenho realiza a instalação e configuração de cada cliente nas empresas que participam da EV em formação. A principal configuração que o coordenador de desempenho deve fornecer durante $o$ processo de instalação do cliente baseia-se na localização do servidor workflow, ou seja, no fornecimento do endereço Internet para que o cliente consiga acessar o processo que deve ser executado.

2. treinamento dos usuários: as pessoas descritas nos modelos e no gerenciamento de acessos devem ser treinadas para a execução do processo. Este treinamento basicamente instrui como cada usuário acessa o sistema workflow, seleciona um dos diferentes papéis disponíveis e executa a função que é de sua responsabilidade. Quando a função corresponde à alguma atividade de campo, ou seja, não apenas processar informações, o usuário requisita para si o controle do processo naquela função e aguarda a sua execução. Executada a função, o usuário assinala algum campo no documento eletrônico e passa adiante a execução do processo.

Aqui vale ressaltar que a janela na qual o usuário acessa o sistema workflow é composta por três escaninhos: entrada, intermediário e saída. No escaninho de entrada encontram-se os processos (pedidos) que estão por serem realizados, onde o usuário pode escolher o pedido que vai realizar e o coloca em seu escaninho intermediário. Quando o processo está em seu escaninho intermediário nenhum outro usuário pode acessá-lo. Terminada a função o processo é colocado no escaninho de saída para que o próximo 
usuário possa enxergá-lo em seu escaninho de entrada. Um exemplo destes escaninhos é apresentado no próximo capítulo.

Após o esclarecimento destes conceitos de utilização para os usuários do sistema workflow é iniciada então a fase de operação onde a principio é realizado um teste de funcionamento. Assim, estas são as duas fases relacionadas a etapa de operação da metodologia:

1. teste: o coordenador de desempenho elabora um pedido fictício (assumindo o papel de um cliente hipotético) e aciona o usuário da primeira função do processo. Este instancia o processo, simula a realização da referida função utilizando o sistema workflow e habilita para que o próximo usuário possa realizar a sua função. Assim é realizado até o final do processo, simulando a realização de um pedido. Caso haja necessidade de uma nova simulação a pedido de algum parceiro ou do próprio coordenador de desempenho o teste é realizado novamente.

2. operação: esta fase corresponde ao início do processo de gerência do pedido e consequentemente da própria existência da EV. Os pedidos são analisados pelos parceiros juntamente com o coordenador de desempenho para avaliar a capacidade de realização dos mesmos. Sendo viável a realização de um pedido, um processo é instanciado no servidor workflow de modo que os usuários possam executá-lo. O coordenador de desempenho controla o mapa de processos instanciados através de um componente do ARIS workflow, viabilizando assim um controle entre os parceiros. Desta maneira, o coordenador pode indicar para os clientes da EV qual status de cada pedido, uma vez que o mapa mostra aonde o mesmo está estacionado, ou seja, em qual parceiro.

A manutenção do sistema workflow para a referida EV é realizada durante a sua existência. A partir do momento em que os parceiros decidirem dissolver a EV, a configuração de tal processo no servidor deixa de ter o status executável. Nesse ponto, o coordenador de desempenho é responsável por armazenar a experiência realizada na forma de modelos de referência, cuja metodologia para esta atividade é definida na próxima seção.

\subsubsection{Geração de Modelos de Referência}

Como foi descrito na seção 2.5.3.1, um modelo de referência deve ser construído de forma modular para que conceitos como adaptabilidade, generalidade e integração de variantes possam ser explorados. No entanto, neste trabalho a exploração do conceito de 
construção modular foi realizada já na fase de elaboração dos modelos por parte de cada parceiro. Em outras palavras, a diferenciação de níveis de abstração (plano genérico, descritivo e detalhado) na modelagem de processos dos parceiros suporta o conceito de modularidade exigido para a elaboração de modelos de referência.

Desta maneira, o coordenador de desempenho já possui os modelos na forma modular na fase de dissolução da EV. Desta forma, duas outras atividades são consideradas necessárias, neste trabalho, para a elaboração dos modelos de referência: a consolidação dos modelos utilizados e a documentação da experiência realizada.

Para a consolidação dos modelos o coordenador de desempenho deve a princípio analisar cada elemento (dos modelos) e realizar uma descrição completa de sua utilização, facilitando a sua reutilização em experiências futuras. Em cada elemento de um modelo na ferramenta ARIS existe um atributo que o descreve detalhadamente, uma vez que apenas o atributo nome pode gerar confusões no entendimento de sua aplicabilidade devido ao seu tamanho restrito.

O coordenador de desempenho realiza ainda a verificação da hierarquização dos modelos, onde o detalhamento de cada função deve ser consolidado, ou seja, dos modelos que estão à ela associados. Ainda como parte da fase de estruturação dos modelos o processamento das informações no processo também é verificado e consolidado. Assim, é analisado não apenas o fluxo de informações entre as funções, suportado pelos eventos, como também o processamento realizado em cada função. A descrição do fluxo de informações é detalhado através do atributo descrição contido nos eventos, enquanto o processamento da informação em cada função é descrito através de um diagrama específico (Diagrama de Associação de Aplicativos), onde são detalhados quais os campos de um documento (entidade) que são ali explorados.

Após a fase de consolidação, o coordenador de desempenho realiza com cada parceiro uma discussão sobre a troca dos modelos resultantes desta experiência com os que estão armazenados na base de dados (modelo de empresa) da OV. Esta troca do modelo antigo depende do esforço de customização que foi necessário para integração da EV que foi dissolvida, sendo então de responsabilidade do parceiro dizer se o modelo resultante é melhor aplicável à outras situações ou não.

Outra etapa fundamental na atividade de geração do modelo de referência é a documentação da experiência realizada. Para isso, foram levantados alguns descritores que auxiliam a caracterização da EV que foi dissolvida e consequentemente suportar a 
reutilização de conceitos em futuras oportunidades que possam ser exploradas dentro da OV. Estes descritores são documentados tanto pelo coordenador de desempenho, que responde à questões gerais, como pelos coordenadores de cada empresa que trazem suas percepções individuais sobre a experiência realizada.

Assim, o coordenador de desempenho é responsável por preencher os seguintes descritores:

- coordenador de desempenho (seu próprio nome);

- período de operação;

- empresas que participaram da EV com os respectivos coordenadores;

- nome do serviço integrado;

- descrição dos serviços de cada parceiro que compunham a solução integrada;

- clientes atendidos;

- setor econômico explorado;

- recursos da TI utilizados;

- nome da base de dados na ferramenta ARIS onde estão armazenados os modelos;

- serviços gargalos, ou seja, aqueles que apresentaram maior quantidade de pedidos acumulados;

- diretório onde estão armazenados os documentos eletrônicos;

Por outro lado, os coordenadores de cada empresa são responsáveis por retratarem a visão individual da experiência realizada através de comentários que descrevem os seguintes itens:

- serviço oferecido;

- nome do coordenador na empresa;

- viabilidade econômica;

- cumprimento de estratégias;

- aspectos sociais e culturais relativos ao comportamento dos outros parceiros no trabalho comunitário;

- informações sobre clientes, mercado e concorrentes; 
- auto-avaliação;

Para otimizar o armazenamento destas informações foi gerada uma base de dados no Microsoft Access onde a consulta a diferentes experiências fica facilitada. O MER correspondente é mostrado na Figura 42. Vale ressaltar que as informações sobre o nome do coordenador responsável, do serviço integrado, da base de dados no ARIS, do diretório onde estão os documentos eletrônicos e o período de operação da EV (data início e data fim) são atributos da entidade EV. O serviço gargalo é indicado através de um atributo lógico no relacionamento entre as entidades EV e Serviço.

A visão individual de cada parceiro é reproduzida de acordo com a entidade de mesmo nome, onde os atributos são do tipo texto e retratam a opinião de cada coordenador sobre a experiência realizada, conforme os itens citados acima.

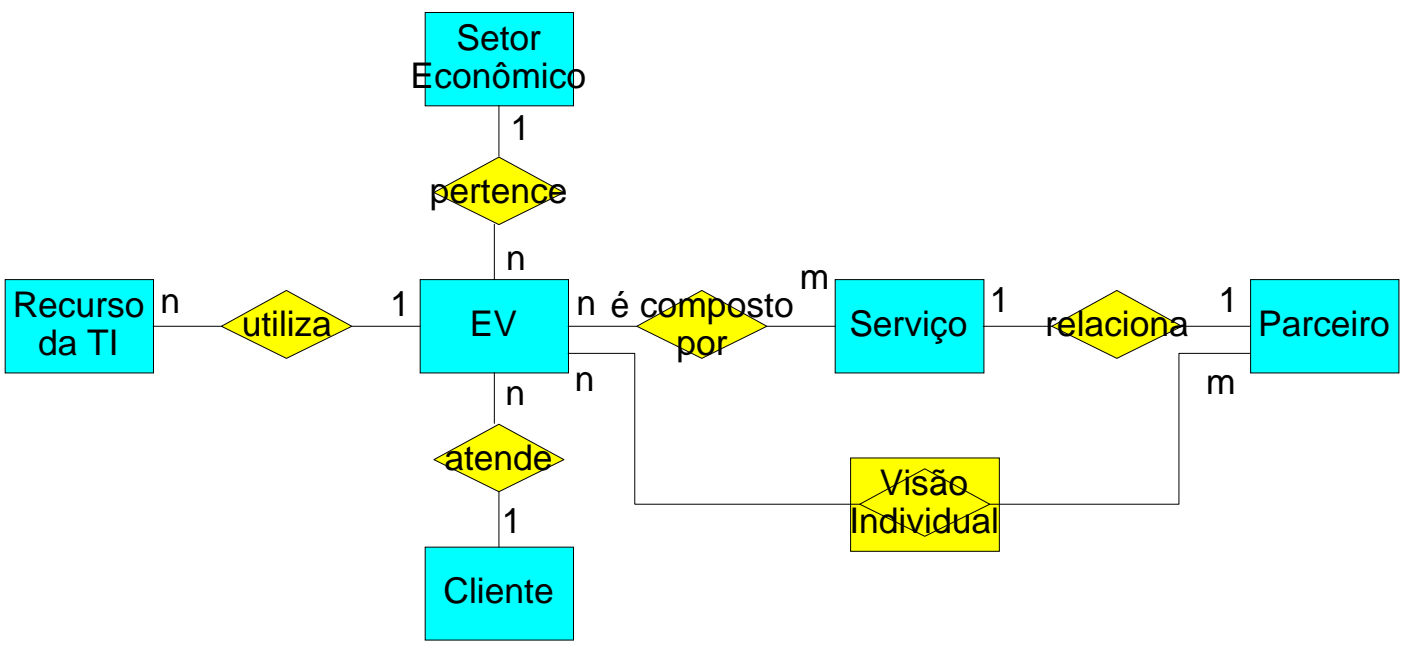

FIGURA 42: MER para a Documentação da EV

É importante notar que apenas a representação na forma de modelos é insuficiente para retratar todo o conhecimento que foi envolvido na realização da EV. Desta maneira, neste trabalho os aspectos representados no MER apresentado acima foram considerados relevantes no sentido de auxiliar a busca por informações de experiências já realizadas dentro da $\mathrm{OV}$, ou seja, por informações contidas em modelos de referência.

Por último vale ressaltar o aspecto evolutivo que os modelos de referência gerados dentro da OV apresentam, uma vez que um parceiro participando de diferentes EV's otimiza não apenas o potencial de integração de seu serviço como também as informações que o descrevem. 


\subsection{Considerações Finais}

Este capítulo apresentou a proposta deste trabalho de doutoramento para a integração de parceiros em Empresas Virtuais, onde diferentes conceitos e ferramentas da área de Integração de Empresas foram abordados e adaptados para este contexto. Através da construção de uma OV, fundamental para o surgimento sistemático de EV's, houve a adaptação do conceito de modelo de empresa para a formalização das informações dos parceiros. A partir disso, foi possível formalizar a aplicação de conceitos e ferramentas no ciclo de vida de uma EV como mecanismos para o processo de integração.

Para a aplicação dos mecanismos elaborados, o próximo capítulo apresenta como exemplo uma OV que oferece produtos e serviços na área de Tecnologia da Informação. Com base na configuração desta $\mathrm{OV}$, um pedido é elaborado envolvendo diferentes produtos e serviços oferecidos por diferentes empresas. A partir deste pedido são aplicadas as atividades de otimização propostas por este trabalho. Neste exemplo é levado em consideração que o processo de geração do modelo de empresa já foi realizado, pois, sendo uma OV fictícia, não seria possível a sua descrição. 


\section{Exemplo}

Como mencionado, a construção de uma OV visa suportar o surgimento sistemático de EV's. Com esta condição, este trabalho elaborou uma proposta de integração de parceiros no ciclo de vida de uma EV. Para ilustrar a aplicação da proposta foi elaborado um exemplo de uma Organização Virtual, onde a oferta de produtos e serviços estão relacionados à área de Tecnologia da Informação. A Organização Virtual exemplo, denominada SoftwareHouse Virtual, é formada por parceiros fictícios e suas estruturas operacional e organizacional são detalhadas na forma de responsabilidades e de processos de coordenação.

O principal recurso utilizado para uma aproximação do mundo real de operação foi a implementação de um "site" Internet, onde uma descrição dos serviços e produtos dos parceiros pode ser acessada de qualquer "browser" que esteja conectado à rede mundial de computadores. Alguns mecanismos de busca de informações que acessam a base de dados da OV foram implementados afim de facilitar a navegação pelo "site".

Por último, uma simulação da realização de um pedido é desenvolvida, envolvendo diferentes serviços que são representados por diferentes parceiros na OV. No exemplo não serão abordadas detalhadamente cada fase do ciclo de vida de uma EV apresentado no capítulo anterior, enfatizando apenas aquelas atividades que se relacionam ao processo de integração de parceiros.

\subsection{A SoftwareHouse Virtual}

A SoftwareHouse Virtual apresenta os três tipos de processos diretos apresentados para a classificação dos serviços em uma OV: Desenvolvimento, Consultoria e Vendas. Os produtos oferecidos pelos parceiros desta OV estão associados aos serviços de Vendas, ou seja, apenas os parceiros que possuem a competência de Vendas que oferecem produtos relacionados à TI. 
A Tabela 4 apresenta os produtos e serviços oferecidos pela SoftwareHouse Virtual. Como pode ser observado, nenhum setor econômico está relacionado diretamente ao nome dos serviços e produtos. Isto significa que dentro de uma $\mathrm{OV}$ as empresas são especializadas em um determinado serviço da TI, mas podem ter como estratégia de negócio atender às necessidades de um setor econômico específico.

TABELA 4: Classificação dos Serviços da SoftwareHouse Virtual

\begin{tabular}{|c|c|c|}
\hline Desenvolvimento & Consultoria & Vendas \\
\hline $\begin{array}{l}\text { DOS } \\
\text { - Clipper } \\
\text { Windows } \\
\text { - Visual Basic } \\
\text { - Delphi } \\
\text { - C++ } \\
\text { Projeto de Base de Dados } \\
\text { - MER } \\
\text { - Oracle } \\
\text { - Informix } \\
\text { Implantação de Redes } \\
\text { - Cabeamento } \\
\text { - Instalação do Software } \\
\text { Gerenciador } \\
\text { Desenvolvimento de "sites" } \\
\text { - Intranet } \\
\text { Implantação de Sistemas } \\
\text { Integrados de Gestão }\end{array}$ & $\begin{array}{l}\text { Otimização de Sistemas } \\
\text { Integrados de Gestão } \\
\text { Reengenharia de Processos } \\
\text { Modelagem de Empresas }\end{array}$ & $\begin{array}{l}\text { Software } \\
\text { - Produtos Microsoft } \\
\text { - Sistemas Dedicados } \\
\text { Hardware } \\
\text { - Multimídia } \\
\text { - Processadores } \\
\text { - Monitores } \\
\text { - Memórias } \\
\text { - Impressoras } \\
\text { - Plotter } \\
\text { Equipamento de Rede } \\
\text { - Hubs } \\
\text { - Cabos } \\
\text { - Placas } \\
\text { - Roteadores } \\
\text { - Modens } \\
\text { Material de Consumo } \\
\text { - Disquetes } \\
\text { - Folhas } \\
\text { - Pastas } \\
\text { Livros }\end{array}$ \\
\hline
\end{tabular}

As competências envolvidas na área de vendas podem ser classificadas em 5 classes diferentes: software, hardware, equipamento de rede, material de consumo e livros. Em outras palavras, para cada uma dessas classes de atuação existem diferentes empresas especializadas na SoftwareHouse Virtual. Atualmente com o advento do comércio eletrônico ou de vendas pela Internet, uma empresa especializada nesta atividade pode alcançar uma larga abrangência de mercado sem estar fisicamente presente nos mesmos. Este mecanismo de vendas pela Internet é reforçado pelo marketing da OV. 
Os serviços relacionados à área de desenvolvimento subdividem-se em cinco classes: desenvolvimento de sistemas de informação, projeto de base de dados, implantação de redes, desenvolvimento de "sites" e implantação de sistemas integrados.

O desenvolvimento de sistemas de informação pode ocorrer também no ambiente DOS como no ambiente Windows, conforme as linguagens apresentadas na tabela. Os serviços relacionados ao projeto de base de dados estão divididos em projeto lógico, que consiste na elaboração do MER, e implementação, a qual pode acontecer para os SGBDR's Oracle e Informix, nas plataformas Windows ou Unix. Os serviços oferecidos para a implantação de redes estão divididos em projeto lógico, cabeamento e instalação de equipamento e softwares (Windows NT e Novell). A implementação de Intranets está relacionada com as empresas que oferecem serviços no desenvolvimento de "sites" Internet. Por último, a SoftwareHouse Virtual oferece ainda na área de desenvolvimento os serviços de implantação de sistemas integrados de gestão, onde as empresas parceiras representam o produto Microsiga. De acordo com a proposta deste trabalho, a cooperação entre PME's deve prevalecer na formação da $\mathrm{OV}$, o que descarta o trabalho com empresas que representam os sistemas integrados de grande porte.

A área de consultoria oferecida pela SoftwareHouse oferece quatro tipos de serviços relacionados diretamente com a TI: melhoria de performance de SGBDR's e de redes, cujos softwares foram apresentados acima, auditoria de sistemas e otimização de sistemas integrados de gestão. Os demais serviços relacionam-se indiretamente com a TI, pois os resultados das ações que compreendem os projetos de reengenharia e modelagem podem gerar serviços que estão classificados na área de desenvolvimento da OV, o que pode, por sua vez, viabilizar cooperações entre os diferentes parceiros.

Como pode ser observado, o primeiro grande benefício que ocorre com a formação de uma OV consiste na participação comum nos mercados das diferentes empresas através de indicações realizadas pelos parceiros.

\subsubsection{Estrutura Organizacional e Operacional}

Para suportar o funcionamento da SoftwareHouse Virtual alguns elementos precisam estar presentes nas estruturas organizacional e operacional. Estes elementos são superficialmente abordados por não consistirem do tema central deste trabalho. No entanto, para aproximar o exemplo da realidade os mesmos são brevemente descritos. 
Toda a estrutura da SoftwareHouse Virtual está montada dentro no Núcleo de Manufatura Avançada - NUMA - da Escola de Engenharia de São Carlos - EESC. No referido laboratório encontram-se as pessoas responsáveis pela coordenação da $\mathrm{OV}$ e os recursos computacionais necessários para suportar a operação da mesma.

Assim, a sede da SoftwareHouse Virtual localiza-se na cidade de São Carlos e a estratégia de atuação concentra-se a princípio em nível regional, abrangendo cidades como Ribeirão Preto, São José do Rio Preto, Uberaba, Americana, Campinas, entre outras. No entanto, no surgimento de oportunidades de negócio, empresas de cidades fora desta região podem se associar a $\mathrm{OV}$, expandindo o mercado atendido pela mesma. Isto indica a estratégia de crescimento da SoftwareHouse Virtual, partindo do nível regional e, conforme a necessidade, expandindo-se para outras regiões.

Os papéis necessários para a SoftwareHouse Virtual são o coordenador de desempenho, o coordenador do pedido e os coordenadores de cada parceiro. Neste exemplo assume-se que a construção da OV já foi realizada, onde todos parceiros, além de estarem conectados, já estão modelados na ferramentas ARIS, ou seja, o modelo de empresa da OV já foi gerado pelo coordenador de desempenho. Portanto, suas atividades referem-se agora às atividades de integração dos parceiros na formação e gerência da EV.

Os coordenadores de cada parceiro, que já forneceram os modelos de seus serviços no formalismo apresentado na seção 4.3 , ou fazem parte de algum processo de coordenação ou ficam na expectativa de surgir alguma oportunidade. Os coordenadores dentro da OV estão conectados via Internet através de uma lista de e-mails, onde os mesmos se mantém informados sobre as atividades que estão acontecendo.

O coordenador de pedido é responsável pelo processo de atendimento ao cliente que se interessa pelos serviços oferecidos pela SoftwareHouse Virtual. A partir de uma solicitação do cliente o coordenador do pedido levanta os serviços necessários e aciona os parceiros correspondentes.

Os principais processos de apoio da SoftwareHouse Virtual são:

- desenvolvimento de serviços integrados de acordo com a competências dos parceiros;

- gerenciamento da informação, onde a principal atividade é manter todos os parceiros atualizados com as novidades que surgem na OV;

- planejamento estratégico que é responsável por indicar quais serviços integrados podem ser explorados em quais mercados; 
- marketing das competências da SoftwareHouse Virtual.

Para cada um destes processos de apoio foram formados grupos (ou times) a partir dos coordenadores de cada parceiro. Estes grupos, além de se encontrarem com uma determinada freqüência, utilizam o sistema de e-mail para a troca de idéias. Os resultados das discussões destes grupos são transferidos à todos os parceiros pelo mesmo meio de comunicação. A participação em cada um destes times é aberta a qualquer parceiro da OV.

Por se tratar de um exemplo torna-se difícil comentar acerca de um ponto importante para a manutenção da estrutura organizacional e operacional de uma OV: a contribuição financeira de cada parceiro. A quantia necessária depende diretamente da negociação entre as empresas que participam de um projeto desta magnitude.

Ainda por se tratar de um exemplo é desnecessário colocar aqui um código de admissão ou de conduta. No entanto, a difusão da ética em cooperação deve ser realizada em qualquer tipo de iniciativa de formação de redes de empresas e colocada na forma de regras gerais de conduta.

\subsection{2 "Site" Internet}

Independente do ramo de negócios de uma empresa, um mecanismo que está se tornando muito importante para a divulgação de seus produtos e serviços é a utilização da Internet. Este tipo de marketing pode ser considerado de baixo custo comparado com outras formas, e tem o benefício de possuir alcance a nível mundial. Neste sentido, a divulgação na Internet da SoftwareHouse Virtual, principalmente por se encontrar no setor de TI, é fundamental para que as competências nela presentes possam ser acessadas e avaliadas por clientes de qualquer ponto da região, obedecendo a estratégia de atuação citada anteriormente. No entanto, é evidente que, no caso de atendimento de clientes ou de admissão de parceiros de outras regiões, o canal de comunicação permanece o mesmo.

Para a divulgação dos serviços e produtos dos parceiros alguns mecanismos de busca foram implementados afim de facilitar a navegação pelo "site". De acordo com estes mecanismos de busca, os serviços e produtos oferecidos pela OV podem ser acessados através de diferentes mecanismos de busca:

- por cidade;

- por nome do serviço; 
- por palavra chave;

- por setor econômico.

Para a implementação destes mecanismos de busca e consequentemente do "site" Internet quatro componentes podem ser destacados, conforme é mostrado na Figura 43. A base de dados correspondente ao MER foi gerada no Microsoft Access, onde alguns formulários também foram gerados para a manutenção da mesma. Assim, o coordenador de desempenho, responsável pela manutenção do "site", cadastra as informações dos parceiros utilizando estes formulários do Access.

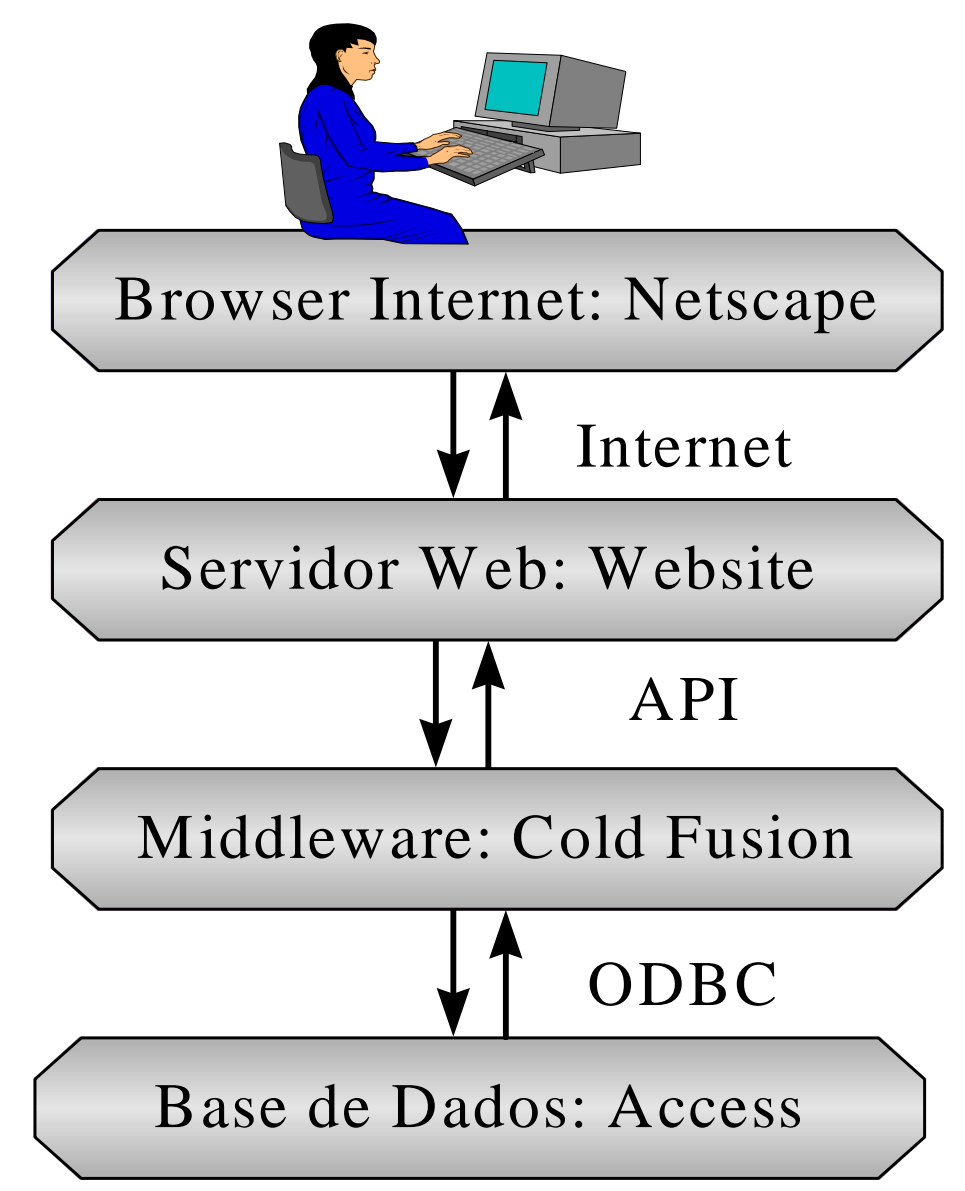

Figura 43: Componentes do "site" Internet

Para que a base de dados (arquivo de extensão MDB) possa ser acessada a partir das páginas de um "Browser" é necessária a utilização de uma classe de software específica para esta finalidade: um "middleware". Este tipo de software viabiliza a comunicação entre o arquivo MDB e o servidor do "site" Internet. Entre o servidor e o "middleware" a comunicação é feita através de um programa de interface ("Application Program Interface" API) e entre o "middleware" e o arquivo MDB através do recurso de conectividade aberta de 
base de dados ("Open Database Connectivity" - ODBC) do Windows. O "middleware" utilizado neste trabalho foi utilizado o Cold Fusion da firma Allaire e o servidor Web foi instalado com o Website 1.0.

A consulta na base de dados é realizada através da linguagem padrão SQL ("Structured Query Language" - SQL), que está embutida dentro do código HTML que implementa as páginas do "site".

A seguir são apresentadas duas das páginas do "site", cujo endereço é http://shv.sem.eesc.sc.usp.br. A página inicial apresenta um menu onde o usuário pode se informar sobre as parcerias que estão sendo realizadas, buscar informações sobre os produtos e serviços oferecidos e observar os setores econômicos que são atendidos pela SoftwareHouse Virtual (Figura 44).

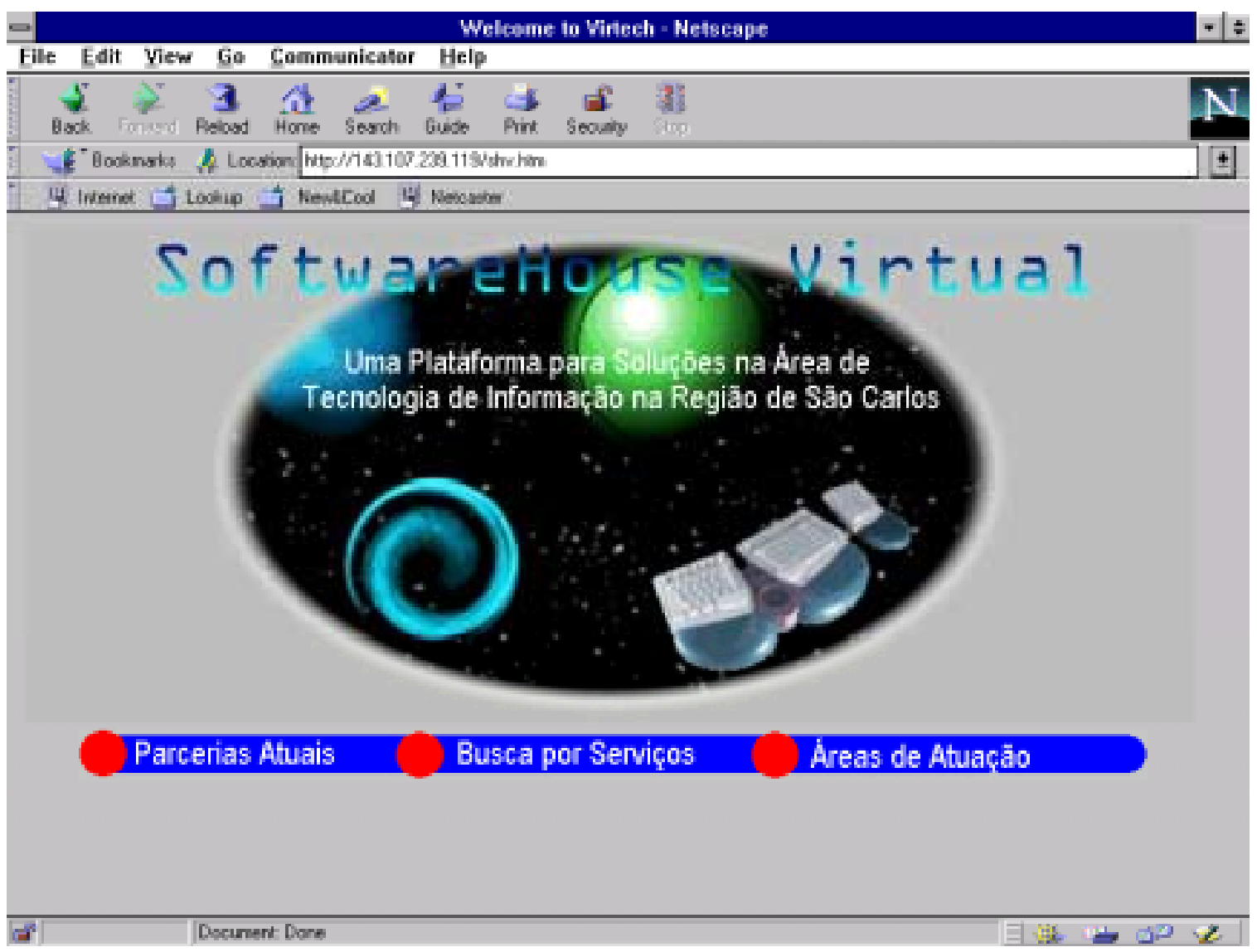

FIGURA 44: Página de Apresentação dos Recursos

A Figura 45 mostra um mecanismo de busca através do fornecimento do nome dos serviços que a SoftwareHouse Virtual oferece. O cliente, mediante as opções apresentadas, pode perguntar sobre um ou mais serviços de acordo com a sua necessidade. Na não 
existência do serviço na lista de opções, o cliente pode requisitar à SoftwareHouse Virtual sobre a possibilidade de sua realização.

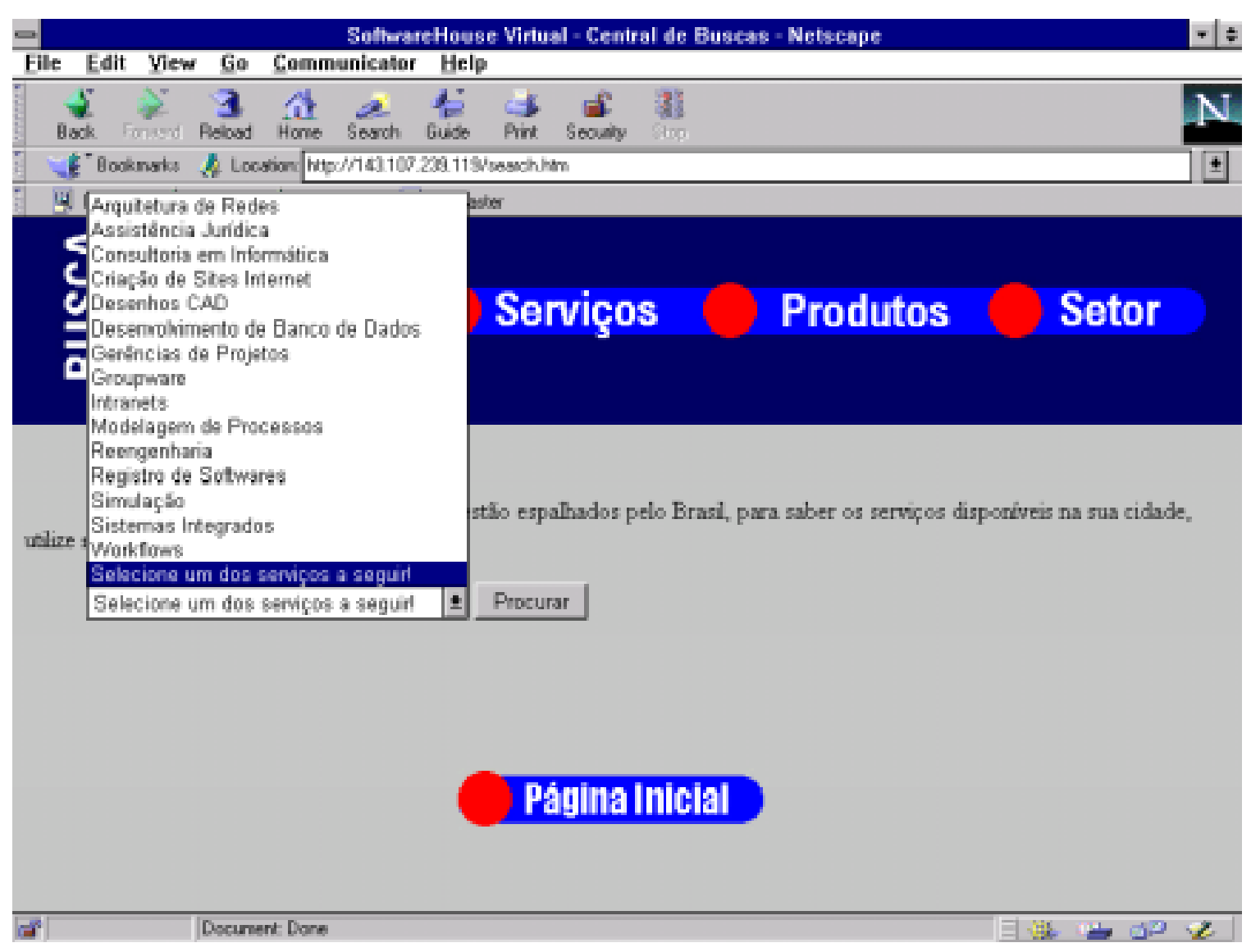

FIGURA 45: Página de Busca pelo Serviço

\subsection{Simulação da Formação e Operação de uma Empresa Virtual}

De acordo com o time responsável pelo processo de desenvolvimento de novos serviços, uma oportunidade a ser explorada pela SoftwareHouse Virtual consiste na integração dos seguintes serviços:

- venda de software;

- venda de hardware;

- venda de equipamentos de rede;

- instalação e configuração do software de rede; 
Este serviço integrado visa atender vários pedidos, ou seja, a EV a ser formada não está diretamente ligada à um cliente específico. De acordo com uma análise do grupo, este serviço pode ser oferecido em diferentes cidades da região e atender diferentes setores como saúde, administração pública, escolas, entre outros. Desta maneira, a primeira fase do método de formação e gerência de uma EV já foi realizada, uma vez que a oportunidade está identificada.

A partir da identificação da oportunidade inicia-se a formação da EV, e consequentemente a aplicação das atividades de integração dos parceiros.

\subsubsection{Integração dos Modelos}

Após a fase de Exploração da Oportunidade do método de formação e gerência da EV, o coordenador de desempenho, já na fase Desenvolver Plano Genérico, identifica os serviços parciais que compõem a solução integrada a ser oferecida pela EV. Com a identificação dos serviços parciais, o coordenador de desempenho cria uma nova base de dados na ferramenta ARIS, gera os modelos ideais e importa os modelos dos parceiros a partir da base de dados que representa a SoftwareHouse Virtual. Neste ponto, o processo de simulação dos parceiros que executam a mesma atividade deveria ser realizado, mas no entanto este aspecto não foi explorado por este exemplo afim de dar maior ênfase nas atividades subsequentes.

Com os modelos dos parceiros escolhidos em uma base de dados específica para a EV sendo formada, inicia-se a fase de Planejamento Detalhado com a elaboração dos seguintes modelos integrados:

- árvore de funções;

- organograma;

- modelo de dados comum;

- EPK global;

A árvore de funções é mostrada na Figura 46, onde pode ser observado que três serviços estão relacionados com a competência de vendas e um com a competência de desenvolvimento. Os serviços de vendas são representados por diferentes parceiros e relacionam-se com diferentes produtos e por isso possuem diferentes atividades de detalhamento. 


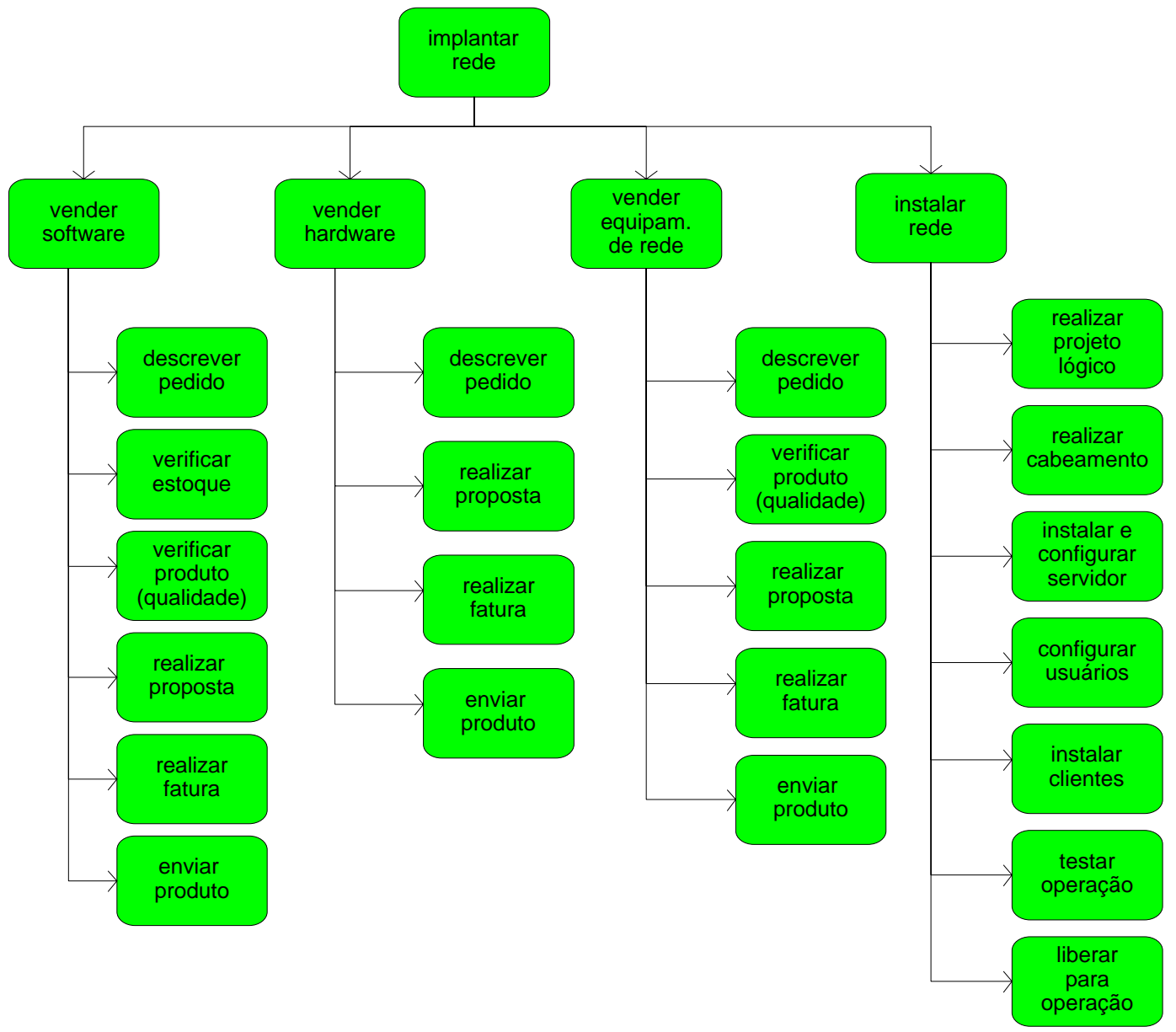

FIGURA 46: Árvore de Funções

O organograma da EV é composto então por quatro unidades organizacionais, cada uma representada por um parceiro da SoftwareHouse Virtual (Figura 47). No organograma, a EV sendo formada é denominada EV Net e apenas o coordenador de cada parceiro é representado no modelo.

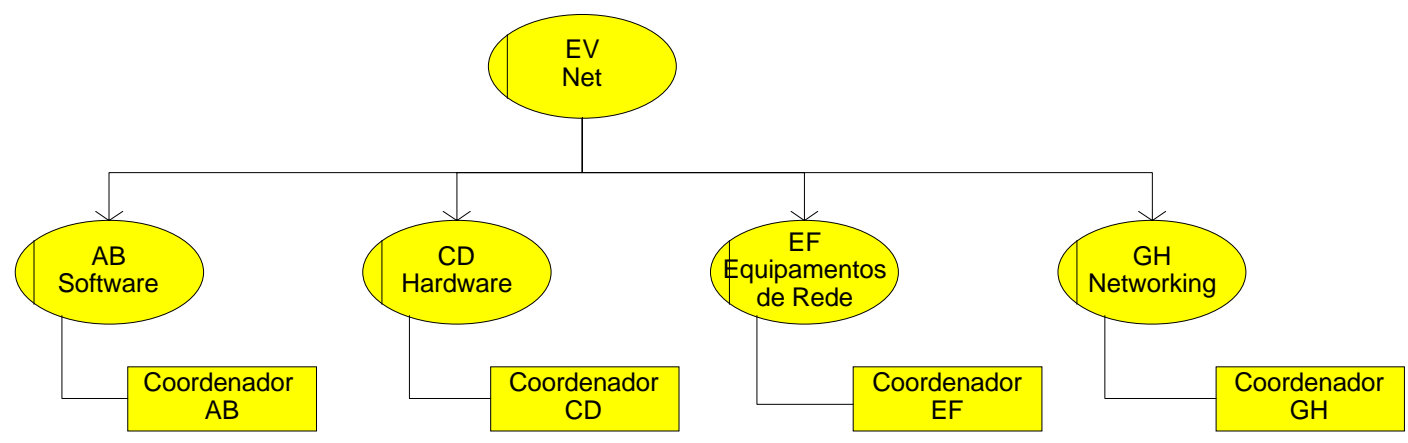

FIGURA 47: Organograma 
O modelo de dados, que suporta a comunicação entre os parceiros, corresponde a elaboração do documento que representa o pedido (Figura 48). Este documento, representado por apenas uma entidade no MER, contém a descrição de cada item que está sendo vendido, o preço cobrado por cada parceiro e data de término de cada serviço parcial.

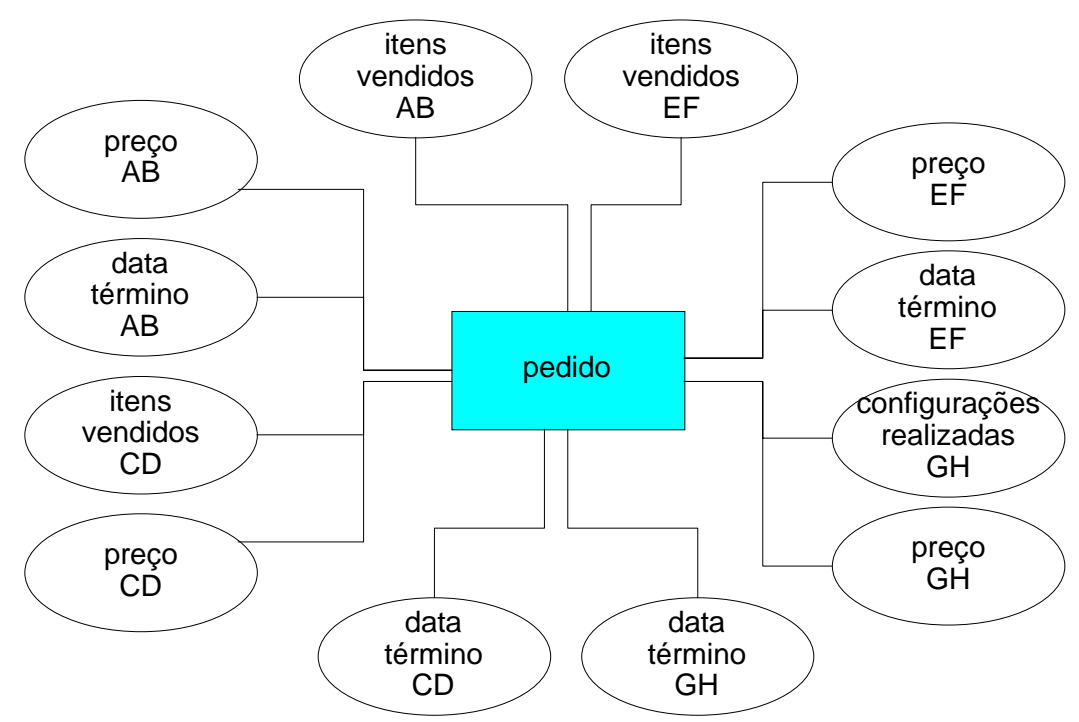

FIGURA 48: MER

Vale ressaltar que o modelo de dados apresenta esta forma para facilitar a implementação do workflow, sendo que para isto o formalismo do MER não é respeitado. Neste modelo poderiam ser definidas duas entidades, Pedido e Parceiro, onde os atributos repetidos para cada parceiro seriam representados na entidade correspondente.

O EPK global é formado, no plano mais abstrato (genérico), das quatro funções definidas no modelo árvore de funções e que representam os quatro serviços parciais da EV (Figura 49). Os serviços são realizados de maneira seqüencial, não havendo paralelização de atividades entre os parceiros. As funções que detalham cada uma das funções macro (serviço de um parceiro) são associadas em outros modelos EPK's, formando um segundo plano de abstração (detalhado). Em outras palavras, cada uma das funções apresentadas no EPK global é detalhada através de outro modelo EPK que contém as funções de detalhamento apresentadas no modelo árvore de funções. 


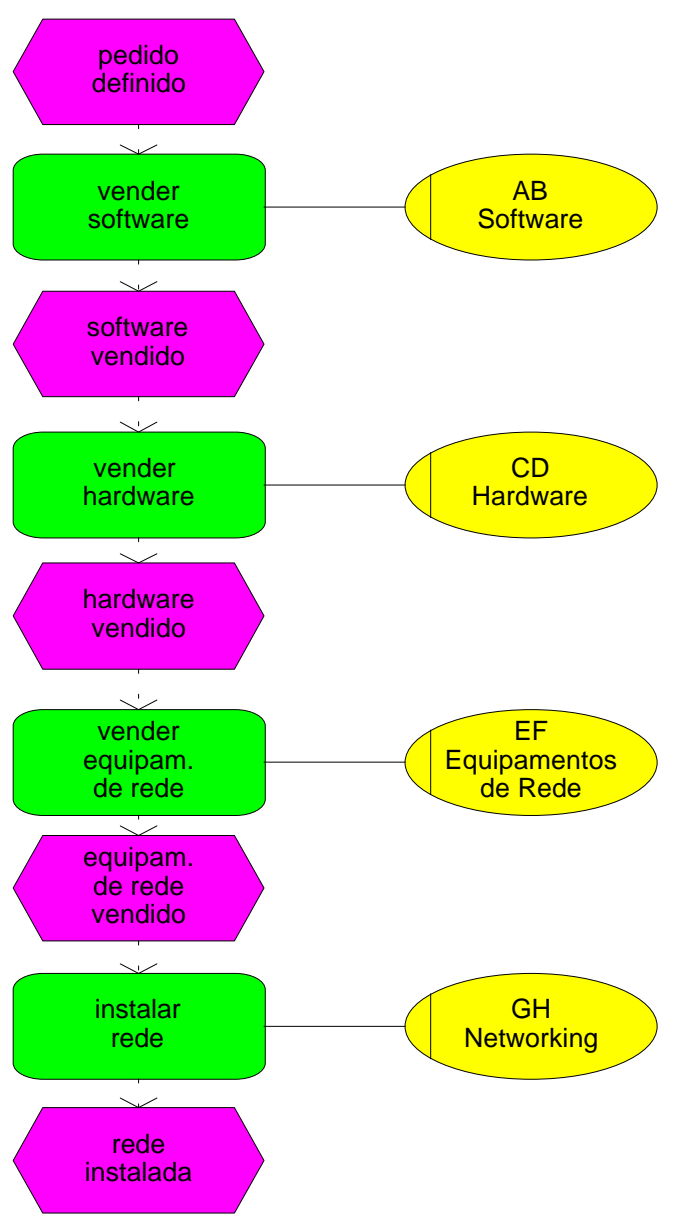

FIGURA 49: EPK Global

\subsubsection{Simulação}

Realizada a integração dos modelos, a fase de otimização é inicializada através da simulação. Para isso, informações sobre tempo, custo e capacidade devem ser confirmadas nas funções que compõem o modelo global. Neste exemplo, o tempo é medido em dias e o custo em reais. A capacidade de realização de cada função é indicada pela sua associação à uma unidade organizacional determinada pelo organograma. Aqui é suposto que existe apenas uma pessoa na unidade organizacional responsável (no parceiro) pela execução da função. Isto é determinado através de um atributo que descreve a unidade organizacional.

O principal objetivo da simulação aqui é encontrar a estrutura ideal de operação, ou seja, integrar os serviços e ajustar a capacidade de execução para o estabelecimento de prazos aceitáveis pelo mercado. Esta atividade corresponde a análise de diferentes cenários 
de operação. Neste exemplo, dois cenários são analisados: com e sem a utilização de um sistema workflow.

O tempo de transmissão de um documento entre os parceiros é reduzido praticamente a zero com a utilização de sistemas worfklow. Neste sentido, os resultados apresentados pelo processo de simulação, na forma de estatísticas, indicam que o tempo total gasto é menor utilizando-se o sistema de workflow. Assim, as estatísticas representam um meio importante na decisão de se utilizar este recurso da TI. A Figura 50 apresenta as estatísticas de um cenário sem o sistema workflow. Como pode ser observado, a simulação gera diferentes instâncias de processos com diferentes atributos tais como tempo de início ("Startzeit"), tempo de parada ("Stopzeit") e o tempo de execução ("Durchlaufzeit") de cada um. A unidade de tempo utilizada está em dias.

\begin{tabular}{|c|c|c|c|c|}
\hline \multicolumn{4}{|c|}{ Simulations-Auswertung } & 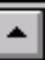 \\
\hline Datei Anzeige & ierkriterium & & & \\
\hline ProzeBstatistik & $\begin{array}{l}\text { Startzeit } \\
\text { [ddd:hh:mm:ss] }\end{array}$ & $\begin{array}{l}\text { Stopzeit } \\
\text { [ddd:hh:mm:ss] }\end{array}$ & $\begin{array}{l}\text { Durchlaufzeit } \\
\text { [ddd:hh:mm:ss] }\end{array}$ & \\
\hline Prozeß-Nr. 1 & 003:00:00:00 & 024:00:00:00 & 021:00:00:00 & \pm \\
\hline Prozeß-Nr. 2 & 009:00:00:00 & 028:00:00:00 & 019:00:00:00 & \\
\hline Prozeß-Nr. 3 & 015:00:00:00 & 032:00:00:00 & 017:00:00:00 & \\
\hline Prozeß-Nr. 4 & 021:00:00:00 & 042:00:00:00 & 021:00:00:00 & \\
\hline Prozeß-Nr. 5 & 027:00:00:00 & 046:00:00:00 & 019:00:00:00 & \\
\hline Prozeß-Nr. 6 & 033:00:00:00 & 050:00:00:00 & 017:00:00:00 & \\
\hline Prozeß-Nr. 7 & 039:00:00:00 & 060:00:00:00 & 021:00:00:00 & \\
\hline Prozeß-Nr. 8 & 045:00:00:00 & 064:00:00:00 & 019:00:00:00 & \\
\hline Prozeß-Nr. 9 & 051:00:00:00 & 068:00:00:00 & 017:00:00:00 & \\
\hline Prozeß-Nr. 10 & 057:00:00:00 & 078:00:00:00 & 021:00:00:00 & \\
\hline Prozeß-Nr. 11 & 063:00:00:00 & 082:00:00:00 & 019:00:00:00 & \\
\hline ProzeB-Nr. 12 & 069:00:00:00 & 086:00:00:00 & 017:00:00:00 & \\
\hline Prozeß-Nr. 13 & 075:00:00:00 & 096:00:00:00 & 021:00:00:00 & \\
\hline Prozeß-Nr. 14 & 081:00:00:00 & 100:00:00:00 & 019:00:00:00 & $\downarrow$ \\
\hline$V$ & \begin{tabular}{|l|l|l|l|}
+ & & & \\
\end{tabular} & & $\Rightarrow$ & \\
\hline
\end{tabular}

\section{FIGURA 50: Tempo Gasto no Cenário sem o Sistema Workflow}

A Figura 51 mostra as estatísticas envolvendo a utilização do sistema workflow. Como pode ser observado, o tempo de execução dos processos instanciados diminuiu, o que representa um melhor desempenho de operação. 


\begin{tabular}{|c|c|c|c|c|}
\hline \multicolumn{4}{|c|}{ Simulations-Auswertung } & - \\
\hline Datei Anzeige & tierkriterium & & & \\
\hline ProzeBstatistik & \begin{tabular}{|l} 
Startzeit \\
[ddd:hh:mm:ss]
\end{tabular} & $\begin{array}{l}\text { Stopzeit } \\
\text { [ddd:hh:mm:ss] }\end{array}$ & $\begin{array}{l}\text { Durchlaufzeit } \\
\text { [ddd:hh:mm:ss] }\end{array}$ & \\
\hline Prozeß-Nr. 1 & 003:00:00:00 & 018:00:00:00 & 015:00:00:00 & \pm \\
\hline Prozeß-Nr. 2 & 009:00:00:00 & 022:00:00:00 & 013:00:00:00 & \\
\hline Prozeß-Nr. 3 & 015:00:00:00 & 026:00:00:00 & 011:00:00:00 & \\
\hline Prozeß-Nr. 4 & 021:00:00:00 & 036:00:00:00 & 015:00:00:00 & \\
\hline Prozeß-Nr. 5 & 027:00:00:00 & 040:00:00:00 & 013:00:00:00 & \\
\hline Prozeß-Nr. 6 & 033:00:00:00 & 044:00:00:00 & 011:00:00:00 & \\
\hline Prozeß-Nr. 7 & 039:00:00:00 & 054:00:00:00 & 015:00:00:00 & \\
\hline Prozeß-Nr. 8 & 045:00:00:00 & 058:00:00:00 & 013:00:00:00 & \\
\hline Prozeß-Nr. 9 & 051:00:00:00 & 062:00:00:00 & 011:00:00:00 & \\
\hline Prozeß-Nr. 10 & 057:00:00:00 & 072:00:00:00 & 015:00:00:00 & \\
\hline Prozeß-Nr. 11 & 063:00:00:00 & 076:00:00:00 & 013:00:00:00 & \\
\hline Prozeß-Nr. 12 & 069:00:00:00 & 080:00:00:00 & 011:00:00:00 & \\
\hline Prozeß-Nr. 13 & 075:00:00:00 & 090:00:00:00 & 015:00:00:00 & \\
\hline Prozeß-Nr. 14 & 081:00:00:00 & 094:00:00:00 & 013:00:00:00 & + \\
\hline$\checkmark$ & \begin{tabular}{|l|l|l|l|}
+ & & & \\
\end{tabular} & & 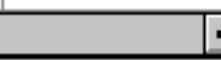 & \\
\hline
\end{tabular}

\section{FIGURA 51: Tempo Gasto no Cenário com o Sistema Workflow}

A simulação neste exemplo foi aplicada apenas para a confirmação do sistema workflow como um recurso tecnológico indispensável na operação da EV, não sendo analisada a estruturação do processo ou a identificação de gargalos de processamento.

\subsubsection{Implantação do Sistema Workflow}

O modelo a ser transformado em executável é o EPK global, onde o processamento de cada função genérica é de responsabilidade de cada parceiro. O processo de gerência do pedido baseia-se no monitoramento da transmissão do documento eletrônico entre os parceiros a fim de cumprir os prazos estabelecidos pelos clientes da SoftwareHouse Virtual.

Para o cadastro de usuários do sistema workflow não foi utilizado o esquema de Papéis. Assim, apenas as pessoas que representam os coordenadores de cada parceiro possuem o direito de acesso ao sistema. Isto é realizado através da opção Gerência de Usuários no componente de modelagem da ferramenta ARIS (Figura 52). Nesta opção, um usuário é cadastrado e associado a um elemento no organograma. Por exemplo José $A B$, coordenador da firma $\mathrm{AB}$ Software, é associado ao elemento coordenador $A B$ do organograma. Assim, quando José $A B$ se 'logar’ no sistema, ele vai executar as funções que estão mapeadas ao elemento coordenador $A B$. 


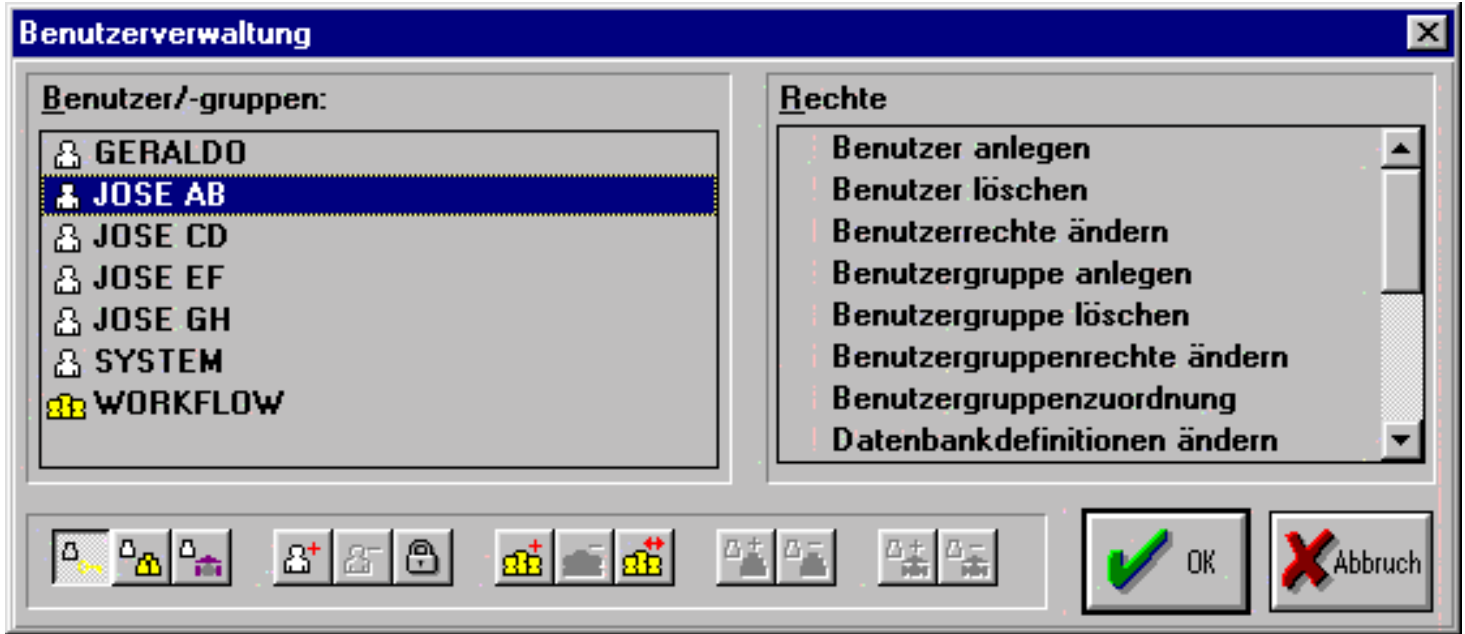

\section{FIGURA 52: Cadastro de Usuários do Sistema Workflow}

Após o cadastro dos usuários o EPK global foi detalhado para que cada função fosse associada ao aplicativo responsável por seu processamento. Assim, um Diagrama de Associação de Aplicativos foi elaborado para conter esta associação. Através dele, quando o usuário ativa uma função para ser processada, o aplicativo (no caso o Word) é aberto automaticamente. A partir da elaboração deste diagrama, o modelo EPK global foi então transformado em modelo executável pelo sistema workflow.

Com a configuração do servidor realizada, as atividades então se concentraram na parte dos clientes, ou seja, nos parceiros. Para cada parceiro foi instalado o software cliente do workflow, onde a principal configuração para viabilizar a comunicação com o servidor consiste no fornecimento do endereço eletrônico.

Estabelecida a comunicação, o parceiro foi treinado para a utilização do sistema workflow. Para isso, um processo exemplo foi instanciado no servidor e todas as etapas foram realizadas. Neste sentido, o coordenador de cada parceiro foi capacitado a executar eletronicamente o processo de gerência do pedido. A Figura 53 mostra a janela de acesso ao sistema workflow, onde podem ser identificados três escaninhos: entrada ("Eingangskorb"), intermediário ("Zwischenablage") e de saída (“Ausgangskorb”). 


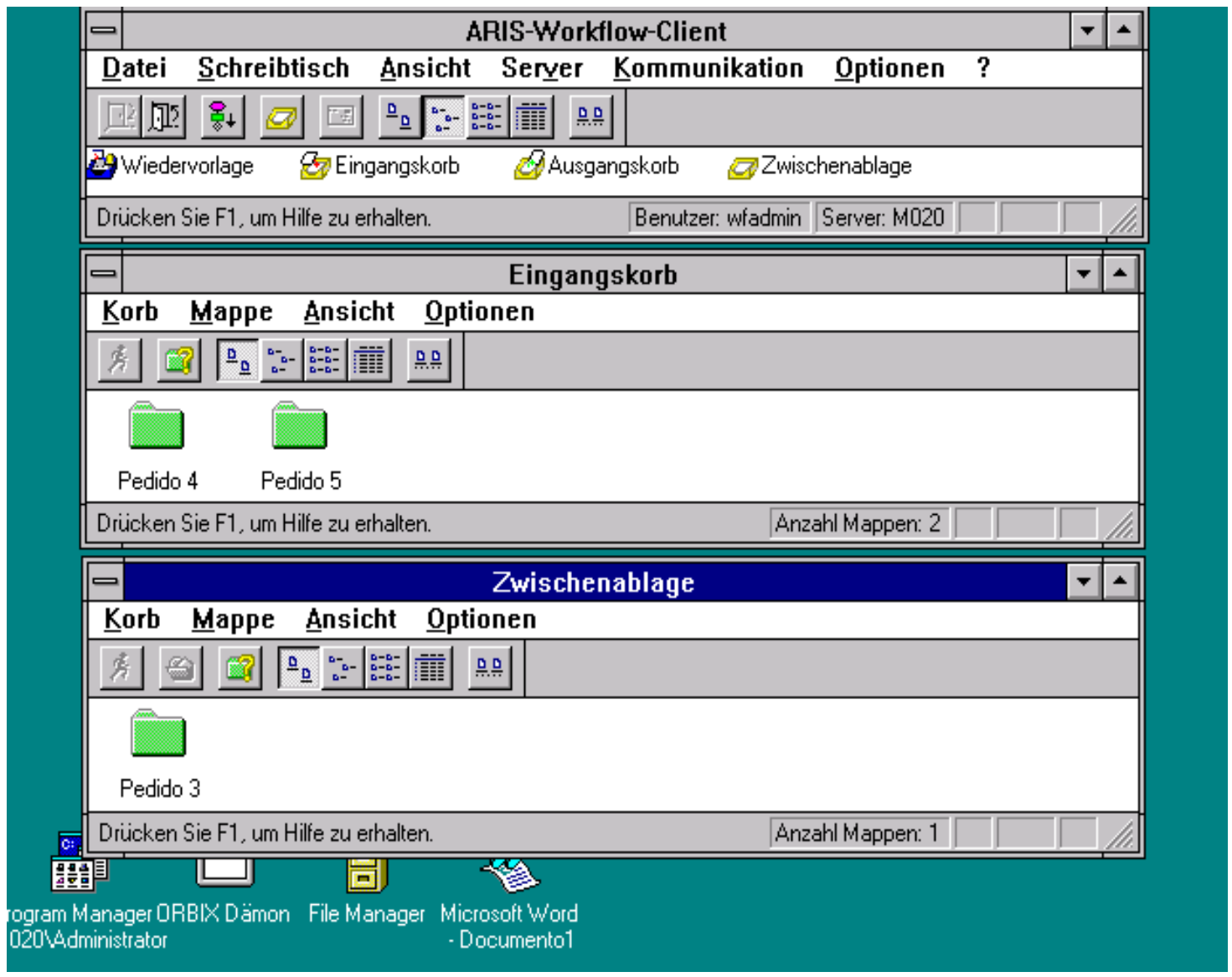

FIGURA 53: Janela do Usuário do Sistema Worklow.

No escaninho de entrada estão todos os pedidos (processos) que estão por serem realizados. Para o processamento de um pedido, o usuário deve transferí-lo para o escaninho intermediário, onde processamento das informações é realizado com o suporte do aplicativo. Terminado o processamento, o documento que representa o pedido é transferido para o escaninho de saída, habilitando que a próxima função seja executada. Neste último processo de transferência as informações processadas são transferidas para o servidor workflow.

Um pedido aceito pela EV representa um processo instanciado no sistema workflow. Assim, com diferentes pedidos em andamento, ou seja, com diferentes processos instanciados no workflow, o coordenador de desempenho tem a possibilidade de monitorálos através de um mapa de processos. Com isso, para um processo instanciado o coordenador de desempenho tem como observar em qual função o pedido se encontra e consequentemente em qual parceiro. A Figura 54 mostra um mapa de processos, onde o processo instanciado Pedido3 encontra-se na terceira função, ou seja, no parceiro que a executa. 


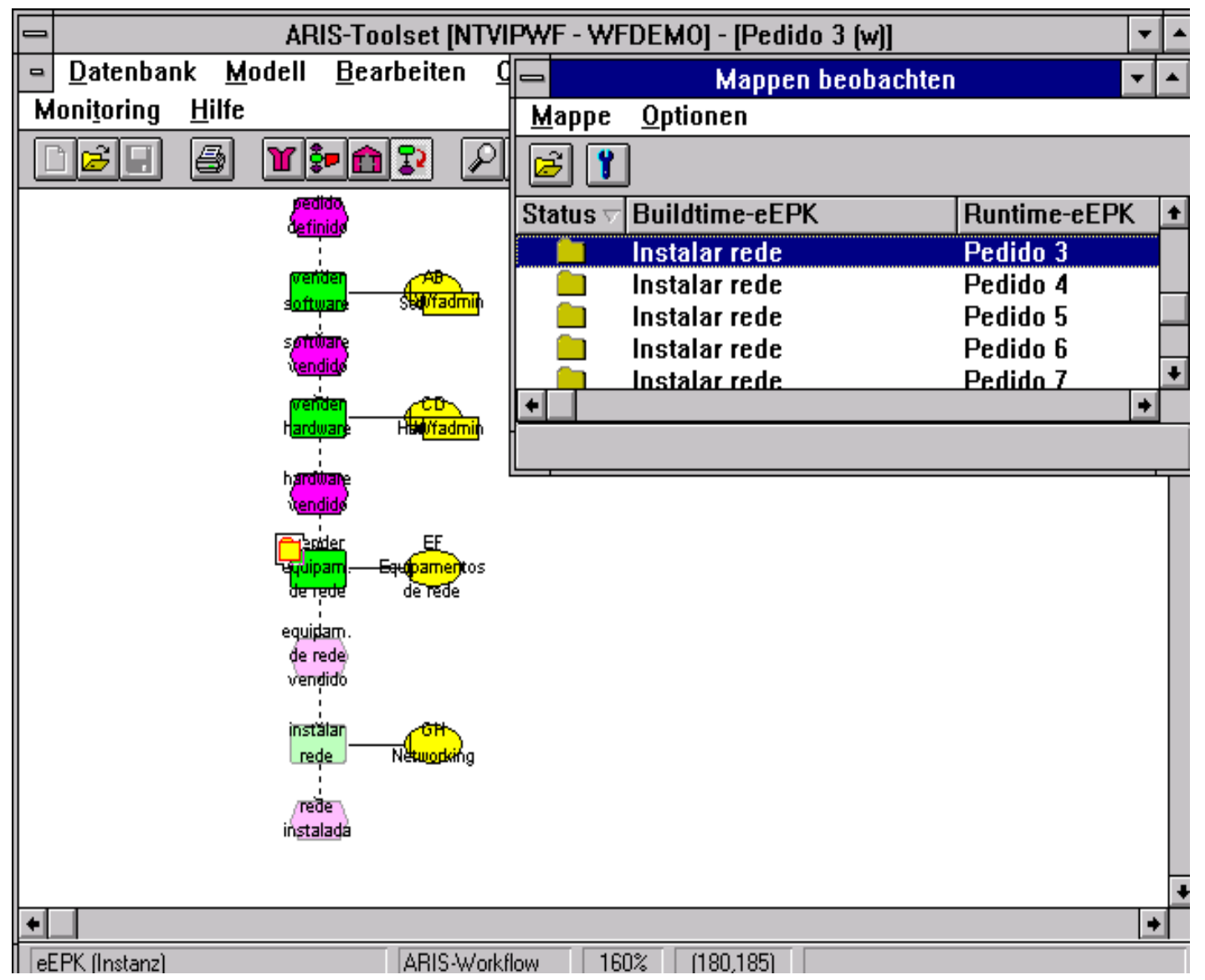

FIGURA 54: Mapa dos Processos Instanciados da EV

A partir do monitoramento do sistema de métricas da EV, identifica-se o momento de se dissolver a EV. A partir desta situação estabelecida, inicia-se a atividade de geração do modelo de referência da experiência realizada.

\subsubsection{Geração do Modelo de Referência}

Neste exemplo, para a implantação do sistema workflow foram utilizadas apenas as funções do nível mais abstrato de representação, presentes no EPK global. Desta maneira, o detalhamento dessas funções não foi utilizado no workflow, sendo apenas descrito para o entendimento do serviço integrado. Isto significa que o nível de integração física entre empresas ocorreu de forma superficial, baseando-se na troca eletrônica de informações genéricas. No entanto, com o fortalecimento do fator confiança entre os parceiros, o nível de integração física pode ser maior. 
Neste sentido, a consolidação semântica dos modelos integrados neste exemplo pode ocorrer apenas para elementos (funções e eventos) mais abstratos. A Figura 55 mostra uma descrição detalhada da função Vender Software.

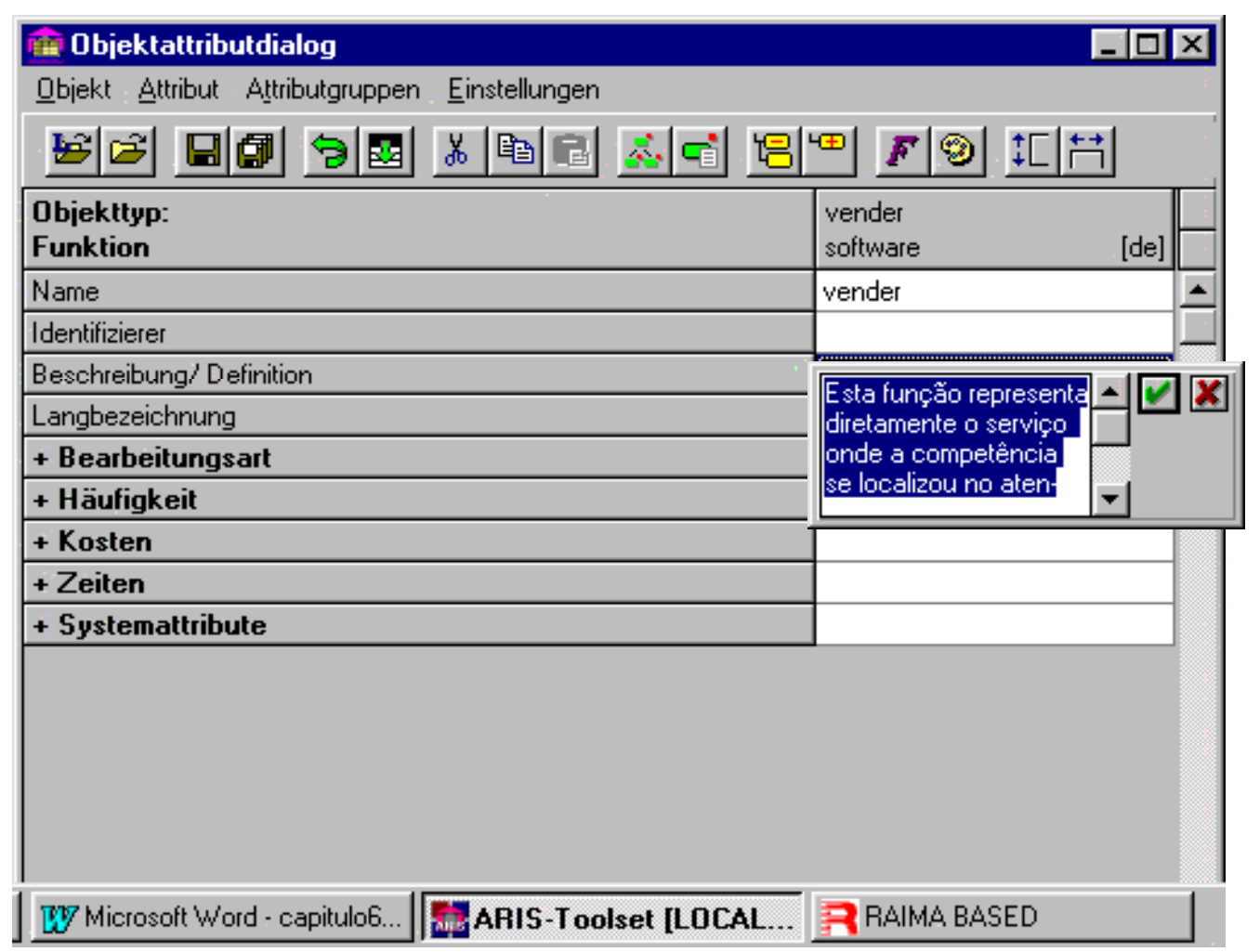

\section{FIGURA 55: Consolidação Semântica de uma Função}

Após a fase de consolidação dos modelos foi realizada a fase de documentação da experiência segundo os descritores citados na seção 5.4.5. Para isso, a base de dados implementada no Access foi utilizada, otimizando assim o armazenamento das informações. A Figura 56 apresenta a janela para a entrada de informações sobre a EV dissolvida. 


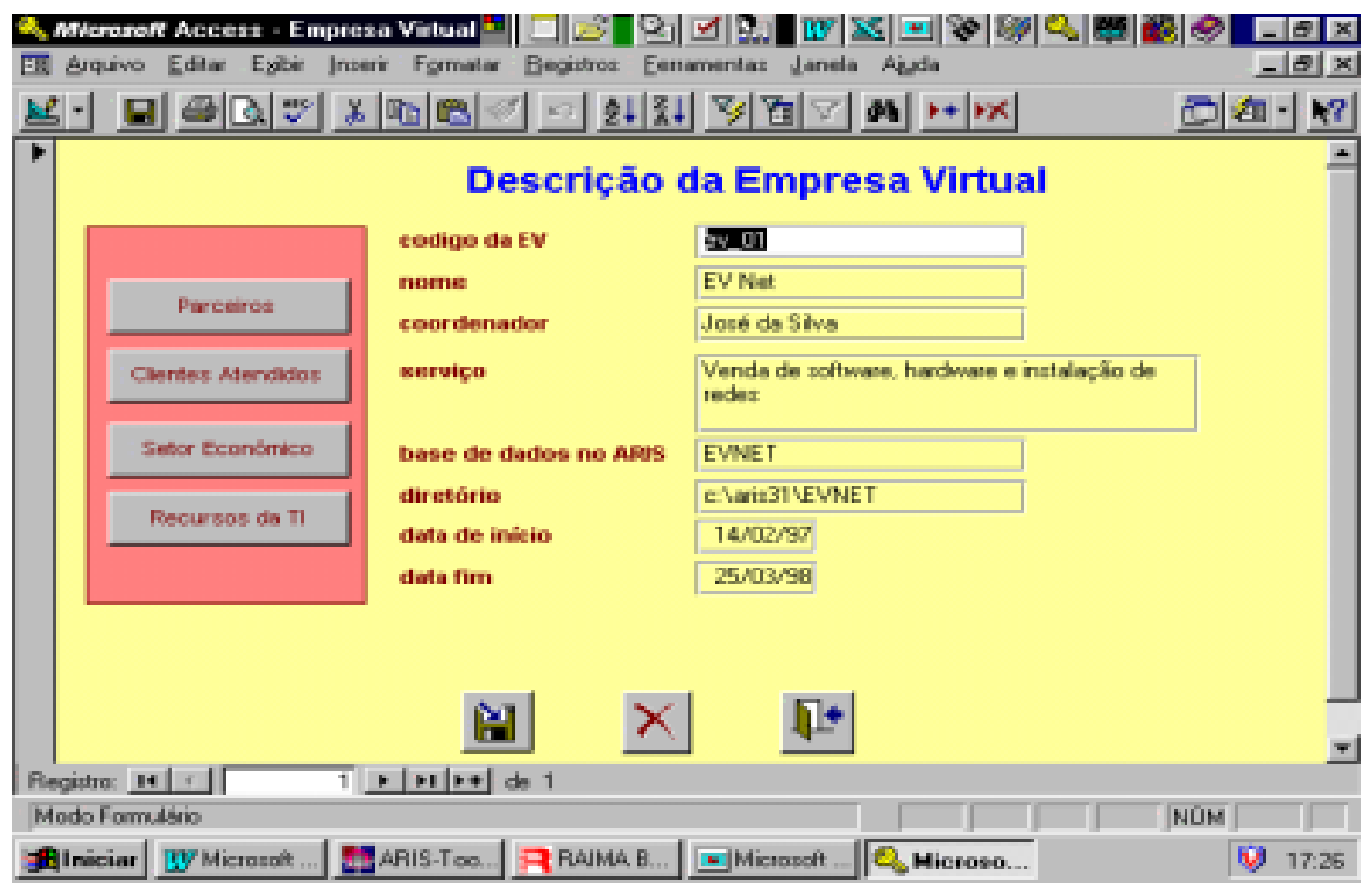

FIGURA 56: Documentação da Experiência Realizada

Desta maneira, todo o ciclo de vida de uma EV foi abordado neste exemplo, onde as atividades de otimização da integração dos parceiros, tema central deste trabalho de doutoramento, foram enfatizadas. 


\section{Conclusões e Trabalhos Futuros}

A revisão bibliográfica deste trabalho mostrou que um novo tipo de cooperação entre empresas está surgindo como uma alternativa para a redução dos custos de transações. O conceito de Empresa Virtual está sendo pesquisado em todo mundo para exploração rápida de oportunidades de mercado, onde cada empresa parceira na cooperação fornece a sua competência, ou seja, o que ela faz com preço e qualidade aceitáveis no mercado consumidor. Vale ressaltar que alguns projetos de pesquisa objetivam a consolidação de PME's por suas características de absorção de mão-de-obra, problema este que afeta todo o planeta.

No entanto, foi verificado que vários autores ressaltam apenas as vantagens de se formar uma Empresa Virtual, não esclarecendo detalhadamente os passos para o estabelecimento da cooperação. Como foi apresentado, há diferentes fatores que influenciam a cooperação, entre os quais pode-se destacar a confiança entre as empresas. De acordo com os projetos apresentados, a formação de uma Organização Virtual, ou seja, de uma rede fixa entre empresas para a troca de informações, foi considerada como uma solução primordial para a elaboração de mecanismos que atenuem os obstáculos encontrados para a formação de uma Empresa Virtual.

Com base na formação de uma Organização Virtual, este trabalho procurou estabelecer mecanismos que suportem a formação e gerência de Empresas Virtuais. Para se atingir este objetivo, diferentes recursos da área de pesquisa Integração de Empresas foram pesquisados a fim de viabilizar a otimização da integração dos parceiros. Durante esta pesquisa foi constatado que qualquer projeto de integração acontece primeiro no mundo lógico, suportado pela utilização de três conceitos fundamentais: metodologia, arquitetura de referência e ferramenta computacional.

Para a representação lógica dos parceiros foi utilizada a arquitetura de referência ARIS, que, através dos métodos de suas diferentes visões, suportou a elaboração do modelo 
de empresa da Organização Virtual. O conceito de modelo de empresa, por sua vez, teve que ser adaptado neste trabalho para a representação de diferentes empresas, ao invés da representação de diferentes departamentos de uma empresa.

O principal motivo para a utilização da arquitetura ARIS foi a funcionalidade oferecida pela ferramenta computacional correspondente. A sua aplicação no contexto de uma Organização Virtual objetivou trazer os benefícios comprovados em diferentes projetos de integração, tanto na área de serviços como no setor produtivo. A manipulação eletrônica da representação lógica das empresas presentes na Organização Virtual consistiu em uma condição fundamental ao processo de integração dos parceiros na formação e gerência de uma Empresa Virtual.

Com a representação eletrônica das informações na Organização Virtual foi possível aplicar diferentes recursos no ciclo de vida de uma Empresa Virtual para a otimização da integração dos parceiros. Assim, a aplicação de recursos como modelagem e simulação de processos, sistemas workflow e modelos de referência representaram a proposta deste trabalho, ou seja, de otimização da tradução do planejamento lógico em operação real de uma Empresa Virtual. Cada um destes recursos trouxeram diferentes vantagens ao processo de integração dos parceiros, entre quais pode-se destacar:

- a modelagem de processos viabiliza a geração de uma base de dados eletrônica contendo informações padronizadas sobre os parceiros da Organização Virtual. Essa padronização das informações suporta o entendimento comum entre as empresas que participam do processo de formação de uma Empresa Virtual;

- a simulação de processos auxilia na tomada de decisões para o estabelecimento das estruturas operacional e organizacional da Empresa Virtual sendo formada. Através de suas estatísticas é possível a comparação pelos parceiros entre diferentes cenários de operação da Empresa Virtual;

- a implantação de sistemas workflow suporta o monitoramento eletrônico do processo de gerência do pedido e consequentemente da operação da Empresa Virtual. O tempo de transferência, agora eletrônica, das informações entre os parceiros é praticamente reduzido a zero, o que otimiza o tempo total de realização de um pedido. Além disso, através da utilização da ferramenta ARIS é possível a transformação direta do modelo que representa as atividades de realização do pedido em processo executável. A cada pedido de um cliente é instanciado um processo na base de dados da ferramenta ARIS. 
Esta integração entre modelo e processo executável facilita a alteração na operação da Empresa Virtual;

- os modelos de referência suportam a elaboração de estruturas ideais para a operação da Empresa Virtual. Com uma análise dos resultados de experiências anteriores é possível evitar que erros se repitam na formação de outras Empresas Virtuais dentro da Organização Virtual.

Para a realização de cada uma das atividades de integração foram estabelecidas diferentes metodologias que indicam a seqüência de passos a serem executados para a utilização dos recursos citados acima. Essas metodologias visam consolidar os processos de coordenação dentro da Organização Virtual, uma vez que, sendo formalizadas, podem ser executadas por diferentes pessoas.

Duas bases de dados foram desenvolvidas no Access para suportar o armazenamento de informações que não podem ser cadastradas diretamente nos modelos da ferramenta ARIS. Uma base de dados complementa a elaboração do modelo de empresa da Organização Virtual e a outra auxilia manutenção dos modelos de referência. A implementação de ambas tem como objetivo a otimização do armazenamento e recuperação das informações que suportam os processos de coordenação de uma Organização Virtual.

Entre as responsabilidades definidas para a coordenação de uma Organização Virtual, a atuação de um coordenador de desempenho mostra-se essencial dentro do processo de integração dos parceiros em uma Empresa Virtual. Ele coordena as atividades de integração propostas neste trabalho, sendo responsável por centralizar a comunicação com cada parceiro, ou seja, com os coordenadores in-/ outsourcing. A sincronização da comunicação entre os parceiros é fundamental para o sucesso da operação de uma Empresa Virtual.

Desta forma, as atividades de integração de parceiros propostas neste trabalho (modelagem e simulação de processos, sistemas workflow e modelos de referência) foram adequadas ao ciclo de vida de uma Empresa Virtual, onde diferentes conceitos foram aplicados.

De acordo com a complexidade do tema deste trabalho não foi possível uma validação real da proposta, pois a formação de uma Organização Virtual depende de habilidades sócio-culturais para a aglutinação de empresas e pessoas onde a exploração de oportunidades de negócios representa o objetivo fundamental. Como foi mencionado, este 
requisito é fundamental para a formação de uma Organização Virtual. Este trabalho focalizou a aplicação de conceitos técnicos na formação de uma Empresa Virtual.

Além disso, para a validação real da proposta é necessária a observação de uma amostra considerável de formações de Empresas Virtuais dentro de uma mesma Organização Virtual, o que pode levar anos. A consideração de apenas uma Organização Virtual também não representa um espaço amostral onde o trabalho pode ser realmente validado.

A aplicação da proposta deste trabalho foi mostrada através da elaboração de um exemplo baseado na experiência de um projeto suíço (Virtual Company) que tem obtido sucesso na oferta de serviços na área da Tecnologia da Informação. Uma oportunidade de negócio envolvendo serviços oferecidos por diferentes empresas foi identificada e, então, foram apresentadas as atividades de integração dos parceiros com a utilização dos recursos selecionados por este trabalho.

Por fim, este trabalho pode ser considerado como uma fonte de referência para a execução de outros trabalhos relacionados a esta área de pesquisa, uma vez que há relativamente poucas opções na literatura em língua portuguesa sobre o tema.

Entre as sugestões para trabalhos futuros encontra-se a exploração das demais camadas de infra-estrutura para a formação de uma Organização Virtual e consequentemente de Empresas Virtuais. Como já foi dito, este trabalho focalizou aspectos técnicos para a integração de parceiros. Assim, futuras pesquisas podem explorar aspectos culturais e legais necessários à formação de uma Organização Virtual. Com base neste trabalho exploratório sobre o tema, pesquisas envolvendo questões legais como contrato e responsabilidade jurídica e questões culturais como confiança e liderança podem ser desenvolvidos.

Além disso, com base na geração de um modelo de empresa a formação e gerência de uma Empresa Virtual e a coordenação da Organização Virtual proposta neste trabalho, outras pesquisas complementares podem ser realizadas para a otimização da integração de parceiros, tais como:

- elaboração de um sistema de métricas de desempenho que monitora a operação da Empresa Virtual, no qual pode ser baseado o plano de reconfiguração ou de dissolução;

- implantação da Gestão Total de Custos dentro da Organização Virtual para a otimização da divisão dos custos de uma cooperação, que influencia diretamente as questões de confiança entre os parceiros 
- implantação de processos para Certificação da Qualidade para garantir uma maior confiança entre os clientes potenciais da Organização Virtual;

- elaboração do processo de planejamento estratégico para a definição de metas de exploração de oportunidades de negócio, ao qual pode ser agregado os processos de marketing e vendas;

- elaboração do processo de desenvolvimento de novos serviços a serem identificados pelo processo de planejamento estratégico;

- implantação de uma Intranet para suportar a comunicação entre os parceiros e consequentemente os processos de coordenação da Organização Virtual;

- desenvolvimento de conceitos para a integração de aplicativos dos parceiros.

Como foi mencionado, esta tese foi direcionada ao setor de serviços na área de Tecnologia de Informação. No entanto, conceitos aqui aplicados podem ser aproveitados para suportar a formação de Organizações e Empresas Virtuais no setor produtivo, onde a necessidade de integração é maior no ponto de vista técnico. Neste sentido, o conceito de modelagem pode ser expandido para que se possa atender os requisitos não apenas de integração de aplicativos como de integração dos mecanismos de gerência da produção. 


\section{Referências Bibliográficas}

ARNOLD, O.; HÄRTLING, M. (1995) Virtuelle Unternehmen: Begrifsbildung und diskussion. Arbeitspapier der Reihe Informations- und Kommunikationssystem als Gestaltungselement Virtueller Unternehmen, n.3, 38 p.

ARNOLD, O. (1996) Spezifikation eines Prototypen zur Koordination in Virtuellen Unternehmen. Arbeitspapier der Reihe "Informations- und Kommunikationssysteme als Gestaltungselement Virtueller Unternehmen". Nr. 10/1996, Bern Leipzig Erlangen-Nürnberg.

BERNUS, P.; NEMES, L. (1995) Enterprise Integration - Engineering Tools for Designing Enterprises. Anais do IFIP TC5 Working Conference on Models and Methodologies for Enterprise Integration. Austrália, p.3-11.

BREMER, C.F. (1995) Proposta de uma Metodologia para o Planejamento e Implantação da Manufatura Integrada por Computador. 214p. Tese (Doutorado) Escola de Engenharia de São Carlos, Universidade de São Paulo.

BREMER, C.F. (1997) Gestão da Produção de Empresas Virtuais. Projeto Integrado de Pesquisa encaminhado ao CNPq. /Plano/

BREMER, C.F.; EVERSHEIM, W.; SCHUCH, S.; MOLINA, A. (1998) Globale Virtuelle Unternehmen. Revista alemã ZWF, p.62-64.

BOOS, F.; JARMAI, H. (1994) Kernkompetenzen - gesucht und gefunden. Harvard Business Manager, no. 16, p.19-26.

BYRNE, J. A.; BRANDT, R.; PORT, O. (1993) The Virtual Corportation. Business Week, p. 41. 
CHÉR, R. (1991) A Gerência da Pequena e Média Empresa. São Paulo, Editora Maltese.

CORRÊA, G. N.; BREMER, C. F. (1997) Experiências Práticas em Organizações e Empresas Virtuais. ENCONTRO NACIONAL DE ENGENHARIA DE PRODUÇÃO.

DANE, F. C. (1990) Research Methods. Califórnia, Estados Unidos, Brooks/Cole Publishing Company.

DAVIDOW, W. H.; MALONE, M. S. (1992) The Virtual Corporation: Structuring and revitalizing the corporation for the 21st century. (HarperBusiness), New York.

DAVIDOW, W. H.; MALONE, M. S. (1993) Das virtuelle Unternehmen: Der Kunde als Co-Produzent. Frankfurt/Main, Campus-Verlag.

EMMRICH, H., GRANDKE, S.; HENTSCHEL, W.; SCHMIDT, P. (1997) Sozialkompetenz als strategischer Erfolgsfaktor im turbulenten Umfeld. Frauenhofer Institut, GiPP Fachforum, Stuttgart, Junho.

FAISST, W. (1995) Welche IV-Systeme sollte ein Virtuelles Unternehmen haben? Arbeitspapier der Reihe "Informations- und Kommunikationssysteme als Gestaltungselement Virtueller Unternehmen". Nr. 10/1995, Bern Leipzig Erlangen-Nürnberg.

FAISST, W.; MERTENS, P. (1997) Auf dem Wege zum Virtuellen Unternehmen Interviewskizzen, Arbeitspapier der Reihe "Informations- und Kommunikationssysteme als Gestaltungselement Virtueller Unternehmen". Nr. 19/1997, Bern Leipzig Erlangen-Nürnberg.

FORSCHUNGSZENTRUM KARLSRUHE (1995) Geschäftsprozeßgestaltung mit intergrierten Prozeß- und Produktmodellen. Rahmenplan, Alemanha.

GALLER, J.; SCHEER, A.-W. (1994) Workflow-Management: Die ARIS-Architektur als Basis eines multimedialen Workflow-System. Caderno Científico no. 108 do Institut für Wirtschaftsinformatik.

GALLER, J. (1997) Vom Geschäftsprozessmodell zum Workflow-Modell: Vorgehen und Werkzeug für einen kooperativen Ansatz. Doktorarbeit, Tese (Doutorado) da Universität des Saarlandes. 
GIELINGH, W.F.; SUHM, A.K. (1993) IMPACCT Reference Model - An Approach to Integrated Product and Process Modeling for Discrete Parts Manufacturing, Berlin.

GRIESE, J. (1992) Auswirkungen globaler Informations- und Kommunikationssysteme auf die Organisation weltweit tätiger Unternehmen. Managementforschung n.2, Berlin-New York.

GORANSON, T. (1995) Agile Virtual Enterprise: Best Agile Practice Reference Base. Working Draft, Janeiro, 11p.

HAMMEL, G.; PRAHALAD, C.K. (1990) The Core Competence of the Corporation. Harvard Business Review, n.68, p. 79-91.

HAMMEL, G.; PRAHALAD, C.K. (1994) Competindo pelo Futuro. Harvard Business Press, Editora Campus.

HARS, A. (1994) Referenzdatenmodelle - Grundlagen effizienter Datenmodellierung. Wiesbaden, Alemanha.

HRONEC, S.M. (1993) Sinais Vitais: Usando Medidas do Desempenho da Qualidade, Tempo e Custo para Traçar a Rota para o Futuro de usa Empresa. São Paulo, McGraw Hill.

IDS (1995) ARIS-Toolset 3.0 - Handbuch Nr. 5 "ARIS-Methodenhandbuch". Manual da firma IDS Prof. Scheer GmbH, Saarbrücken.

IDS (1996a) Handbuch - ARIS Simulation. Manual da firma IDS Prof. Scheer GmbH, Saarbrücken.

IDS (1996b) Modellierung von Geschäftsprozessen für die Steureung mit ARISWorkflow. Manual da firma IDS Prof. Scheer GmbH, Diretrizes para a Utilização do Componente Workflow da Ferramenta ARIS, Saarbrücken.

IDS (1996c) Handbuch - ARIS Referenzemodelle. Manual da firma IDS Prof. Scheer GmbH, Elaboração de Modelos de Referência Utilizando a Ferramenta ARIS, Saarbrücken.

JÜRGENS, V. (1997) Chancen für grössere Unternehmen - Idenfikation von Kernprozessen. In: SEMINÁRIO DA UNIVERSIDADE DE St. GALLEN, Fevereiro, Suíça. 
KATZY, B. R.; SCHUH, G.; MILLARG, K. (1996) Die Virtuelle Fabrik - Produzieren im Netzwerk. Technische Rundschau Transfer, Nr. 43, Universität St. Gallen, Suíça.

KATZY, B. R. (1997a) Optmierung der Wertschöpfungskette. In: SEMINÁRIO DA UNIVERSIDADE DE St. GALLEN, Fevereiro, Suíça.

KATZY, B. R. (1997b) Das Konzept der Virtuellen Fabrik. In: SEMINÁRIO DA UNIVERSIDADE DE St. GALLEN, Fevereiro, Suíça.

KAUFMAN, F.; KOKALJ, L.; MAY-STROBL, E. (1990) EG-Binnenmarkt - Die grenzüberschreitende Kooperation mittelständischer Unternehmen - Empirische Anaylse von Möglichkeiten, Voraussetzungen und Erfahrungen. Verlag C.E. Poeschel, Stuttgart.

KLABUNDE, S.; WITTMAN, M. (1997) Referenzmodelle und -bibliotheken: Ein Thesenpapier im Rahmen des Forschungsverbundprojektes "Geschäftsprozeßgestaltung mit integrierten Prozeß- und Produktmodellen”. Saarbrücken. /Relatório Técnico da Universität des Saarlandes/

KOCIAN, C.; MILIUS, F.; NÜTTGENS, M.; SANDER, J.; SCHEER, A.-W. (1995) Kooperationsmodelle für vernetzte KMU-Strukturen. Caderno Científico no. 120 do Institut für Wirtschaftsinformatik, Saarbrücken.

KOCIAN, C.; SCHEER, A.-W. (1996) Kiesel - Das Virtuelle Umweltkompetenzzentrum Theorie und Praxis der Virtuellen Unternehmung. M\&C Management.

KOCIAN, C.; CORRÊA, G.N.; SCHEER, A.-W. (1997) Das Virtuelle Zentrum: Rahmenkonzept für Entstehung und Management von Virtuellen Unternehmen. I\&M Information Management, Vol. 3, Agosto, p.59-64.

KOSANKE, K. (1996) Unternehmensmodellierung in dynaminschen Netzwerk. In: SEMINÁRIO DA UNIVERSIDADE DE St. GALLEN, Setembro, Suíça.

LANG, A.; PIGNEUR, Y. (1997) An Electronic Market of Individual Human Competencies for Team Building. Publicação do Institut für Wirtschaftsinformatik, Universität Bern, Suíça, Newsletter, n. 3, Vol.1, p. 4-12, www.virtual-organization.net, junho.

MENDES, J. V. (1996) Desenvolvimento de um Método para Modelagem de Operação no Contexto de uma Metodologia de Integração de Empresas. Dissertação (Mestrado), Escola de Engenharia de São Carlos, Universidade de São Paulo. 
MERTENS, P.; FAISST, W. (1995) Virtuelle Unternehmen - eine Organisationsform für die Zukunft?. Revista alemã Technologie \& Management, n. 44, p. 6168.

MILLARG, K. (1997) Die Rollen in der Virtuellen Fabrik. In: SEMINÁRIO DA UNIVERSIDADE DE St. GALLEN, Fevereiro, Suíça.

MOWSHOWITZ, A. (1986) Social Dimensions of Office Automation. In: Yovitz, Avances in Computers, n.25, p.335-404.

MÜLLER, R. (1997) Kernkompetenzfokussierung. In: SEMINÁRIO DA UNIVERSIDADE DE St. GALLEN, Fevereiro, Suíça.

NELL, J.G. (1995) Enterprise Representation: An Analysis of Standard Issues. Anais do IFIP TC5 Working Conference on Models and Methodologies for Enterprise Integration, Austrália, p. 56-68.

NETAGE, (1996) Four Ages of Organization. http://www.netage.com/Knowledge/NetAge_bk/age.html (15 Nov.).

ODENDAHL, C.; HIRSCHMANN, P.; SCHEER, A.W. (1997) Cooperation Exchanges as Media for the Intialization of Virtual Enterprise. Publicação do Instituto de Sistemas de Informações da Universidade de Bern - Suíça, Newsletter $\mathrm{N}^{\circ} 3$ Vol.1, p. 13-19, www.virtual-organization.net, junho.

OLBRICH, T. J. (1994) Das Modell der Virtuellen Unternehmen als unternehmensinterne Organisations- und unternehmensexterne Kooperationsform. Revista alemã Information Management, p. 29.

OTT, M.; NASTANSKY, L. (1997) Modelling Organizational Forms of Virtual Enterprises, The Use of CSCW Environments for a Team Based, Distributed Design of Virtual Organizations. In: Proceedings IT-Vision, Virtual Enterprises $\&$ Networked Solutions, New Perspectives on Management, Communication and Information Technology, ESTIEM, VISION Week, Abril.

REIß, M.; BECK, T.C. (1995) Kernkompetenzen in virtuellen Netzwerken. In: Corsten, H.; Will, Th. (Hrsg.): Unternehmensführung im Umbruch, (Pohlhammer), Stuttgart.

REITER, B. S.; STICKEL, E. (1997) Business Process Modeling. Springer Verlag, Alemanha. 
RENTES, A. F. (1995) Proposta de uma Metodologia de Integração com Utilização de Conceitos de Modelagem de Empresas. Tese (Doutorado), Escola de Engenharia de São Carlos, Universidade de São Paulo.

RENTES, A. F.; SOUZA, F. B.; CAMPEÃO, P.; SUGA, R. A. (1996) Uma Proposta de uma Metodologia de Integração de Empresas. Congreso Latino Americano de Administracion - XXXI Asamblea Anual CLADEA, Santiago, Chile.

ROZENFELD, H.; TAKAHASHI, S.; RENTES, A. F. (1992) Modelagem de Empresas: Requisito para a Manufatura Integrada por Computador (CIM). Apresentado ao 50 Congresso Nacional de Automação Industrial - CONAI 92, São Paulo, 1992.

ROZENFELD, H. (1996) Para Integrar a Manufatura é Importante o Domínio dos Business Processes. Revista Máquinas e Metais, Outubro.

SAARBRUCKER ZEITUNG (1996) Gartner Group ranks the BPR tool by IDS Prof. Scheer first among the leading tools/ Annual market growth between 30 and 40 per cent. Saarbrïcken, Julho.

SCHEER, A.-W. (1991) Architektur integrierter Informationssysteme - Grundlagen der Unternehmensmodellierung. Berlin Heidelberg.

SCHEER, A.-W. (1995) Wirtschaftsinformatik - Referenzemodelle für industrielle Geschäftsprozesse. Springer Verlag, Alemanha.

SCHEER, A.-W. (1996) ARIS-House of Business Engineering. Caderno Científico no. 133 do Institut für Wirtschaftsinformatik, Saarbrücken, Alemanha.

SCHUH, G. (1997) Informationstechnologie als Wegbereiter für den Wertschöpfungsverbund. In: SEMINÁRIO DA UNIVERSIDADE DE St. GALLEN, Fevereiro, Suíça.

SOMMERLAD, K. W. (1996) Virtuelle Unternehmen - juristisches Niemandsland?. Revista alemã Office Management, p.22-23.

SYDOW, J. (1996) Virtuelle Unternehmung - Erfolg als Vertrauensorganisation. Revista alemã Office Management, p. 10-13.

TOFFLER, A. (1980) A Terceira Onda. Editora Record, Rio de Janeiro.

TREGOE, B.B. et al. (1993) Visão Empresarial na Prática. Editora Campus, Rio de Janeiro. 
WfMC

(1997)

The

Workflow

Reference

Model, http://www.aiai.ed.ac.uk/wfmc/DOCS/refmodel/ (12 Aug.)

WILLIAMS, T.J.; BERNUS, P.; NEMES, L. (1995) The Concept of Enterprise Integration. Anais do IFIP TC5 Working Conference on Models and Methodologies for Enterprise Integration, Austrália, p.8-19.

ZIMMERMANN, V. (1996) Referenzmodelle für Prozesse und Produkte zum Engineering von Geschäftsprozessen, Apresentação no GiPP-Fachforum `96, Munique.

ZWICKER, H.-R. (1996) Die virtuelle Firma - ein zukunftsweisendes Modell für Kleinunternehmen. Revista alemã Information Management, p.36-38. 


\section{Anexo I - Descrição de Alguns Métodos da Ferramenta ARIS}

Este anexo visa apresentar uma descrição de alguns métodos da ferramenta ARIS utilizados neste trabalho assim como seus principais elementos. Desta forma, a seguir são apresentados o EPK, a Árvore de Funções, o Organograma e o MER.

\section{EPK}

Com a ajuda do método EPK a estrutura operacional da empresa é representada, ou seja, a apresentação da ligação entre objetos de dados, funções e organização e consequentemente a apresentação de processos.

A seqüência de funções no sentido de um processo de negócio é apresentada na forma de diagramas. Cada função possui um evento inicial e um evento resultante, ou seja, eventos inicializam funções e armazenam seus resultados na forma de informação. A mudança de estado presente em um evento pode se relacionar com a entrada de uma informação (p.ex. "Procura do cliente identificada") ou com uma mudança de status da informação (p.ex. "proposta foi rejeitada").

A ligação entre eventos e funções pode acontecer diretamente ou pela utilização de conectores lógicos (AND, OR, XOR) onde um evento pode inicializar mais de uma função e uma função pode originar mais de um evento resultante. A ligação entre eventos e função com a utilização ou não de conectores lógicos são responsáveis pela representação do processo de negócio.

Além de eventos, funções e conectores lógicos existem outros elementos que podem ser utilizados em um EPK como mostra a figura seguinte. 


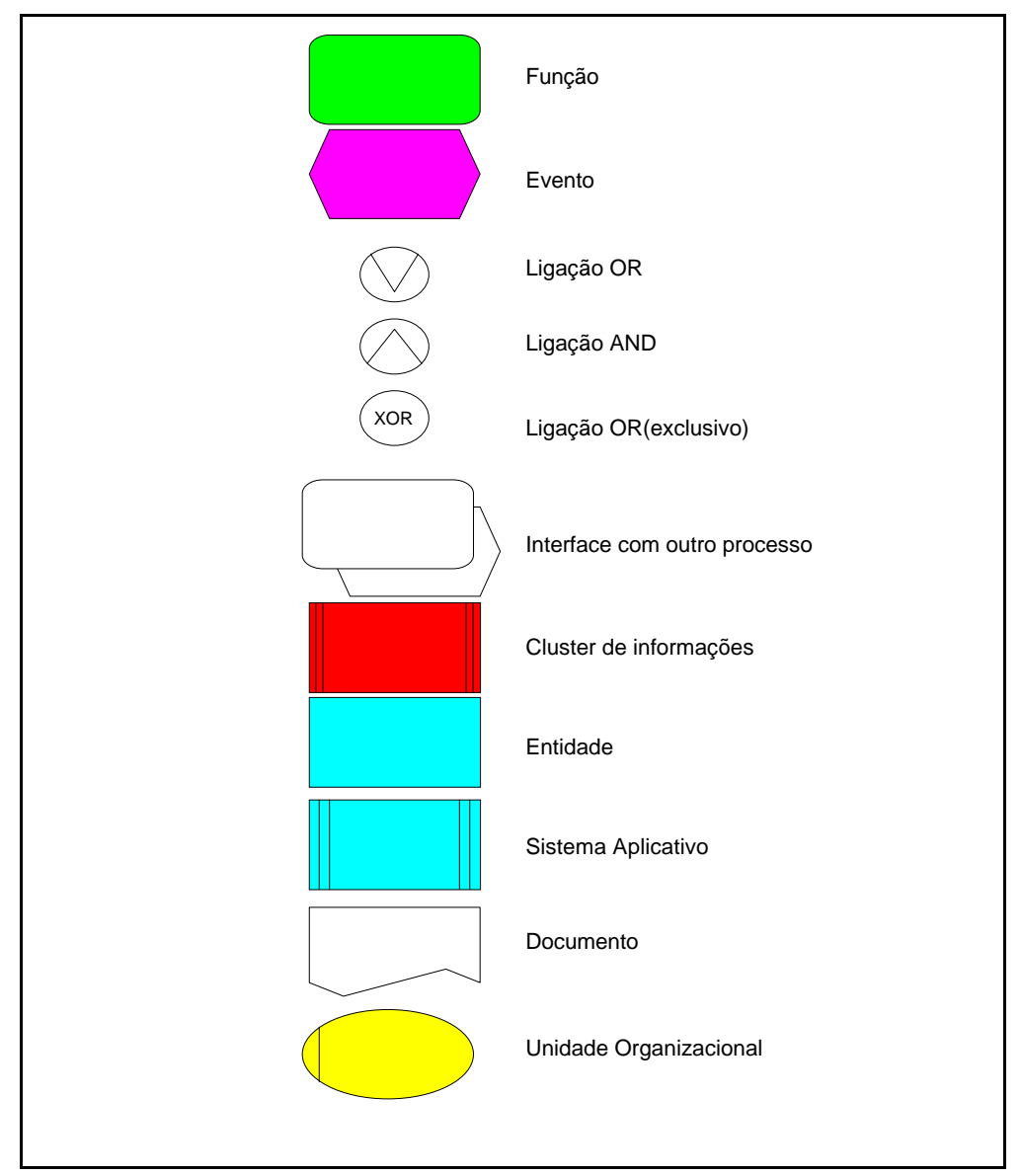

\section{Principais Elementos do método EPK}

\section{Árvore de Funções}

Árvore de funções servem para a apresentação da construção hierárquica das funções que uma empresa realiza. O relacionamento das funções com suas "sub-funções" na forma de uma árvore pode ser orientada por departamentos ou por processos. Neste trabalho foi utilizada a orientação por processos.

Funções podem ser descritas em diferentes níveis de abstração. O nível mais alto contém as funções macros que representam os processos de negócios. Como exemplo, para a representação da realização de um pedido de cliente, as funções do nível mais alto seriam desde análise da procura do cliente até o envio do produto. O termo Função pode ser utilizado em qualquer nível da arvore. No entanto, outros termos como funções parciais, 
funções elementares, entre outros podem ser aplicados para a redução da complexidade da representação do processo.

A divisão da árvore de funções pode acontecer em diferentes níveis de hierarquia, onde as funções representadas no nível mais baixo são denominadas como funções elementares. Assim, funções elementares são funções que não são mais divisíveis, ou seja, não faz sentido detalhá-las em um outro nível de abstração.

A apresentação de funções na forma de uma árvore de funções serve para a redução da complexidade, mas no entanto é estática. A representação lógica e temporal das funções é feita através do método EPK.

O único elemento deste método é, então, a função.

\section{Organograma}

Uma típica forma de apresentação da estrutura organizacional é o organograma. Nele são apresentadas as unidades organizacionais de acordo com diferentes critérios de estruturação de uma empresa. Uma unidade organizacional pode ser definida como uma portadora de funções necessária à realização das metas da empresa. Assim como a árvore de funções, o relacionamento entre as unidades organizacionais representas os diferentes níveis de hierarquia em uma organização.

Além disso, diferentes elementos podem ser utilizados para a descrição da estrutura organizacional. Para a apresentação de cada posto de trabalho na empresa existe um elemento de mesmo nome, ou seja, Posto de Trabalho. Tanto à uma unidade organizacional como à um posto de trabalho podem ser relacionadas pessoas, que na ferramenta ARIS também são representadas por um elemento. $\mathrm{O}$ relacionamento entre uma pessoa e uma unidade organizacional expressa que esta pessoa é uma funcionária de tal unidade organizacional; o relacionamento entre uma pessoa e um posto de trabalho expressa que esta pessoa ocupa determinado posto de trabalho na empresa. Por último, uma locação corresponde à um dos endereços da empresa, no qual diferentes unidades organizacionais podem ser relacionadas.

A modelagem da estrutura organizacional de uma empresa através do organograma é o ponto de saída para a definição da topologia de rede que deve ser utilizada. A ligação entre 
os diferentes elementos no organograma representa o cabeamento que deve ser realizado dentro da empresa, onde diferentes locações também devem ser prevista.

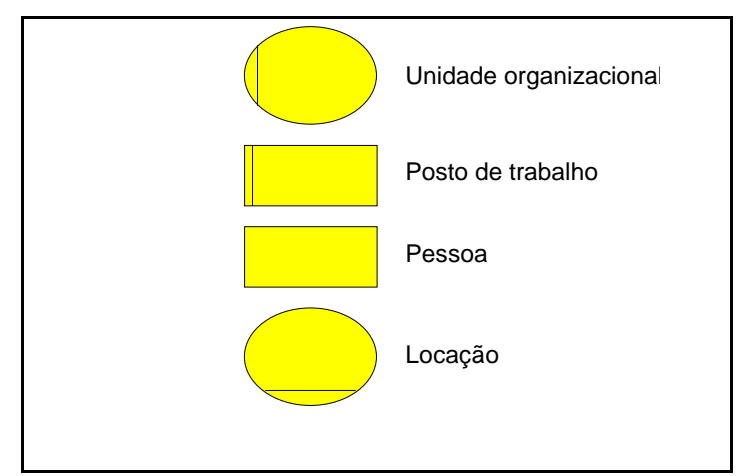

Principais Elementos do método Organograma

\section{MER}

Com a ajuda de MER's a visão de dados de uma empresa é apresentada no plano semântico, onde estão presentes os objetos e relacionamentos que são relevantes à sua operação. Os elementos básicos de um MER, como o próprio nome diz, são a entidade e o relacionamento, os quais representam as informações de uma empresa.

Além destes, diferentes elementos podem ser utilizados para a redução da complexidade, entre os quais pode-se destacar os atributos que descrevem uma entidade, o processo de generalização de entidades e a agregação. A generalização acontece quando mais de uma entidade possui alguns atributos semelhantes. A agregação é originada a partir de um relacionamento que se torna uma entidade. 


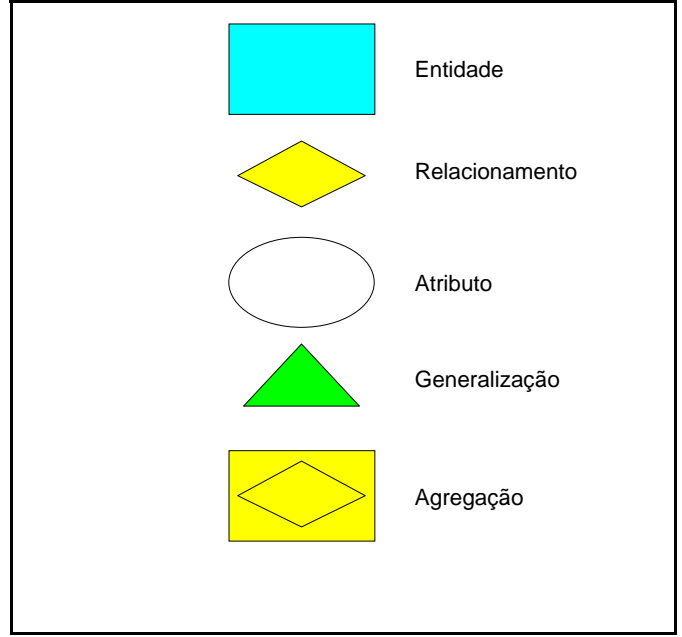

Principais Elementos do Método MER 